Algoritmos de estimação de distribuição baseados em árvores filogenéticas 

SERVIÇO DE PÓS-GRADUAÇÃO DO ICMC-USP

Data de Depósito: 6 de novembro de 2014

Assinatura:

\title{
Algoritmos de estimação de distribuição baseados em árvores filogenéticas
}

\author{
Antonio Helson Mineiro Soares
}

Orientador: Prof. Dr. Alexandre Cláudio Botazzo Delbem

Tese apresentada ao Instituto de Ciências Matemáticas e de Computação - ICMC/USP, como parte dos requisitos para obtenção do título de Doutor em Ciências de Computação e Matemática Computacional. EXEMPLAR REVISADO

USP - São Carlos

Novembro/2014 
Ficha catalográfica elaborada pela Biblioteca Prof. Achille Bassi e Seção Técnica de Informática, ICMC/USP, com os dados fornecidos pelo(a) autor(a)

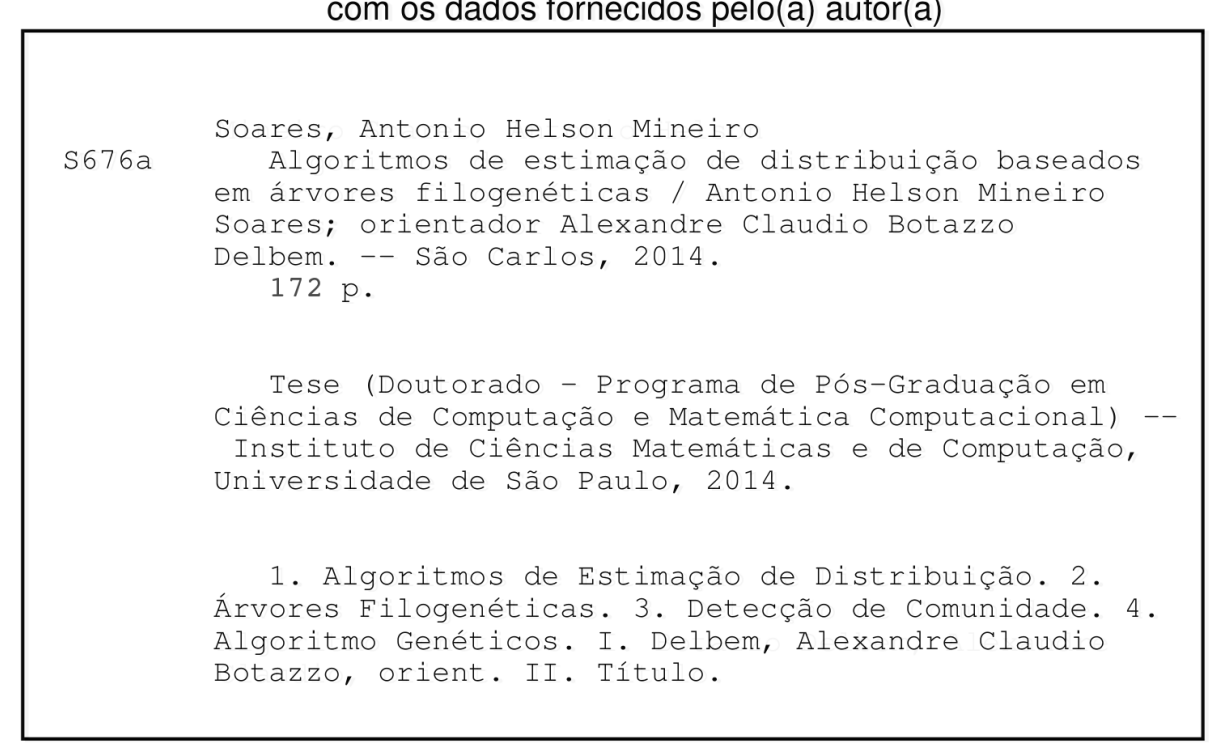


Dedico este trabalho aos meus pais. 



\section{Agradecimentos}

A todos os meus familiares que deram todo o tipo de apoio, em especial, meu pai, minha mãe, meu irmão e minha irmã, que sempre acreditaram em mim e na minha capacidade.

A minha esposa, Edna Maria Sousa Oliveira, que esteve ao meu lado sempre, incondicionalmente, e juntamente com meu filho Benjamin Hadeson Oliveira Soares, são meu suporte para qualquer coisa.

Ao meu orientador prof. Alexandre Cláudio Botazzo Delbem, pelo apoio, amizade e enorme dedicação à este trabalho, que ao cobrar resultados me fazia entender como é ser um bom pesquisador.

Aos amigos do laboratório (LCR): Jean, Erinaldo, Marcilyanne, Valéria, Antônio, Arnaldo, Tiago, Márcio, Felipe, André, Daniel, Sérgio e Márcio Crocomo pela amizade e por sempre pararem para uma boa discussão.

Ao programa de pós-graduação do ICMC, pela oportunidade de participar deste doutorado.

À CAPES, pelo apoio financeiro no início desta pesquisa.

À FAPESP, pelo suporte financeiro destinado à execução desta pesquisa por mais de 3 anos, além do suporte financeiro (BEPE) durante a pesquisa realizada no exterior. 



\section{Resumo}

$\mathcal{A}$

lgoritmos Evolutivos que utilizam modelos probabilísticos de distribuição dos valores das variáveis (para orientar o processo de busca da solução de problemas) são chamados Algoritmos de Estimação de Distribuição (AEDs). Esses algoritmos têm apresentado resultados relevantes para lidar com problemas relativamente complexos. $\mathrm{O}$ desempenho deles depende diretamente da qualidade dos modelos probabilísticos construídos que, por sua vez, dependem dos métodos de construção dos modelos. Os melhores modelos em geral são construídos por métodos computacionalmente complexos, resultando em AEDs que requerem tempo computacional alto, apesar de serem capazes de explorar menos pontos do espaço de busca para encontrar a solução de um problema. Este trabalho investiga modelos probabilísticos obtidos por algoritmos de reconstrução de filogenias, uma vez que alguns desses métodos podem produzir, de forma computacionalmente eficiente, modelos que representam bem as principais relações entre espécies (ou entre variáveis). Este trabalho propõe algumas estratégias para obter um melhor uso de modelos baseados em filogenia para o desenvolvimento de AEDs, dentre elas o emprego de um conjunto de filogenias em vez de apenas uma filogenia como modelo de correlação entre variáveis, a síntese das informações mais relevantes desse conjunto em uma estrutura de rede e a identificação de grupos de variáveis correlacionadas a partir de uma ou mais redes por meio de um algoritmo de detecção de comunidades. Utilizando esses avanços para a construção de modelos, foi desenvolvido uma nova técnica de busca, a Busca Exaustiva Composta, que possibilita encontrar a solução de problemas combinatórios de otimização de diferentes níveis de dificuldades. Além disso, foi proposta uma extensão do novo algoritmo para problemas multiobjetivos, que mostrou ser capaz de determinar a fronteira Pareto-ótima dos problemas combinatórios investigados. Por fim, o AED desenvolvido possibilitou obter um compromisso em termos de número de avaliações e tempo de computação, conseguindo resultados similares aos dos melhores algoritmos encontrados para cada um desses critérios de desempenho nos problemas testados. 


\section{Abstract}

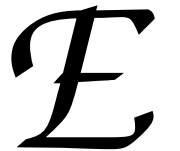

volutionary Algorithms that use the distribution of values of variables as probabilistic models (to direct the search process of problem solving) are called Estimation of Distribution Algorithms (EDAs). These algorithms have presented relevant performance in handling relatively complex problems. The performance of such algorithms depends directly on the quality of probabilistic models constructed that, in turn, depend on the methods of model building. The best models are often constructed by computationally complex methods, resulting in AEDs that require high running time although they are able to explore less points in the search space to find the solution of a problem. This work investigates probabilistic models obtained by algorithms of phylogeny reconstruction since some of them can produce models in an efficient way representing the main relationships among species (or among variables). This work proposes some strategies for better use of phylogeny-based models in the development of EDAs, such as the employment of a set of phylogenies instead of only one phylogeny as a model of correlation among variables, the synthesis of the most relevant information from a set of phylogenies into a structure of network and the identification groups of correlated variables from one or more networks by an algorithm of community detection. Using those advances for model construction, a new search technique, called Composed Exhaustive Search, was developed in order to find solutions for combinatorial optimization problems with different levels of difficulty. In addition, an extension of the new algorithm for multi-objective problems was proposed, which was able to determine the Pareto-optimal front of the combinatorial problems investigated. Finally, the developed EDA makes possible to obtain a trade-off in terms of number of evaluations and running time, finding results that are similar to the ones achieved by the best algorithms found for each one of these performance criteria in the problems tested. 



\section{Lista de Figuras}

1.1 Uma filogenia para um grupo de plantas usando sequências de nucleotídeos do conjunto teste rbcL_55 (Cancino \& Delbem, 2007) e o algoritmo NJ (Seção 3.1.1). 3

2.1 Etapas de uma geração de um EA típico. . . . . . . . . . . . . . . . . . 8

2.2 Recombinação (a) e Mutação (b) em um GA. . . . . . . . . . . . . . . . . . . . . 9

2.3 Problemas de otimização com 5 bits baseado em funções cujo argumento é a soma dos 5 bits. . . . . . . . . . . . . . . . . . 10

2.4 Tamanho da população $m$ para que, com confiança $\alpha=0,05$, para amostrar adequadamente as instâncias de cada BB. . . . . . . . . . . . . . . . . . 12

2.5 Etapas de um EDA típico. . . . . . . . . . . . . . . . . . . . . . . . 13

2.6 Funcionamento do CGA, supondo $n=10$ (variação de probabilidade $\pm 1 / n=$

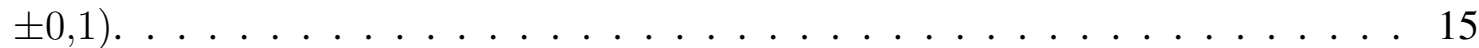

2.7 Construção de um modelo pelo ECGA e sua avaliação pelo $C_{c} \ldots \ldots$. . . . . . . . 17

2.8 Construção de BN (a) e modelo de distribuição de probabilidades usado pelo BOA (b), obtido a partir das relações de dependência presentes na BN. . . . . . . . . . . 18

2.9 Ilustração do funcionamento do CD-BOA, obtida de (Crocomo, 2012). . . . . . . . 21

2.10 Funcionamento do StrOp, figura retirada de Crocomo (2012) . . . . . . . . . . . . . 22

3.1 Primeira iteração do NJ: (a) Árvore-estrela e (b) Árvore após a inclusão do nó ancestral $u \ldots \ldots \ldots \ldots \ldots \ldots \ldots$

3.2 Matriz Distância $D$ e filogenia obtida pelo NJ. . . . . . . . . . . . . . . . . . . . . 29

3.3 Matriz distância e filogenia obtida pelo UPGMA. . . . . . . . . . . . . . . 30

4.1 Etapas do $\Phi$ GA . . . . . . . . . . . . . . . . . . . . 36

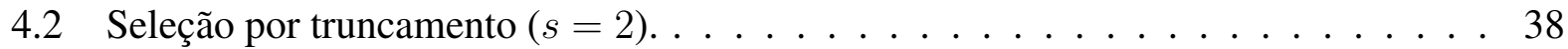

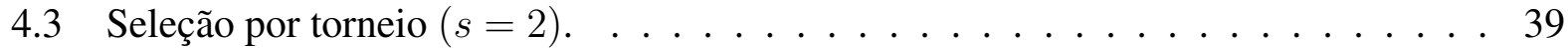

$4.4 \beta_{t}$ a cada iteração do NJ, em que a $t$-ésima aresta é adicionada, $40 \leq t \leq 75$ corresponde às ligações de nós internos na árvore. . . . . . . . . . . . . . . . . 42

4.5 Principais etapas da ES em cada BB e composição da solução do problema original. 43

5.1 Exemplo de estrutura com três comunidades em uma rede. . . . . . . . . . . . . 46

5.2 Exemplo de cálculo de $Q$ para uma rede 6 nós e 6 arestas. . . . . . . . . . . . . . . 47

5.3 Princípio de funcionamento do AdClust: nó em destaque possui $F_{\text {out }}>F_{\text {in }}$ e, portanto, passa a pertencer à comunidade A. . . . . . . . . . . . . . . . 49

5.4 Clados hipotéticos que poderiam ser obtidos de uma mesma filogenia. . . . . . . . 50 
5.5 Clados mais plausíveis. . . . . . . . . . . . . . . . . . . 51

5.6 Rede $T$, formada pela união das filogenias $F_{1}$ e $F_{2} \ldots \ldots \ldots \ldots \ldots$. . . . 51

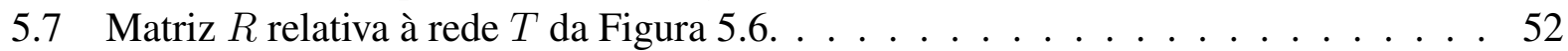

5.8 (a) Relações diretas de $F_{1}$ (Figura 5.6), (b) Relações diretas de $F_{2}$ (Figura 5.6) e as respectivas Matrizes de Adjacências. . . . . . . . . . . . . . . 52

5.9 Rede obtida após união de $F_{1}$ e $F_{2}$ (Figura 5.6) e sua Matriz de Adjacências resultante. . . . . . . . . . . . . . . . . . . . . . . . 52

6.1 (a) Exemplo de População Inicial $(n=10, \ell=9)$ para o problema composto por 3 funções armadilhas $\operatorname{ftrap} 3(k=3)$ e População de Selecionados por torneio de $3 \operatorname{com} \Phi=0,50$ e $\Phi=1,00$, (b) distribuição dos fitness na População Inicial aleatória $(n=1000, \ell=30)$ para um problema composto por 6 funções armadilhas ftrap5 $(k=5)$ e Populações de Selecionados (torneio de 8), em que os modos ("picos") da distribuição correspondente são salientados usando $\Phi=0,50$

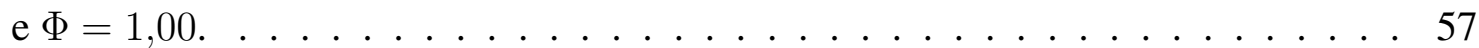

6.2 Matriz Distância calculada por meio da MI . . . . . . . . . . . . . . . . . 58

6.3 Diferentes árvores geradas pelo NJ permutando aleatoriamente linhas e colunas de uma mesma Matriz Distância. As faixas iguais de uma filogenia para a outra destacam subestruturas comuns.

6.4 Conversão de filogenia no formato Newick para Matriz de Adjacências. Neste exemplo, nós com índices maiores que 8 são nós internos da filogenia. . . . . . . . 59

6.5 Diferentes particionamentos gerados a partir das três permutações (Figura 6.3) sobre uma mesma Matriz de Adjacências (Figura 6.2) usando o FA. . . . . . . . . . . 60

6.6 Exemplo de conversão entre partições (vetor de rótulos), representação em Matriz de Adjacências e a Rede de Folhas correspondente. . . . . . . . . . . . . . . . . 61

6.7 Rede de Folhas e Redes Equivalentes obtidas de duas reamostragens de População Inicial. . . . . . . . . . . . . . . . . . . . . . . . . 62

6.8 Identificação dos BBs (comunidades) do problema através da Redes Equivalentes e particionamentos Reamostrais. . . . . . . . . . . . . . . . . . . . . . 64

6.9 Diagrama resumindo o CPA. . . . . . . . . . . . . . . . . . . . . . . 65

6.10 (a) Problema com 3 ftrap3 aditivamente separáveis, (b) Problema com uma ftrap3 separável e 3 ftrap 3 sobreposta de um bit e (c) Problema com 4 ftrap 3 com sobreposição de um bit. . . . . . . . . . . . . . . . . . . . . . . . . . . . . 67

6.11 Distribuição dos fitness na População Inicial aleatória $(n=1000, \ell=30)$ para um problema composto por 6 funções armadilhas ftrap5 $(k=5)$ e Populações de Selecionados (torneio de 8), em que os dois modos da distribuição correspondente são salientados usando $\Phi=2,00 \ldots \ldots \ldots \ldots$. . . . . . . . . . . . 70

6.12 As quatro Etapas da CES com base em $C_{1}$ e $C_{2}$, soluções preditas nas vizinhanças do ótimo global e melhor ótimo local. . . . . . . . . . . . . . . . . . . . 73

6.13 Esquema de paralelização da construção do Particionamento Final (Seção 6.1) do CPA usando $A B C+1$ Elementos de Processamento. . . . . . . . . . . . . . 74

6.14 Combinação de instâncias de BBs de soluções no extremo da Fronteira Paretoótima para o problema ftrap5 vs inv-ftrap5 (Seção 8.4). . . . . . . . . . . . . . 77

6.15 Combinação de instâncias de BBs de solução da Fronteira Pareto-ótima para o problema ftrap4 vs inv-ftrap3.

6.16 Principais etapas da moOPA, em que o bloco com o nome NÚCLEO é mostrado na Figura 6.9 . . . . . . . . . . . . . . . . . . . . 77

7.1 Exemplos de funções armadilhas: (a) f3deceptive e (b) ftrap5. . . . . . . . . . 81 
7.2 Função armadilha ftrap2.

7.3 Modelo de função armadilha apresentando os parâmetros utilizados para verificar

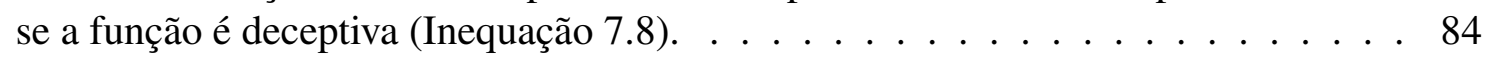

7.4 Função fbbipolar. . . . . . . . . . . . . . . . . . 85

8.1 Comparação em NA entre BOA $(v=4)$, CD-BOA, StrOp e StrOp+REDA $\left(v_{l}=3\right.$ e $v_{u}=7$ ) e OPA para problemas compostos por 5 ftraps com $k$ variando de 3 a 6 .

8.2 Desempenho em NA sobre diferentes tipos de funções deceptivas com $\ell=90$ para os algoritmos BOA $(v=4)$, CD-BOA, StrOp e StrOp+REDA $\left(v_{l}=3\right.$ e $\left.v_{u}=7\right)$. . 94

8.3 Comparação em NA da OPA com BOA $(v=4)$, CD-BOA, StrOp e StrOp+REDA $\left(v_{l}=3\right.$ e $\left.v_{u}=7\right)$ para o problema composto por funções ftrap5. . . . . . . . 95

8.4 Comparação em TE da OPA com BOA $(v=4)$, CD-BOA, StrOp e StrOp+REDA $\left(v_{l}=3\right.$ e $\left.v_{u}=7\right)$ para o problema composto por funções ftrap5. . . . . . . . 96

8.5 Configuração do tempo de comunicação entre os Elementos de Processamento da Figura 6.13. . . . . . . . . . . . . . . . . . . . . . . . 98

8.6 NA da OPA variando a quantidade de reamostragens de 1 a 10 para o problema composto por funções ftrap $5 \operatorname{com} \ell=90 \ldots \ldots$. . . . . . . . . . . 99

8.7 TE da OPA pela quantidade de reamostragens de 1 a 10 para o problema composto por funções $f t r a p 5$ com $\ell=90 \ldots \ldots$. . . . . . . . . . . . . . 100

8.8 NA para o Experimento 4 (funções ftrap5 com $\ell=90$ ) refeito variando $\Phi$ entre

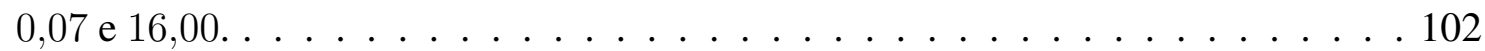

8.9 TE para o Experimento 4 (funções ftrap5 com $\ell=90$ ) refeito variando $\Phi$ entre

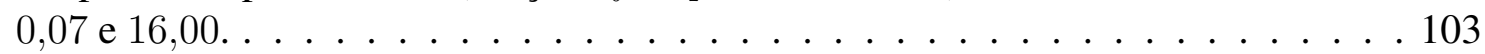

8.10 Comparação entre NA da OPA, com BOA $(v=4)$, StrOp e StrOp+REDA (ambos com $v_{l}=3$ e $v_{u}=7$ ) para o problema composto por funções ftrap5. . . . . . . 104

8.11 Comparação entre TE da OPA, com BOA $(v=4)$, StrOp e StrOp+REDA (ambos com $v_{l}=3$ e $v_{u}=7$ ) para o problema composto por funções ftrap5. . . . . . . 105

8.12 Problemas armadilha compostos por ftrap5 para (a) $\ell=30$, (b) $\ell=60 \ldots$. . . . 106

8.13 Problemas armadilha compostos por ftrap5 para (a) $\ell=90$, (b) $\ell=120$, (c)

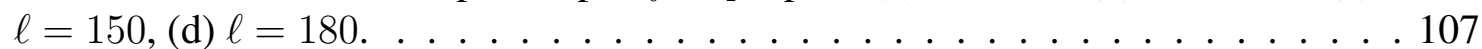

8.14 NA da $\mathrm{OPA}_{1,00}$ comparado ao BOA $(v=4)$ e $\operatorname{StrOp}+\operatorname{REDA}\left(v_{l}=3\right.$ e $\left.v_{u}=7\right)$ para o problema composto por funções ftrap5 com sobreposição de dois bits. . . . 109

8.15 NA da $\mathrm{OPA}_{1,00}$ comparado ao CD-BOA e StrOp+REDA (ambos com $v_{l}=1 \mathrm{e}$ $v_{u}=1$ ) para o problema OneMax. . . . . . . . . . . . 111

8.16 NA da $\mathrm{OPA}_{1,00}$ comparado ao CD-BOA e StrOp+REDA (ambos com $v_{l}=1 \mathrm{e}$ $v_{u}=1$ ) para o problema BinInt. . . . . . . . . . . . . . 112

8.17 NA da $\mathrm{OPA}_{1,00}$ para um problema em que metade do cromossomo é composto por funções ftrap5 com sobreposição de dois bits e a outra metade é composto por funções ftrap5. . . . . . . . . . . . . . . . . . . . . 113

8.18 Mapeamento de todas as soluções no espaço de objetivos e conjunto Pareto-ótimo (pontos circulados) para o problema multiobjetivo ftrap5 vs inv-ftrap5 de tamanhos $\ell=30$.

8.19 Relação do problema multiobjetivo ftrap5 vs inv-ftrap5 . . . . . . . . . . . . . 116

8.20 Comparação do desempenho da moOPA com os principais MOEAs da literatura. . 117

8.21 TE do problema multiobjetivo ftrap5 vs inv-ftrap5 obtido para a moOPA. . . . . . 118

8.22 Comparativo de ótimos locais e globais da ftrap4 e inv-ftrap3. . . . . . . . . . . . 119

8.23 Mapeamento de todas as soluções no espaço de objetivos e conjunto Pareto-ótimo (pontos circulados) de tamanho $\ell=12$. 
8.24 NA da moOPA para o problema multiobjetivo ftrap4 vs inv-ftrap3. . . . . . . . . 121

8.25 TE da moOPA para o problema multiobjetivo ftrap4 vs inv-ftrap3. . . . . . . . . . 122

A.1 Principais etapas de um ciclo de execução da CPA-FO. . . . . . . . . . . . . . . 142

B.1 Extrusora com todas as possíveis variáveis envolvidas, adaptada de Gaspar-cunha (2004) . . . . . . . . . . . . . . . . . . . . . 146

B.2 Exemplo do $\mathrm{CPA}_{R}$ para um problema de navegação de robôs, identificando os estados do ambiente para: (a) 5 amostras de sinais de laser, (b) 10 amostras de sinais de laser, (c) 15 amostras de sinais de laser, (d) 20 amostras de sinais de laser. 151

B.3 Exemplo do $\mathrm{CPA}_{R}$ para um problema de navegação de robôs, identificando os estados do ambiente para (a) 25 amostras de sinais de laser, (b) 30 amostras de sinais de laser, (c) 35 amostras de sinais de laser, (d) 40 amostras de sinais de laser. 152

B.4 Exemplo do $\mathrm{CPA}_{R}$ para um problema de navegação de robôs, identificando os estados do ambiente para (a) 45 amostras de sinais de laser, (b) 50 amostras de sinais de laser, (c) 55 amostras de sinais de laser, (d) 60 amostras de sinais de laser. 153

B.5 Exemplo do $\mathrm{CPA}_{R}$ para um problema de navegação de robôs, identificando os estados do ambiente para (a) 65 amostras de sinais de laser, (b) 70 amostras de sinais de laser, (c) 75 amostras de sinais de laser, (d) 80 amostras de sinais de laser. 154

B.6 Exemplo do $\mathrm{CPA}_{R}$ para um problema de navegação de robôs, identificando os estados do ambiente para (a) 85 amostras de sinais de laser, (b) 90 amostras de sinais de laser, (c) 95 amostras de sinais de laser, (d) 100 amostras de sinais de laser.155

C.1 CPA $_{M}$, o NÚCLEO-1 (definido na Figura 6.9) usa a MI como métrica de distância; enquanto o NÚCLEO-2, a NCD. . . . . . . . . . . . . . . . . . . 158

C.2 Função Rosenbrock para duas variáveis. . . . . . . . . . . . . . . . . . . . 158

C.3 (a) Máscara, indicando o tipo de variáveis do problema (desconhecida pelo CPA $_{M}$ ) e (b) Particionamento em BBs obtido pelo $\mathrm{CPA}_{M} \ldots \ldots$. . . . . . . . . . . . . 159

D.1 Etapas da identificação de $\mathrm{BBs}$ do $\mathrm{CPA}_{G}$ para sequências de DNA, usando métricas de distâncias biológicas, em que NÚCLEO definido na Figura 6.9 . . . . . . . . . . 161

F.1 Relação de substituição proposto por JC . . . . . . . . . . . . . . . . . . . . . . . 168

F.2 Relações de substituição proposto por Kimura. ～. . . . . . . . . . . . . . . . . 168

F.3 Três árvores geradas pelo NJ usando diferentes métricas: (a) JC, (b) KI e (c) F84. . 170 


\section{Lista de Tabelas}

2.1 Exemplo de distribuição de probabilidades de um particionamento. . . . . . . . . . . 15

2.2 Exemplo da representação de um modelo usando 1 bit para armazenar as duas possíveis instâncias da partição $[0,1,2,3,4]$, ( $q$ é a quantidade do cromossomo 00000 na população de tamanho $n) \ldots \ldots \ldots \ldots \ldots$

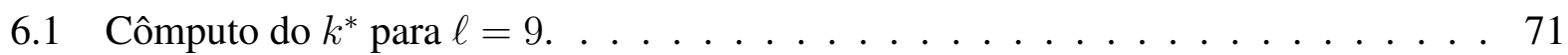

6.2 Relação de $k^{*}$ para valores de $\ell$ entre 5 e $180 \ldots \ldots \ldots$. . . . . . . . . . 71

A.1 Número de acertos (encontrados pelo CPA-FO) e desvios (Equação A.1) de valores para todos os conjuntos. . . . . . . . . . . . . . . . . . . 142

B.1 Distribuição dos $\mathrm{BBs}(\mathrm{BB}[0]$ e $\mathrm{BB}[1])$ obtidas pelo $\mathrm{CPA}_{R}$ para os problemas do conjunto A (condições operacionais) para soluções selecionadas na $5^{\mathrm{a}}$ e $50^{\mathrm{a}}$ gerações do RPSGAe. . . . . . . . . . . . . . . . . . . . . . . . . . . . . 148

B.2 Distribuição dos $\mathrm{BBs}(\mathrm{BB}[0], \mathrm{BB}[1]$ e $\mathrm{BB}[2])$ obtidas pelo $\mathrm{CPA}_{R}$ para os problemas do conjunto $B$ (condições geométricas) para soluções selecionadas na $5^{\mathrm{a}}$ e $50^{\mathrm{a}}$ gerações do RPSGAe. . . . . . . . . . . . . . . . . . . . . . . . . . . . 148

B.3 Distribuição dos BBs (BB[0], BB[1], BB[2] e $\mathrm{BB}[3])$ obtidas pelo $\mathrm{CPA}_{R}$ para os problemas do conjunto $\mathrm{C}$ (condições operacionais + geométricas) para soluções selecionadas na $5^{\mathrm{a}}$ e $50^{\mathrm{a}}$ geraçõoes do RPSGAe. . . . . . . . . . . . . . . . . . . 149

D.1 Clados obtidos pelo $\mathrm{CPA}_{G}$ para o conjunto rbcL_55. . . . . . . . . . . 163

D.2 Clados obtidos pelo $\mathrm{CPA}_{G}$ para o conjunto 20mams. . . . . . . . . . . . . 164 



\section{Lista de Abreviaturas e Siglas}

AdClust Adaptive Clustering

ASDPs Additively Separable Deceptive Problems

BN Bayesian Network

BOA Bayesian Optimization Algorithm

BB Building Block

CPA Clustering based on Phylogram Analysis

CD-BOA Community Detection BOA

CGA Compact Genetic Algorithm

CES Composed Exhaustive Search

DE Differential Evolution

EDA Estimation of Distribution Algorithm

EA Evolutionary Algorithm

ES Exhaustive Search

ECGA Extended Compact Genetic Algorithm

EO Extreme Optimization

FA Fast Algorithm

GA Genetic Algorithm

hBOA Hierarchical Bayesian Optimization Algorithm

MPM Marginal Product Models

MOEDA Multiobjective Estimation of Distribution Algorithm

MOEA Multiobjective Evolutionary Algorithm

moECGA Multiobjective Extended Compact Genetic Algorithm

mohBOA Multiobjective Hierarchical Bayesian Optimization Algorithm

moOPA Multiobjective Optimization based on Phylogram Analysis

MOOP Multiobjective Optimization Problems 
mo $\Phi$ GA Multiobjective Phylogenetic Algorithm

MI Mutual Information

NJ Neighbor Joining

NCD Normalized Compression Distance

NA Número de Avaliações

OPA Optimization based on Phylogram Analysis

$\Phi \mathbf{G A}$ Phylogenetic Algorithm

PMBGA Probabilistic Model Building Genetic Algoritm

REDA Resampling for EDAs

StrOp Straight Optimization

TE Tempo de Execução

UPGMA Unweighted Pair Group Method with Arithmetic 


\section{Sumário}

$\begin{array}{lll}\text { Resumo } & \text { i }\end{array}$

$\begin{array}{lll}\text { Abstract } & \text { iii }\end{array}$

Lista de Figuras $\quad$ iv

$\begin{array}{lll}\text { Lista de Tabelas } & \text { viii }\end{array}$

Lista de Abreviaturas e Siglas $\quad$ xi

1 Introdução $\quad 1$

2 Algoritmo de Estimação de Distribuição $\quad 7$

2.1 Computação Evolutiva . . . . . . . . . . . . . . . . . . 7

2.2 Algoritmos Genéticos . . . . . . . . . . . . . . . . . . 8

2.3 Blocos Construtivos . . . . . . . . . . . . . . . . . . . . 9

2.4 Algoritmos de Estimação de Distribuição . . . . . . . . . . . . . . . . . . . . 13

2.5 Algoritmo Genético Compacto . . . . . . . . . . . . . . . . . . . . . . . 14

2.6 Algoritmo Genético Compacto Estendido . . . . . . . . . . . . . . . . . . . 14

2.7 Algoritmo de Otimização Bayesiana . . . . . . . . . . . . . . . . . . . . . . . 17

2.8 Algoritmo de Otimização Bayesiana Hierárquico ～. . . . . . . . . . . . . . . . . 19

2.9 Algoritmo de Otimização Bayesiana com Detecção de Comunidades . . . . . . . . 20

2.10 Otimização Direta . . . . . . . . . . . . . . . . . . . . . 21

2.11 Algoritmos Evolutivos Multiobjetivos . . . . . . . . . . . . . 22

2.12 Considerações finais . . . . . . . . . . . . . . . . 23

3 Métodos de Reconstrução Filogenética $\quad 25$

3.1 Métodos de Agrupamento . . . . . . . . . . . . . . . . . 25

3.1 .1 Neighbor Joining . . . . . . . . . . . . . . . . . 26

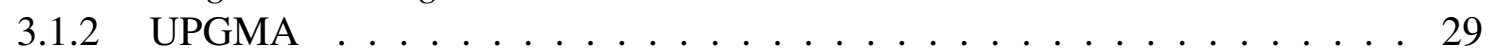

3.2 Métodos de Otimalidade . . . . . . . . . . . . . . . . . . . . . . . . . . . . . . . . 30

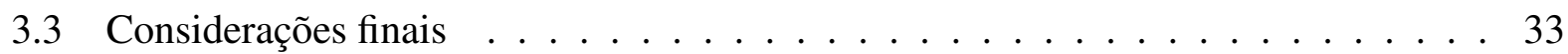


4 Algoritmo Filogenético $\quad 35$

4.1 Operadores de Seleção . . . . . . . . . . . . . . . . . . . . . . . 37

4.1 .1 Seleção por truncamento . . . . . . . . . . . . . . . . . 37

4.1 .2 Seleção por torneio . . . . . . . . . . . . . . . . . 39

4.2 Identificação dos BBs . . . . . . . . . . . . . . . . . . . . . 41

4.3 Busca Exaustiva . . . . . . . . . . . . . . . . . . . 41

4.4 Considerações finais . . . . . . . . . . . . . . . . . . . 43

5 Detecção de Comunidades em Filogenias $\quad 45$

5.1 Detecção de Comunidades . . . . . . . . . . . . . . . . . . . . 45

5.1 .1 Algoritmo Rápido . . . . . . . . . . . . . . . . . 46

5.1 .2 Agrupamento Adaptativo . . . . . . . . . . . . . . . . . 47

5.1 .3 Otimização Extrema . . . . . . . . . . . . . . . . . . . . . 48

5.2 Detecção de Comunidades em Filogenias . . . . . . . . . . . . . . . . . 50

5.3 Considerações finais . . . . . . . . . . . . . . . . . 53

6 Análise de Filogramas e Métodos de Agrupamento e Otimização 55

6.1 Descrição do CPA . . . . . . . . . . . . . . . . . . . . 56

6.2 Identificação de Partições e Sobreposições . . . . . . . . . . . . . . . . . . 66

6.3 Otimização baseada na Análise de Filogramas . . . . . . . . . . . . . . . . 68

6.4 Busca Exaustiva Composta . . . . . . . . . . . . . . . . . . . . . 69

6.5 Complexidade de tempo da OPA . . . . . . . . . . . . . . . . 74

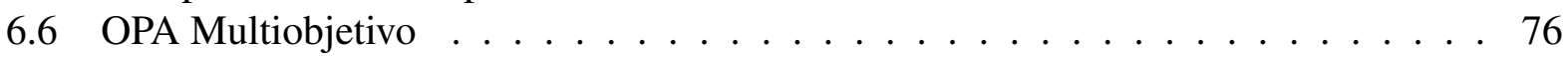

7 Problemas para avaliação de EDAs $\quad 79$

7.1 OneMax, BinInt e o problema de convergência à deriva . . . . . . . . . . . . 80

7.2 Funções armadilha . . . . . . . . . . . . . . . . . . 80

7.3 Problemas Multimodais . . . . . . . . . . . . . . . . 83

7.4 Problemas deceptivos aditivamente separáveis . . . . . . . . . . . . . . . . . . 84

7.5 Sobreposição de BBs e problemas hierárquicos . . . . . . . . . . . . . 85

8 Análise de desempenho da OPA $\quad 89$

8.1 Critérios e recursos utilizados . . . . . . . . . . . . . . . . . . 89

8.2 Avaliação com problemas deceptivos . . . . . . . . . . . . . . . . . . 91

8.3 Avaliação com problemas OneMax, BinInt e com sobreposição de BBs . . . . . . 107

8.4 Avaliação com problemas multiobjetivos . . . . . . . . . . . . . . . . 114

8.5 Considerações finais . . . . . . . . . . . . . . . . 123

9 Conclusões e Trabalhos Futuros $\quad 125$

A CPA em Dimensionamento de lotes multi-nível 141

B CPA em problemas com variáveis contínuas 145

B.1 Problema da extrusora . . . . . . . . . . . . . . . . . 145

B.2 Problema de navegação de Robô . . . . . . . . . . . . . . . 150

$\begin{array}{lll}\text { C } & \text { CPA em problemas com variáveis mistas } & 157\end{array}$

$\begin{array}{ll}\text { D CPA em reconstrução filogenética } & 161\end{array}$ 
E Número de Avaliações da Busca Exaustiva Composta

F Métricas de Distância 


\section{Introdução}

Os EAs são técnicas para exploração de espaço de busca ${ }^{1}$ que simulam aspectos da Teoria da Evolução das Espécies (Darwin, 1859, 2003) e têm sido aplicadas com sucesso em diversos problemas do mundo real. Uma linha de pesquisa importante (mais recente) sobre EAs desenvolve os Algoritmos de Estimação de Distribuição (EDAs, do inglês Estimation of Distribution Algorithms) (Larrañaga \& Lozano, 2001; Pelikan et al., 2002, 2006). Esses algoritmos constroem modelos de distribuição dos valores das variáveis de acordo com um conjunto de amostras, selecionadas em regiões promissoras do espaço de busca. A partir do modelo pode-se gerar novas soluções com valores para cada variável que são coerentes com tais regiões. Em geral, um modelo é construído a cada iteração (geração de um $\mathrm{EA}^{2}$ ) buscando representar as principais características de soluções das regiões promissoras. A partir do modelo podem ser geradas novas soluções, amostrando melhor as regiões promissoras.

A qualidade do modelo afeta diretamente a taxa de convergência do algoritmo e sua capacidade de encontrar a solução ótima do problema. Em outras palavras, a simples utilização de um modelo probabilístico não garante o sucesso de um EDA. Sob certas condições, um EDA pode ter comportamento similar a um EA comum (Harik et al., 1999; Mühlenbein, 1997). Um exemplo típico é a relação entre o Algoritmo Genético (GA, do inglês Genetic Algorithm) e o Algoritmo Genético Compacto (CGA, do inglês Compact Genetic Algorithm) (Harik et al., 1999), que utiliza

\footnotetext{
${ }^{1} \mathrm{O}$ espaço de busca é composto por todas as possíveis soluções de um determinado problema (soluções viáveis ou candidatas) (Gaspar-Cunha et al., 2012).

${ }^{2}$ Uma geração é o processo em que cada solução na população é avaliada, alguns indivíduos são selecionados, recombinados e/ou mutados para formar uma nova população. A nova população então é utilizada como entrada para a próxima geração do algoritmo (Gaspar-Cunha et al., 2012).
} 
um modelo probabilístico monovariado e apresenta desempenho similar ao do GA (Harik et al., 1999) para vários problemas em que foram testados.

Uma vantagem de um modelo monovariado é que a construção deste modelo requer relativamente pouco tempo computacional. Por outro lado, o Algoritmo de Otimização Bayesiano (BOA, do inglês Bayesian Optimization Algorithm) (Pelikan et al., 1999) requer tempo computacional significativamente maior para construção de seus modelos multivariados e multimodais (Redes Bayesianas, Seção 2.7), com a vantagem de resolver eficientemente alguns tipos de problemas que eram desafios para vários EAs.

Assim, um aspecto importante em EDAs é avaliar o compromisso entre a qualidade do modelo construído e a eficiência do processo de construção do próprio modelo (Pelikan et al., 2002). A pesquisa desenvolvida neste trabalho foca em estratégias para se obter um melhor compromisso entre esses aspectos. Um caminho para isso é a decomposição (de forma exata ou aproximada) de problemas relativamente complexos em subproblemas mais simples. A partir de modelos relativos a esses subproblemas, modelos para o problema completo podem ser obtidos de forma mais eficiente, mantendo a qualidade de representação das regiões promissoras.

Uma estratégia de decomposição em subproblemas é a identificação de Blocos Construtivos (BBs, do inglês Building Blocks), que são grupos de variáveis fortemente correlacionadas. A teoria apresentada em Goldberg (2002) mostra que EDAs mais eficazes e eficientes em geral constroem modelos probabilísticos que mapeiam mais BBs corretamente (amostram várias instâncias ótimas deles) e melhor utilizam essas informações para gerar novas soluções. Além disso, tais EDAs devem garantir que as instâncias ótimas dos BBs prevaleçam em relação às sub-ótimas e que a convergência à deriva (convergência prematura para qualquer valor de uma ou mais variáveis (Goldberg, 2002)) seja evitada.

Este trabalho investiga aspectos dos métodos da Biologia Computacional utilizados para determinar correlação entre objetos biológicos que podem beneficiar a identificação de BBs, buscando a decomposição de um problema em subproblemas. Esses métodos tem origem na área de reconstrução de filogenias, campo da Biologia que investiga as relações evolutivas entre espécies e demais objetos biológicos (Felsenstein, 2003; Cancino, 2008). A palavra filogenia tem origem nas palavras filo (grupo) e genia (gêneses, origem), por exemplo, a partir de características morfológicas podem ser construídas representações das relações evolutivas, que são chamadas de árvores filomorfológicas. As relações podem também ser determinadas a partir de sequências de genes dos objetos biológicos, produzindo as chamadas árvores filogenéticas. O nome árvore filogenética tem sido usado tanto para filogenias obtidas de dados morfológicos quanto de sequências genéticas. Neste trabalho, são construídas filogenias a partir de vários tipos de dados, buscando determinar grupos de objetos (filos) correlacionando esses dados.

Uma filogenia pode ser representada por uma árvore (um grafo conexo e acíclico) que reflete relações entre um conjunto de espécies. Usualmente, as árvores filogenéticas são árvores binárias em que as folhas representam as espécies, assim, as folhas são rotuladas com o nome de uma espécie correspondente. A Figura1.1 mostra uma filogenia que destaca as relações evolutivas entre 
um grupo de plantas. As folhas representam espécies existentes atualmente, enquanto os nós internos indicam ancestrais hipotéticos ou espécies extintas.

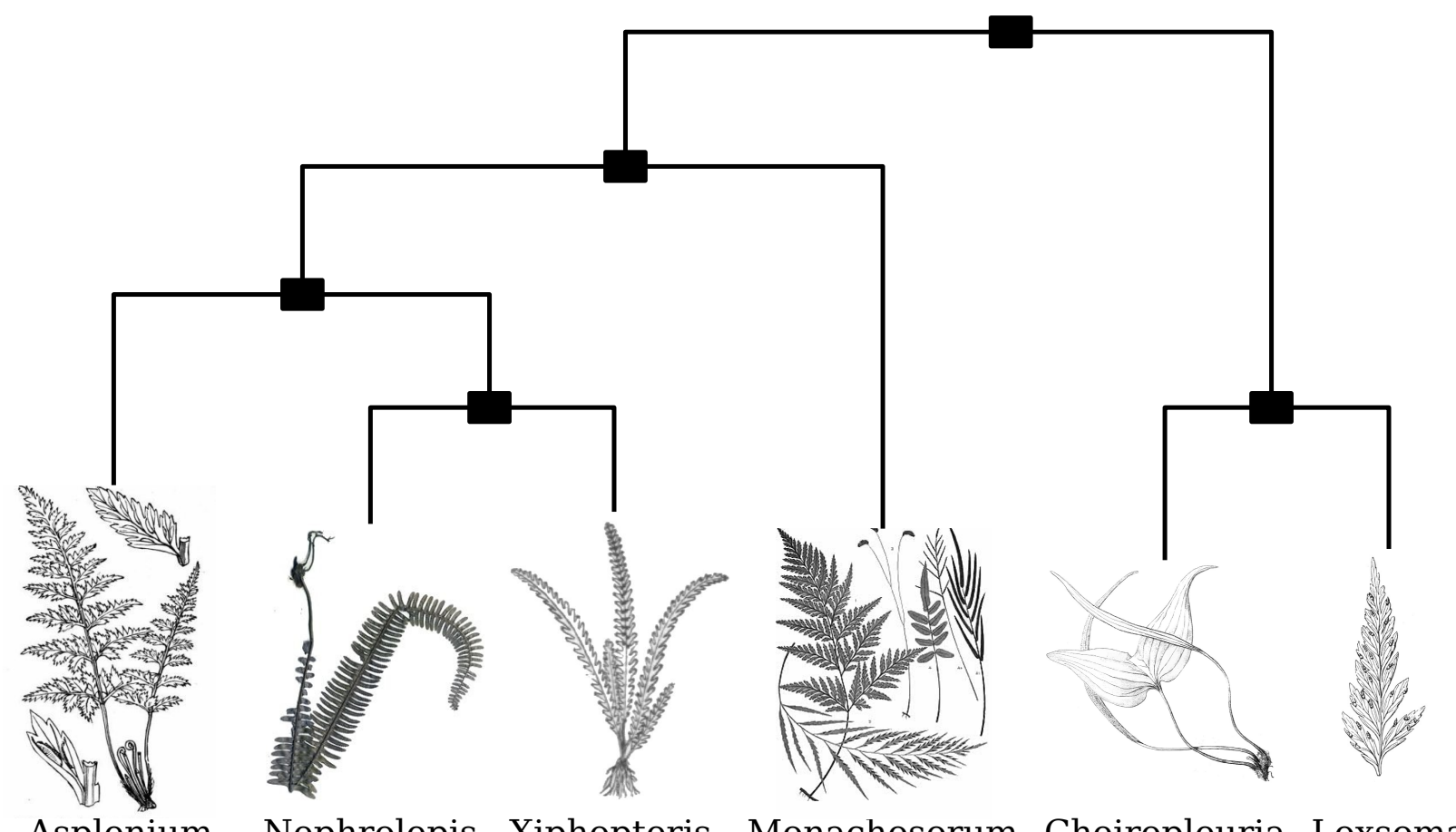

Asplenium Nephrolepis Xiphopteris Monachosorum Cheiropleuria Loxsoma

Figura 1.1: Uma filogenia para um grupo de plantas usando sequências de nucleotídeos do conjunto teste rbcL_55 (Cancino \& Delbem, 2007) e o algoritmo NJ (Seção 3.1.1).

Ao longo do século XX, diversos modelos probabilísticos foram desenvolvidos para construir filogenias. A complexidade do processo de construção de árvores que explicariam a evolução de um conjunto de espécies aumenta consideravelmente conforme o número de espécies e informações sobre as mesmas aumentam. $\mathrm{O}$ aumento da capacidade de processamento dos computadores que ocorreu nas últimas décadas possibilitou que diversos algoritmos fossem desenvolvidos e aplicados com sucesso, produzindo melhores filogenias.

As relações evolutivas entre objetos biológicos podem ser interpretadas como relações hierárquicas entre variáveis de um problema de otimização, em que cada objeto corresponde a uma combinação de possíveis valores de uma das variáveis. Com base nessa interpretação, a filogenia é um modelo probabilístico naturalmente capaz de representar relações relativamente complexas entre BBs, como as que ocorrem em problemas deceptivos hierárquicos (Goldberg, 2002).

Um trabalho preliminar que buscou explorar modelos baseados em filogenia no desenvolvimento de EDAs foi proposto em Melo et al. (2011). Este algoritmo, denominado Algoritmo FiloGenético ( $\Phi \mathrm{GA}$, do inglês PhyloGenetic Algorithm) utiliza o algoritmo Junção de Vizinhos (NJ, do inglês Neighbor Joining) (Saitou \& Nei, 1987; Studier \& Keppler, 1988) (ver Seção 3.1.1) para construir modelos mais representativos dos dados amostrados.

Este trabalho de doutorado estende o $\Phi \mathrm{GA}$ de forma a se obter um novo método computacionalmente eficiente e capaz de gerar modelos mais representativos, possibilitando gerar EDAs 
que apresentam melhor desempenho. Com isso, busca-se ampliar os tipos de problemas que se consegue resolver com um mesmo EDA. Primeiramente, foi desenvolvido um novo método para identificação de BBs, denominado Agrupamento baseado em Análise de Filogramas ${ }^{3}$ (CPA, do inglês Clustering based on Phylogram Analysis). Esse algoritmo inova ao construir um conjunto de filogenias em vez de apenas uma filogenia, utilizando para isso métodos de reamostragem paralelizados. Como cada reamostragem não requer a avaliação de novas soluções, o custo computacional do conjunto de filogenias pode ser, de certa forma, controlado. Com isso, obtém-se um compromisso entre a representatividade dos modelos e o custo computacional deles.

O CPA transforma o conjunto de filogenias em uma estrutura de rede. Nesse processo são salientadas as relações entre variáveis que são consenso nas várias filogenias construídas por reamostragem. Essas relações são utilizadas para compor uma rede destacando as variáveis do problema fortemente correlacionadas. Por fim, algoritmos de detecção de comunidades da área de Redes Complexas (Donetti \& Muñoz, 2004; Duch \& Arenas, 2005) são utilizados para automaticamente detectar comunidades (BBs) a partir da rede. Mostra-se que o CPA pode identificar relações entre variáveis envolvendo diferentes níveis de dificuldade de detecção, como BBs descorrelacionados, com algumas sobreposições ou mesmo com sobreposições entre todos os BBs do problema. $\mathrm{O}$ CPA por si só possibilita encontrar agrupamentos para uma diversidade de tipos de dados com potencial para aplicações em vários problemas do mundo real. Resultados preliminares com esse tipo de uso do CPA são mostrados nos Apêndices A, B, C e D.

A partir do modelo probabilístico obtido pelo CPA, este trabalho propõe um método de exploração de informações de cada $\mathrm{BB}$ e de suas relações, além de realizar estimativas da vizinhança do ótimo global e melhor ótimo local para determinação da solução ótima de problemas combinatórios. Esse método, denominado Busca Exaustiva Composta (CES, do inglês Composed Exhaustive Search), juntamente com o CPA, compõem um novo EDA, a Otimização baseada em Análise de Filogramas (OPA, do inglês Optimization based on Phylogram Analysis). Resultados experimentais mostram que a OPA é capaz de resolver, de forma eficaz, problemas combinatórios de benchmark de EDAs com eficiência computacional similar à obtida pelos melhores algoritmos encontrados para cada um dos problemas testados. No caso, os algoritmos da literatura usados para comparação de desempenho foram o Algoritmo de Otimização Bayesiana (BOA, do inglês Bayesian Optimization Algorithm) e suas extensões denominadas BOA com Detecção de Comunidades (CD-BOA, do inglês Community Detection BOA) e Otimização Direta (StrOp, do inglês Straight Optimization). Além disso, uma extensão multiobjetivo da OPA mostrou ser capaz de encontrar de forma eficiente a fronteira Pareto-ótima completa dos problemas investigados.

Este trabalho está organizado como segue. O Capítulo 2 introduz os Algoritmos Evolutivos, com destaque para os EDAs. O Capítulo 3 revisa os métodos de reconstrução filogenética mais utilizados na literatura. O Capítulo 4 descreve os fundamentos do Algoritmo FiloGenético. O Ca-

\footnotetext{
${ }^{3}$ Filograma é uma árvore representando uma filogenia que indica as relações entre taxa e também fornece uma estimativa de tempo ou taxa de evolução. Cladogramas não representam esse aspecto temporal (Salemi \& Vandamme, 2003).
} 
pítulo 5 introduz os principais algoritmos de detecção de comunidades em Redes Complexas. O Capítulo 6 descreve o CPA e a OPA. O Capítulo 7 apresenta os problemas usados para comparação dos algoritmos, que são benchmarks da literatura para explorar aspectos de problemas combinatórios que são desafiadores para EDAs, e também para outros EAs. O Capítulo 8 apresenta a análise de desempenho dos algoritmos. Por fim, o Capítulo 9 destaca as principais contribuições do método proposto e sugere trabalhos futuros baseados no CPA e na OPA. 



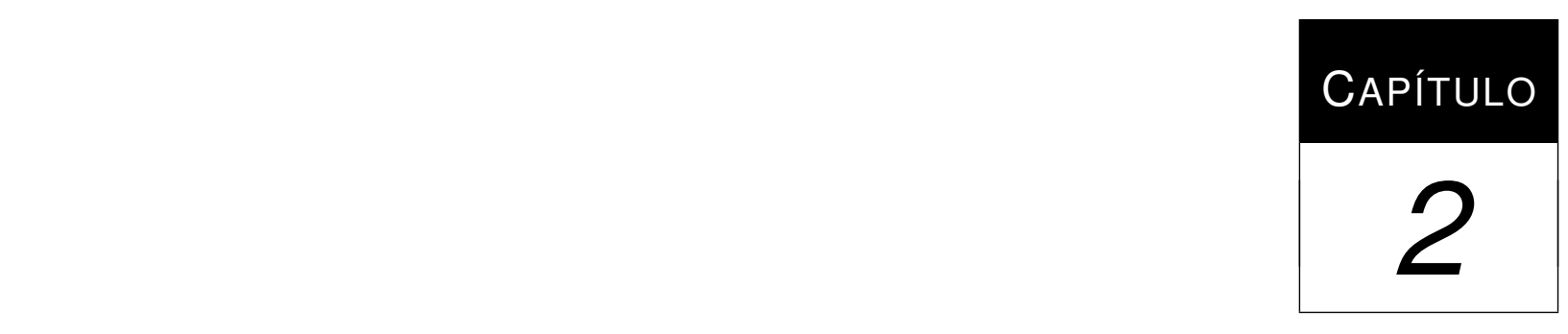

\section{Algoritmo de Estimação de Distribuição}

Alguns dos principais EDAs da literatura são apresentados neste capítulo. Com isso, pode-se entender os principais aspectos teóricos que fundamentam esses algoritmos, conhecer as classes de problemas (baseados em benchmarks da literatura) que podem resolver com eficácia e eficiência, além de suas limitações. A partir desse contexto, é possível especular sobre novos EDAs para se resolver problemas mais difíceis ou, com maior eficiência computacional.

Inicialmente, este Capítulo introduz a área de Computação Evolutiva (Seção 2.1) e os GAs (Seção 2.2), em geral utilizados como referência na descrição dos EDAs. A Seção 2.3 apresenta o problema de identificação dos BBs. A Seção 2.4 introduz os EDAs. A Seção 2.5 descreve o Algoritmo Genético Compacto. A Seção 2.6 explica o Algoritmo Genético Compacto Estendido. As Seções 2.7 a 2.10 descrevem o Algoritmo de Otimização Bayesiana e as principais características de outros algoritmos baseados em Redes Bayesianas. A Seção 2.11 apresenta conceitos sobre EAs Multiobjetivos. Por fim, a Seção 2.12 destaca os aspectos relevantes apresentados neste capítulo.

\subsection{Computação Evolutiva}

A Computação Evolutiva abrange um conjunto de EAs baseados na Teoria da Evolução das Espécies proposta por Darwin (Darwin, 1859). Cientistas da área de Biologia interessaram-se pelos EAs para o entendimento de processos evolutivos e a simulação de modelos de Evolução Natural. Cientistas de computação e engenheiros investigam o desenvolvimento desses algoritmos e o potencial deles para resolver uma série de problemas considerados complexos (DeJong, 2008).

Os principais componentes de um sistema evolutivo (DeJong, 2008) são: 
1. Uma ou mais populações de indivíduos concorrendo por recursos limitados;

2. A noção de mudanças dinâmicas nas populações devido ao nascimento e à morte dos indivíduos;

3. O conceito de aptidão, que reflete a habilidade do indivíduo para sobreviver e poder reproduzir;

4. A variação na hereditariedade, ou seja, os novos indivíduos preservam características dos seus pais, embora não sejam iguais.

Um EA típico mimetiza um sistema evolutivo conforme descrito a seguir. Inicialmente, uma população é formada gerando um conjunto inicial de vetores aleatórios descrevendo características de um indivíduo. Então os vetores são avaliados segundo algum critério, isto é, atribui-se um nível de aptidão para cada indivíduo. Com base na aptidão, seleciona-se um subconjunto deles, a partir dos quais são gerados novos vetores (mimetizando o processo de reprodução) que compõem uma nova população. Essa sequência de etapas forma um ciclo chamado de geração, conforme sintetizado na Figura 2.1.

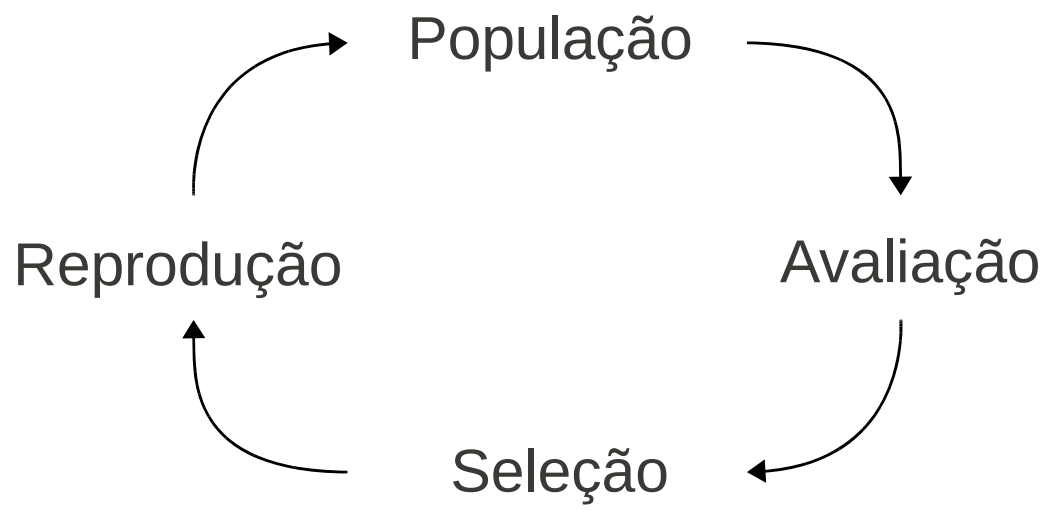

Figura 2.1: Etapas de uma geração de um EA típico.

\subsection{Algoritmos Genéticos}

Um GA é um tipo de EA inspirado tanto em mecanismos da Teoria da Evolução (a seleção das soluções mais promissoras para um problema) quanto da Genética (variáveis do problema são armazenadas em uma estrutura que representa computacionalmente um cromossomo, junto à qual ocorre recombinação e mutação (Gaspar-Cunha et al., 2012)). Esses algoritmos ganharam destaque principalmente a partir dos anos 1990s com aplicação em problemas das áreas de engenharia, otimização, inteligência computacional, bioinformática, entre outras (DeJong, 2008; Deb, 2001; 
Goldberg, 2002). Os cromossomos são usualmente cadeias de caracteres binários. A avaliação de cada indivíduo de uma população é realizada pela função objetivo do problema, que retorna um valor denominado aptidão (ou fitness) do indivíduo.

Com base nas aptidões, os indivíduos em geral são selecionados utilizando critérios como roleta $^{1}$, torneio ${ }^{2}$ ou truncamento ${ }^{3}$. Em seguida aplicam-se operadores de reprodução sobre os selecionados. Os operadores de reprodução do GA são a recombinação (também chamada de crossover) e a mutação. Esses operadores são fundamentais para o desempenho do GA, uma vez que definem como o espaço de busca será explorado a partir dos indivíduos de uma população. A recombinação mimetiza o processo de crossing-over da Genética separando cada vetor (cromossomos de dois indivíduos selecionados para reproduzir, também chamados de pais) em dois com base em uma posição do vetor, denominada de ponto de corte. Todas as possíveis combinações dessas partes são geradas (sem repetição de posição), gerando dois novos vetores (indivíduos).

O operador de mutação sorteia uma posição de um vetor e altera o seu valor (em geral a troca do valor de um bit). A Figura 2.2 mostra a reprodução de um GA a partir de dois indivíduos selecionados (Pai1 e Pai2) em que os operadores de recombinação e mutação são utilizados em sequência.

É importante notar na Figura 2.2 que a escolha do ponto de corte dos progenitores não leva em conta as correlações entre as variáveis. A determinação desse tipo de relação pode ser utilizada para aumentar o desempenho de EAs para problemas de maior complexidade, conforme mostra a Seção 2.3.

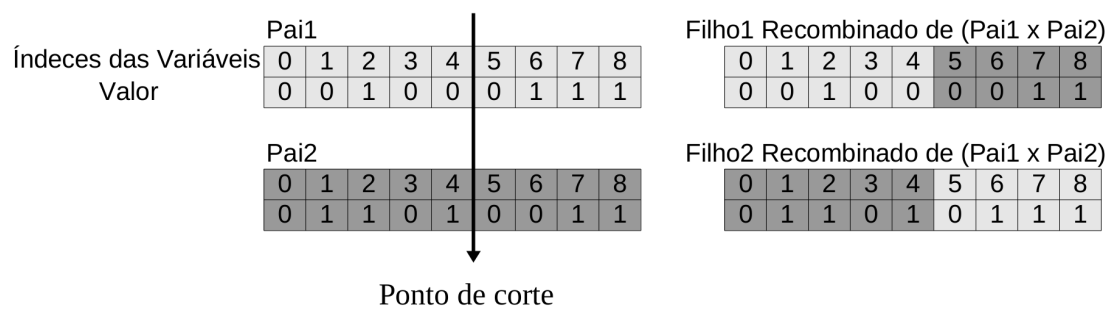

(a)

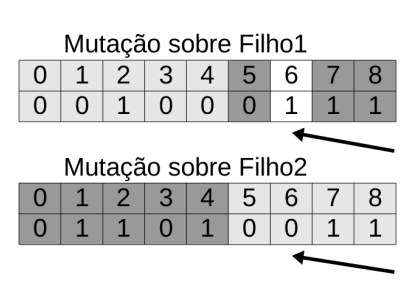

(b)

Figura 2.2: Recombinação (a) e Mutação (b) em um GA.

\subsection{Blocos Construtivos}

A dificuldade de um problema tem relação direta com a quantidade de variáveis a serem otimizadas e com a cardinalidade dessas (no caso de variáveis discretas), além de outros aspectos.

\footnotetext{
${ }^{1}$ Os indivíduos são ordenados de acordo com uma distribuição de probabilidades que decresce conforme também decresce o fitness (Gaspar-Cunha et al., 2012).

${ }^{2}$ Pequenos grupos de indivíduos são formados, de cada grupo é selecionado o indivíduo de maior fitness (GasparCunha et al., 2012).

${ }^{3}$ Os $n_{s}$ melhores indivíduos de uma população são selecionados, descartando o restante (Gaspar-Cunha et al., 2012).
} 
Por exemplo, ao trabalhar com variáveis binárias, tem-se um espaço de busca de tamanho $2^{\ell}$, em que $\ell$ é o número de variáveis. Outros dois fatores muito importantes são: a quantidade de BBs e o número de variáveis que os compõem. Para ilustrar a importância desses fatores, considere os três problemas distintos, representados na Figura 2.3. Nesses problemas, cinco variáveis binárias ( 5 bits) de um indivíduo são somados compondo o argumento $(u)$ de cada função de avaliação (fitness), conforme explicado a seguir:

1. Problema OneMax: consiste em maximizar a quantidade de variáveis iguais as de um ponto no espaço de busca (alvo). A Figura 2.3(a) mostra um exemplo em que o alvo é o vetor [11111]. Nesse caso, o fitness é diretamente igual à quantidade de variáveis com valor 1 ;

2. Problema de Senha: o fitness é 0 para todos os pontos do espaço de busca, exceto para um (o alvo). A Figura 2.3(b) ilustra esse problema para o caso em que o alvo é [11111];

3. Problema Armadilha (ftrap5) (Figura 2.3(c)): consiste em encontrar o máximo da função da Equação 2.1.

$$
\begin{gathered}
\max _{x} \operatorname{ftrap} 5(x), x \in\{0,1\}^{5}, \\
\operatorname{ftrap5}(x)=\operatorname{trap} 5\left(x_{0}+x_{1}+x_{2}+x_{3}+x_{4}\right), \\
\operatorname{trap} 5(u)= \begin{cases}5 & \text { se } u=5, \\
4-u & \text { se } u<5 .\end{cases}
\end{gathered}
$$

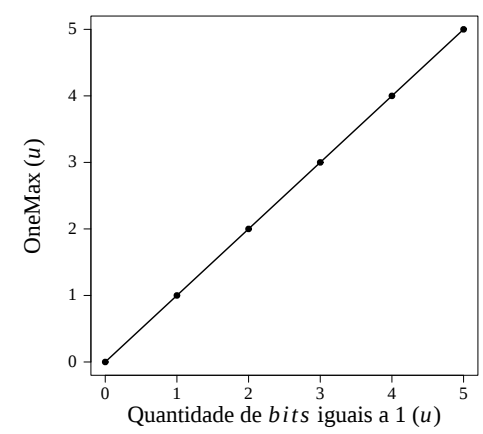

(a)

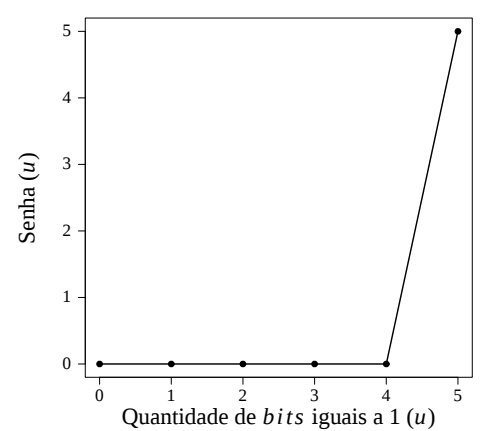

(b)

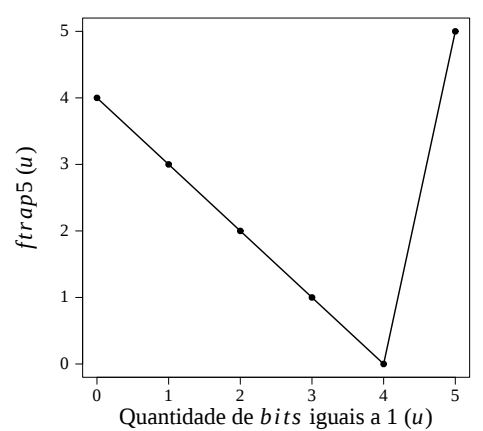

(c)

Figura 2.3: Problemas de otimização com 5 bits baseado em funções cujo argumento é a soma dos 5 bits.

Ao modificar o valor de um único bit de entrada no problema OneMax, a contribuição no fitness devido a uma mudança no valor de uma variável pode ser sempre determinada independentemente 
dos valores das demais variáveis. Com isso, a solução ótima pode ser construída investigando-se separadamente o melhor valor para cada variável. Assim, cada variável pode ser vista como um BB da solução do problema.

Por outro lado, nos problemas de Senha e Armadilha, ao modificar o valor de um bit sem considerar os valores das outras variáveis não se consegue determinar se a modificação do bit resulta em uma solução mais próxima no espaço de busca da solução ótima global. Nesses dois problemas é preciso sempre analisar os valores dos 5 bits em conjunto para avaliar o quanto a modificação de um bit aproxima a nova solução ao ótimo global. Esses 5 bits nos problemas de senha e armadilha são fortemente correlacionados e formam um único BB de tamanho 5.

A partir deste ponto, pode-se verificar que, embora todos esses 3 problemas tenham o mesmo espaço de busca $\left(2^{5}\right)$, os problemas de Senha e Armadilha são mais difíceis, pois seus BBs são de tamanho 5; enquanto o BB do problema OneMax é de tamanho 1. No problema OneMax, um algoritmo de busca local, é suficiente para garantir o ótimo global do problema (11111). No entanto, para o problema de Senha, uma meta-heurística ${ }^{4}$ pode ser tão eficiente quanto um algoritmo de busca aleatória, pois amostragens no espaço de busca quase sempre não retornam informação que possibilite orientar o algoritmo para o ótimo global. No problema Armadilha, a informação obtida de algumas amostras do espaço de busca em geral direciona o algoritmo para ótimos locais, ao invés do ótimo global. Nesse caso, o ótimo local é chamado de armadilha no contexto de EDAs.

Problemas mais complexos podem ser definidos a partir da composição dos problemas OneMax, Senha e Armadilha. Considere, por exemplo, o problema composto pelo somatório de três problemas Armadilha de 5 bits aplicando ftrap 5 a cada 5 bits disjuntos de uma string de 15 bits. Nesse caso, o número de BBs $(m)$ é igual a 3 e o tamanho de cada BB $(k)$ é 5.

Para problemas desse tipo, pode-se evitar que EAs fiquem presos em ótimos locais se o processo de busca ocorrer principalmente entre os BBs, preservando as melhores instâncias de cada BB (Goldberg, 2002). Para isso, a população inicial deve possuir um ou mais representantes de cada instância possível de um BB. Além disso, o operador de recombinação deve focar em combinar as instâncias mais promissoras de cada BB, preservando as melhores instâncias encontradas para cada um.

A Equação 2.2 (Goldberg, 2002) pode ser utilizada para estimar o tamanho da População Inicial de forma a se amostrar com alta probabilidade todas as possíveis instâncias de um BB.

$$
n=\chi^{k}(k \ln \chi-\ln \alpha)
$$

em que $n$ é o tamanho da população, $\chi$ é a cardinalidade das variáveis, $k$ é o tamanho de cada BB e $\alpha$ é a probabilidade de uma instância de um BB não estar representada na população. Como em

\footnotetext{
${ }^{4}$ Meta-heurísticas são heurísticas estocásticas de propósito geral que compreendem metodologias de exploração de espaços de soluções candidatas capazes de gerenciar operadores computacionais de busca local e de busca global, promovendo robustez e eficácia na procura de soluções (Gaspar-Cunha et al., 2012; Glover \& Kochenberger, 2003; Talbi, 2009; Alba et al., 2005).
} 
geral usa-se $\alpha=1 / m$ (aceita-se errar a instância de um $\mathrm{BB}^{5}$ ), pode-se reescrever a Equação 2.2, obtendo a Equação 2.3:

$$
n=\chi^{k}\left(k \ln \chi-\ln m^{-1}\right)
$$

ou

$$
n=\chi^{k}(k \ln \chi+\ln m)
$$

A Figura 2.4 apresenta as curvas teóricas sobre o tamanho da População Inicial necessária para amostrar adequadamente as possíveis instâncias dos BBs na população, além dos pontos obtidos experimentalmente (Apêndice $B$ de Crocomo (2012)). Observe que a complexidade de um problema aumenta conforme $k$ e $m$ aumentam. O tamanho do BB impacta mais na complexidade do problema do que o número de BBs.

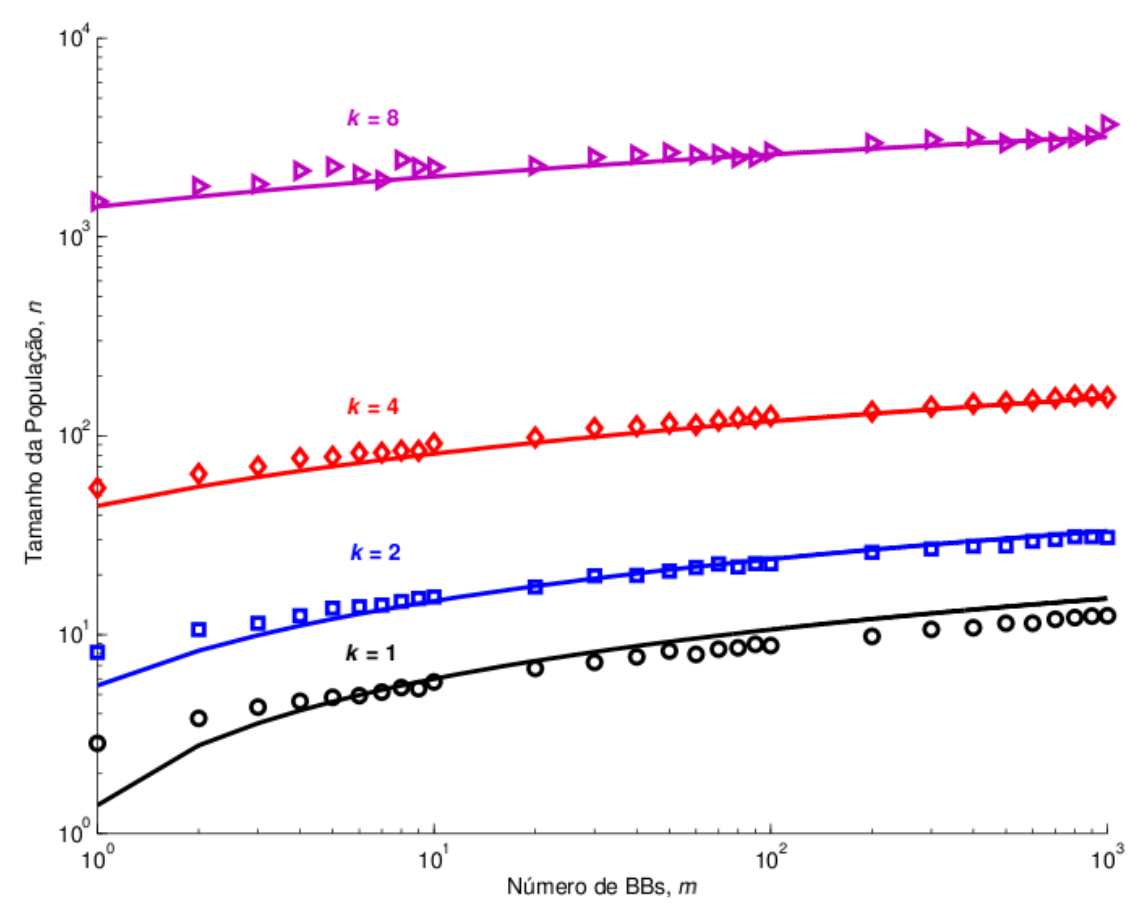

Figura 2.4: Tamanho da população $m$ para que, com confiança $\alpha=0,05$, para amostrar adequadamente as instâncias de cada BB.

No entanto, uma amostragem inicial adequada não é o suficiente para que o ótimo global seja alcançado. É necessário combinar as instâncias ótimas de cada BB antes de o algoritmo convergir. Para isso, é importante que tais instâncias não sejam eliminadas prematuramente. Isso pode ser atingido por meio da identificação dos grupos de variáveis correlacionadas, que formam BBs. Com base nesses grupos, a recombinação pode ser direcionada para misturar as melhores instâncias de

${ }^{5}$ É importante observar que a não aceitação de erro em geral implica em parâmetros com valores que tendem para o infinito, no caso, populações infinitas. Assim algum nível de erro é considerado para realizar estimativas a partir de modelos teóricos. 
BBs. Por exemplo, isso pode ocorrer combinando a instância ótima de um BB associado a uma função ftrap5 em um indivíduo com a ótima de outro BB associado a outra ftrap5 presente em outro indivíduo, aumentando a probabilidade de compor a solução ótima do problema.

\subsection{Algoritmos de Estimação de Distribuição}

Os EDAs, introduzidos por Mühlenbein (1997), utilizavam distribuição dos valores das variáveis para melhorar o procedimento de recombinação. Posteriormente, outros trabalhos incorporaram métodos para identificar correlações entre variáveis (Larrañaga \& Lozano, 2001). Esses modelos probabilísticos, de forma direta ou indireta, geram aproximações dos BBs de um problema.

A Figura 2.5 apresenta as etapas de um EDA. A diferença essencial em relação a um EA típico (Figura 2.1) é a construção de um modelo probabilístico com base nos indivíduos selecionados e o processo de reprodução baseado no modelo.

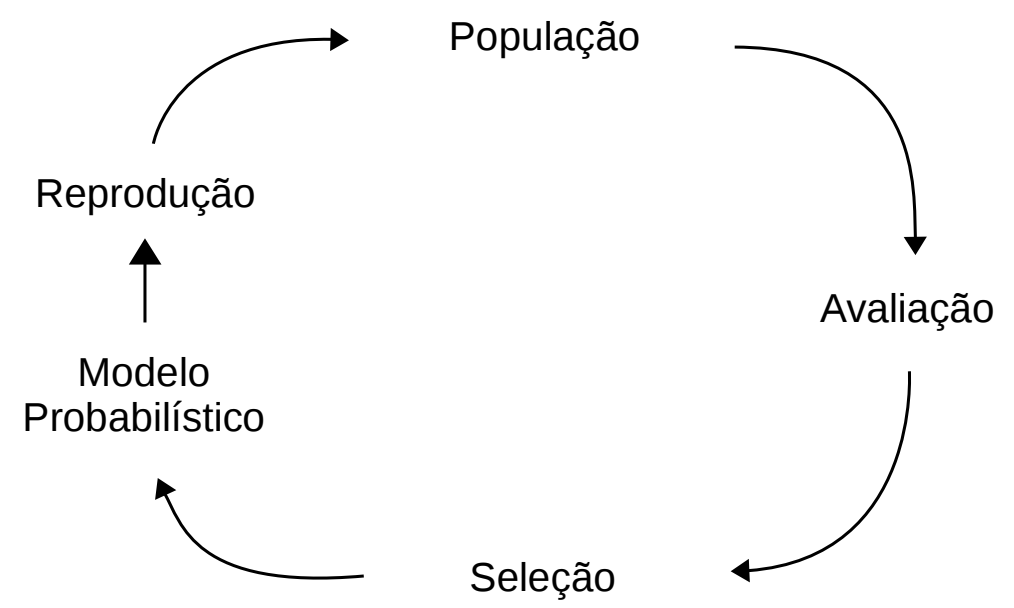

Figura 2.5: Etapas de um EDA típico.

Modelos que representem as melhores instâncias de cada BB podem evitar a convergência prematura para um ótimo local (armadilha) e requerer menos avaliações de soluções candidatas até convergir para o ótimo global. A representatividade do modelo pode melhorar com o aumento do número de amostras (indivíduos selecionados da população). Dessa forma, um EDA pode necessitar de uma população muitas vezes maior que um EA típico para que seu modelo seja vantajoso. O custo de uma população maior pode ser compensado por uma quantidade de gerações do EDA menor que a do EA.

Por outro lado, a construção do modelo probabilístico representativo por meio de um algoritmo computacionalmente eficiente é um dos principais desafios na área de EDAs. Em geral, tal construção requer alto custo computacional, com o custo aumentando com nível da representatividade do modelo. 
Na sequência são apresentados os algoritmos CGA, ECGA e BOA (Seções 2.5 a 2.7), que são exemplos de EDAs com resultados bem consolidados na literatura e que utilizam algoritmos para a criação e avaliação do modelo probabilístico que variam de simples a relativamente complexos. Dessa forma, ilustra-se como modelos melhores em geral requerem algoritmos computacionalmente mais complexos. A partir desse cenário, pode-se melhor definir caminhos promissores na investigação por EDAs que sejam mais eficazes e eficientes.

\subsection{Algoritmo Genético Compacto}

Uma das maneiras mais simples de construção de um modelo probabilístico é assumir que todas as variáveis do problema são independentes, isto é, BBs de tamanho um. O Algoritmo Genético Compacto (CGA, do inglês Compact Genetic Algorithm) (Harik et al., 1999) utiliza esse tipo de modelo. O CGA pode ser visto como a implementação de um GA por meio de um modelo probabilístico.

A população de indivíduos do CGA não é representada explicitamente como no GA. Em seu lugar, é utilizado um vetor de probabilidades do tamanho do cromossomo. Cada posição desse vetor indica a probabilidade do respectivo bit do cromossomo ser igual a 1 . Dessa forma, a população inicial (aleatória) é representada pelo vetor com probabilidade 0,5 para cada bit.

Para representar regiões promissoras do espaço de busca, as probabilidades no modelo podem ser alteradas. Como o modelo representa uma estatística sobre uma população de tamanho $n$, o "peso" ou a contribuição de cada indivíduo na população na amostragem do espaço de busca é de $1 / n$. Assim, as probabilidades de cada variável no modelo são alteradas pelo valor de $\pm 1 / n$ na direção de um indivíduo promissor. Para definir a direção, dois indivíduos são amostrados (gerados) a partir do modelo, o de melhor fitness (vencedor) fornecerá a direção para atualizar o modelo. Esse processo repete-se até que todas as probabilidades convirjam para zero ou um. A Figura 2.6 ilustra o funcionamento do CGA.

Por não utilizar uma população explícita, o CGA é um algoritmo eficiente em termos de consumo de memória. É possível demonstrar que o CGA tem desempenho similar ao de um GA para vários problemas (Harik et al., 1999).

\subsection{Algoritmo Genético Compacto Estendido}

O modelo probabilístico do CGA não considera correlações de variáveis, isto é, BBs maiores que um. Conforme apresentado na Seção 2.4, a identificação dessas correlações beneficia a amostragem das melhores instâncias dos BBs e também a combinação delas buscando gerar a solução ótima. Nessa linha de investigação foi desenvolvido o ECGA (do inglês, Extended Compact Genetic Algorithm), que possui um método que aprende as correlações de variáveis. Por meio desse método, chamado linkage learning, vários possíveis agrupamentos de variáveis são avalia- 


\begin{tabular}{|c|c|c|c|c|c|c|c|}
\hline \multirow[t]{2}{*}{$\begin{array}{l}\text { 1)Inicializa Modelo } \\
\text { Probabilístico }\end{array}$} & & 0,5 & 0,5 & 0,5 & 0,5 & & \multirow{4}{*}{\begin{tabular}{l|l|} 
& 3)Competição \\
\multirow{2}{*}{ Perdedor } \\
\end{tabular}} \\
\hline & Indivíduo & \multicolumn{4}{|c|}{ Cromossomo } & Fitness & \\
\hline \multirow{2}{*}{$\begin{array}{l}\text { 2)Gera } 2 \text { Indivíduos } \\
\text { a partir do Modelo }\end{array}$} & $A$ & 0 & 1 & 0 & 0 & 1 & \\
\hline & $B$ & 1 & 0 & 1 & 1 & 3 & \\
\hline \multirow{2}{*}{$\begin{array}{l}\text { 4)Atualiza Modelo } \\
\text { Probabilístico na } \\
\text { direção do vencedor }\end{array}$} & & $+0,1$ & $-0,1$ & $+0,1$ & $+0,1$ & & \\
\hline & & 0,6 & 0,4 & 0,6 & 0,6 & & \\
\hline
\end{tabular}

Figura 2.6: Funcionamento do CGA, supondo $n=10$ (variação de probabilidade $\pm 1 / n= \pm 0,1)$.

dos. Então, constrói-se uma distribuição de probabilidade para cada BB (partição) do agrupamento (particionamento) escolhido.

Avaliar todos os possíveis particionamentos das variáveis pode ser inviável computacionalmente. Assim, o linkage learning do ECGA parte do particionamento em que cada variável é uma partição e explora a vizinhança de todos os pares de junções (compondo uma partição maior) de certa partição com as demais. Esse processo pode obter particionamentos significativamente representativos de forma relativamente eficiente.

A partir do particionamento obtido são calculadas as probabilidades de ocorrência de cada instância de cada BB, conforme exemplificado a seguir. A Tabela 2.1 representa uma distribuição de probabilidades de um particionamento de quatro variáveis $(0,1,2$ e 3$)$. Entre colchetes estão as variáveis de um mesmo BB. $P[]$ mostra a probabilidade da partição correspondente. Por exemplo, a partição [0] contém somente a variável zero e a probabilidade de uma instância dessa partição ser zero é 0,8 e de ser 1 é 0,2 .

O particionamento completo contém as partições [0], [1,3] e [2]. Isso indica que o modelo representa as variáveis 0 e 2 independentemente e as variáveis 1 e 3 em conjunto. De acordo com a distribuição de probabilidades do exemplo, a solução candidata não pode ser gerada com o valor na posição 3 diferente do valor na posição 1 , visto que as probabilidades da partição $[1,3]$ para as combinações de valores (01) e (10) são iguais a 0. Portanto, a partir desse modelo podem ser amostradas as instâncias: 0000, 0010, 1000, 1010, 0101, 0111, 1101, 1111, mas não podem ser geraras as instâncias: 0001, 0011, 1001, 1011, 0100, 0110, 1100, 1110.

Tabela 2.1: Exemplo de distribuição de probabilidades de um particionamento.

\begin{tabular}{cc|cc|cc}
{$[0]$} & $P_{[0]}$ & {$[1,3]$} & $P_{[1,3]}$ & {$[2]$} & $P_{[2]}$ \\
\hline \hline 0 & 0,8 & 00 & 0,4 & 0 & 0,5 \\
1 & 0,2 & 01 & 0 & 1 & 0,5 \\
& & 10 & 0 & & \\
& & 11 & 0,6 & & \\
\hline
\end{tabular}


Considere uma população com $n$ indivíduos, em que uma parte deles possue representação 00000 e a restante, 11111. Para armazenar essa população poderiam ser usados $5 n$ bits. Por outro lado, um modelo que usasse o particionamento $[0,1,2,3,4]$ (todas as variáveis na mesma partição) poderia precisar representar a probabilidade de cada uma das 32 combinações de bits $\left(2^{5}\right.$ bits), independentemente do tamanho de $n$. Além disso, detectando que somente 00000 e 11111 teriam probabilidade maior que 0 de ocorrer, o cromossomo 00000 poderia ser representado por um bit 0 e o cromossomo 11111 somente pelo bit 1. Com isso, é possível representar a população usando apenas $n$ bits (1 bit por indivíduo), resultando no modelo mostrado na Tabela 2.2.

Tabela 2.2: Exemplo da representação de um modelo usando 1 bit para armazenar as duas possíveis instâncias da partição [0,1,2,3,4], ( $q$ é a quantidade do cromossomo 00000 na população de tamanho $n$ ).

\begin{tabular}{cc}
{$[0,1,2,3,4]$} & $P_{[0,1,2,3,4]}$ \\
\hline \hline 0 & $q / n$ \\
1 & $(n-q) / n$ \\
\hline
\end{tabular}

Uma estimativa da quantidade de bits necessária para implementar um modelo de distribuição (conforme Tabela 2.2) pode ser obtida pela Equação 2.4. Essa estimativa é chamada de Complexidade da População Comprimida, ou simplesmente $C_{p}$.

$$
\begin{gathered}
C_{p}=n \sum_{i=1}^{m} C_{p_{i}} \\
C_{p_{i}}=\sum_{j=1}^{2^{k_{i}}}-p_{i j} \log _{2}\left(p_{i j}\right),
\end{gathered}
$$

em que $p_{i j}$ é a frequência da $j$-ésima instância possível para a partição $i, j \in\left[1,2^{k_{i}}\right]$ para a partição $i$, tal que $k_{i}$ é o tamanho da partição e $m$ é o número de partições no modelo. Em outras palavras, $p_{i j}=n_{i j} / n$, em que $n$ é o tamanho da população de selecionados que possui $n_{i j}$ réplicas da $j$-ésima instância da partição $i$.

A quantidade de bits necessária para representar todas as probabilidades marginais é chamada de Complexidade do Modelo, $C_{m}$. A Equação 2.5 calcula $C_{m}$. A complexidade total do modelo é chamado Critério de Complexidade Combinada, $C_{c}$, tal que $C_{c}=C_{p}+C_{m}$.

$$
C_{m}=\log _{2} n \sum_{i=1}^{m}\left(2^{k_{i}}-1\right)
$$

Em resumo, o ECGA utiliza um algoritmo guloso (Cormen et al., 2001) que explora vários possíveis particionamentos para modelar os indivíduos selecionados de uma população. Cada particionamento é avaliado pelo $C_{c}$. O particionamento de menor $C_{c}$ é escolhido. A Figura 2.7 sintetiza a construção e a avaliação de um modelo pelo ECGA. 


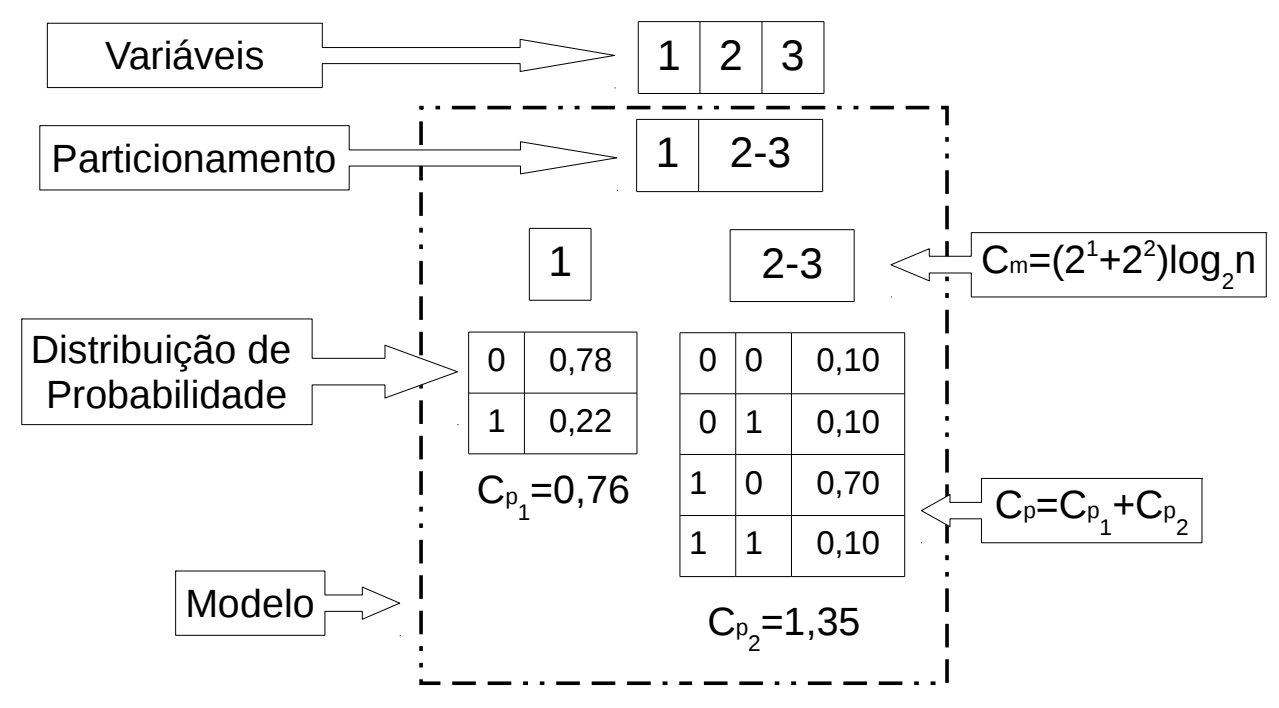

Figura 2.7: Construção de um modelo pelo ECGA e sua avaliação pelo $C_{c}$.

A Seção 2.7 descreve o BOA, um dos principais EDAs da literatura que também é capaz de construir modelos que detectam correlações entre variáveis formando BBs maiores que um. É importante observar que o BOA é utilizado neste trabalho para comparação de desempenho com a OPA, proposta no Capítulo 6.

\subsection{Algoritmo de Otimização Bayesiana}

O BOA utiliza um modelo probabilístico relativamente complexo, uma Rede Bayesiana (BN, do inglês Bayesian Network) (Pelikan et al., 1999) para modelar soluções promissoras e, consequentemente, orientar a exploração do espaço de busca. Nessa rede, cada nó representa uma variável do problema e cada aresta orientada uma possível correlação entre duas variáveis.

Após a geração de uma População Inicial aleatória e uma seleção de soluções promissoras, o BOA constrói uma BN. Para isso, são necessários uma técnica de busca para a construção da rede e uma métrica que avalie a qualidade de cada rede. De maneira simplificada, a Figura 2.8 descreve o funcionamento do BOA: (a) a BN é construída formando componentes conexos (Diestel, 2006); (b) é estimada uma distribuição de probabilidades condicionais é estimada conforme as relações representadas na $\mathrm{BN}$.

BNs podem gerar modelos multivariados, que não correspondem a um particionamento exato do conjunto das variáveis, ou podem também possuir partições com variáveis sobrepostas. Assim, as BNs tem se mostrado vantajosas em relação aos modelos do ECGA para problemas com sobreposição de BBs e hierárquicos, dentre outros.

Uma variável e o nó correspondente são ambos denotados por $X_{i}$. Cada variável corresponde a uma posição $i$ em um vetor binário $X$, que representa uma solução. O relacionamento entre $X_{i} \mathrm{e}$ $X_{j}(i \neq j)$ é indicado por uma aresta orientada (arco) entre $X_{i}$ e $X_{j}$. Uma BN é um grafo acíclico 


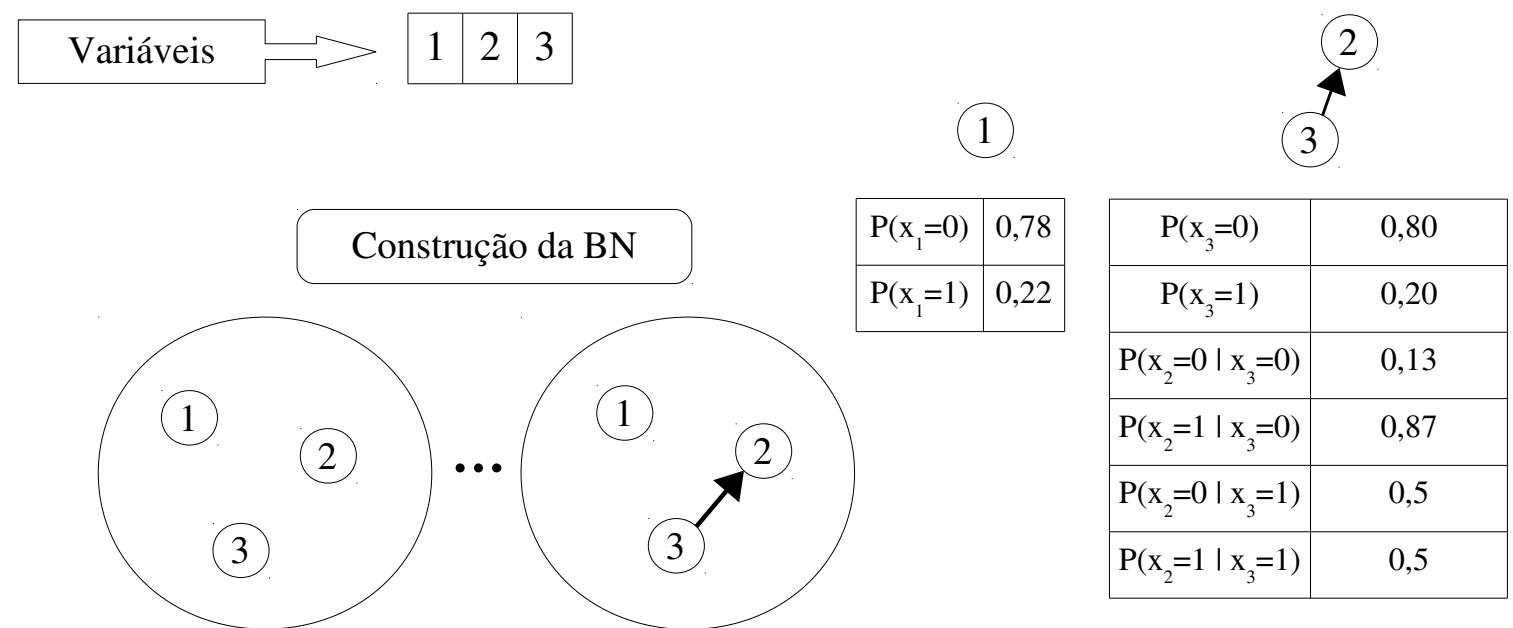

(a)

(b)

Figura 2.8: Construção de BN (a) e modelo de distribuição de probabilidades usado pelo BOA (b), obtido a partir das relações de dependência presentes na BN.

com arestas orientadas, associada a distribuição de probabilidades $P(X)$ (Equação 2.6) obtidas a partir de probabilidades condicionais $P\left(X_{i} \mid \pi_{i}\right)$.

$$
P(X)=\prod_{i=1}^{\ell} P\left(X_{i} \mid \pi_{i}\right)
$$

em que, $X=\left(X_{0}, \ldots, X_{\ell-1}\right)$ é um vetor de variáveis, $\ell$ é o tamanho do vetor, $\pi_{i}$ são as variáveis pais de $X_{i}$ na rede (nós que contêm arcos apontando para $\left.X_{i}\right) ; P\left(X_{i} \mid \pi_{i}\right)$ é a probabilidade de $X_{i}$ condicional aos valores de seus pais $\left(\pi_{i}\right)$.

As probabilidades podem ser calculadas e utilizadas para gerar novas soluções candidatas, a partir das quais uma nova BN é construída, produzindo melhores soluções a cada iteração do algoritmo. Para isso, é necessário um modelo para a construção de uma BN, dado um conjunto de dados de entrada. O algoritmo K2 (Cooper \& Herskovits, 1992) é o método utilizado pelo BOA para a construção de BNs.

A métrica de uma $\mathrm{BN}\left(B_{s}\right)$ calculado pelo algoritmo K2 a partir de um conjunto de dados $(D)$, chamada de $P\left(B_{s}, D\right)$, é descrita pela Equação 2.7 .

$$
P\left(B_{s}, D\right)=P\left(B_{s}\right) \prod_{i=1}^{\ell} \prod_{j=1}^{q_{i}} \frac{\left(r_{i}-1\right) !}{\left(N_{i j}+r_{i}-1\right) !} \prod_{k=1}^{r_{i}} N_{i j k} !,
$$

em que $P\left(B_{s}\right)$ refere-se à informação prévia sobre a qualidade da rede $\left(P\left(B_{s}\right)=1\right.$ se não há conhecimento a priori), $\ell$ é o número de variáveis $X_{i}, q_{i}$ é o número de possíveis valores encontrados na base de dados para as variáveis pais $\pi_{i}$ de $X_{i} ; r_{i}$ é o número de possíveis valores associados à variável $X_{i} ; N_{i j k}$ é o número de casos em $D \operatorname{com} X_{i}=v_{i k}$ e $\pi_{i}=w_{i j}$, em que $v_{i k}$ representa o 
$k$-ésimo valor possível (entre os $r_{i}$ valores existentes) da variável $X_{i}$, e $w_{i j}$ a $j$-ésima combinação possível (das $q_{i}$ combinações existentes em $D$ para os valores das variáveis pais de $X_{i}, N_{i j}$ é o número de ocorrências que possuem $\pi_{i}=w_{i j}$, dado por: $N_{i j}=\sum_{k=1}^{r_{i}} N_{i j k}$. Um exemplo didático do cálculo de $P\left(B_{s}, D\right)$ é apresentado em Crocomo (2012).

A Equação 2.7 pode ser reescrita utilizando a função $g$, dada pela Equação 2.8.

$$
g\left(i, \pi_{i}\right)=\prod_{j=1}^{q_{i}} \frac{\left(r_{i}-1\right) !}{\left(N_{i j}+r_{i}-1\right) !} \prod_{k=1}^{r_{i}} N_{i j k} !
$$

O algoritmo K2 é iniciado a partir de um grafo sem arcos (BBs de tamanho um), então uma busca gulosa a cada iteração escolhe um novo arco que será inserido na rede. A modificação na pontuação da BN pela inserção de um arco é dada por $g\left(i, \pi_{i}\right)$.

Os fatoriais na Equação 2.8 em geral produzem números muito grandes, podendo causar overflow de representação numérica. Para se evitar isso, utiliza-se a forma logarítmica da expressão, substituindo $g(i, p i)$ por $\ln (g(i, p i))$, conforme a Equação 2.9 .

$$
\ln \left(g\left(i, \pi_{i}\right)\right)=\sum_{j=1}^{q_{i}} \ln \left(\left(r_{i}-1\right) !\right)-\ln \left(\left(N_{i j}+r_{i}-1\right) !\right)+\sum_{k=1}^{r_{i}} \ln \left(N_{i j k} !\right)
$$

As relações de três níveis de relações em uma BN, requerida pelo cálculo de $N_{i j k}$, pode tornar a exploração do espaço de busca da BNs computacionalmente inviável dependendo do tamanho e da estrutura da BN. Para controlar esse aspecto, o BOA utiliza uma estimativa inicial do tamanho esperado dos BBs do problema, denominado $v$. Uma outra estratégia para contornar isso foi proposta em Crocomo (2012), que resultou no CD-BOA (Seção 2.9).

\subsection{Algoritmo de Otimização Bayesiana Hierárquico}

O BOA hierárquico (hBOA, do inglês hierarchical BOA) busca melhor mapear as relações entre variáveis de um problema. Para isso, o hBOA usa uma estratégia que lhe possibilita representar certo nível de hierarquia de dependência entre variáveis. Esse algoritmo pode resolver vários problemas separáveis e hierárquicos (Capítulo 7). O hBOA tem duas diferenças principais em relação ao BOA:

1. Usa Árvores de Decisão ao invés de tabelas de probabilidades conjuntas. As árvores possibilitam basicamente aprender as relações (arestas) $\left(i, \pi_{i}\right)$ mais relevantes e, por meio de podas da árvore, eliminar relações pouco significativas. Isso reduz o número de arestas na BN aumentando a eficiência do hBOA (Pelikan \& Goldberg, 2001). As árvores de certa forma mapeiam relações hierárquicas entre grupos de variáveis. Assim, para problemas que podem ser decompostos em subproblemas de forma hierárquica, em geral, o hBOA apresenta melhor desempenho que o BOA; 
2. Aplica um método de niching chamado RTR (Restricted Tournament Replacement) (Harik, 1994). Para cada nova solução gerada, vários indivíduos são selecionados aleatoriamente na população e o indivíduo mais similar à nova solução é substituído se tiver fitness pior, caso contrário não é substituído. O RTR busca garantir a preservação da diversidade de soluções promissoras, além de tornar o algoritmo mais eficiente.

\subsection{Algoritmo de Otimização Bayesiana com Detecção de Comunidades}

A BN obtida pelo BOA pode ser melhorada significativamente, por meio de um algoritmo de detecção de comunidades da área de Redes Complexas (Newman \& Girvan, 2004). Essa técnica foi denominada de Algoritmo de Otimização Bayesiana com Detecção de Comunidade (CD-BOA, do inglês Community Detection-BOA).

A Figura 2.9 destaca os dois novos procedimentos adicionados ao BOA original, indicados pelas Setas 3 e 4. Tanto o BOA quanto o CD-BOA começam gerando uma População Inicial aleatória. Em seguida, são executadas as seguintes etapas:

1. As soluções da população são avaliadas para a determinação de um conjunto de indivíduos promissores (selecionados). No CD-BOA e BOA, a seleção utilizada foi o truncamento, em que a metade das soluções com melhores valores de fitness é escolhida;

2. Uma BN é gerada a partir de um algoritmo K2 (Seção 2.7), passando o parâmetro de entrada $v_{l}$ (lower $v$, número máximo de nós pais na primeira execução recursiva da $\mathrm{BN}$ ) no lugar do parâmetro $v$ utilizado no BOA;

3. Um algoritmo de detecção de comunidades é aplicado sobre a BN para identificar BBs. O algoritmo de detecção utilizado é o Algoritmo Rápido adaptado (aFA, do inglês adapted Fast Algorithm) também proposto em Crocomo (2012), como uma extensão do Algoritmo Rápido (FA, do inglês Fast Algorithm) (Newman \& Girvan, 2004). O tamanho máximo das comunidades encontradas é limitado pelo parâmetro $v_{u}$ (upper $v$, número máximo de nós pais após a estrutura de comunidades ser detectada na BN). Observe que somente o CDBOA possui esta Etapa 3 (ver Seta 3 na Figura 2.9) e o parâmetro $v_{u}$ não é usado no BOA;

4. Conexões entre nós de uma mesma comunidade são adicionadas, aumentando a força de relações entre essas variáveis. Observe que a BN é gerada a partir de um conjunto de dados amostrados (conjunto de indivíduos selecionados na Etapa 1), com isso, algumas relações entre variáveis podem não estar amostradas no conjunto, principalmente, conforme $k$ e $m$ aumentam (ver Seção 2.3). O algoritmo K2 realiza uma busca gulosa para a construção da BN, com isso, não são analisadas todas as possíveis topologias de redes, construindo em 
geral uma rede sub-ótima, isto é, com imperfeições. Dessa forma, a detecção de comunidades funciona como uma técnica de reparo, efetuando algumas mudanças que possibilitam construir BNs mais confiáveis. Esta Etapa 4 também não ocorre no BOA;

5. Novas soluções são geradas a partir da BN obtida. Essa etapa é realizada da mesma forma que no BOA (Figura 2.8).

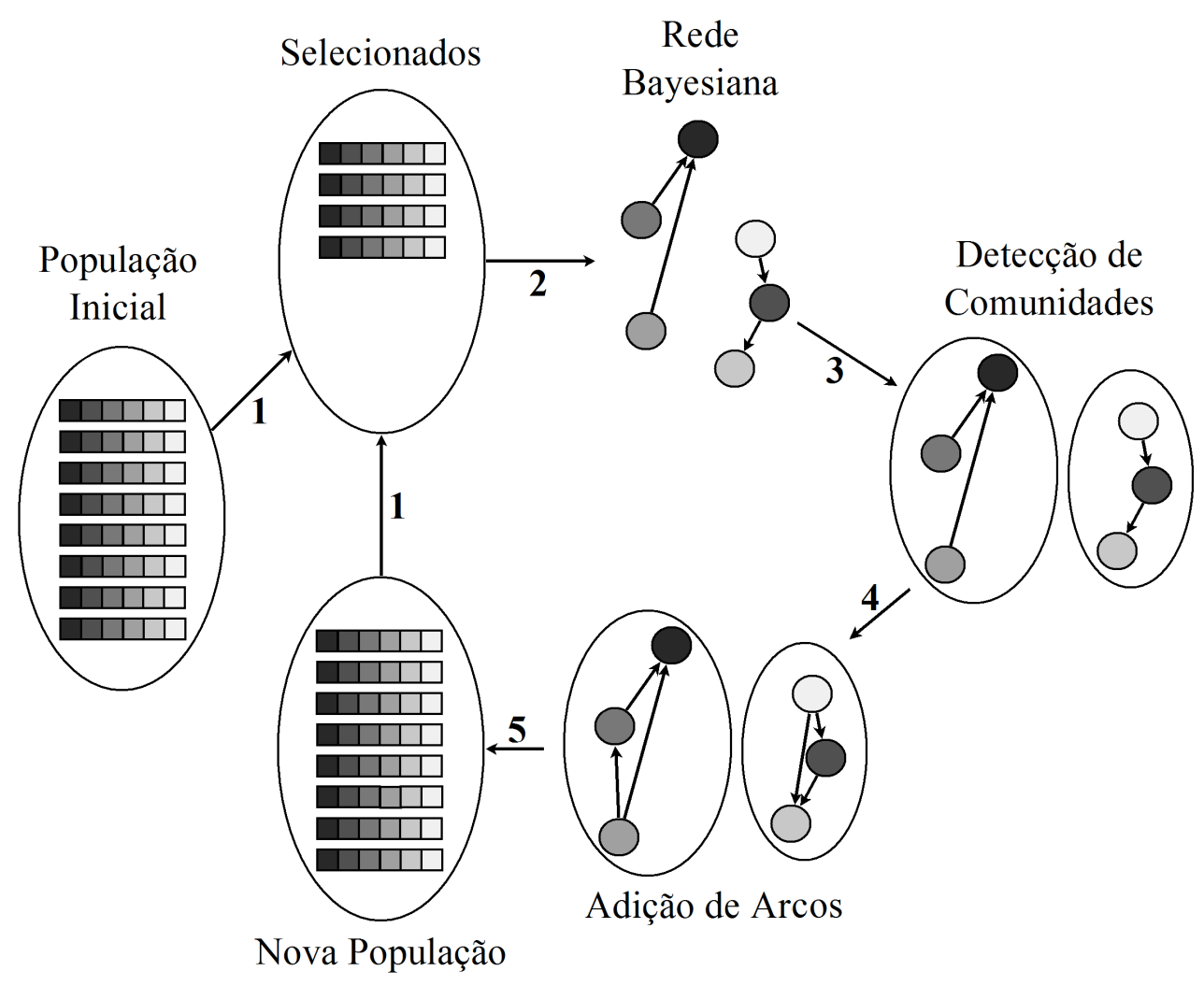

Figura 2.9: Ilustração do funcionamento do CD-BOA, obtida de (Crocomo, 2012).

Por fim, é importante observar que os parâmetros $v_{l}$ e $v_{u}$ do CD-BOA substituem o $v$ do BOA. Apesar de usar um parâmetro a mais que o BOA, o CD-BOA requer menos informação que o BOA, uma vez que os dois parâmetros do CD-BOA definem o intervalo $\left[v_{l}, v_{u}\right]$ em que se espera que estejam todos os tamanhos de BBs do problema; enquanto o BOA pode requerer uma aproximação mais precisa dos tamanhos dos BBs, dada por $v$ para atingir nível similar de desempenho. $\mathrm{O}$ uso de $v_{l}$ e $v_{u}$ é mais evidente e importante em problemas com BBs de tamanhos bem distintos, em que $v$ não é uma estimativa adequada.

\subsection{Otimização Direta}

O algoritmo de Otimização Direta (StrOp, do inglês Straight Optimization) foi proposto pelo mesmo autor do CD-BOA. Seu funcionamento sintetizado na Figura 2.10, consiste basicamente de uma iteração do CD-BOA seguida de uma otimização em que se compõe a solução final. A 
Etapa $A$ (uma iteração do CD-BOA) é representada pelas Setas 1, 2 e 3; enquanto a Etapa $B$ (otimização), é representada pela Seta 4.

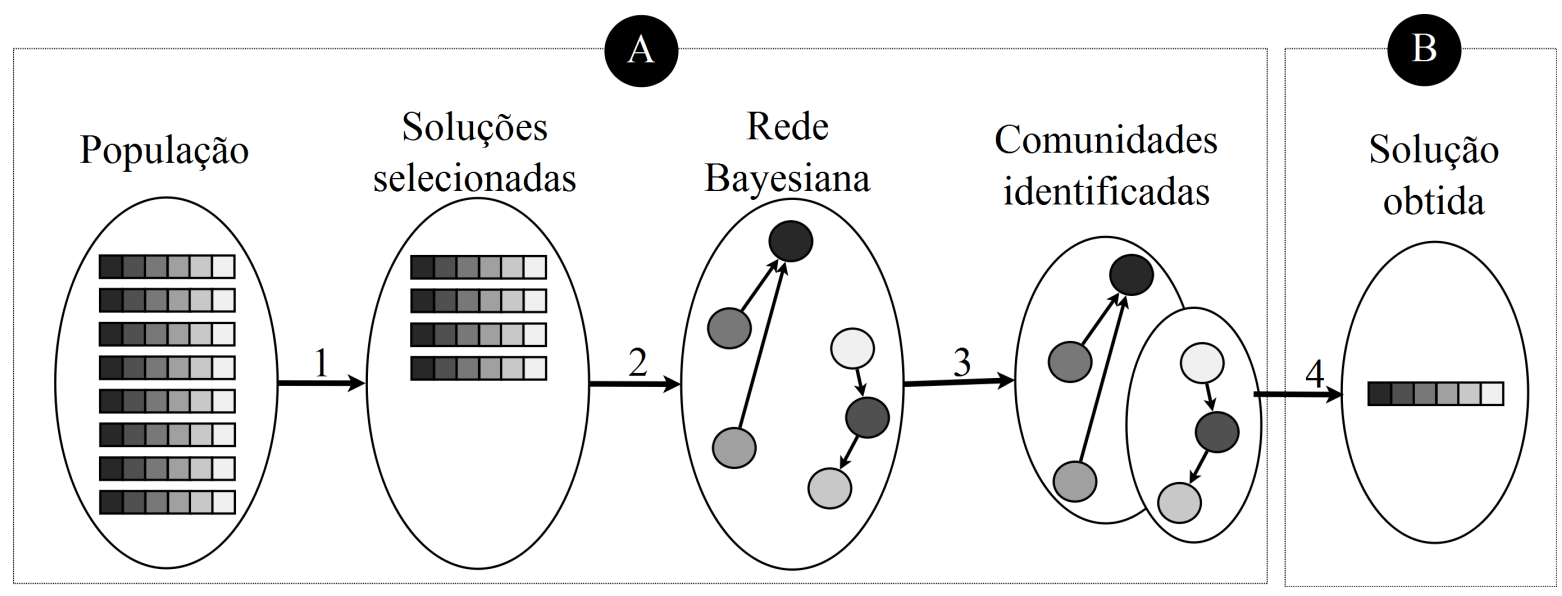

Figura 2.10: Funcionamento do StrOp, figura retirada de Crocomo (2012).

A Etapa B (representada pela Seta 4) utiliza uma Busca Exaustiva (ES, do inglês Exhaustive Search) (ver Seção 4.3) aplicada a cada BB identificado na Etapa A. O StrOp possui eficiência computacional diferenciada para ASDP (Seção 7.4), pois esse algoritmo em geral consegue determinar, com precisão, os subproblemas independentes que compõem um ASDP e encontra o valor ótimo de cada subproblema. A partir desses resultados, o StrOp constrói então a solução ótima do problema.

\subsection{Algoritmos Evolutivos Multiobjetivos}

Os Algoritmos Evolutivos Multiobjetivos (MOEAs, do inglês Multiobjective Evolutionary Algorithms) estão entre as mais importantes contribuições da computação evolutiva em otimização. Em Problemas de Otimização Multiobjetivos (MOOPs, do inglês Multiobjective Optimization Problems), as soluções são avaliadas em relação a um conjunto de objetivos.

As funções objetivo empregadas nos MOOPs podem ser organizados em um vetor de objetivos $F(x)=\left[f_{1}(x), \ldots, f_{N O}(x)\right]^{T}$, em que $x \in \Omega$, sendo $\Omega$ o espaço de decisão e $x$ um ponto (solução candidata) nesse espaço, $f_{i}: \Omega \rightarrow \Gamma, i=1, \ldots, N O$, em que $\Gamma^{N O}$ é o espaço dos objetivos. Os objetivos de $F$ podem conflitar um com o outro, busca-se então encontrar soluções que possuam o melhor compromisso possível entre os objetivos. Esse compromisso pode ser formulado conforme seque.

Definição 1. Diz-se que um vetor $z=\left[z_{1}, \ldots, z_{N O}\right]^{T}$ domina um outro vetor $w=\left[w_{1}, \ldots, w_{N O}\right]^{T}$, o que é denotado por $z \prec w$, se e somente se, $z_{i} \leq w_{i}$ e $z_{i} \neq w_{i}$ para $\forall i \in 1, \ldots, N O$ e $\exists j \in 1, \ldots, N O$ tal que $z_{j}<w_{j}$.

Definição 2. Uma solução factível $x^{*} \in \Omega$ do problema de minimizar $F(x)$ tal que $x \in \Omega$ é chamada uma solução Pareto-ótima, se e somente se, $\nexists y \in \Omega$ tal que $F(y) \prec F\left(x^{*}\right)$. O conjunto de 
todas as soluções Pareto-ótimas é chamado de conjunto Pareto-ótimo. A imagem desse conjunto no espaço dos objetivos é chamada de fronteira Pareto-ótima.

Diversos MOEAs foram propostos baseados no conceito do dominância (e outros conceitos relacionados) (Zhou et al., 2011). Dentre elas, pode-se destacar o NSGA-II (Deb et al., 2000) e o SPEA-2 (Zitzler \& Thiele, 1999)), que foram aplicados a diversos problemas do mundo real. Entretanto, em Deb (1999) mostra-se que esses algoritmos possuem certa dificuldade ao se aumentar o número de objetivos, ocorrendo convergência prematura em diversos problemas. Além disso, tais MOEAs em geral garantem apenas soluções com certa proximidade da fronteira Pareto-ótima, não obtendo soluções na fronteira.

Existem também alguns Algoritmos de Estimação de Distribuição Multiobjetivos (MOEDA, do inglês Multiobjective Estimation of Distribution Algorithm) desenvolvidos mais recentemente. Dentre eles podem se destacar o moECGA (do inglês, Multiobjective Extended Compact Genetic Algorithm)(Sastry et al., 2005), o mohBOA (do inglês, Multiobjective Hierarchical Bayesian Optimization Algorithm)(Pelikan et al., 2005) e o moథGA (Martins et al., 2011), que são, respectivamente as extensões multiobjetivo de ECGA (Seção 2.6), do BOA (Seção 2.7) e do ФGA (Capítulo 4). Esses MOEDAs podem ser descritos de forma simplificada como o seu correspondente mono-objetivo trocado o critério de seleção por um.

Em especial, o moథGA gera soluções candidatas a partir das instâncias de BBs obtidas aplicando o $\Phi$ GA para cada objetivo separadamente. Por fim, o critério de dominância é usado para determinar um conjunto de soluções não-dominadas a partir dessas soluções candidatas. Para os problemas testados em (Martins et al., 2011), o mo $\Phi$ GA mostrou ser capaz de encontrar o conjunto Pareto-ótimo completo com um número de avaliações significativamente inferior ao do mohBOA, por exemplo.

\subsection{Considerações finais}

Esse Capítulo apresentou os conceitos básicos de EAs, introduziu alguns dos principais EDAs e os princípios de MOEAs. Dentre esses algoritmos, os EDAs têm apresentado desempenho relevante (como técnicas de busca e otimização) quando aplicados a problemas relativamente complexos.

Um dos principais desafios para o aumento de desempenho dos EDAs são a obtenção de algoritmos que construam melhores modelos probabilísticos sem aumentar demasiadamente o tempo computacional. Os EDAs em geral necessitam de algum conhecimento a priori sobre o domínio do problema (como estimativa do tamanho esperado dos BBs), o que não se sabe para vários problemas do mundo real. Os resultados promissores do $\Phi \mathrm{GA}$ e do mo $\Phi \mathrm{GA}$ em relação a esses aspectos desafiadores motivaram o desenvolvimento do algoritmo de Otimização baseado em Análise de Filogramas (OPA, Seção 6.3), proposto neste trabalho. 

CAPÍTULO

3

\section{Métodos de Reconstrução Filogenética}

Filogenias são em geral utilizadas para representar hipóteses da história evolutiva de espécies ou de outros objetos biológicos. A inferência da árvore que se adéqua melhor a um conjunto de dados é uma tarefa computacionalmente complexa se o número de objetos for relativamente grande. Existem vários métodos para a inferência de filogenias, os quais podem ser classificados de diferentes maneiras segundo a literatura pesquisada (Salemi \& Vandamme, 2003; Morrison, 1996; Page \& Holmes, 1998; Swofford et al., 1996). Neste trabalho foi adotada a classificação elaborada por Swofford et al. (1996), segundo a qual os métodos de reconstrução de filogenia podem ser divididos em duas classes: os métodos de agrupamento ou algorítmicos (Seção 3.1) e os métodos baseados em critérios de otimalidade (Seção 3.2).

\subsection{Métodos de Agrupamento}

Os métodos de agrupamento realizam uma série de junções sucessivas de dois nós folhas (espécies) ou nós internos por meio de um nó ancestral conectado a esses dois nós. Esse processo continua até que não haja mais nós para juntar, formando uma árvore. Nessa categoria, dois algoritmos destacam-se por terem uma implementação simples em relação a algoritmos baseados em critérios de otimalidade (Seção 3.2) e apresentarem eficiência computacional que possibilita lidar com conjunto de dados relativamente grandes: o Método de Agrupamento de Pares não Ponderado baseado na Média Aritmética (UPGMA, do inglês Unweighted Pair Group Method with Arithmetic) (Sokal \& Michener, 1975) e o algoritmo Junção de Vizinhos (NJ, do inglês Neighbor Joining) (Saitou \& Nei, 1987; Studier \& Keppler, 1988), um dos algoritmos mais utilizados na 
literatura da área. A eficiência computacional desses métodos deve-se ao fato deles não exigirem a avaliação de um grande número de possíveis árvores, conforme requerem os métodos de otimalidade (Seção 3.2). A princípio, os métodos de agrupamento constroem apenas uma árvore como resposta.

Os métodos de agrupamento partem de uma Matriz Distância. O cálculo dessa matriz em Biologia geralmente baseia-se em um conjunto de sequências de DNA. Para se determinar distâncias nesse contexto, usam-se métricas baseadas em modelos de substituição de nucleotídeos. Esses modelos consideram diferentes níveis de detalhamento em relação à taxa de ocorrência de cada tipo de substituição de nucleotídeos. No Apêndice F são explicadas as métricas: Jukes e Cantor (Jukes \& Cantor, 1969), Kimura 2-Parâmetros (Kimura, 1980) e o modelo proporcional de Felsenstein, denominado F84 (Felsenstein, 2003). Existem também métricas para sequência de aminoácidos, possibilitando que métodos de agrupamento gerem filogenias de proteínas. Tanto para sequências de nucleotídeos quanto de aminoácidos, em geral as sequências precisam ser primeiramente alinhadas de forma a se conseguir aplicar adequadamente medidas de distância, como as descritas no Apêndice F. A determinação do melhor alinhamento de múltiplas sequências é um problema computacionalmente complexo. Para se contornar essa dificuldade, é em geral utilizado um alinhamento aproximado das sequências que pode ser obtido, por exemplo, pelo algoritmo CLUSTAL (HIGGINS \& Sharp, 1988) e suas extensões (Larkin et al., 2007).

Os métodos de agrupamento podem ser aplicados para dados envolvendo outros tipos de objetos se uma Matriz Distância for obtida. Para isso, pode ser utiliza uma métrica adequada para cada tipo de objeto como, por exemplo, a Informação Mútua (MI, do inglês Mutual Information) (Apêndice F) ou pode ser empregada uma métrica "universal" (que independe do tipo de dado) como a Distância de Compressão Normalizada (NCD, do inglês Normalized Compression Distance) (Apêndice F).

\subsubsection{Neighbor Joining}

A partir das distâncias entre variáveis obtidas por uma métrica (como por exemplo a MI) uma Matriz Distância é obtida, a qual estima a intensidade das relações entre cada par de amostras dos dados. Observe que, em um problema de otimização, cada amostra pode ser um conjunto de valores para uma variável que estão presentes nas soluções promissoras encontradas. Usando essa matriz, pode-se aplicar um método de reconstrução de filogenias.

O NJ é um dos métodos de agrupamento mais utilizados em Bioinformática, para a construção de filogenias sem raiz (Saitou \& Nei, 1987; Studier \& Keppler, 1988). Esse método baseia-se no princípio da Evolução Mínima (Rzhetsky \& Nei, 1993), para a construção de uma estrutura de dados da árvore binária. Esse princípio considera que a melhor hipótese filogenética pode ser obtida encontrando, entre todas as topologias de possíveis árvores para um conjunto de dados, a que possui menor soma das distâncias entre os nós da árvore. Na verdade, o NJ não garante a árvore 
de menor soma das distâncias, em geral esse algoritmo obtém uma aproximação significativa desta árvore, com custo computacional relativamente baixo.

A árvore obtida pelo NJ apresenta em suas arestas as distâncias distribuídas de forma que, o caminho de um nó folha $i$ até um outro $j$, se somados os pesos (distâncias) associadas a suas arestas, terá o mesmo valor na posição $(i, j)$ da Matriz Distância (fornecida para construir a árvore). Essa propriedade é chamada de aditividade e garante que as distâncias entre pares de sequências sejam iguais a soma dos pesos nos ramos que os conectam por meio da árvore. Essa soma recebe o nome de distância patrística (Fitch \& Margoliash, 1967; Fourment \& Gibbs, 2006).

A construção da árvore pelo NJ ocorre como descrito na sequência. Inicia-se com uma árvoreestrela (sem raiz). É realizada uma junção de dois nós da árvore-estrela, os quais são substituídos, na árvore-estrela, por um nó adicional $u$ que representa o ancestral em comum deles. Com isso, a cada junção, a árvore perde dois nós e ganha um, sendo que o comprimento do ramo que se liga a este novo nó deve ser calculado. Essas junções são realizadas em sequência, até que a árvore fique com apenas dois nós. A Figura 3.1 exemplifica a primeira iteração do algoritmo.

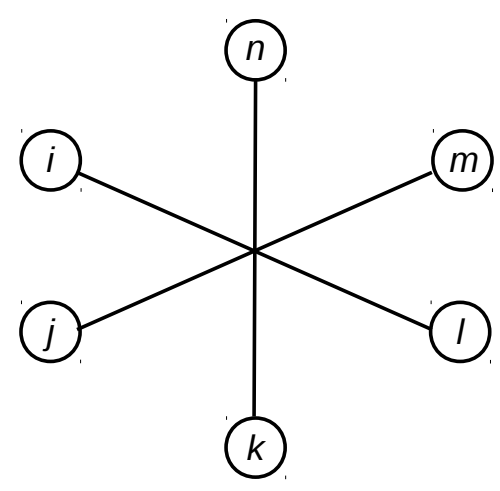

(a)

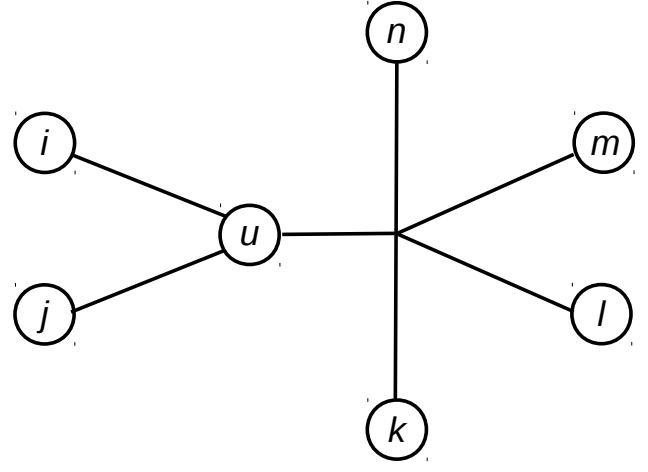

(b)

Figura 3.1: Primeira iteração do NJ: (a) Árvore-estrela e (b) Árvore após a inclusão do nó ancestral $u$.

Três etapas são essenciais ao longo desse processo de junções sucessivas:

1. Determinação dos dois nós da árvore-estrela atual que sofrerão junção. Essa escolha deve buscar que a nova árvore tenha um valor mínimo para o somatório do comprimento de todos os ramos. A partir dos valores da Matriz Distância $D$ de entrada (por exemplo obtida utilizando a F84), uma matriz $M$ é calculada conforme descreve a Equação 3.1. Então o par escolhido para junção é aquele que possui o menor valor na matriz $M$.

$$
M_{i j}=D_{i j}-\frac{R_{i}+R_{j}}{n-2}
$$


em que $R_{i}$, dado pela Equação 3.2, é a divergência de rede, definida como a soma de todas as distâncias referentes à variável $i$.

$$
R_{i}=\sum_{j, i \neq j} D_{i j}
$$

2. Cálculo do comprimento dos ramos dos dois nós $i$ e $j$ (Equações 3.3 e 3.4), escolhidos para sofrer junção, até o novo nó $u$ da árvore.

$$
\begin{gathered}
S_{i u}=\frac{D_{i j}}{2}+\frac{R_{i}-R_{j}}{2(n-2)} \\
S_{j u}=\frac{D_{i j}}{2}+\frac{R_{j}-R_{i}}{2(n-2)},
\end{gathered}
$$

3. Cálculo da nova Matriz Distância $D^{\prime}$ (Equação 3.5), após a junção, com dimensão $(n-1) \times$ $(n-1)$, uma vez que o novo nó agora substitui na matriz $D$ as duas folhas agrupadas.

$$
D_{k u}^{\prime}=\frac{D_{i k}+D_{j k}}{2}-\frac{D_{i j}}{2} \text {, para todo nó } k \neq i \text { e } j \text {. }
$$

O corpo principal do algoritmo NJ contém instruções para a realização de uma única junção, uma vez recebida a Matriz Distância $D$ como argumento de entrada. Com isso, cada nova Matriz Distância (com uma dimensão a menos) é um novo argumento de entrada para realizar a próxima junção. Esse processo é repetido até restarem apenas dois nós na matriz, que serão agrupados originando ao último nó a ser adicionado à árvore final.

A Complexidade do NJ (Studier \& Keppler, 1988) é $O\left(\ell^{3}\right)$, em que $\ell$ é o número de amostras no conjunto de dados, ou o número de variáveis em um problema de otimização. Essa complexidade deve-se ao fato de o computo das Equações 3.1 a 3.5 serem $O\left(\ell^{2}\right)$, o qual é repetido por $O(\ell)$ iterações (até restar dois nós na matriz). A Figura 3.2(b) representa a filogenia produzida pelo NJ a partir da Matriz Distância $D$, mostrada na Figura 3.2(a).

É importante observar que o NJ retorna uma árvore mesmo quando a suposição de aditividade não se mantém, o que resulta em valores diferentes em posições simétricas em relação à diagonal principal da matriz. Mesmo nesses casos, a árvore gerada pelo NJ pode ser utilizada como uma estimativa da árvore verdadeira quando se lida com grande número de taxa. Uma medida da qualidade de aproximação da árvore por ser obtida pela medida do desvio em relação à aditividade, o qual corresponde à, que é a soma ponderada do valor absoluto das diferenças entre as distâncias patrísticas (Seção 3.1.1) e as distâncias entre cada par de taxa (obtidas diretamente da comparação entre as sequências), conforme o critério de otimalidade utilizado no Método de Fitch and Margoliash (Fitch \& Margoliash, 1967). 


\begin{tabular}{|c|c|c|c|c|c|c|}
\hline & $i$ & $j$ & $k$ & $I$ & $m$ & $n$ \\
\hline$i$ & 0 & 5 & 4 & 7 & 6 & 8 \\
\hline$j$ & 5 & 0 & 7 & 10 & 9 & 11 \\
\hline$k$ & 4 & 7 & 0 & 7 & 6 & 8 \\
\hline$I$ & 7 & 10 & 7 & 0 & 5 & 9 \\
\hline$m$ & 6 & 9 & 6 & 5 & 0 & 8 \\
\hline$n$ & 8 & 11 & 8 & 9 & 8 & 0 \\
\hline
\end{tabular}

(a)

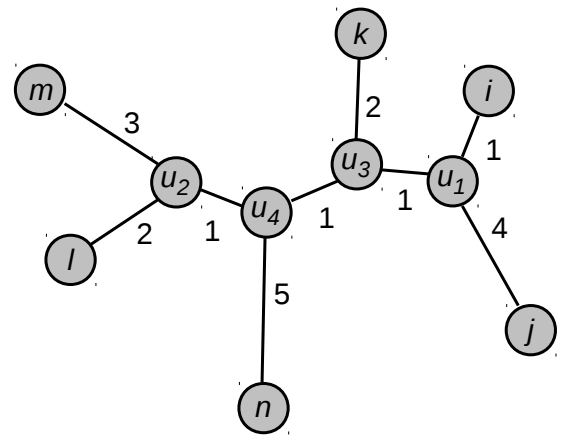

(b)

Figura 3.2: Matriz Distância $D$ e filogenia obtida pelo NJ.

\subsubsection{UPGMA}

Um outro método de agrupamento por distância utilizado na reconstrução de filogenias (Sokal \& Michener, 1975) é o UPGMA. Esse método considera que a evolução ocorre em taxa constante em relação a um ancestral comum. Isso é chamado de relógio evolutivo. Seu uso resulta em uma árvore ultramétrica, ou seja, as distâncias da raiz a qualquer folha são iguais.

Os procedimentos de cálculos do UPGMA são parecidos com o do NJ. Parte-se de uma árvoreestrela inicial com todos os nós interligados, executando-se as seguintes etapas:

1. Considere cada nó $i$ como um cluster simples $C_{i}=i$;

2. Selecione diretamente da Matriz Distância $D$ o par de nós $(i, j)$ com a menor distância;

3. Una os clusteres de $i$ e $j\left(C_{i}\right.$ e $C_{j}$ respectivamente) adicionando um nó interno $u$ (ancestral comum) na árvore de forma que conecte $i$ e $j$ formando o cluster $C_{u}=C_{i} \cup C_{j}$;

4. Recalcule as distâncias entre os clusteres usando a Equação 3.6

$$
D\left(C_{k},\left(C_{i} \cup C_{j}\right)\right)=\frac{1}{\left|C_{i}\right|+\left|C_{j}\right|}\left[\left|C_{i}\right| D\left(C_{k}, C_{i}\right)+\left|C_{j}\right| D\left(C_{k}, C_{j}\right)\right]
$$

5. Retorne ao Passo 2 enquanto houver mais de um cluster, desconsiderando os pares já escolhidos.

Observe que $\left|C_{i}\right| D\left(C_{k}, C_{i}\right)=\sum_{r \in C_{k}} \sum_{s \in C_{i}} D(r, s)$, portanto, o armazenamento das distâncias entre clusteres obtidas a cada junção, em geral, reduz significativamente o tempo computacional, possibilitando a implementação do UPGMA em $O\left(\ell^{2}\right)$ (Gronau \& Moran, 2007; Eppstein, 1998). Apesar dessa vantagem computacional, tem sido mais intenso na literatura o uso do NJ, uma vez que a ultrametricidade não ocorre nunca de forma perfeita, mesmo quando a taxa de evolução é 
mais ou menos constante ${ }^{1}$. Além disso, mesmo quando o número de mutações em um ramo é o esperado, as distâncias entre pares de sequências e as distâncias patrísticas podem não estar correlacionadas, assim, a suposição de aditividade também pode não ser mantida. A Figura 3.3(b) mostra a filogenia produzida pelo UPGMA a partir da Matriz Distância $D$, apresentada na Figura 3.3(a).

\begin{tabular}{|c|c|c|c|c|c|c|}
\hline & $i$ & $j$ & $k$ & $I$ & $m$ & $n$ \\
\hline$i$ & 0 & 5 & 4 & 7 & 6 & 8 \\
\hline$j$ & 5 & 0 & 7 & 10 & 9 & 11 \\
\hline$k$ & 4 & 7 & 0 & 7 & 6 & 8 \\
\hline $\boldsymbol{I}$ & 7 & 10 & 7 & 0 & 5 & 9 \\
\hline $\boldsymbol{m}$ & 6 & 9 & 6 & 5 & 0 & 8 \\
\hline $\boldsymbol{n}$ & $\mathbf{8}$ & 11 & 8 & 9 & 8 & 0 \\
\hline
\end{tabular}

(a)

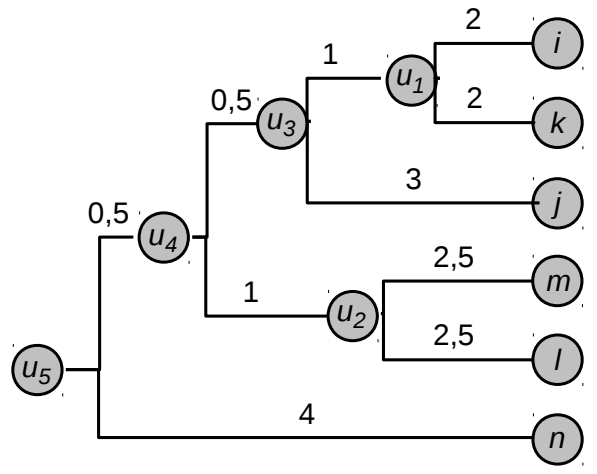

(b)

Figura 3.3: Matriz distância e filogenia obtida pelo UPGMA.

\subsection{Métodos de Otimalidade}

Os métodos de agrupamento possuem como principais vantagens a relativa facilidade de implementação e eficiência computacional (Page \& Holmes, 1998). Entretanto, esses métodos produzem somente uma única árvore, impossibilitando a avaliação de outras árvores candidatas possivelmente melhores. Por outro lado, os métodos de otimalidade podem escolher a melhor filogenia de uma amostragem do espaço de possíveis topologias de árvore de acordo com algum critério.

Esse critério é utilizado para atribuir a cada árvore um valor que é função da representatividade que um árvore possui para um conjunto de dados. Esta função pode ser, por exemplo, baseada em um modelo de como as sequências evoluem. Por meio do critério de otimalidade, a qualidade de cada árvore é avaliada possibilitando escolher aquela, dentre várias hipóteses, que melhor explica os dados.

Os métodos baseados em critério de otimalidade devem resolver dois subproblemas:

1. A partir de um conjunto de dados e uma árvore com número de nós folhas igual ao número de espécies (objeto), determinar o número máximo de eventos evolutivos sobre a estrutura da árvore que explica as relações entre esses objetos. Isso pode ser realizado em tempo polinomial;

2. De todas as possíveis árvores, determinar qual delas resulta no menor número de eventos evolutivos.

\footnotetext{
${ }^{1} \mathrm{O}$ sorteio de uma moeda pode ilustrar esse fato. A chance de uma moeda cair com cara para cima é 0,5 , mas a fração do número observado de caras a partir de vários lançamentos em geral irá desviar de 0,5.
} 
Dos métodos de otimalidade na literatura, destacam-se: (i) a Máxima Parcimônia (Fitch, 1981), (ii) a Máxima Verossimilhança (Felsenstein, 1981) e (iii) Inferência Bayesiana (Ronquist \& Huelsenbeck, 2003).

O objetivo da Máxima Parcimônia é procurar a árvore (ou árvores) cujo número total de mudanças evolutivas seja mínima. Tais mudanças referem-se as diferenças entre os estados dos nós conectados pelos extremos de cada ramo. O método fundamenta-se no princípio filosófico conhecido como a navalha de Occam (Felsenstein, 2003): se existem várias hipóteses que forneçam explicações igualmente válidas para algum fenômeno, a mais simples delas tende a ser a correta. Na prática, o método busca definir as sequências de nucleotídeos dos nós internos de forma que a contagem $(\operatorname{Parc}(T))$ de mudanças de nucleotídeos entre cada par de nós adjacentes na árvore seja mínima. As Equações 3.7 e 3.8 sintetizam esse processo.

$$
\operatorname{Parc}(T)=\sum_{j=1}^{N} \operatorname{Parc}_{j},
$$

em que $N$ é a quantidade de caracteres de cada sequência de dados (por exemplo, uma sequência de DNA) de $\ell$ espécies ( $\ell$ amostras), $\operatorname{Parc}_{j}$ representa o valor de parcimônia para a posição $j$ da sequência considerando cada par de nós conetados nos ramos de uma árvore $T$.

$$
\operatorname{Parc}_{j}=\sum_{(v, u) \in R} C_{v_{j}, u_{j}}
$$

em que $R$ é o conjunto de ramos $(v, u)$ de $T, v_{j}$ e $u_{j}$ são os estados no sítio $j$ das sequências correspondentes aos nós $v$ e $u$, respectivamente; $C_{v_{j}, u_{j}}$ é o custo de mudar do estado $v_{j}$ para o estado $u_{j}$ no sítio $j$.

O chamado Pequeno Problema de Parcimônia, corresponde a determinar o valor mínimo de $\operatorname{Parc}(T)$ para uma determinada topologia $T$. Porém, encontrar a árvore (ou árvores) $T^{*}$ tal que $\operatorname{Parc}\left(T^{*}\right)$ seja mínima no espaço de árvores é uma tarefa muito complexa. Tal problema é conhecido como o grande problema de parcimônia, o qual é NP-difícil (Felsenstein, 2003). Para o resolvê-lo, podem ser usadas técnicas exatas para um número moderado de espécies ou técnicas heurísticas nos demais casos, tais como: Troca dos Vizinhos mais Próximos (NNI, do inglês Nearest Neighbor Interchange); Poda e Enxerto de Subárvore (SPR, do inglês Subtree Prunning and Regrafting) e Bisseção e Reconexão de Árvore (TBR, do inglês Tree Bisection and Reconnection). Em (Cancino, 2008) são descritas essas técnicas em mais detalhes.

Essas estratégias de busca em geral são utilizadas também no método de reconstrução de filogenia por Máxima Verossimilhança (Gascuel, 2007). O critério de verossimilhança considera, além das mudanças de nucleotídeos em cada posição da sequência, a probabilidadede ocorrer cada tipo de mudança. Essa probabilidade segue modelos evolutivos considerando aspectos como substituições de nucleotídeos por transversões e transições ( $T V$ e $T S$ ) (Apêndice F). 
A verossimilhança fornece a probabilidade $\operatorname{Prob}(D \mid \theta)$ de o conjunto de sequências $D$ ajustarse ao modelo $\theta=\{T, B, M\}$, em que $T$ é uma topologia da árvore, $B$ é o conjunto de comprimento de ramos de $T$, e $M$ é o modelo de substituição de sequências. O objetivo do critério de máxima verossimilhança é encontrar os parâmetros do modelo $\theta$, tal que a função de verossimilhança do modelo $\theta$ definida na Equação 3.9, seja maximizada.

$$
L=\prod_{j=1}^{N} \operatorname{Prob}\left(D^{j} \mid \theta\right),
$$

em que $\operatorname{Prob}\left(D^{j} \mid \theta\right)$ representa a verossimilhança no sítio $j$ e $D^{j}$ os valores de cada sequência nesse sítio. Em geral usa-se $\ln (L)$ de forma a evitar "overflow" de representação numérica. Essa quantidade estima as probabilidades de cada modelo $\theta$ considerando todos os possíveis estados dos nós internos.

O cálculo de verossimilhança precisa de duas premissas (Felsenstein, 2003): (i) os sítios das sequências evoluem de forma idêntica e independente; (ii) a probabilidade de um nó possuir um determinado estado é função apenas do estado anterior. Os programas de Máxima Verossimilhança utilizam as mesmas heurísticas de buscas topológicas descritas para os programas de Máxima Parcimônia: NNI, SPR e TBR. Especificamente para uso em verossimilhança, existem implementações como o PHYML (Guindon \& Gascuel, 2003) e RAxML (Stamatakis, 2005), que fornecem diferenciais principalmente em termos de eficiência computacional.

A Inferência Bayesiana (Ronquist \& Huelsenbeck, 2003; Huelsenbeck et al., 2001) é um método estatístico mais recentemente utilizado para reconstrução de filogenia. O principal aspecto da Inferência Bayesiana é o cálculo da probabilidade a posteriori das diferentes árvores e parâmetros do modelo evolutivo em função de um conjunto de dados. Sejam $D$ um conjunto de dados, $\tau_{i}$ a $i$ ésima topologia do conjunto de $N_{T}$ topologias possíveis para $n$ espécies e $\varphi=(B, M)$ um modelo em que $B$ é o conjunto dos comprimentos de ramos de $\tau_{i}$ e $M$ corresponde aos parâmetros do modelo de substituição de sequências. A probabilidade a posteriori de $\tau_{i}$ dado $D, P\left(\tau_{i} \mid D\right)$ é expressa pela Equação 3.10, que requer o somatório, para todas as topologias existentes, da integral sobre todos os valores possíveis dos parâmetros em $\varphi$.

$$
P\left(\tau_{i} \mid D\right)=\frac{P\left(D \mid \tau_{i}, \varphi\right) \rho\left(\tau_{i}, \varphi\right)}{\sum_{j=0}^{N_{T}} \int P\left(D \mid \tau_{i}, \varphi\right) \rho\left(\tau_{i}, \varphi\right) d \varphi},
$$

em que $P\left(D \mid \tau_{i}, \varphi\right)$ é a verossimilhança da árvore $\tau_{i}$ e $\rho\left(\tau_{i}, \varphi\right)$ é o produto das probabilidades $a$ priori da topologia $\tau_{i}$ e dos parâmetros em $\varphi$.

Os mesmos modelos de substituição de nucleotídeos usados na máxima verossimilhança podem ser usados na Inferência Bayesiana. O programa MrBayes (Ronquist \& Huelsenbeck, 2003) usa as Cadeias Markovianas para gerar uma variedade de topologias e estimar uma distribuição das probabilidades de filogenias (Yang, 2006), possibilitando o cálculo da probabilidade a posteriori. 
Do ponto de vista de eficiência computacional, esse método requer mais tempo computacional que os demais podendo ser inviável sua utilização para um número de sequências relativamente grande (várias centenas ou milhares). Por outro lado, conforme mostrado em Rokas et al. (2003), trabalhar com grande número de sequências é fundamental para reduzir a proporção de relações incongruentes de uma filogenia. Em Mansour (2013), mostra-se que é possível reduzir incongruências a partir de várias filogenias produzidas por métodos de agrupamento, como o CPA proposto no Capítulo 6 (ver Seção 3.1), com a vantagem deste possuir custo computacional significativamente mais baixo.

\subsection{Considerações finais}

A utilização de critérios de otimalidade implica na procura de soluções ótimas dentro de um espaço de busca de topologias de árvore que cresce rapidamente com o tamanho do conjunto de dados. Dessa forma, tal procura pode ser computacionalmente custosa para conjunto de dados com várias centenas ou milhares de objetos. Nesses casos, os métodos de reconstrução de filogenias baseados em agrupamento, NJ e UPGMA, destacam-se pela relativa eficiência computacional e simplicidade de implementação. Nesse contexto, o NJ mostra-se mais interessante que o UPGMA por gerar uma aproximação mais adequada da árvore verdadeira. Além disso, a qualidade das filogenias obtidas por esse algoritmo pode ser melhorada aplicando técnicas de reamostragem.

Este Capítulo apresentou os principais métodos de reconstrução de filogenias (agrupamento e otimalidade). O Capítulo 4 mostra que filogenias podem ser utilizadas como modelos probabilísticos de correlação de variáveis em problemas de otimização. 



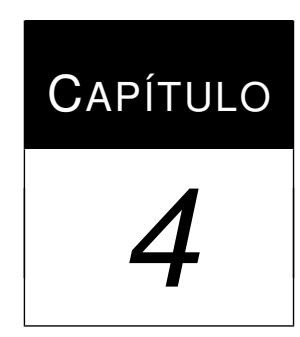

\section{Algoritmo Filogenético}

Este capítulo apresenta o primeiro EDA que utiliza modelo probabilístico gerado por um método de reconstrução de árvores filogenéticas. Uma filogenia pode ser utilizada como modelo probabilístico para um EDA ao se considerar as variáveis de um problema como objetos biológicos. Com base nessa modelagem, as variáveis fortemente correlacionadas (compondo em geral BBs) pertencem a um mesmo clado (grupo que envolve um ancestral e todas as espécies descendentes dele) (Seção 5.2). Dessa forma, uma filogenia pode ser útil no mapeamento dos potenciais BBs de um problema. Por exemplo, um EDA pode construir soluções promissoras ao evitar que instâncias improváveis de BBs sejam geradas por um operador de recombinação. Esse primeiro EDA baseado em filogenia foi denominado Algoritmo FiloGenético ( $\Phi \mathrm{GA}$, PhyloGenetic Algorithm) e tem sido fonte de pesquisas no grupo SEE (Sistemas Embarcados e Evolutivos) do ICMC/USP (Instituto de Ciências Matemáticas e de Computação/Universidade de São Paulo).

O problema de reconstrução filogenética por si só pode ser visto como um problema de otimização, no qual se deve determinar a árvore ótima segundo algum critério. A determinação de filogenias é um problema complexo dado que o número de possíveis árvores filogenéticas cresce exponencialmente com o número de espécies (amostras) analisadas (Capítulo 3). Observe que um número de amostras representativo é fundamental para se obter uma filogenia adequada (Cancino \& Delbem, 2007; Rokas et al., 2003), assim como é fundamental também para os modelos probabilísticos utilizados em um EDA (Goldberg, 2002; Melo, 2009).

Diferentemente de algoritmos como BOA (Seções 2.7) e ECGA (Harik et al., 2006), que utilizam a construção de vários modelos probabilísticos ao longo das gerações (iterações, ver Seção 2.2), o ФGA pode identificar todos os BBs de um ASDP (e consequentemente o ótimo global 
dele) a partir do modelo produzido na primeira geração (iteração, ver Seção 2.2) do algoritmo. A Figura 4.1 resume as etapas utilizadas pelo $\Phi \mathrm{GA}$.

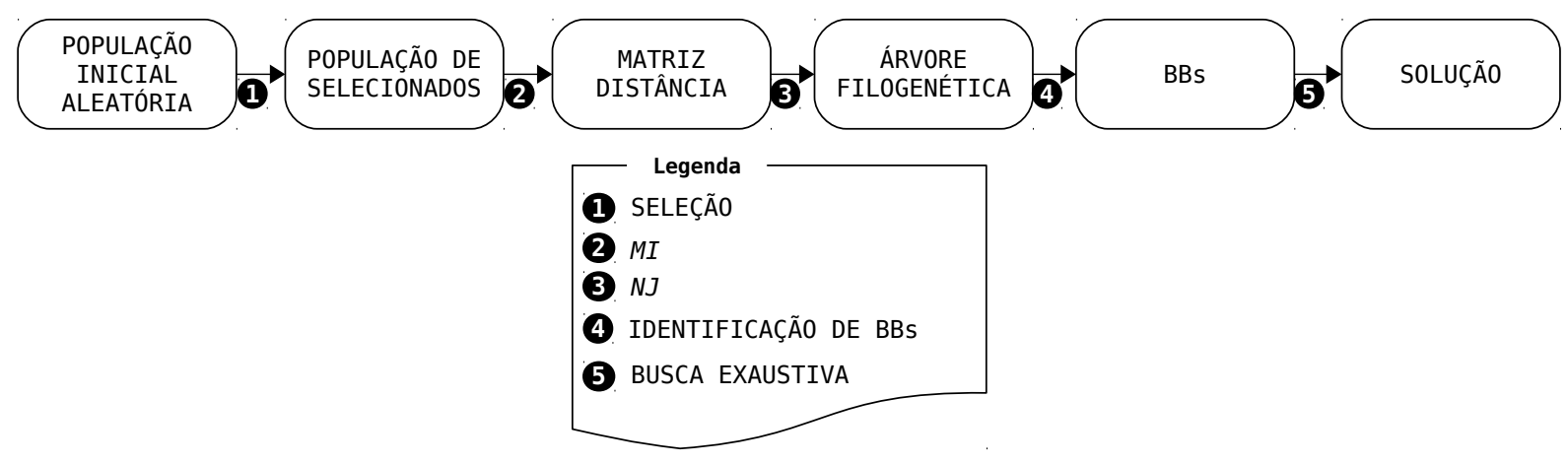

Figura 4.1: Etapas do $\Phi G A$.

Em ASDP, as variáveis que estão em BBs distintos não possuem correlação, assim, a decomposição do problema em subproblemas corresponde a associar as variáveis de um mesmo BB a um subproblema. Determinados os subproblemas, pode-se buscar pelas soluções de cada um deles e usar tais soluções para compor a solução do problema original. Isso pode ocorrer, por exemplo, misturando as melhores instâncias encontradas de cada BB (soluções candidatas de cada subproblema) e selecionando a(s) melhor(es) combinação(ões). Por outro lado, as variáveis dentro de um BB são altamente correlacionadas, podendo esconder uma armadilha, que direciona o algoritmo de busca para um ótimo local. Assim, a busca por melhores instâncias de um BB deve ser mais cuidadosa.

O $\Phi$ GA implementa esse processo de decomposição de um ASDP em subproblemas a partir de uma filogenia construída para as variáveis (objetos biológicos) do problema. Inicialmente uma população de indivíduos (representando soluções candidatas para o problema) é gerada de forma aleatória. Então, ocorre a seleção, buscando obter uma amostragem representativa das melhores soluções para o problema (mapeando as regiões promissoras do espaço de busca). A partir dessas soluções, inicia-se a criação do modelo probabilístico, neste caso, uma árvore filogenética.

Dois aspectos são fundamentais para o sucesso do $\Phi \mathrm{GA}$ :

1. O operador de seleção utilizado (em geral os EDAs de maior sucesso possuem diferenciais em relação a esse operador (Goldberg, 2002; Pelikan et al., 1999));

2. O critério de identificação de clados (BBs) a partir de uma filogenia. Observe que os trabalhos da própria área de reconstrução filogenética não fornecem um método ou procedimento sistematizado para isso. Essa tarefa tem sido realizada pelos biólogos em geral com base no conhecimento ad hoc deles;

3. A determinação das instâncias mais promissoras de um BB. 
Cada uma dessas etapas do $\Phi$ GA são detalhadas nas Seções 4.1 (Operador de Seleção), 4.2 (Identificação de BBs) e 4.3 (Busca Exaustiva).

\subsection{Operadores de Seleção}

As Seções 4.1.1 e 4.1.2 apresentam os processos de seleção por truncamento e torneio, além dos seus modelos teóricos, conforme proposto em Goldberg (2002). Esses modelos e resultados experimentais mostram que o truncamento e o torneio são mais adequados para EDAs que seleção proporcional como, por exemplo, a roleta (DeJong, 2008). Primeiramente, descreve-se a seleção por truncamento (Seção 4.1.1), que possui um modelo que pode ser deduzido mais facilmente. A Seção 4.1.2 apresenta a seleção por torneio, que é o operador utilizado no $\Phi$ GA.

\subsubsection{Seleção por truncamento}

A seleção por truncamento escolhe exatamente os $s$ melhores indivíduos de uma população (em geral para reprodução, Seção 2.2). É razoável supor que esses indivíduos englobem parte dos indivíduos com a melhor instância de um certo BB, uma vez que a configuração ótima de um BB deve corresponder a uma contribuição significativa no fitness, colocando provavelmente os indivíduos com tal instância entre os $s$ melhores. Para isso, deve-se supor também que $s$ seja adequado para selecionar os melhores sem ser restrito demais (sem eliminar todas as instâncias ótimas de um BB) e $n$ (tamanho da população) seja tal que possibilite que a melhor ou melhores instâncias de cada BB possuam várias réplicas na população.

Em outras palavras, a seleção por truncamento ordena as soluções com base no fitness e replica os $s$ melhores indivíduos $\lceil n / s\rceil$ vezes até completar uma população de selecionados de $n$ indivíduos (observe que $\lceil n / s\rceil \times s \geq n$ ). A Figura 4.2 mostra um exemplo de truncamento a partir de dez indivíduos, Ind.1 a Ind10, com valores de fitness, respectivamente, Fit.1 a Fit.10. Dessa forma, cada instância ótima de BB é também replicada aproximadamente $s$ vezes, supondo que quase todas estariam entre os $s$ melhores indivíduos. Assim, pode-se aplicar diretamente a Equação 4.1 para a seleção por truncamento.

$$
P_{t+1}=s P_{t}
$$

em que $P_{t}$ é a probabilidade da melhor instância de um BB estar no indivíduo sorteado para reproduzir na geração $t$, isto é, $P_{t}$ é a proporção na população de indivíduos com tal instância.

Aplicando sucessivamente a Equação 4.1 da geração inicial até a geração $t$, obtém-se:

$$
\begin{gathered}
P_{1}=s P_{0}, \\
P_{2}=s P_{1}=s s P_{0}=s^{2} P_{0}
\end{gathered}
$$




\begin{tabular}{|c|c|c|}
\hline & & \\
\hline Ind.1 - Fit.20 & Ind.10 - Fit.30 & Ind.10 - Fit.30 \\
\hline Ind.2 - Fit.11 & Ind.1 - Fit.20 & Ind.1 - Fit.20 \\
\hline Ind.3 - Fit.1 & Ind.7 - Fit.15 & Ind.7 - Fit.15 \\
\hline Ind.4 - Fit.2 & Ind.2 - Fit.11 & Ind.2 - Fit.11 \\
\hline Ind.5 - Fit.5 & Ind.6 - Fit.10 & Ind.6 - Fit.10 \\
\hline Ind.6 - Fit.10 & Ind.9 - Fit.8 & Ind.10 - Fit.30 \\
\hline Ind.7 - Fit.15 & Ind.5 - Fit.5 & Ind.1 - Fit.20 \\
\hline Ind.8 - Fit.1 & Ind.4 - Fit. 2 & Ind.7 - Fit.15 \\
\hline Ind.9 - Fit.8 & Ind.3 - Fit.1 & Ind.2 - Fit.11 \\
\hline Ind.10 - Fit.30 & Ind.8 - Fit.1 & Ind.6 - Fit.10 \\
\hline $\begin{array}{c}\text { População } \\
\text { Inicial } \\
\text { Aleatória }\end{array}$ & $\begin{array}{l}\text { População } \\
\text { Ordenada } \\
\text { por fitness }\end{array}$ & $\begin{array}{l}\text { População de } \\
\text { Selecionados }\end{array}$ \\
\hline
\end{tabular}

Figura 4.2: Seleção por truncamento $(s=2)$.

$$
P_{t}=s P_{t-1}=s s P_{t-2}=\ldots=s^{t} P_{0} .
$$

Portanto, $P_{t}=s^{t} P_{0}$. Como $P_{0}=\frac{1}{n}$ (supõe-se que a instância ótima tenha sido amostrada inicialmente pelo menos uma vez) e $P_{t}=\frac{n-1}{n}$ (critério de convergência), obtém-se:

$$
\frac{n-1}{n}=s^{t} \frac{1}{n}:: n-1=s^{t}:: \ln (n-1)=t \ln s:: t=\frac{\ln (n-1)}{\ln s}:: t=\frac{\ln n}{\ln s} .
$$

A Equação 4.2 indica que a instância do BB requer então $O(\ln n)$ gerações para dominar a população. O processo é relativamente rápido uma vez que um método de seleção proporcional (como a roleta) requer um tempo $O(n \log n)$ para uma função de fitness $f(x)=x^{c}$ ( $c$ uma constante positiva maior que 1) podendo passar para $O\left(2^{\ell}\right)$ (em que $\ell$ é o tamanho do problema) se considerado o problema BinInt (Seção 7.1) (Goldberg, 2002).

No entanto, esse ponto positivo pode atrapalhar as recombinações (Seção 2.2) das melhores instâncias de BBs diferentes, uma vez que o algoritmo pode convergir antes que as melhores instâncias de cada BB tenham sido combinadas. Em outras palavras, estariam sendo selecionados indivíduos com melhores instâncias de BBs, na população, porém ainda não haveria um indivíduo com todas as melhores instâncias de todos os BBs compondo o ótimo global no momento da convergência.

Para evitar isso, é importante que as recombinações sejam de qualidade e que um número significativo delas ocorram em uma mesma geração. Isso em geral pode ser atingido por um EDA utilizando um modelo probabilístico de correlação entre variáveis. No $\Phi \mathrm{GA}$, a filogenia construída é utilizada para orientar a combinação de instâncias de BBs na geração dos novos indivíduos. 


\subsubsection{Seleção por torneio}

No torneio, sorteiam-se aleatoriamente $s$ indivíduos de uma população, somente o melhor deles é escolhido. Nesse tipo de seleção de indivíduos com a melhor instância do BB podem não competir em um ou mais torneios. Assim, a seleção por torneio não garante que todos os $s$ melhores indivíduos ganhem sempre. Isso pode ser útil uma vez que instâncias ótimas de um BB podem estar combinadas com instâncias que não possibilitam destaque significativo do indivíduo correspondente entre os $s$ melhores (como ocorre por truncamento). Na seleção por torneio, indivíduos fora do subconjunto dos $s$ melhores e com alguma instância ótima de BB podem ganhar torneios beneficiando tal instância (que não foi amostrada entre os $s$ melhores indivíduos) a estar presente na população de selecionados. A Figura 4.3 exemplifica o efeito do torneio em uma população.

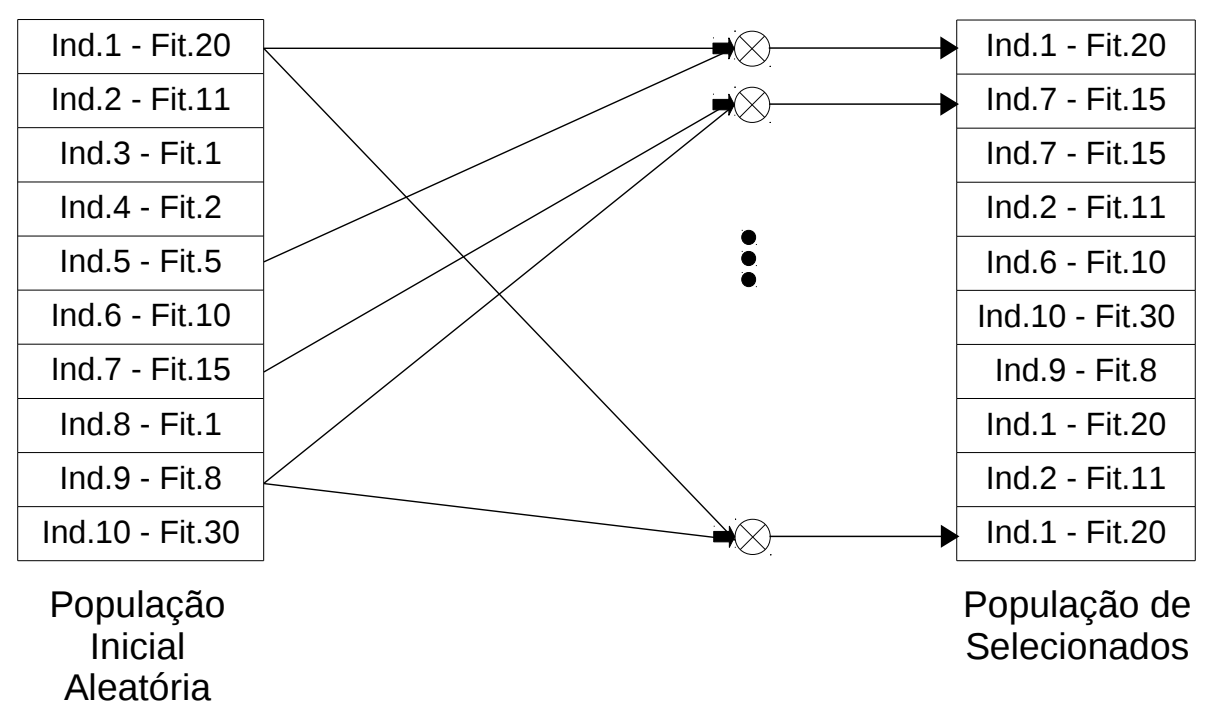

Figura 4.3: Seleção por torneio $(s=2)$.

A cada sorteio de um indivíduo para competir no torneio, a probabilidade de tal instância ótima de um BB não estar no indivíduo sorteado é $\left(1-P_{t}\right)$. A probabilidade de não estar em nenhum dos $s$ indivíduos que participam do torneio é de $\left(1-P_{t}\right)^{s}$. Assim, a taxa esperada de, entre os $s$ competidores do torneio, ocorrer pelo menos um com a referida instância é $1-\left(1-P_{t}\right)^{s}$. Como essa instância é supostamente ótima, é alta a chance do competidor que a contém ganhar o torneio. Assumindo essa chance como $100 \%$, o número esperado de tais instâncias entre $n$ indivíduos selecionados ( $n$ aplicações de torneio de $s$ ) é $\left[1-\left(1-P_{t}\right)^{s}\right] n$ e a proporção desses indivíduos na população pode ser estimado pela Equação 4.3.

$$
P_{t+1}=1-\left(1-P_{t}\right)^{s}
$$

Fazendo $Q_{t}=1-P_{t}$ (proporção de indivíduos com instâncias ruins do BB), a Equação 4.3 resulta em $Q_{t+1}=Q_{t}^{s}$. Aplicando essa equação a partir da geração inicial $\left(t_{0}\right)$ até a geração $t$, 
obtém-se:

$$
\begin{gathered}
Q_{1}=Q_{0}^{s}, \\
Q_{2}=Q_{1}^{s}=\left(Q_{0}^{s}\right)^{s}=Q_{0}^{s^{2}} \\
\vdots \\
Q_{t}=Q_{t-1}^{s}=\left(Q_{t-2}\right)^{s^{2}}=\ldots=Q_{0}^{s^{t}}
\end{gathered}
$$

Portanto, $Q_{t}=Q_{0}^{s^{t}}$. Como $P_{0}=\frac{1}{n}$ e $P_{t}=\frac{n-1}{n}$ (Seção 4.1.1), então $Q_{0}=\frac{n-1}{n}$ e $Q_{t}=\frac{1}{n}$, obtém-se:

$$
\begin{aligned}
\frac{1}{n}=\left(\frac{n-1}{n}\right)^{s^{t}}:: & \ln \frac{1}{n}=s^{t} \ln \frac{n-1}{n}:: \ln \ln \frac{1}{n}=t \ln s+\ln \ln \left(1-\frac{1}{n}\right) \\
t & \ln s=\ln \ln \frac{1}{n}-\ln \ln \left(1-\frac{1}{n}\right) .
\end{aligned}
$$

Usando a aproximação $\ln (1-x) \approx-x$, para $x$ pequeno ${ }^{1}$,

$$
t \ln s=\ln \ln \frac{1}{n}-\ln \frac{-1}{n}:: t \ln s=\ln \ln n^{-1}-\ln \left(-n^{-1}\right):: t \ln s=\ln (-\ln n)+\ln (-n),
$$

como a parte real de $\ln (-x)$ é $\ln x$, pode-se escrever:

$$
t=\frac{\ln n+\ln \ln n}{\ln s}
$$

O termo $\ln \ln n$ é dominado por $\ln n$ e, então, pode ser ignorado para $n$ não pequeno, resultando que $t=O(\ln n)$, assim como obtido para a seleção por truncamento.

Em relação a solução por truncamento, o torneio tem a vantagem de ser estocástico, fornecendo uma certa flexibilidade que o torna mais robusto a eventuais tendências que possam ser geradas em um processo de amostragem da População Inicial. Por exemplo, $n$ pode não ser suficientemente grande, ou mesmo o nível de aleatoriedade na população obtida não estar adequada. Isso, por exemplo, pode resultar em soluções com instâncias ótimas de BBs, mas com fitness inferior aos dos $s$ melhores. Outro caso ocorre quando a contribuição de cada BB na composição do valor de fitness é significativamente diferente. Por exemplo, no problema BinInt (Seção 7.1), a razão entre as contribuições de quaisquer dois BBs é exponencial.

\footnotetext{
${ }^{1}$ Com $x<0,1$, a precisão na aproximação é de $10^{-1}$. Esse nível de aproximação ocorre por exemplo para população com tamanho $n=10: \ln \left(1-\frac{1}{10}\right)=-0,10536 \mathrm{e}-\frac{1}{10}=-0,10000$.
} 


\subsection{Identificação dos BBs}

Uma vez que uma árvore foi reconstruída, é realizada uma divisão da árvore em subárvores que representem as folhas mais fortemente correlacionadas. Essas subárvores são chamadas de clados na Biologia (Seção 5.2). Pode-se dizer que a identificação do clado tem sido um procedimento empírico que depende de conhecimento ad hoc dos biólogos.

Tal processo pode ser visto como a escolha das arestas da árvore (em geral mais próximas de sua raiz) que devem ser removidas gerando um conjunto de subárvores (clados). As arestas a serem removidas representariam relações ancestrais que se tem pouca confiança.

A detecção das relações fracas pode ser feita por um procedimento que mede a variação da força dessas relações, conforme se percorre a árvore dos nós folha em direção à raiz. O NJ (Seção 3.1.1) e o UPGMA (Seção 3.1.2) inserem arestas diretamente relacionadas aos menores valores na Matriz Distância a cada iteração dos algoritmos. Assim a partir de certa iteração, essas distâncias são relativamente grandes.

Os resultados experimentais com dados sintéticos (em que se conhece de antemão as relações) demonstram que a partir de certa iteração, as arestas adicionadas não são significativamente representativas, isto é, não há informação suficiente para confirmar a relevância de tais relações. A variação dos valores da matriz ao decorrer das iterações do NJ mostra que há um salto no valor das distâncias quando o algoritmo passa a agrupar subárvores correspondentes a BBs diferentes. Isso pode ser identificado utilizando a Equação 4.6 (Vargas et al., 2010a).

$$
\begin{gathered}
\beta_{t}=\frac{\alpha_{t}-\alpha_{t-1}}{\alpha_{t}} . \\
\alpha_{t}=\operatorname{Média}(M, t)-\operatorname{Mínimo}(M, t) .
\end{gathered}
$$

A Figura 4.4 representa a variação de $\beta_{t}$ no decorrer das iterações do NJ aplicado a Populações de Selecionados diferentes, cada uma obtida aplicando um conjunto de torneio sobre a mesma População Inicial. Nesse exemplo, usa-se um ASDP com $\ell=90$ variáveis e BBs de tamanho $m=5$ correlacionados pela ftrap5 (Seção 7.2). Na Figura 4.4, é evidente que, para alguns valores de $t, \beta_{t}$ distancia-se do padrão de valores inferiores a 1 . O primeiro $\beta_{t}>1$ ocorre para $t=70$, que corresponde a primeira ligação entre subárvores com nós folhas em BBs diferentes. Generalizando essa propriedade, BBs de ASDPs podem ser identificados calculando $t^{*}=\left\{\operatorname{Mínimo}(t) \mid \beta_{t}>\right.$ 1 e $t>\ell\}$, em que $\ell$ é o número de folhas (variáveis do problema).

\subsection{Busca Exaustiva}

Identificados todos os subproblemas independentes (BBs) de um ASDP, o processo para a obtenção de uma solução completa é uma tarefa relativamente simples. Pode-se utilizar uma Busca 


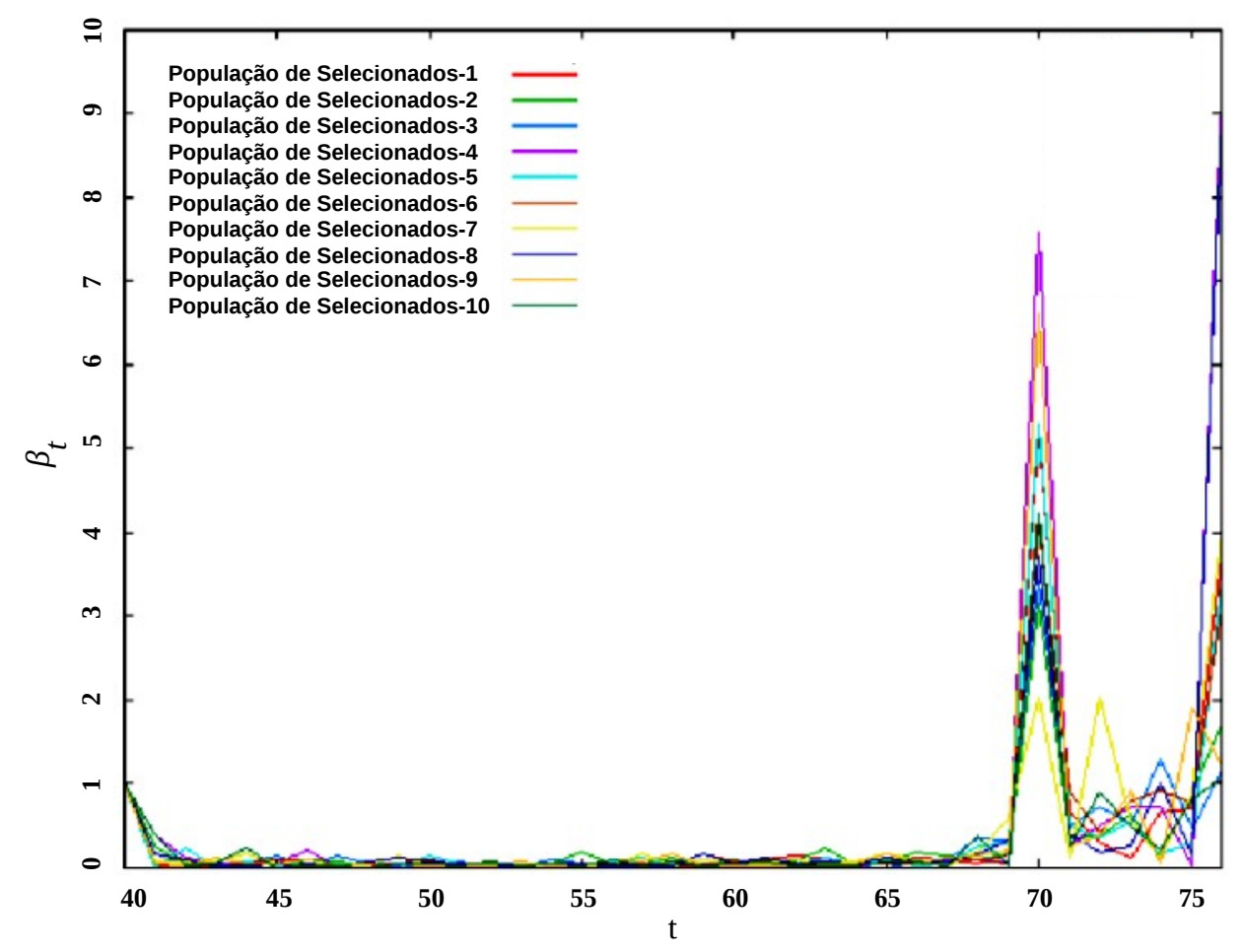

Figura 4.4: $\beta_{t}$ a cada iteração do $\mathrm{NJ}$, em que a $t$-ésima aresta é adicionada, $40 \leq t \leq 75$ corresponde às ligações de nós internos na árvore.

Exaustiva (ES, do inglês Exhaustive Search) em cada subproblema para encontrar as melhores soluções de cada um. Então, agrupam-se as melhores soluções de cada subproblema para a composição da solução completa do problema original. Como os subproblemas identificados geralmente são pequenos (por exemplo, todos os BB possuem tamanho menor que 10 variáveis para os problemas testados nesta tese), a ES não é em geral uma etapa de alto custo computacional.

A Figura 4.5 exemplifica a ES utilizada. Neste exemplo, as soluções são compostas de nove bits e as partições encontradas (cada uma formada por três bits) pelo algoritmo são representadas por rótulos iguais (no caso, usam-se os rótulos 0,3 e 6). Inicialmente, são verificadas as pontuações de cada solução considerando todas as possíveis instâncias da partição representada pelo primeiro $\mathrm{BB}$, enquanto os valores das varáveis dos outros BBs são fixados (por exemplo, no valor dos bits do melhor indivíduo até então encontrado). A melhor solução é selecionada e o procedimento repetese, testando todas as possíveis instâncias no segundo BB com os valores das variáveis do primeiro e do terceiro BBs fixados e, assim por diante. A união das melhores instâncias encontradas para cada partição é a solução final do problema.

A ES avalia uma quantidade de soluções que aumenta exponencialmente com o tamanho dos BBs identificados, dado por $k$. Dessa forma, o número de avaliações a serem realizadas é de: $\frac{\ell}{k} \chi^{k}$, em que $\chi$ é a cardinalidade das variáveis de um problema combinatório ( $\chi=2$ nos problemas testados neste trabalho). A complexidade de tempo de $C_{E S}$ é dada pela Equação 4.8.

$$
C_{E S}=O\left(\frac{\ell}{k} \chi^{k}\right)
$$


\begin{tabular}{|l|l|l|l|l|l|l|l|l|l}
\hline 0 & 1 & 1 & 1 & 0 & 0 & 1 & 1 & 0
\end{tabular}$\quad$ Indivíduo da População Inicial Aleatória com maior Fitness

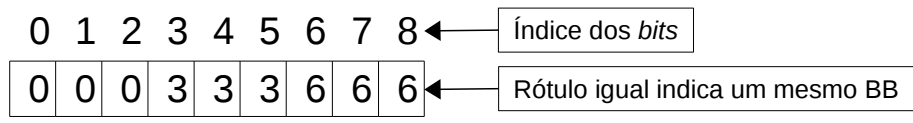

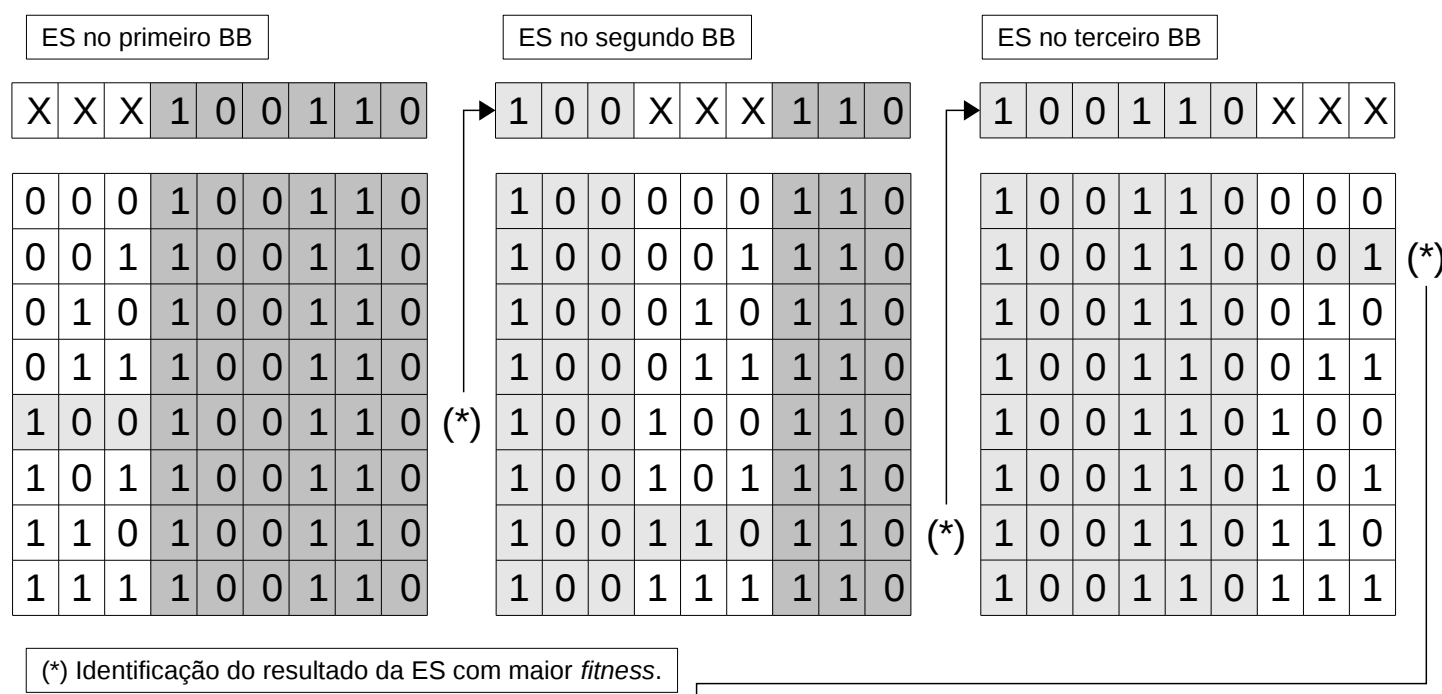

\begin{tabular}{|l|l|l|l|l|l|l|l|l|}
\hline 1 & 0 & 0 & 1 & 1 & 0 & 0 & 0 & 1 \\
\hline
\end{tabular}

Resultado da ES: Solução para o problema

Figura 4.5: Principais etapas da ES em cada BB e composição da solução do problema original.

\subsection{Considerações finais}

Neste Capítulo, foi apresentado o $\Phi \mathrm{GA}$, que usa métodos de reconstrução de filogenias como modelo probabilístico para a resolução de problemas de otimização. $\Phi$ GA é capaz de resolver exatamente ASDPs. Além disso, apresenta tempo computacional relativamente baixo para a construção de um modelo probabilístico baseado em filogenias. Uma extensão interessante do $\Phi$ GA, chamado mo $\Phi$ GA (Martins et al., 2011) (Seção 2.11), foi desenvolvida para problemas multiobjetivos envolvendo funções objetivo conflitantes de ASDPs. O moథGA mostrou-se capaz de encontrar a fronteira Pareto-ótima (completa) de forma eficiente (complexidade de tempo subquadrática) para os casos testados.

O princípio de exploração de BBs do $\Phi$ GA possibilita também o desenvolvimento de diversas extensões suas, buscando melhorar a taxa com que o método encontra a solução ótima (sua eficácia) para uma maior diversidade de problemas, além da redução da complexidade de tempo (sua eficiência). Nesse cenário, destaca-se a possibilidade de combinação com algoritmos de detecção de comunidades de forma similar ao realizado no trabalho de Crocomo (2012) que, ao estender o BOA para CD-BOA, obteve desempenho significativamente melhor, além de reduzir a sensibilidade do BOA em relação ao parâmetro $v$, relacionado ao número esperado do tamanho dos BBs 
(Seção 2.9). Em relação ao $\Phi$ GA, a detecção das comunidades pode substituir o método de detecção de BBs do $\Phi$ GA na Seção 4.2, buscando com isso reduzir o número de avaliações, aumentar a quantidade de tipos de problemas que o algoritmo pode resolver e reduzir a sensibilidade a parâmetros conforme possibilitou o CD-BOA. Para isso, é necessário investigar os principais técnicas de detecção de comunidades da área de Redes Complexas. Uma síntese desse estudo é apresentada no Capítulo 5. 
CAPÍTULO

\section{5}

\section{Detecção de Comunidades em Filogenias}

Algoritmos de detecção de comunidades possuem potencial para utilização em EDAs, ao serem utilizados como estratégia para se identificar BBs, que podem ser vistos como comunidades da área de Redes Complexas (Donetti \& Muñoz, 2004; Duch \& Arenas, 2005). Essa área de pesquisa tem produzido diversos algoritmos para detecção de comunidades que, buscam melhor identificá-las a partir de uma dada rede. Por outro lado, o custo computacional do processo de detecção deve ser considerado pelo EDA, assim, este Capítulo apresenta as principais técnicas encontradas na literatura (Seção 5.1) que também possuem complexidade computacional conhecida. A Seção 5.2 mostra como detectar comunidades a partir de uma filogenia.

\subsection{Detecção de Comunidades}

Comunidades ou agrupamentos de objetos podem ser representados por conjuntos de nós, em que cada nó é um objeto, com várias ligações entre si e poucas com outros nós da rede (que podem pertencer a outras comunidades). A Figura 5.1 mostra uma rede com nove nós (rotulados de 0 a 8 ) e três comunidades destacadas por três grandes círculos.

$\mathrm{Na}$ área de Redes Complexas, vários algoritmos de detecção de comunidades têm sido propostos (Donetti \& Muñoz, 2004; Duch \& Arenas, 2005). Algoritmos que enumeram todas as comunidades de uma rede são inviáveis para redes grandes (Duch \& Arenas, 2005). Por isso, há trabalhos na literatura que investigam algoritmos que buscam detectar o melhor agrupamento dos nós em comunidades utilizando tempo de computação aceitável na prática. 


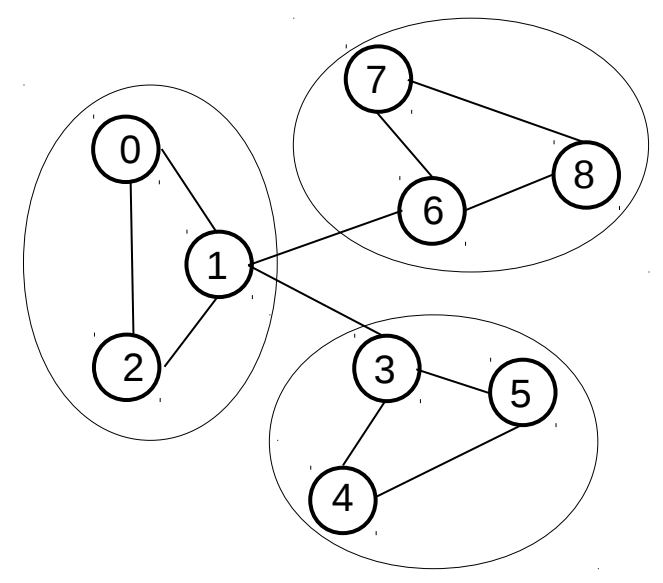

Figura 5.1: Exemplo de estrutura com três comunidades em uma rede.

A métrica $Q$ (Newman \& Girvan, 2004), chamada modularidade da rede, tem sido utilizada para avaliar a qualidade de um arranjo de nós em comunidades. Quanto maior o valor de $Q$, melhor a proposta da divisão da rede em comunidades. Dentre os algoritmos que utilizam a métrica para identificar comunidades, pode-se destacar: o Algoritmo Rápido (FA, do inglês Fast Algorithm) (Newman \& Girvan, 2004) (Seção 5.1.1), o Agrupamento Adaptativo (AdClust, do inglês Adaptive Clustering) (Ye et al., 2008) (Seção 5.1.2) e a Otimização Extrema (EO, do inglês Extreme Optimization) (Duch \& Arenas, 2005) (Seção 5.1.3).

\subsubsection{Algoritmo Rápido}

Uma das principais técnicas desenvolvidas para detecção de comunidades em redes foi o FA, que utiliza a métrica $Q$, definida conforme segue. Sejam duas comunidades $i$ e $j$ de uma rede, $e_{i j}$ é a fração do número de arestas que conectam as comunidades $i$ e $j$ em relação ao total de arestas da rede. Define-se $e_{i i}$ como o número de arestas dentro da comunidade $i$ dividido pelo total de arestas. O FA busca identificar as comunidades de uma rede que maximize a fração de arestas que conectam nós de uma mesma comunidade, ou seja, maximizar $\sum_{i} e_{i i}$.

Por outro lado, essa medida pode não avaliar adequadamente a qualidade das comunidades, uma vez que seu valor máximo é facilmente atingido quando todos os nós da rede pertencem à mesma comunidade. Para isso, mais um componente é utilizado: $a_{i}=\sum_{j} e_{i j}$, a fração das arestas da rede conectada um ou mais nós da comunidade $i$. A partir das frações $e_{i i}$ e $a_{i}$, define-se o índice de modularidade $Q$, conforme a Equação 5.1. A modularidade estima o quanto a fração $e_{i i}$ distancia-se do valor esperado de ligações na comunidade $i: a_{i} \times a_{i}$, isto é, a probabilidade de uma aresta ligada à comunidade $i$, ter seu outro extremo ligado a outro nó da comunidade $i$. A Figura 5.2 exemplifica o cálculo de $Q$.

$$
Q=\sum_{i}\left(e_{i i}-a_{i}^{2}\right) .
$$




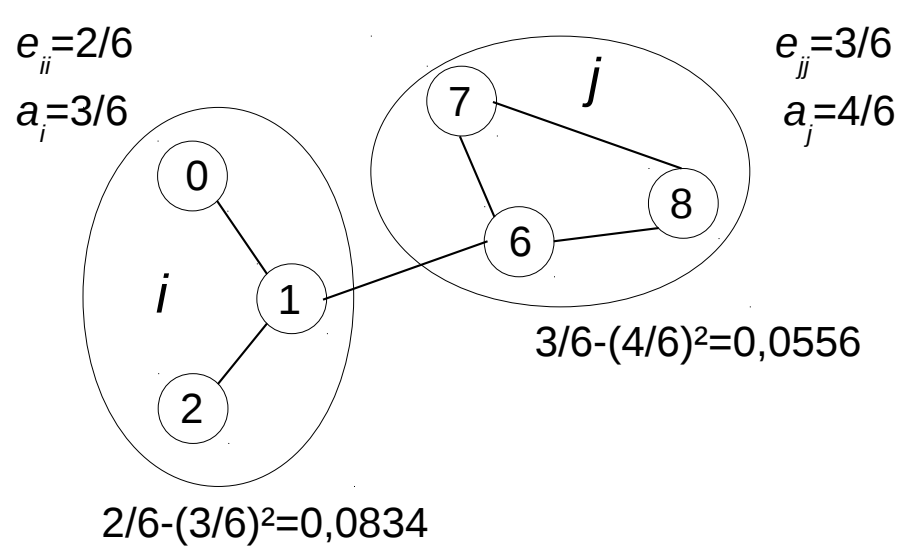

$Q=0,0834+0,0556=0,1390$

Figura 5.2: Exemplo de cálculo de $Q$ para uma rede 6 nós e 6 arestas.

Busca-se então, maximizar $Q$ em função de todas as possíveis divisões da rede em comunidades. Newman \& Girvan (2004) desenvolveram um algoritmo guloso (Cormen et al., 2001) capaz de identificar comunidades de uma rede com eficiência relativamente alta. Inicialmente, o FA considera o particionamento em que cada nó da rede forma uma comunidade. Então, comunidades são agrupadas em pares considerando todos os pares possíveis. A divisão com maior $Q$ entre todos os novos particionamentos investigados é armazenado. Nesse estágio, há dois particionamentos possíveis: o inicial e o que acaba de ser armazenado. Em seguida, o processo continua agrupando somente duas comunidades a partir do último particionamento armazenado, calculando $Q$ para cada um deles e armazenando somente o de maior $Q$. Esse processo, repete-se até que haja apenas uma comunidade. Por fim, o particionamento com maior valor de $Q$ entre todos os armazenados é a saída do FA.

É importante ressaltar que apenas comunidades que possuam pelo menos uma aresta ligando seus nós podem ser possivelmente unidas pelo algoritmo. A variação em $Q$, ao se unir duas comunidades, é dada pela Equação 5.2.

$$
\Delta Q=e_{i j}+e_{j i}-2 a_{i} a_{j}=2\left(e_{i j}-a_{i} a_{j}\right),
$$

em que o valor inicial de $e_{i j}$ é igual à metade do grau de cada comunidade, se vista como um nó.

A complexidade do FA é dada por $C_{F A}=O((a+\ell) \ell)$ (Newman \& Girvan, 2004), em que $a$ é o número de arestas na rede e $\ell$, seu número de nós.

\subsubsection{Agrupamento Adaptativo}

O princípio do AdClust é o de que cada nó adapte-se em sua vizinhança, podendo ir para comunidades vizinhas que exerçam uma maior "atração" do que sua comunidade atual. Esse procedimento é realizado até que um equilíbrio seja atingido, naturalmente obtendo um melhor valor 
para a modularidade $Q$ proposta em Newman \& Girvan (2004). Forças de atração de um nó, são definidas pelas Equações 5.3 e 5.4:

$$
\begin{gathered}
F_{\text {in }}^{(v)}=e_{\text {in }}^{(v)}-\frac{k\left(d_{\text {in }}^{(v)}-k\right)}{2 E}, \\
F_{\text {out }}^{(u)}=\max _{u \in C}\left\{e_{\text {out }}^{(u)}-\frac{k d_{\text {out }}^{(u)}}{2 E}\right\},
\end{gathered}
$$

em que:

- $F_{i n}^{(v)}$ é a força de atração para a comunidade $v$ em que o nó está;

- $F_{\text {out }}^{(u)}$ é a força de atração sobre o nó exercida pela comunidade vizinha $u$;

- $e_{i n}^{(v)}$ é o número de arestas que conectam o nó a sua atual comunidade $v$;

- $d_{i n}^{(v)}$ é o grau total dos nós dentro da comunidade $v$;

- $e_{\text {out }}^{(u)}$ é o número de arestas que conectam o nó à comunidade vizinha $u$;

- $d_{\text {out }}^{(u)}$ é o grau total dos nós dentro da comunidade $u$;

- $k$ é o grau do nó;

- E é o número total de arestas da rede;

- $C$ representa o conjunto de comunidades com pelo menos uma aresta conectada ao nó, com exceção da comunidade ao qual o nó pertence.

Em outras palavras, as Equações 5.3 e 5.4 representam o número real de arestas que ligam certo nó à comunidade, menos o número esperado de arestas ligadas à comunidade que um nó de mesmo grau teria. Se existir $F_{\text {out }}$ maior do que $F_{\text {in }}$, o nó muda de comunidade (vai para a comunidade que exerce maior atração). A Figura 5.3 ilustra esse comportamento.

Em comparação com o FA, esse método introduz uma rotina adicional de ordem $O(\ell)$. Ye et al. (2008) afirmam que as estruturas de comunidade detectadas pelo AdClust, apresentam em geral melhor modularidade $Q$ do que as estruturas encontradas pelo FA.

\subsubsection{Otimização Extrema}

O EO busca determinar melhores estruturas dividindo as comunidades existentes. Essa técnica baseia-se em uma métrica que verifica a contribuição de cada nó para o valor de modularidade total. Tal valor é dado pela Equação 5.5.

$$
q_{i}=k_{r_{i}}-k_{i} a_{r_{i}}
$$




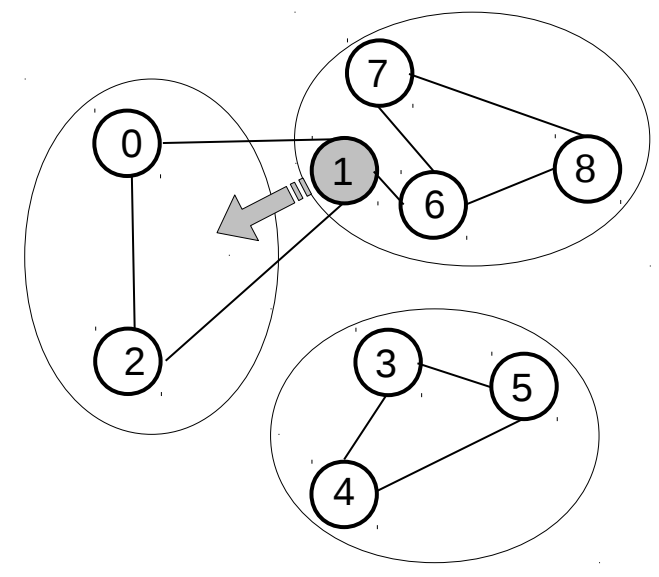

Figura 5.3: Princípio de funcionamento do AdClust: nó em destaque possui $F_{\text {out }}>F_{\text {in }}$ e, portanto, passa a pertencer à comunidade $\mathrm{A}$.

em que:

- $q_{i}$ é a contribuição do nó $i$ para a modularidade $Q$;

- $r_{i}$ é a $i$-ésima comunidade;

- $k_{r(i)}$ é o número de arestas que o nó $i$ possui para nós da mesma comunidade;

- $k_{i}$ é o grau do nó $i$;

- $a_{r(i)}$ é a fração das arestas com pelo menos um nó pertencente a comunidade $r_{i}$.

- $M$ é a quantidade de arestas da rede.

A Equação 5.5 é calculada seguindo a ideia de que a modularidade $Q$ (Newman \& Girvan, 2004) pode ser reescrita como um somatório das contribuições individuais de cada nó, como mostra a Equação 5.6.

$$
Q=\frac{1}{2 M} \sum_{i} q_{i} .
$$

Para obter a contribuição relativa de cada nó para o valor de modularidade, a contribuição individual $q_{i}$ é dividida pelo grau do nó $i$, representado por $k_{i}$, resultando na contribuição relativa do nó $i$, conforme a Equação 5.7.

$$
\lambda_{i}=\frac{q_{i}}{k_{i}}=\frac{k_{r(i)}}{k_{i}}-a_{r(i)} .
$$


O EO propõe substituir a seleção do nó com menor contribuição relativa por uma probabilidade de selecionar um determinado nó (Boettcher \& Percus, 2002). Essa probabilidade é dada pela Equação 5.8. A complexidade do algoritmo é a mesma que o AdClust.

$$
P(q) \alpha q^{-\tau}
$$

em que:

- $q$ é o ranque do nó, sua posição em um vetor dos $\lambda_{i}$ 's ordenados de forma decrescente;

- $\tau=1+\frac{1}{\ln (\ell)}$, em que $\ell$ é o número de nós da rede.

Em Ye et al. (2008), o EO e o AdClust apresentaram melhores valores de modularidade para problemas de benchmark, mostrando similaridade entre o desempenho das duas técnicas, além de resultados relativamente melhores que o FA. Apesar do FA não apresentar os melhores resultados no trabalho de Ye et al. (2008), o algoritmo possui a menor complexidade (Newman \& Girvan, 2004) dentre as três principais técnicas de detecção de comunidades. Crocomo (2012) realizou um estudo preliminar comparando essas três técnicas no contexto de EDAs e concluiu que o FA produziu particionamentos em comunidades com modularidade maior que AdClust e EO, preservando sua vantagem em relação a tempo computacional.

\subsection{Detecção de Comunidades em Filogenias}

Uma tarefa importante e difícil é identificar a que grupo evolutivo (clado) certa espécie pertence. Dada uma filogenia, clados hipotéticos agrupam os parentes mais próximos de cada ramo de uma filogenia do nível mais baixo (folha) ao mais alto (raiz) até que todas as espécies façam parte de um só clado. A Figura 5.4 ilustra os possíveis clados que contêm as espécies Nephrolepis e Xiphopteris, que são sequências de DNA do conjunto teste rbcL_55 (Cancino \& Delbem, 2007).

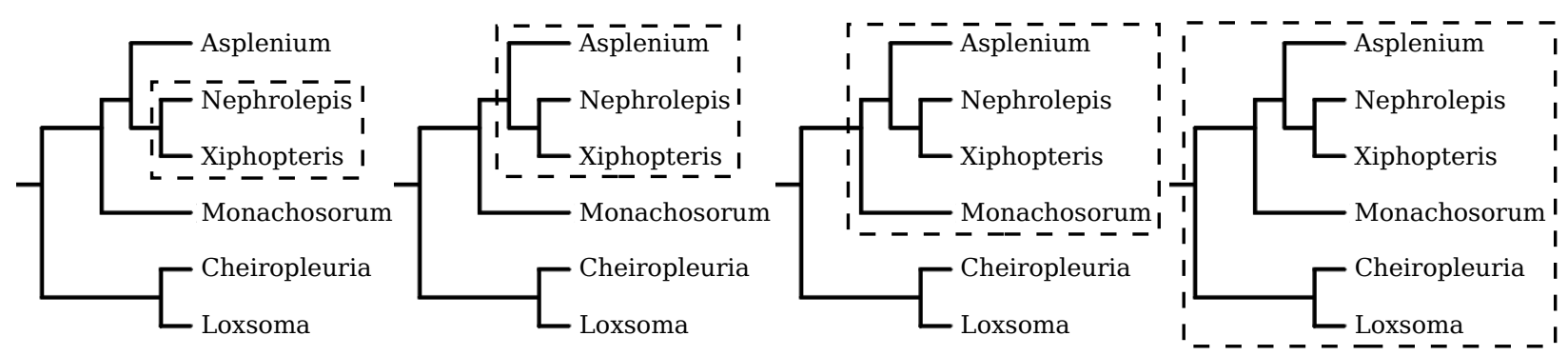

Figura 5.4: Clados hipotéticos que poderiam ser obtidos de uma mesma filogenia.

Em geral, conhecimento a priori sobre as espécies investigadas, além da distância (ou tempo de derivação) entre as espécies, possibilita escolher qual das hipóteses de clados é a mais plausível. Por outro lado, a comparação de diversas filogenias hipotéticas sobre o mesmo conjunto de dados (por exemplo, obtidas utilizando métricas de distância diferentes, mas adequadas para um mesmo 
contexto, ver Apêndice F) podem ser utilizadas para determinar clados. A Figura 5.5 mostra os clados mais plausíveis, ou mais frequentes, obtidos com base em informações das filogenias da Figura 5.4.

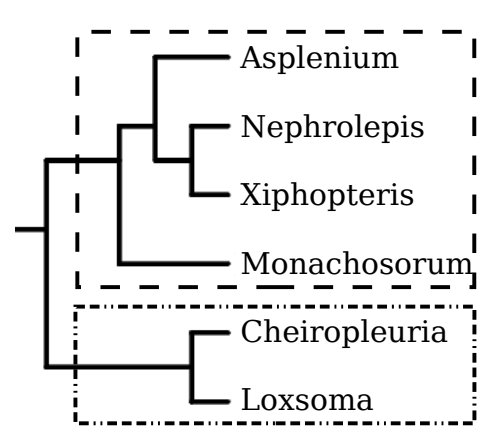

Figura 5.5: Clados mais plausíveis.

Uma forma de conseguir a identificação dos clados é por meio da união de diversas filogenias, formando uma rede. A Figura 5.6 ilustra a construção de uma rede composta por duas filogenias.

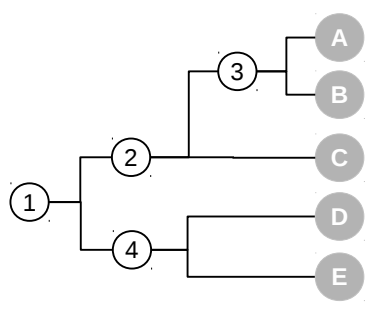

F1

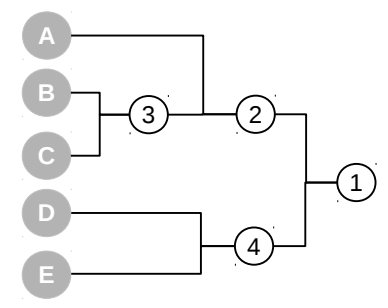

F2

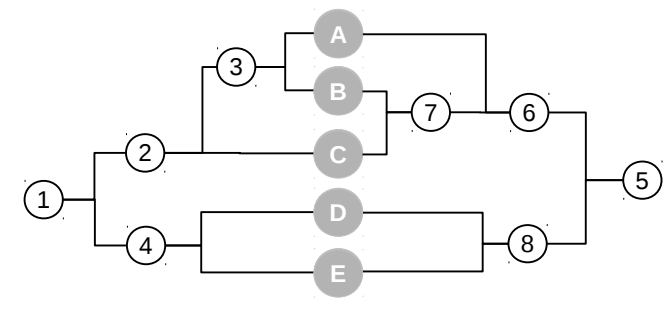

$T$

Figura 5.6: Rede $T$, formada pela união das filogenias $F_{1}$ e $F_{2}$.

Quanto mais árvores, melhor o consenso de clados entre as filogenias, salientando as relações mais confiáveis. Resultados experimentais de Mansour (2013) mostraram que o FA não é computacionalmente eficiente mesmo para redes compostas com poucas filogenias e apenas uma centena de espécies. Esse desempenho deve-se ao fato de o FA construir uma matriz $R$ de dimensão $(r \times r)$ em que $r$ é diretamente proporcional ao número de nós folhas $\ell$ de cada filogenia. O número de nós da Rede é $r=(\ell-1) f+\ell$, em que $\ell$ é o número de folhas na árvore (número de espécies), $(\ell-1)$ é o número de nós internos por filogenia e $f$ é o número de filogenias compondo a rede. Observe que o FA é cúbico em relação a $r$ (Seção 5.1.1), isto é, $O\left(r^{3}\right)$ ou $O\left(\ell^{3} f^{3}\right)$. A Figura 5.7 mostra a Matriz de Adjacências $R$ representando a rede $T$ da Figura 5.6.

Para contornar essa dificuldade, propõe-se neste trabalho a construção de uma rede que contenha somente as relações mais diretas entre folhas da árvore (taxa). Inicialmente, considera-se uma rede $T$ sem arestas. Então, para cada par de folhas conectados diretamente por um ancestral comum, insere-se uma aresta entre as folhas. A Figura 5.8(a) mostra as relações entre nós folhas ( $A-B$ e $D-E$ ) na rede $T_{1}$ após inserções com base na filogenia $F_{1}$ da Figura 5.6. Considerando $F_{2}$ da Figura 5.6, uma rede $T_{2}$ recebe as arestas $B-C$ e $D-E$ (Figura 5.8(b)). A identificação 
$R$

\begin{tabular}{|c|c|c|c|c|c|c|c|c|c|c|c|c|c|}
\hline & A & B & C & D & E & $\mathbf{1}$ & $\mathbf{2}$ & $\mathbf{3}$ & $\mathbf{4}$ & $\mathbf{5}$ & $\mathbf{6}$ & $\mathbf{7}$ & $\mathbf{8}$ \\
\hline A & 0 & 0 & 0 & 0 & 0 & 0 & 0 & 1 & 0 & 0 & 1 & 0 & 0 \\
\hline B & 0 & 0 & 0 & 0 & 0 & 0 & 0 & 1 & 0 & 0 & 0 & 1 & 0 \\
\hline C & 0 & 0 & 0 & 0 & 0 & 0 & 1 & 0 & 0 & 0 & 0 & 1 & 0 \\
\hline D & 0 & 0 & 0 & 0 & 0 & 0 & 0 & 0 & 1 & 0 & 0 & 0 & 1 \\
\hline E & 0 & 0 & 0 & 0 & 0 & 0 & 0 & 0 & 1 & 0 & 0 & 0 & 1 \\
\hline 1 & 0 & 0 & 0 & 0 & 0 & 0 & 1 & 0 & 1 & 0 & 0 & 0 & 0 \\
\hline 2 & 0 & 0 & 1 & 0 & 0 & 1 & 0 & 1 & 0 & 0 & 0 & 0 & 0 \\
\hline 3 & 1 & 1 & 0 & 0 & 0 & 0 & 1 & 0 & 0 & 0 & 0 & 0 & 0 \\
\hline 4 & 0 & 0 & 0 & 1 & 1 & 1 & 0 & 0 & 0 & 0 & 0 & 0 & 0 \\
\hline 5 & 0 & 0 & 0 & 0 & 0 & 0 & 0 & 0 & 0 & 0 & 1 & 0 & 1 \\
\hline 6 & 1 & 0 & 0 & 0 & 0 & 0 & 0 & 0 & 0 & 1 & 0 & 1 & 0 \\
\hline 7 & 0 & 1 & 1 & 0 & 0 & 0 & 0 & 0 & 0 & 0 & 1 & 0 & 0 \\
\hline 8 & 0 & 0 & 0 & 1 & 1 & 0 & 0 & 0 & 0 & 1 & 0 & 0 & 0 \\
\hline
\end{tabular}

Figura 5.7: Matriz $R$ relativa à rede $T$ da Figura 5.6.

final dos clados ocorre na rede resultante da união (soma lógica) das redes $T_{1}$ e $T_{2}$, conforme representado na Figura 5.9. Como a rede resultante $R$ tem dimensão $\ell \times \ell$, o FA aplicado a $R$ requer tempo $O\left(\ell^{3}\right)$.

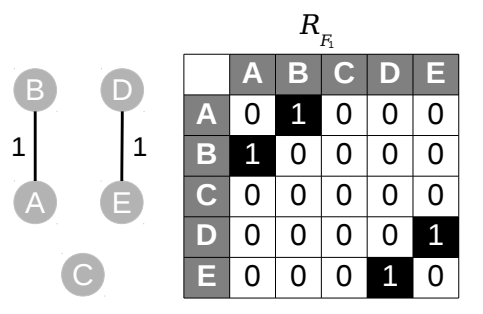

(a)

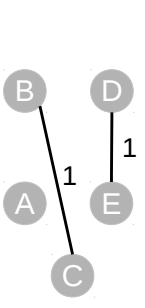

C

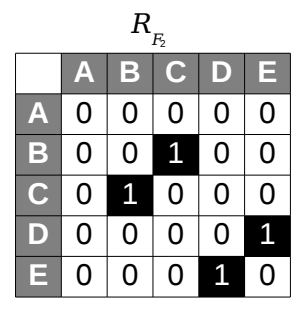

(b)

Figura 5.8: (a) Relações diretas de $F_{1}$ (Figura 5.6), (b) Relações diretas de $F_{2}$ (Figura 5.6) e as respectivas Matrizes de Adjacências.

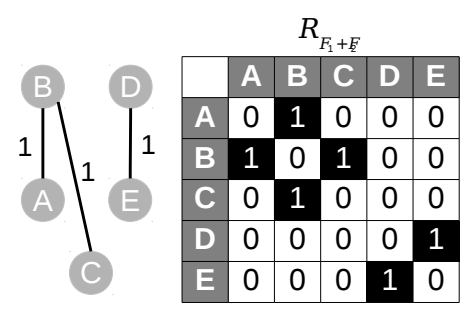

Figura 5.9: Rede obtida após união de $F_{1}$ e $F_{2}$ (Figura 5.6) e sua Matriz de Adjacências resultante.

Observe pelas Figuras 5.7, 5.8 e 5.9 como a dimensão da Matriz $R_{F_{1}}$ e $R_{F_{1}+F_{2}}$ é menor em relação a $R$ obtida de $T$ (Figura 5.7). A menor dimensão possibilita o FA lidar em tempo relativamente baixo, com conjunto de dados com $\ell$ maior. Além disso, os possíveis erros de ligação entre as folhas podem ser minimizados na detecção de comunidades (clados) proposta. Quanto mais árvores, maior a chance de ocorrerem arestas "corretas" (ou relativamente confiáveis) frente 
às "erradas" (não confiáveis). Com isso, o número de arestas dentro da comunidade tende a ser maior que o número de arestas entre as comunidades (Seção 5.1.1), evidenciando os clados para o FA.

\subsection{Considerações finais}

Neste Capítulo foi apresentado as principais técnicas de detecção de estruturas de comunidades da área de Redes Complexas que utilizam o cálculo de modularidade para avaliar particionamentos de uma rede em comunidades e que possuem complexidade computacional relativamente baixa. Esse tipo de algoritmo pode ser utilizado para agrupamento de dados, ou mesmo para determinar a correlação entre as variáveis de um problema, conforme proposto neste trabalho.

Uma rede pode também ser composta a partir de um conjunto de árvores (que representam de forma hierárquica relações entre variáveis, nós), conforme proposto em Mansour (2013). Esse conjunto pode ser obtido por um processo de reamostragem utilizando várias vezes um algoritmo de construção de árvore (NJ, por exemplo) sobre os dados reorganizados (como por exemplo na reamostragem por Bootstrap, Felsenstein (2003)).

A rede composta a partir dos vários nós pode ser grande em relação ao tamanho de cada árvore. Com isso um algoritmo de detecção de comunidades relativamente eficiente como o FA, pode não atingir a eficiência desejada com a rede, uma vez que sua complexidade é $O\left(\ell^{3} f^{3}\right)$. Neste Capítulo foi também apresentada uma nova estratégia para composição de uma rede que possui complexidade $O\left(\ell^{3}\right)$. Essa estratégia, então, mostra-se promissora para o desenvolvimento de novos EDAs, que podem ser mais eficientes ao se basearem nessa estratégia. 



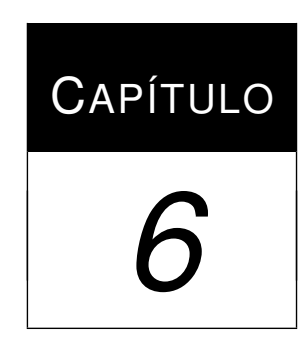

\section{Análise de Filogramas e Métodos de Agrupamento e Otimização}

Este Capítulo propõe um novo algoritmo baseado no $\Phi$ GA proposto por Vargas \& Delbem (2009) (descrito no Capítulo 4). Chamado de Agrupamento baseado em Análise de Filogramas (CPA, do inglês Clustering based on Phylogram Analysis), o novo algoritmo possui quatro inovações principais são: $(i)$ uso de um Conjunto de Árvores em vez de apenas uma como modelo de correlação entre variáveis, (ii) síntese das informações relevantes do Conjunto de Árvores em uma estrutura de Rede (Capítulo 5), (iii) uso de um algoritmo de detecção de comunidades (FA, Seção 5.1.1) para identificar os blocos construtivos (BBs, Seção 2.3) do problema a partir de uma ou mais Redes e (iv) o uso de reamostragens em várias etapas do algoritmo para tornar as redes mais representativas das correlações entre variáveis presentes no problema.

É importante destacar que o conceito de BBs usado no $\Phi \mathrm{GA}$ (Capítulo 4) pode ser estendido para o de clados (Seção 5.2) ao se combinar várias árvores em uma ou mais redes. Um clado envolvendo dados não biológicos corresponde a uma partição de variáveis em que pode estar presente mais de um BB fortemente correlacionado, por exemplo, por sobreposição entre elas (o que possui certa correspondência como a presença de material genético em comum em dados biológicos). A partir dos BBs obtidos pelo CPA, um novo EDA é proposto neste Capítulo a Otimização baseada em Análise de Filogramas (OPA, do inglês Optimization based on Phylogram Analysis), além de uma extensão da OPA para problemas com múltiplos objetivos.

A Seção 6.1 descreve todas as etapas do CPA. A Seção 6.2 explica a identificação de BBs para vários tipos de problemas usando o CPA. A Seção 6.3 descreve algumas propostas de EDAs para solução de problemas combinatórios que usam o particionamento gerado pelo CPA. A Seção 6.4 
propõe uma nova técnica de busca, a Busca Exaustiva Composta, que utiliza o particionamento obtido pelo CPA para solução de problemas, resultando na OPA. A Seção 6.5 calcula a complexidade da OPA. A Seção 6.6 descreve a extensão multiobjetivo da OPA.

\subsection{Descrição do CPA}

O CPA possui oito etapas principais. Essas etapas incluem passos do $\Phi \mathrm{GA}$ e as inovações presentes no CPA. As Figuras 6.1 a 6.8 ilustram o funcionamento de cada Etapa. A Figura 6.9 apresenta o diagrama geral do CPA contendo cada uma das etapas, descritas a seguir.

\section{Etapa 1: População de Selecionados}

Inicialmente uma população de tamanho $n$ é gerada aleatoriamente e seus indivíduos avaliados pelo fitness (Capítulo 2). É importante ressaltar que, somente nesta Etapa 1 do CPA, o Número de Avaliações (NA) é contabilizado, pois nas demais Etapas nenhum novo indivíduo é avaliado.

Em seguida, a Etapa 1 realiza uma reamostragem por torneio (Seção 4.1.2) sobre a População Inicial aleatória de tamanho $n$, selecionando $n_{s}$ indivíduos. O parâmetro $\Phi \in \mathbb{R}^{+}$multiplica $n$, o tamanho da População Inicial, definindo o tamanho da População de Selecionados $n_{s}$, de forma que $n_{s}=\Phi n$. A Figura 6.1(a) sintetiza a Etapa 1 e a Figura 6.1(b) exemplifica o efeito do torneio em conjunto com o parâmetro $\Phi$ sobre a distribuição de fitness da População Inicial.

\section{Etapa 2: Matriz Distância}

Para cada reamostragem (População de Selecionados), é calculada uma Matriz Distância usando uma Métrica (Apêndice F) aplicada a cada par de variáveis do problema. Para problemas de variáveis binárias, usa-se a métrica MI (Apêndice F); para variáveis reais ou mistas, pode-se utilizar a NCD (Apêndice F). É possível ainda calcular distâncias utilizando conhecimento a priori sobre o domínio do problema. Por exemplo, para sequências de DNA, pode-se aplicar as métricas baseadas em modelos evolutivos (Felsenstein, 2003) (Apêndice F). A Figura 6.2 exemplifica a Etapa 2. 
População Inicial

População de Selecionados

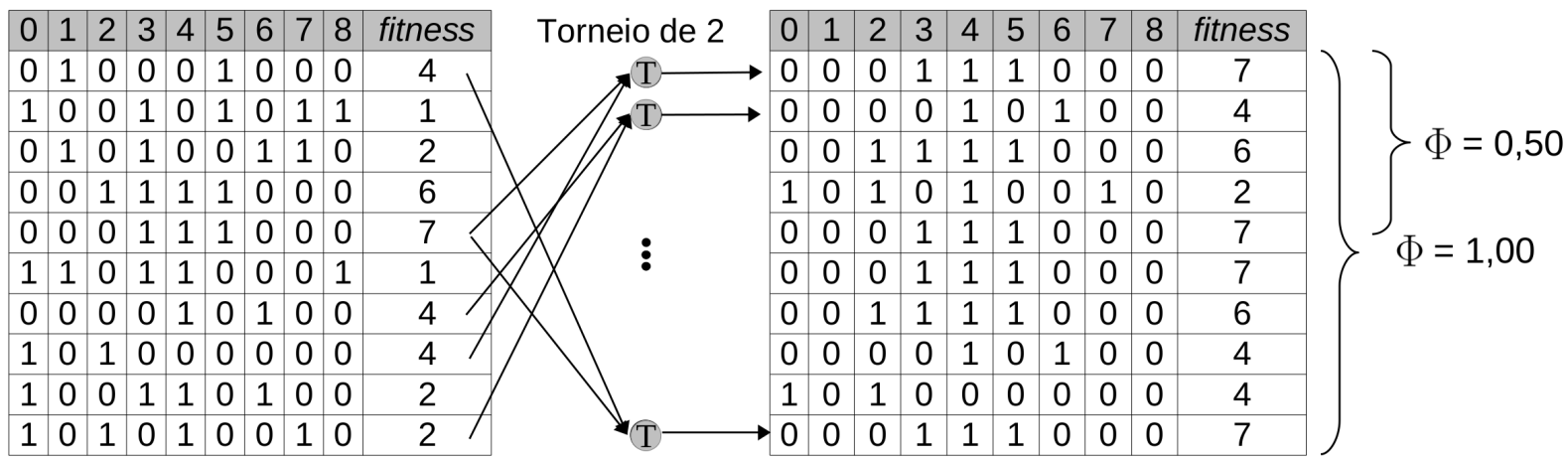

(a)

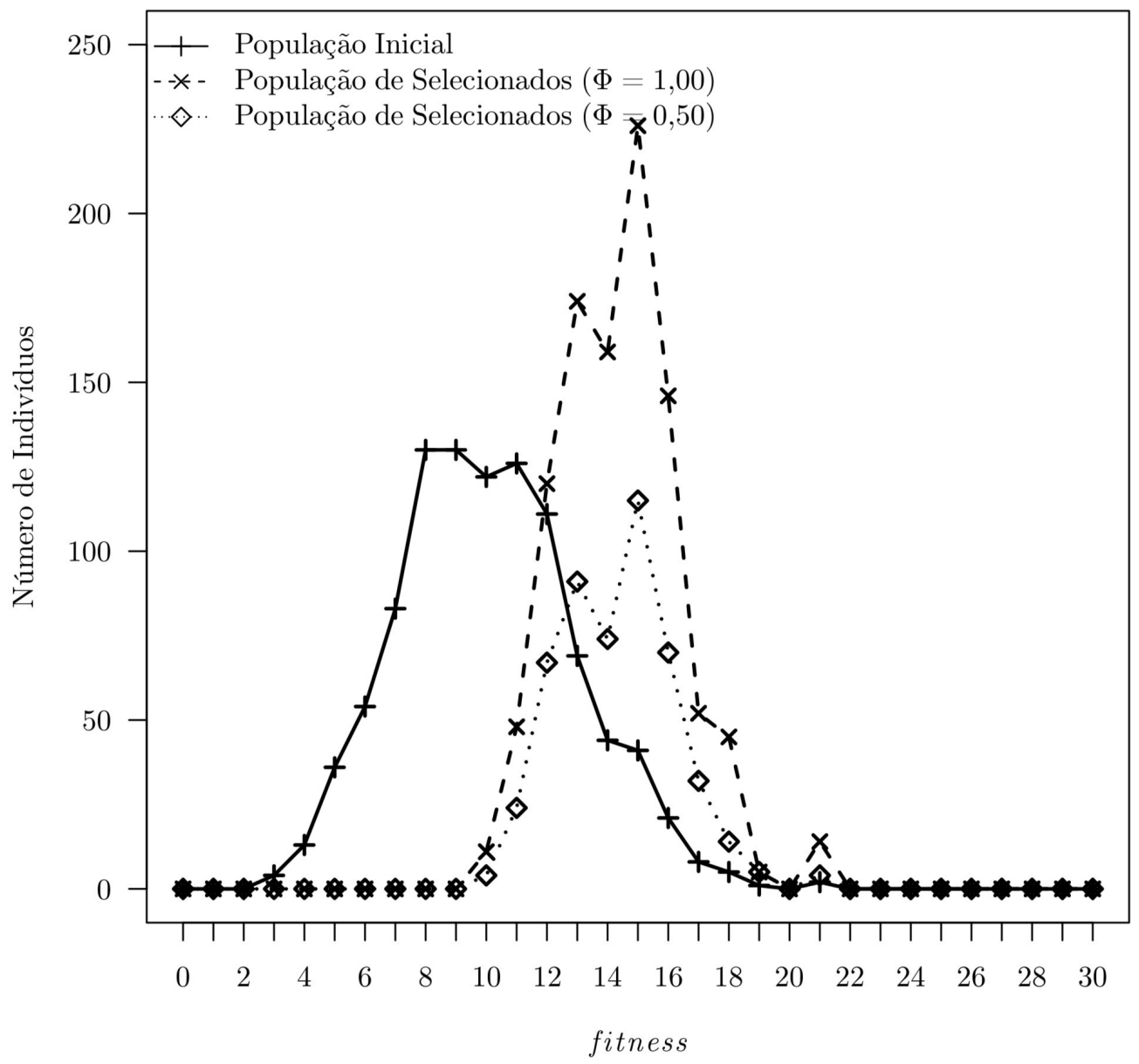

(b)

Figura 6.1: (a) Exemplo de População Inicial $(n=10, \ell=9)$ para o problema composto por 3 funções armadilhas ftrap3 $(k=3)$ e População de Selecionados por torneio de $3 \operatorname{com} \Phi=0,50$ e $\Phi=1,00$, (b) distribuição dos fitness na População Inicial aleatória $(n=1000, \ell=30)$ para um problema composto por 6 funções armadilhas ftrap5 $(k=5)$ e Populações de Selecionados (torneio de 8), em que os modos ("picos") da distribuição correspondente são salientados usando $\Phi=0,50$ e $\Phi=1,00$. 
População de Selecionados

\begin{tabular}{|c|c|c|c|c|c|c|c|c|c|}
\hline 0 & 1 & 2 & 3 & 4 & 5 & 6 & 7 & 8 & fitness \\
\hline 0 & 0 & 0 & 1 & 1 & 1 & 0 & 0 & 0 & 7 \\
\hline 0 & 0 & 0 & 0 & 1 & 0 & 1 & 0 & 0 & 4 \\
\hline 0 & 0 & 1 & 1 & 1 & 1 & 0 & 0 & 0 & 6 \\
\hline 1 & 0 & 1 & 0 & 1 & 0 & 0 & 1 & 0 & 2 \\
\hline 0 & 0 & 0 & 1 & 1 & 1 & 0 & 0 & 0 & 7 \\
\hline
\end{tabular}

Matriz Distância

\begin{tabular}{|l|c|c|c|c|c|c|c|c|c|}
\cline { 2 - 10 } \multicolumn{1}{c|}{} & 0 & 1 & 2 & 3 & 4 & 5 & 6 & 7 & 8 \\
\hline 0 & 0,000 & 1,754 & 1,111 & 1,899 & 1,907 & 1,914 & 1,829 & 1,872 & 1,889 \\
\hline 1 & 1,754 & 0,000 & 1,683 & 1,966 & 1,967 & 1,984 & 1,622 & 1,933 & 1,948 \\
\hline 2 & 1,111 & 1,683 & 0,000 & 1,888 & 1,957 & 1,943 & 1,750 & 1,864 & 1,923 \\
\hline 3 & 1,899 & 1,966 & 1,888 & 0,000 & 1,789 & 1,895 & 1,988 & 1,803 & 1,949 \\
\hline 4 & 1,907 & 1,967 & 1,957 & 1,789 & 0,000 & 1,984 & 1,918 & 1,865 & 1,939 \\
\hline 5 & 1,914 & 1,984 & 1,943 & 1,895 & 1,984 & 0,000 & 1,914 & 1,930 & 1,955 \\
\hline 6 & 1,829 & 1,622 & 1,750 & 1,988 & 1,918 & 1,914 & 0,000 & 1,670 & 1,672 \\
\hline 7 & 1,872 & 1,933 & 1,864 & 1,803 & 1,865 & 1,930 & 1,670 & 0,000 & 1,857 \\
\hline 8 & 1,889 & 1,948 & 1,923 & 1,949 & 1,939 & 1,955 & 1,672 & 1,857 & 0,000 \\
\hline
\end{tabular}

Figura 6.2: Matriz Distância calculada por meio da MI.

\section{Etapa 3: Árvores}

A partir da Matriz Distância calculada na Etapa 2, a Etapa 3 gera uma filogenia (que pode representar relações hierárquica entre as variáveis) usando NJ (Seção 3.1.1). Como esse algoritmo é do tipo guloso, a filogenia encontrada pode não ser ótima, mas em geral é uma aproximação adequada da melhor filogenia. Quando colunas e linhas da Matriz Distância são permutadas, o NJ em geral constrói árvores sub-ótimas diferentes para cada permutação. Um aspecto importante dessas diferentes árvores é a presença de subestruturas comuns. A Figura 6.3 mostra três árvores diferentes originadas da mesma Matriz Distância por meio de permutações de colunas e linhas, destacando as subestruturas que se preservaram nas três.
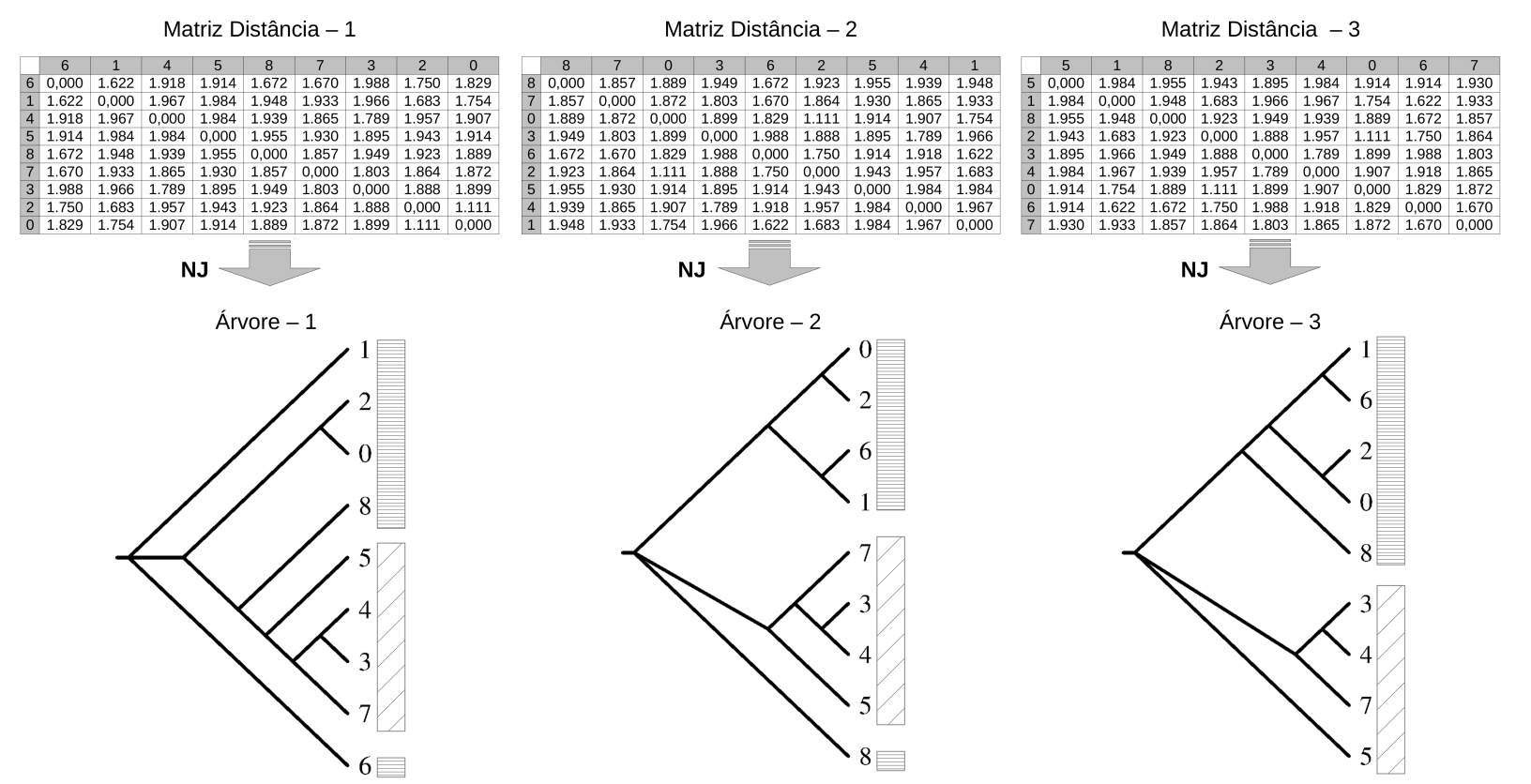

Figura 6.3: Diferentes árvores geradas pelo NJ permutando aleatoriamente linhas e colunas de uma mesma Matriz Distância. As faixas iguais de uma filogenia para a outra destacam subestruturas comuns. 


\section{Etapa 4: Redes Completas}

A Etapa 4 converte o formato Newick (Felsenstein, 2003) de saída do NJ (usualmente empregado por ferramentas de bioinformática como PHYLIP (Felsenstein, 2000)) para o formato de Matriz de Adjacências. Isso possibilita aplicar o algoritmo de detecção de comunidades da área de Redes Complexas (Capítulo 5) proposto na Etapa 5. A Figura 6.4 ilustra essa conversão.

O uso do formato Newick e sua conversão para Matriz de Adjacências possibilita também que diversos algoritmos de reconstrução de árvores possam ser considerados na Etapa 3 (Filogenias) do CPA. Além disso, outros algoritmos de detecção de comunidades em redes, diferentes do proposto na Etapa 5, podem ser aplicados diretamente a partir dessa matriz. É importante também observar que, neste texto, o termo filogenia está sempre associado a dados no formato Newick e o termo Rede, a uma Matriz de Adjacências.
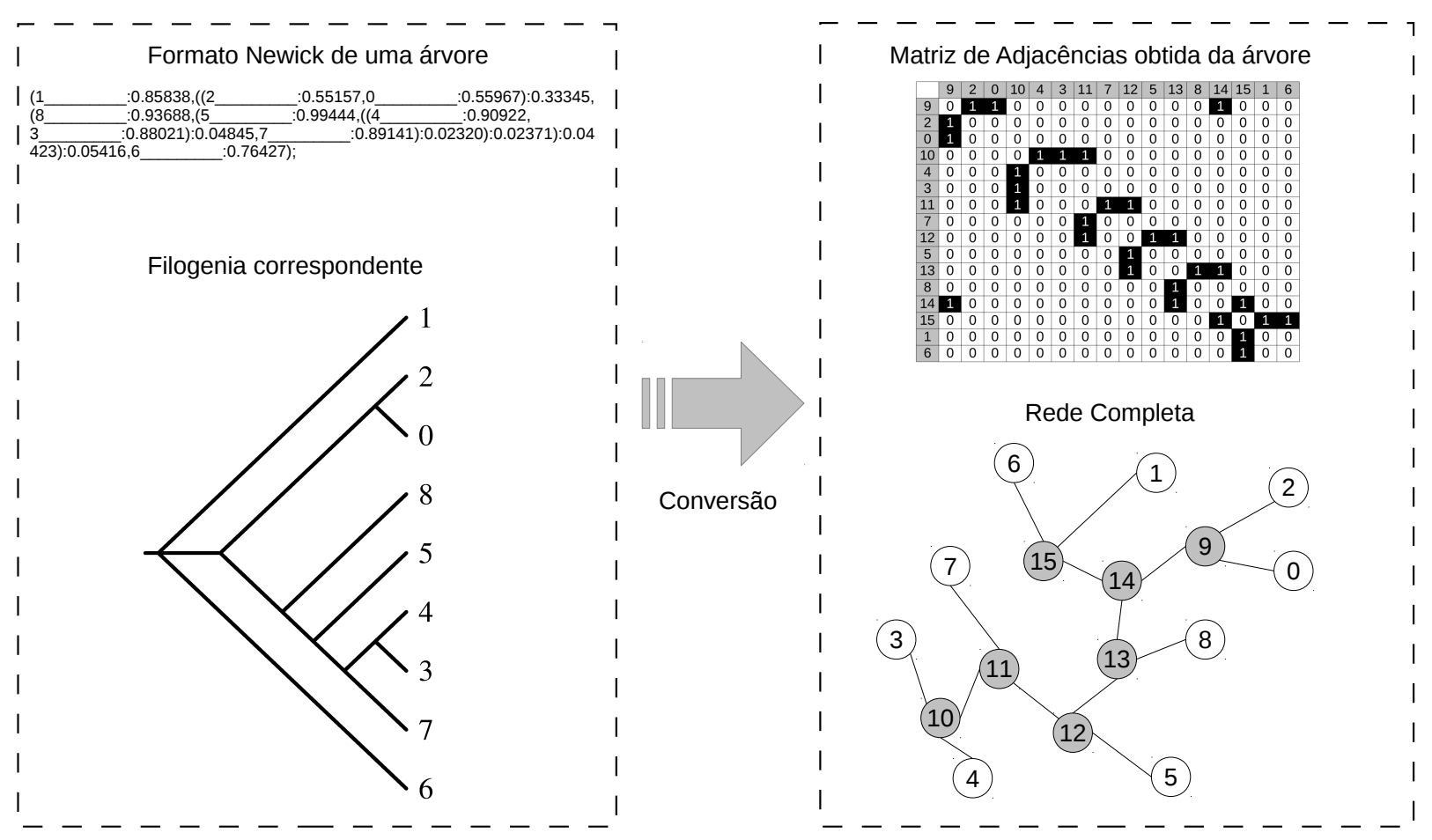

Figura 6.4: Conversão de filogenia no formato Newick para Matriz de Adjacências. Neste exemplo, nós com índices maiores que 8 são nós internos da filogenia. 


\section{Etapa 5: Particionamentos}

Com base na Rede representada pela Matriz de Adjacências obtida na Etapa 4, a Etapa 5 determina um conjunto de possíveis particionamentos das variáveis do problema. Para isso, aplica-se uma técnica de detecção de comunidades. No trabalho de Crocomo (2012), o FA (Seção 5.1.1) mostrou-se o algoritmo mais indicado. Assim como o NJ, o FA também é um algoritmo guloso, para o qual permutações aleatórias de linhas e colunas da Matriz de Adjacências produzem em geral particionamentos diferentes.

Para lidar com esse aspecto do FA, várias permutações são geradas produzindo um conjunto de particionamentos, a partir dos quais se pode eliminar as partições menos frequentes. Observe que os particionamentos diretamente resultantes do FA contemplam também todos os nós da filogenia, nós internos e nós folhas (representantes das variáveis do problema), uma vez que a Matriz de Adjacências de entrada contempla todos os nós da filogenia. A Etapa 5 remove os nós internos, assim, a saída desta Etapa contém somente os nós folhas. A Figura 6.5 mostra particionamentos derivados de três permutações da Matriz de Adjacências.

Matriz de Adjacências - 1

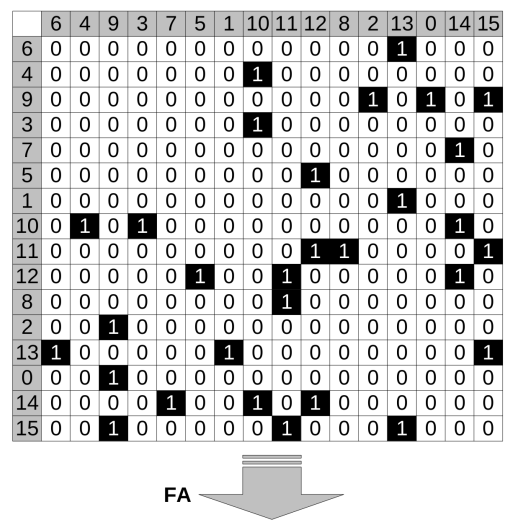

Particionamento-1 (Todos os nós)

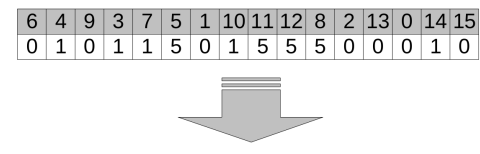

Particionamento-1 (Nós Folha)

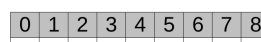

Matriz de Adjacências - 2

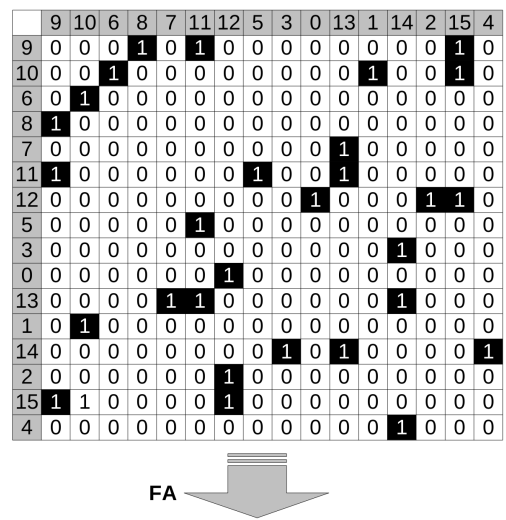

Particionamento-2 (Todos os nós)

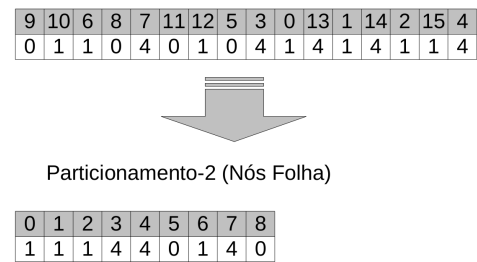

Matriz de Adjacências - 3

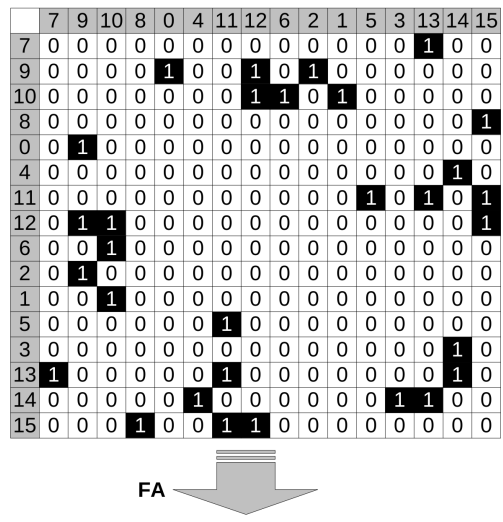

Particionamento-3 (Todos os nós)

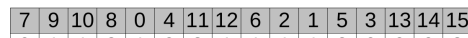

$\begin{array}{lllllllllllllllll}0 & 1 & 1 & 3 & 1 & 0 & 3 & 1 & 1 & 1 & 1 & 3 & 0 & 0 & 0 & 3\end{array}$

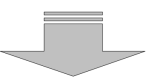

Particionamento-3 (Nós Folha)

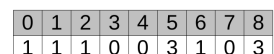

Figura 6.5: Diferentes particionamentos gerados a partir das três permutações (Figura 6.3) sobre uma mesma Matriz de Adjacências (Figura 6.2) usando o FA. 


\section{Etapa 6: Redes de Folhas}

A Etapa 6 simplesmente converte cada particionamento de nós folhas (obtidos na Etapa 5) no formato de Matriz de Adjacências que representa um grafo denominado Rede de Folhas. Para isso, considera-se que todos os nós de uma mesma partição formam um clique de grafo (Diestel, 2006). Esse formato de matriz é necessário para a Etapa 7, que também representa os índices de linhas e colunas em uma ordem padrão. No caso, usou-se a ordem crescente de índices. A Figura 6.6 exemplifica o processo de conversão realizado pela Etapa 6 . Índice de variáveis ( 0 a 8) e respectivos
rótulos $(0,3$ e 6$)$ indicando cada partição

\begin{tabular}{l|l|l|l|l|l|l|l|l|}
0 & 1 & 2 & 3 & 4 & 5 & 6 & 7 & 8 \\
\hline 0 & 0 & 0 & 3 & 3 & 3 & 6 & 6 & 6 \\
\hline
\end{tabular}

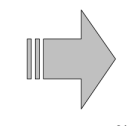

Conversão

Matriz de Adjacências representando o particionamento

\begin{tabular}{|l|l|l|l|l|l|l|l|l|l|}
\hline & 0 & 1 & 2 & 3 & 4 & 5 & 6 & 7 & 8 \\
\hline 0 & 0 & 1 & 1 & 0 & 0 & 0 & 0 & 0 & 0 \\
\hline 1 & 1 & 0 & 1 & 0 & 0 & 0 & 0 & 0 & 0 \\
\hline 2 & 1 & 1 & 0 & 0 & 0 & 0 & 0 & 0 & 0 \\
\hline 3 & 0 & 0 & 0 & 0 & 1 & 1 & 0 & 0 & 0 \\
\hline 4 & 0 & 0 & 0 & 1 & 0 & 1 & 0 & 0 & 0 \\
\hline 5 & 0 & 0 & 0 & 1 & 1 & 0 & 0 & 0 & 0 \\
\hline 6 & 0 & 0 & 0 & 0 & 0 & 0 & 0 & 1 & 1 \\
\hline 7 & 0 & 0 & 0 & 0 & 0 & 0 & 1 & 0 & 1 \\
\hline 8 & 0 & 0 & 0 & 0 & 0 & 0 & 1 & 1 & 0 \\
\hline
\end{tabular}

Rede de Folhas

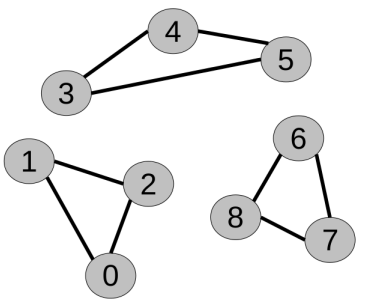

Figura 6.6: Exemplo de conversão entre partições (vetor de rótulos), representação em Matriz de Adjacências e a Rede de Folhas correspondente. 


\section{Etapa 7: Redes Equivalentes}

Todas as Matrizes de Adjacências representando os particionamentos encontradas a partir de cada Rede de Folhas de uma mesma População de Selecionados (mesma reamostragem, ver Etapa 1) são somadas (soma lógica ou operador Booleano OU (Lipschutz \& Lipson, 2004)). O resultado é a Matriz de Adjacências Equivalente, que corresponde ao que foi denominado Rede Equivalente. A Figura 6.7 exemplifica a Etapa 7 mostrando duas Redes Equivalentes relativas a duas reamostragens, cada Rede Equivalente obtida de duas Matrizes de Adjacências oriundas da mesma reamostragem (População de Selecionados).
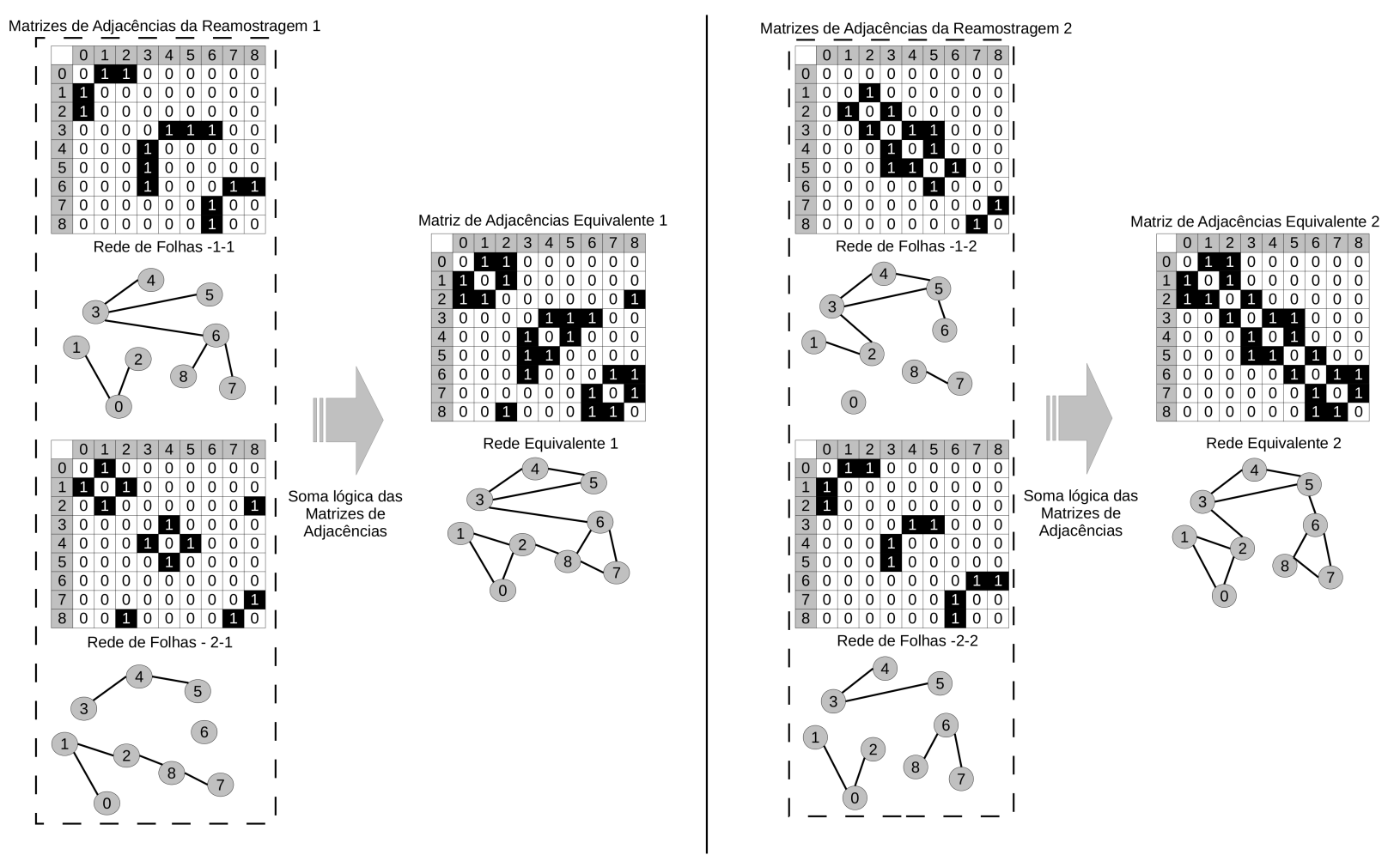

Figura 6.7: Rede de Folhas e Redes Equivalentes obtidas de duas reamostragens de População Inicial. 


\section{Etapa 8: Particionamento Reamostral e Final}

Novamente o FA é aplicado, desta vez, sobre cada Matriz de Adjacências Equivalente (Rede Equivalente, ver Etapa 7) produzindo um Particionamentos Reamostral, isto é, um resultado para cada reamostragem (População de Selecionados, ver Etapa 1). Em seguida todas as Matrizes de Adjacências Equivalentes são somadas pelo mesmo procedimento descrito na Etapa 7, produzindo uma única Matriz de Adjacências, denominada Matriz de Adjacências Final (representada pela Rede Final). Por fim, o FA é aplicado sobre a Rede Final obtendo o Particionamento Final. A Figura 6.8 sumariza a Etapa 8 em um exemplo.

Nesta etapa o CPA revela, de certa forma, que de quantidade é possível extrair qualidade (informação relevante), uma vez que a inclusão de relações presentes em uma Rede de baixa qualidade (por exemplo com a ligação errônea de duas partições) tende a não interferir no resultado final das comunidades identificadas a partir da Rede Final. Isso deve-se ao fato de a importância de uma possível relação entre nós que não é evidente ser relativamente pequena frente a importância das arestas corretamente incluídas que, em geral, ocorrem em maior número. A soma dessas Matrizes possibilita entender uma das propriedades do CPA, a de que partições menores podem se tornar maiores (ou formar clados) ao se verificar consensos entre essas partições; ou simplesmente, podem se tornar mais representativas ou confiáveis por meio da inclusão de arestas entre seus nós.

Por fim, a Figura 6.9 apresenta um diagrama que sintetiza todas as etapas do CPA. 


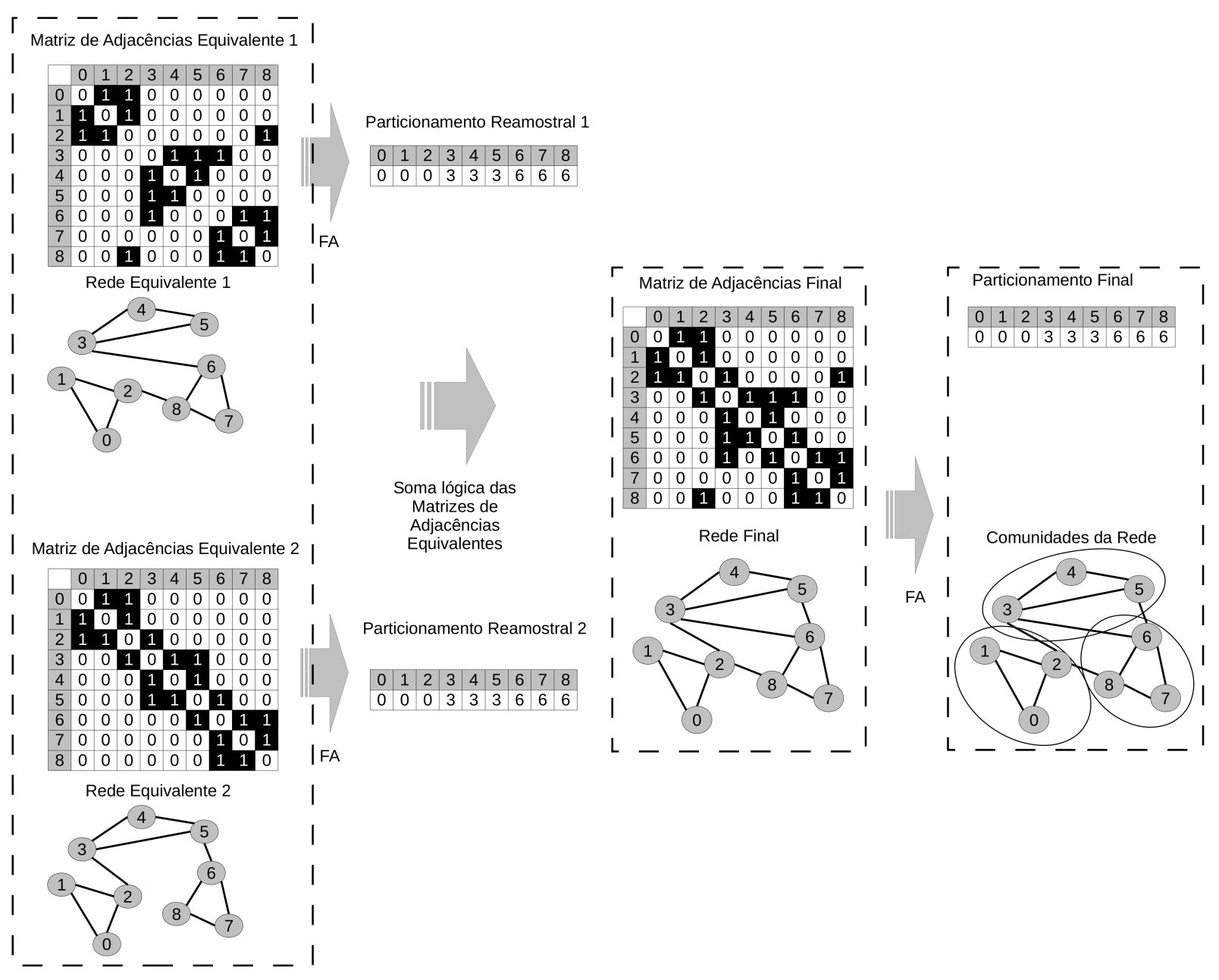

Figura 6.8: Identificação dos BBs (comunidades) do problema através da Redes Equivalentes e particionamentos Reamostrais. 


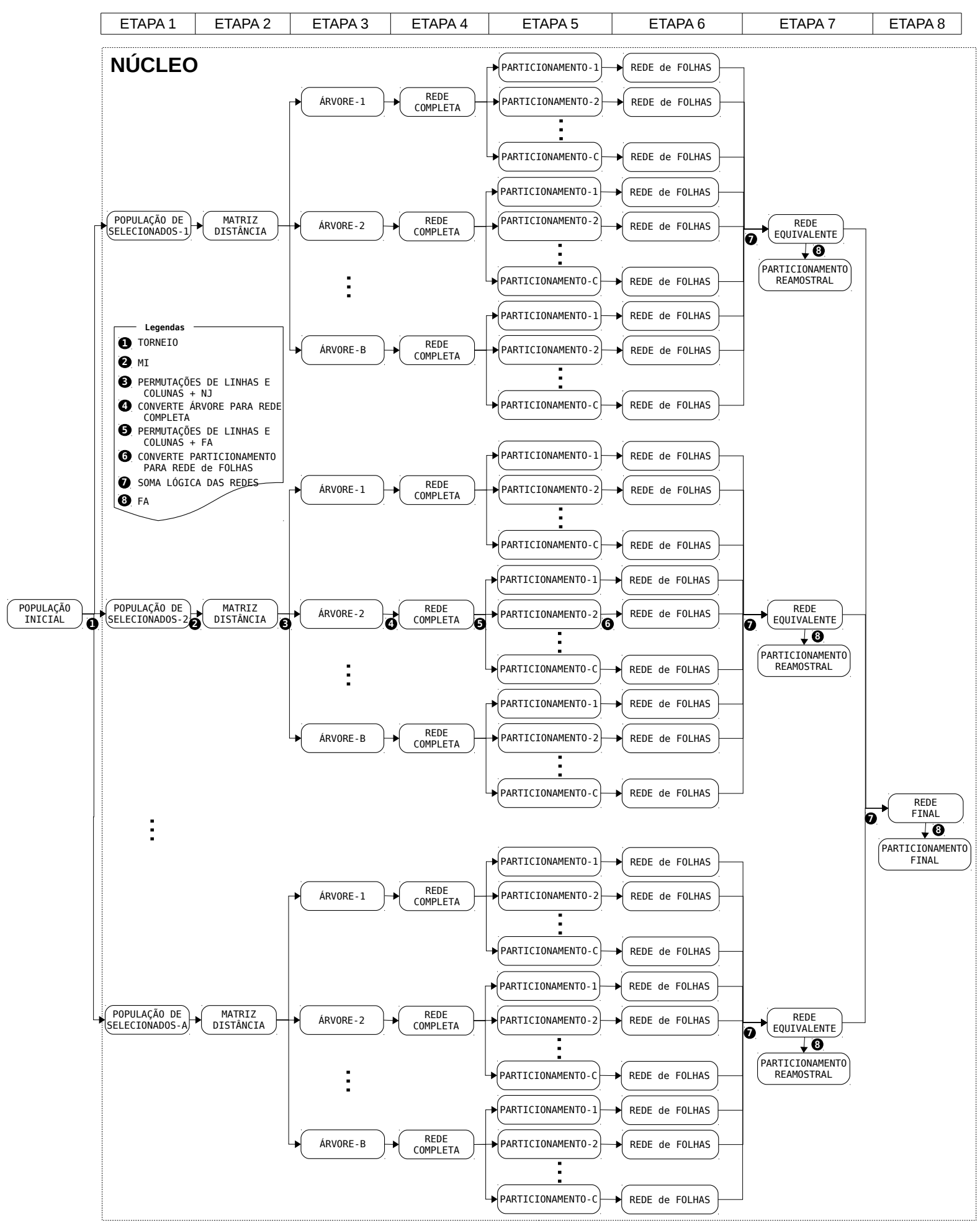

Figura 6.9: Diagrama resumindo o CPA. 


\subsection{Identificação de Partições e Sobreposições}

O CPA possibilita não somente identificar BBs presentes em ASDP (Seção 7.4), mas também sobreposição de partições em problemas combinatórios mais complexos. Nesse caso, a interação entre as variáveis em geral não é única, indicando que há vários níveis de relações com intensidades diferenciadas. Uma forma de representar essas relações entre BBs é por meio de uma de filogenia, que pode ser utilizada para descrever agrupamentos hierárquicos.

Sobreposições representadas de forma hierárquica possuem relação direta com árvores, em que, taxa com ancestral comum possuem alta homologia (similaridade com origem comum, com sobreposição de material genético). Por outro lado, taxa com parentesco de maior distância (nós internos mais ao topo da filogenia) possuem baixa correlação que, em geral, pode ser desprezada na prática (a presença de pouco material genético em comum, não garante que esse material possua a mesma origem ${ }^{1}$ ).

As relações relevantes em uma filogenia estão em uma mesma subárvore, denominada clado. No contexto de partições de variáveis, clados correspondem a subconjuntos de BBs com sobreposição que não é razoável desprezar. Neste texto, o termo partição pode corresponder diretamente a um BB ou a um subconjunto deles sobrepostos, formando um clado.

É importante observar que a composição de Redes Equivalentes por soma lógica (Etapa 7) tende a agrupar as variáveis, fazendo com que essas componham somente uma partição, independente do número de ligações que uma variável tenha entre dois ou mais BBs. Para avaliar isso, o CPA usa os Particionamentos Reamostrais, verificando se o Particionamento Final (consenso dos Particionamentos Reamostrais) é representativo, isto é, se os clados formados por composição de BBs são confiáveis. Neste trabalho, considera-se que uma partição do Particionamento Final não é significativa se esta não estiver presente na metade dos Particionamentos Reamostrais.

Na sequência, é ilustrado como o CPA identifica partições (BBs e clados) a partir de amostras de particionamentos obtidos de: (i) ASDP (Figura 6.10(a)), (ii) problemas com alguma sobreposição de BBs (Figura 6.10(b)) e (iii) problemas em que não há BBs não sobrepostos (Figura 6.10(c)).

${ }^{1}$ Por exemplo, o material comum pode ser de Elementos de Transposição (Philippsen, 2014). 


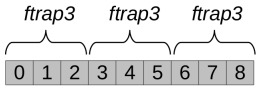

\begin{tabular}{|c|c|c|c|c|c|c|c|c|}
\hline Amostragem & 0 & 1 & 2 & & 5 & 6 & & 8 \\
\hline Particionamento-1 & 0 & 0 & 0 & 3 & 3 & 6 & & 7 \\
\hline Particionamento-2 & 0 & 1 & 0 & & 3 & 6 & & 7 \\
\hline Particionamento-3 & 0 & 0 & 0 & & 3 & 6 & & 6 \\
\hline Particionamento-4 & 0 & 0 & 0 & & 3 & 6 & & 7 \\
\hline Particionamento-5 & 0 & 0 & 0 & & 3 & 6 & & 6 \\
\hline Particionamento- 6 & 0 & 0 & 0 & 3 & 3 & 6 & & 6 \\
\hline Particionamento-7 & 0 & 0 & 2 & & 3 & 6 & & 6 \\
\hline Particionamento-8 & 0 & 1 & 0 & & 4 & 6 & & 6 \\
\hline Particionamento-9 & 0 & 0 & 0 & & 3 & 6 & & 6 \\
\hline Particionamento-10 & 0 & 1 & 0 & & 3 & 6 & & 6 \\
\hline articionamento Final & 0 & 0 & 0 & 3 & 3 & 6 & & 6 \\
\hline clados & 0 & 0 & 0 & 3 & 3 & 6 & & 6 \\
\hline
\end{tabular}

(a)

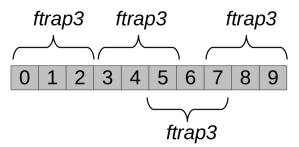

\begin{tabular}{|c|c|c|c|c|c|c|c|c|c|c|}
\hline Amostragem & 0 & & 2 & 3 & 4 & & & & & 9 \\
\hline Particionamento- 1 & 0 & 0 & 0 & 3 & 3 & & & & & 7 \\
\hline Particionamento-2 & 0 & 1 & 0 & 3 & 3 & 3 & 6 & & & 7 \\
\hline Particionamento-3 & 0 & 0 & 0 & 3 & 3 & 3 & 6 & & & 6 \\
\hline Particionamento-4 & 0 & 0 & 0 & 3 & 4 & 3 & 6 & & & 7 \\
\hline Particionamento-5 & 0 & 0 & 0 & 3 & 3 & 3 & 6 & & & 6 \\
\hline Particionamento- 6 & 0 & 0 & 0 & 3 & 3 & & & & & 7 \\
\hline Particionamento-7 & 0 & 0 & 2 & 3 & 3 & & & & & 6 \\
\hline Particionamento-8 & 0 & 1 & 0 & 3 & 4 & 4 & & & & 8 \\
\hline Particionamento-9 & 0 & 0 & 0 & 3 & 3 & 3 & 6 & & & 6 \\
\hline Particionamento-10 & 0 & 1 & 0 & 3 & & 3 & & & & 8 \\
\hline Particionamento Final & 0 & 0 & 0 & 3 & & & & & & 6 \\
\hline clados & 0 & 0 & 0 & 3 & 3 & 3 & 3 & & & 3 \\
\hline
\end{tabular}

(b)
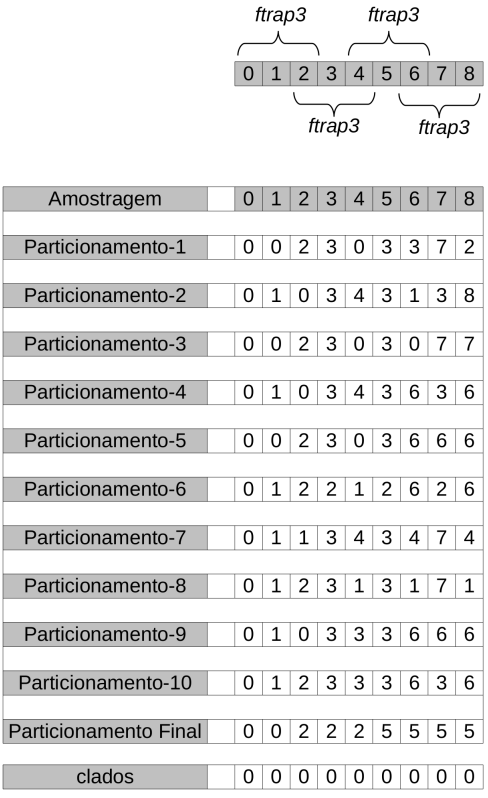

(c)

Figura 6.10: (a) Problema com 3 ftrap 3 aditivamente separáveis, (b) Problema com uma ftrap3 separável e 3 ftrap 3 sobreposta de um bit e (c) Problema com 4 ftrap 3 com sobreposição de um bit. 


\subsection{Otimização baseada na Análise de Filogramas}

O Particionamento gerado pelo CPA pode ser utilizado como uma etapa de um EDA para resolução de problemas de otimização. Isso pode ser realizado, por exemplo, acrescentando um método que explore o espaço de busca com base em cada partição do particionamento encontrado pelo CPA (Etapa 8, ver Seção 6.1). Nesse sentido, pode-se destacar duas estratégias da literatura: (i) Otimização Direta (StrOp, do inglês Straight Optimization), que corresponde basicamente a fazer uma ES (Seção 4.3) em cada partição (BB) identificado e (ii) Aplicação do método Differential Evolution (DE) (Qu \& Suganthan, 2010), que converte a sequência de bits de cada partição no número inteiro correspondente, gerando metavariáveis inteiras.

A estratégia ( $i$ ) foi proposta em Crocomo et al. (2013) e realiza uma ES sobre as partições obtidas na primeira geração do BOA (Seção 2.7). Chamado de StrOp, esse método mostrou-se capaz de encontrar a solução de ASDP com redução significativa de NA, atingiu até $78 \%$ a menos de NA quando comparado ao BOA. Além disso, apresentou eficácia (porcentagem de repetições de testes, com sementes diferentes para o gerador de números aleatórios que encontram o ótimo) igual ou acima de 95\%, similar ao nível observado para o BOA.

Na estratégia (ii), o DE explora o espaço de busca das metavariáveis. Em Melo et al. (2011) encontram-se mais detalhes sobre esse método, que ao ser combinado com o $\Phi$ GA foi renomeado para $\Phi D E$. As metavariáveis inteiras (obtidas com base nas partições encontradas pelo $\Phi \mathrm{GA}$ ) possibilitaram encontrar melhores soluções que o DE para os problemas combinatórios testados. $\Phi \mathrm{DE}$ demonstrou maior eficiência, precisando de apenas cerca de $50 \%$ das avaliações totais do ECGA ((Harik et al., 2006)) para resolver ASDP com tamanho do BB $k=8$.

Um outro aspecto revelante para o desenvolvimento de EDAs a partir do particionamento gerado pelo CPA é que esse particionamento é significativamente confiável. Conforme mostrado em Mansour (2013), os clados obtidos por uma estratégia similar a do CPA aproximam os clados de uma filogenia construída pelo método de Inferência Bayesiana (Ronquist \& Huelsenbeck, 2003; Huelsenbeck \& Ronquist, 2001; Huelsenbeck et al., 2001) (Capítulo 5) ${ }^{2}$ para sequências de nucleotídeos com tamanhos variando de 12 a 500.

Esses resultados motivaram o desenvolvimento de um EDA que utiliza uma nova estratégia de busca nas partições. Essa estratégia busca conciliar as vantagens presentes no StrOp (mais adequado para ASDP, ver Seção 7.4) e também as do DE (apropriado para problemas mais complexos), para obter um único algoritmo para um espectro maior de problemas. O EDA baseado nessa estratégia de busca foi denominado Otimização baseada em Análise de Filos (OPA, do inglês Optimization based on Phylogram Analysis).

\footnotetext{
${ }^{2}$ Com base no Capítulo 5 pode-se verificar que a diferença mais evidente entre a proposta de Mansour (2013) e o CPA é a eficiência computacional. A maior qualidade dos clados identificados ocorre basicamente por reamostragens em mais estágios do CPA do que ocorre na outra proposta.
} 
A Seção 6.4 apresenta a estratégia de busca em partições proposta para se obter um EDA a partir do CPA, produzindo a OPA. Essa estratégia de busca foi denominada de Busca Exaustiva Composta (CES, do inglês Composed Exhaustive Search).

\subsection{Busca Exaustiva Composta}

A CES é uma proposta para encontrar a solução ótima para os problemas combinatórios (Goldbarg \& Luna, 2000) a partir das partições encontradas pelo CPA (Seção 6.1). Trabalhos anteriores (Seção 6.3) têm explorado como o conhecimento sobre partições de um problema (BBs) pode contribuir para resolução mais eficiente de problemas combinatórios de larga-escala.

Vargas et al. (2010b,a) propuseram o QGA (Capítulo 4), que realiza uma ES (Seção 4.3) em cada partição encontrada. Esse algoritmo pode garantir a solução ótima de ASDP (Seção 7.4) se a População Inicial for amostrada com base no modelo $n=\chi^{k}(k \ln \chi+\ln m)$ (Equação 2.3, Seção 2.3).

A CES generaliza o processo de busca a partir dos particionamentos encontrados pelo CPA para determinar a solução ótima de ASDPs e de outros problemas mais complexos, em que alguns BBs possuem sobreposição ou até mesmo todos os BBs apresentam sobreposição. Em termos de eficiência computacional, o desenvolvimento da CES buscou também que a eficiência do EDA que a utiliza se mantivesse próxima a dos algoritmos com melhor desempenho encontrado para cada tipo de problema combinatório testado.

A CES possui quatro Etapas principais, que são descritas a seguir e sumarizadas na Figura 6.12:

1. Encontrar uma solução próxima ao ótimo global e outra na vizinhança do melhor ótimo local a partir da População de Selecionados do CPA. Essas soluções são utilizadas para avaliar novas soluções geradas pela ES aplicada em uma partição. Em cada avaliação de uma solução, fixam-se os valores dos bits que estão fora da partição (em que ocorre a busca), esses valores são obtidos da solução na vizinhança do ótimo global (ou local).

É importante destacar que a modelagem da competição entre instâncias ótima e ótima local de um BB proposto por Goldberg (2002) resultou em um modelo teórico que corrobora o fato de que soluções com várias instâncias de BBs da solução ótima e do melhor ótimo local salientam-se na População de Selecionados, se a População Inicial for amostrada aleatoriamente e com $n$ maior ou igual ao obtido por meio da Equação 2.3 (Seção 2.3). Com base em uma População de Selecionados com essas características, um algoritmo de agrupamento, como o algoritmo k-Vizinhos mais Próximos (kNN, do inglês $k$-Nearest Neighbors) (Hall et al., 2008), pode ser utilizado para dividir essa população em dois grupos, um para cada vizinhança das duas instâncias competidoras. A Figura 6.11 ilustra o aspecto multimodal da distribuição da População de Selecionados. Esse aspecto pode ser salientado por meio de uma reamostragem utilizando torneio com $\Phi=2,00$ (Seção 4.1.2). Por fim, bastaria encontrar as duas soluções mais diferentes entre os dois grupos (buscando maximizar a 
significância da diferença entre elas), obtendo dessa forma uma solução próxima do ótimo global e outra próxima ao melhor ótimo local (apesar de não se saber qual delas pertence a qual vizinhança a princípio). Para problemas combinatórios, pode-se evitar o algoritmo de agrupamento, calculando a distância de Hamming (Hamming, 1950) entre soluções da População de Selecionados e escolhendo o par de soluções (um de cada agrupamento, a princípio) correspondente à maior distância.

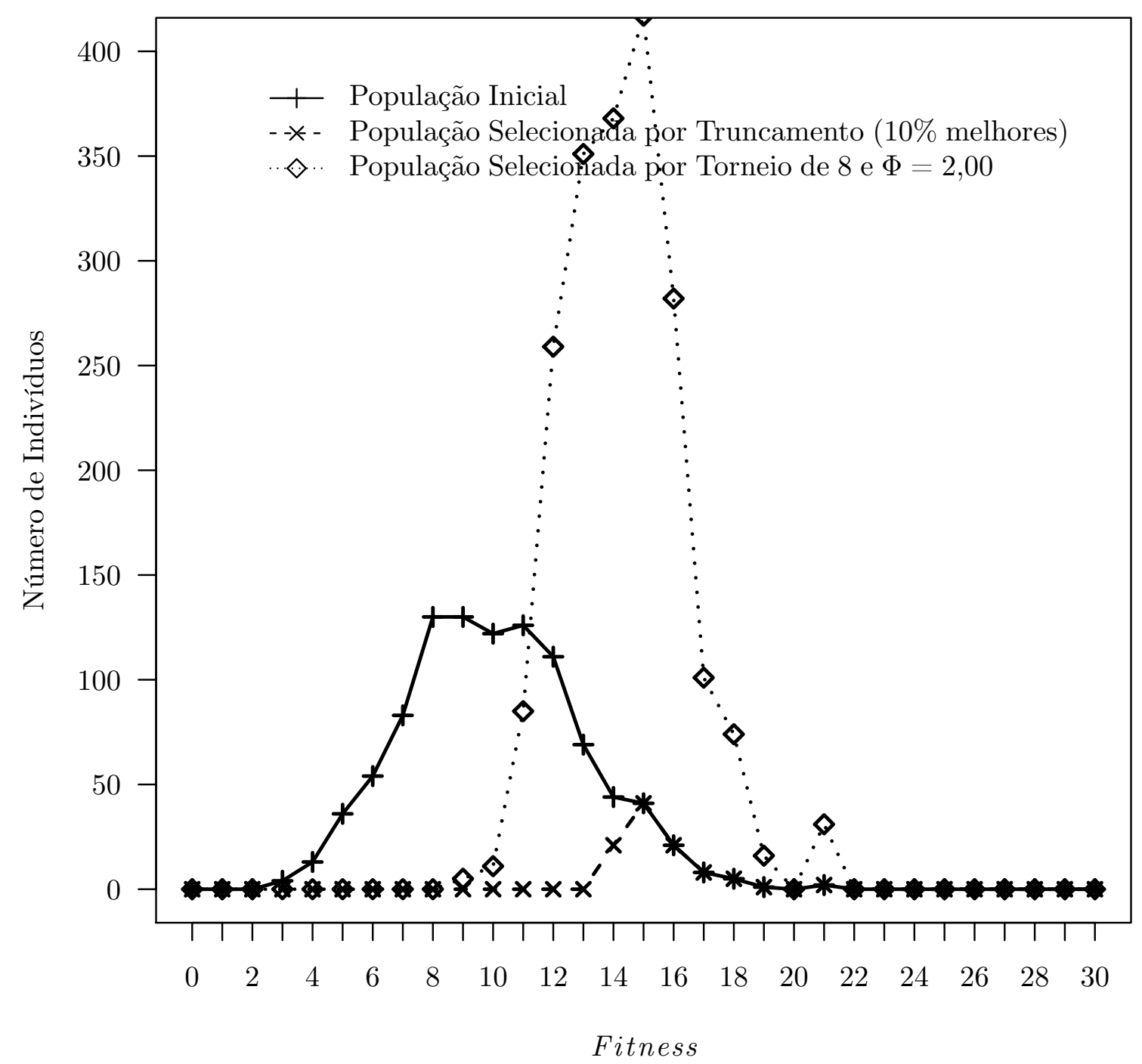

Figura 6.11: Distribuição dos fitness na População Inicial aleatória $(n=1000, \ell=30)$ para um problema composto por 6 funções armadilhas $\operatorname{ftrap} 5(k=5)$ e Populações de Selecionados (torneio de 8), em que os dois modos da distribuição correspondente são salientados usando

$$
\Phi=2,00 .
$$


2. Determinar o melhor tamanho $k$ para as partições $\left(k^{*}\right)$ de um particionamento, que pode conter sobreposição (clados, ver Seção 6.2). Nesses casos, pode-se escolher o tamanho mais conveniente do BB envolvido em um clado ${ }^{3}$. Com essa escolha, controla-se o Número de Avaliações (NA) e Tempo de Execução (TE) do algoritmo evitando clados relativamente grandes, em que a ES usual é proibitiva. A Tabela 6.1 mostra passo a passo como encontrar o $k^{*}$ para um problema de tamanho $\ell=9$. O NA da CES é determinado pela Equação 6.1, cuja dedução é apresentada no Apêndice E. A Tabela 6.2 relaciona vários valores para $\ell$ (tamanho de problema) e $k$ (tamanho de $\mathrm{BB}$ ).

$$
N A=2\left(\lfloor m\rfloor 2^{k}+(\lceil m\rceil-\lfloor m\rfloor) 2^{\ell-\lfloor m\rfloor k}+2^{\lceil m\rceil}\right) .
$$

A Apêndice E também mostra que a complexidade da CES, $C_{C E S}$, é $O\left(\frac{\ell}{k} 2^{k}\right)$. Com base na Tabela 6.2, pode-se verificar que a taxa de crescimento de $k$ de acordo com $\ell$ pode ser aproximada por $2 \log \ell$. Assumindo que esse comportamento mantenha-se para $\ell$ maiores que os avaliados na Tabela 6.2, $C_{C E S}=O\left(\frac{\ell^{3}}{\log \ell}\right)$ (Apêndice E).

Tabela 6.1: Cômputo do $k^{*}$ para $\ell=9$.

\begin{tabular}{|r|r|r|r|r|r|}
\hline \multicolumn{1}{|c|}{$k$} & $m=\ell / k$ & $\lfloor m\rfloor$ & $\ell-\lfloor m\rfloor k$ & $\lceil m\rceil$ & $N A$ \\
\hline 1 & 9 & 9 & 0 & 9 & 1060 \\
\hline 2 & 4.5 & 4 & 1 & 5 & 100 \\
\hline$k^{*}=3$ & $\mathbf{3}$ & $\mathbf{3}$ & $\mathbf{0}$ & $\mathbf{3}$ & $\mathbf{6 4}$ \\
\hline 4 & 2.25 & 2 & 1 & 3 & 84 \\
\hline 5 & 1.8 & 1 & 4 & 2 & 104 \\
\hline 6 & 1.5 & 1 & 3 & 2 & 152 \\
\hline 7 & 1.2857 & 1 & 2 & 2 & 272 \\
\hline 8 & 1.125 & 1 & 1 & 2 & 524 \\
\hline 9 & 1 & 1 & 0 & 1 & 1028 \\
\hline
\end{tabular}

Tabela 6.2: Relação de $k^{*}$ para valores de $\ell$ entre 5 e 180 .

\begin{tabular}{|l|r|r|r|r|r|r|r|r|r|r|r|r|r|}
\hline$\ell$ & 5 & 10 & 15 & 20 & 25 & 30 & 35 & 40 & 45 & 50 & 55 & 60 & 65 \\
\hline$k^{*}$ & 3 & 3 & 3 & 4 & 5 & 5 & 5 & 5 & 6 & 6 & 7 & 7 & 7 \\
\hline \hline$\ell$ & 70 & 75 & 80 & 85 & 90 & 95 & 100 & 105 & 115 & 120 & 130 & 140 & 180 \\
\hline$k^{*}$ & 7 & 8 & 8 & 8 & 9 & 9 & 9 & 9 & 9 & 10 & 10 & 10 & 12 \\
\hline
\end{tabular}

3. Com o valor de $k^{*}$, uma ES é executada encontrando a instância ótima da partição. Entretanto, não apenas a instância ótima é armazenada, mas também o complemento desta instância. Observe que a instância encontrada diretamente pela ES pode pertencer à armadilha (instâncias do clado presentes na solução correspondente ao melhor ótimo local). A teoria de EDAs em Goldberg (2002) mostra que ambas as instâncias predominam na População de

\footnotetext{
${ }^{3}$ Observe que o resultado da ES em um grupo de bits menor que o tamanho de um BB (e o complemento desse resultado) produz uma estimativa de uma vizinhança da instância ótima do BB ou de um ótimo local.
} 
Selecionados (ver os modos dessa distribuição na Figura 6.11). Observe que a armadilha (se houver) não pode estar na vizinhança da solução ótima, pois senão, uma ES em torno desta vizinhança convergiria de forma relativamente rápida evitando a armadilha (então não seria uma armadilha).

4. Como resultado da Etapa 3 (de uma ES para cada partição de tamanho $k$ ), tem-se os ótimos e seus complementos para cada partição. A partir desses resultados, a CES faz a combinação de todos os valores de instâncias obtidas. A combinação com melhor avaliação é, então, a solução encontrada para o problema.

A CES é ativada se a partição encontrada pelo CPA é maior que um número $k_{\max }^{*}$ de bits, que pode ser informado como um parâmetro de entrada da OPA. Neste trabalho, usou-se $k_{\max }^{*}=10 \mathrm{em}$ todos os testes. Quando a partição é grande, ou por exemplo envolve todo o cromossomo, pode-se inferir que: (i) não foi possível encontrar as correlações das variáveis do problema (por exemplo devido a uma baixa reamostragem); (ii) as variáveis são descorrelacionadas; (iii) trata-se de um problema com muitas variáveis compondo um único BB (como por exemplo uma única armadilha com vários bits). A Figura 6.12 sintetiza as quatro etapas da CES em um exemplo, em que $C_{1}$ e $C_{2}$ são os indivíduos da População de Selecionados preditos nas vizinhanças do ótimo global e melhor ótimo local (Etapa 1). 


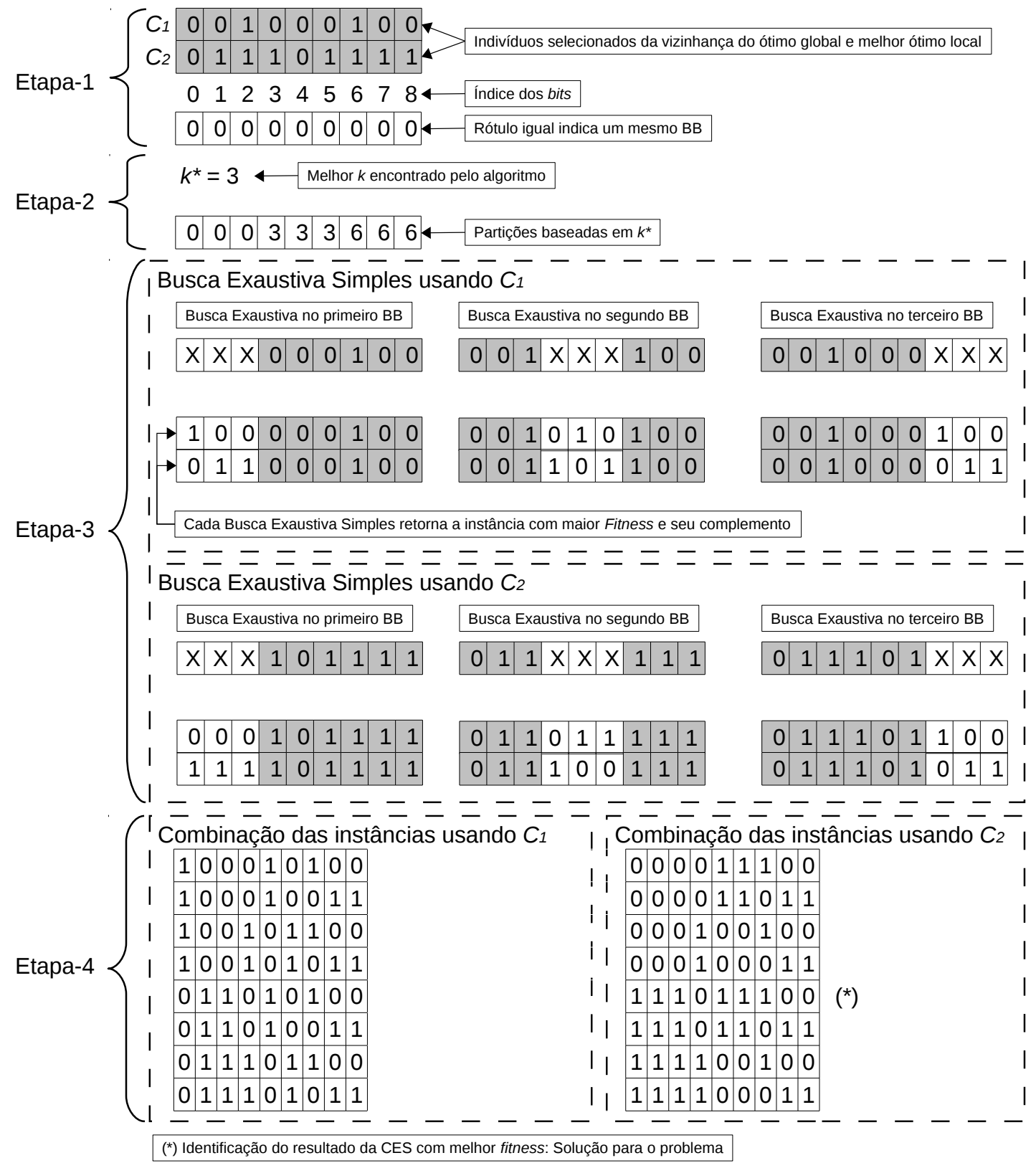

Figura 6.12: As quatro Etapas da CES com base em $C_{1}$ e $C_{2}$, soluções preditas nas vizinhanças do ótimo global e melhor ótimo local. 


\subsection{Complexidade de tempo da OPA}

Na busca de maior eficiência em termos de NA, é preciso reduzir o tempo computacional total do algoritmo ou o tamanho da População Inicial da OPA, uma vez que o NA é aproximadamente o tamanho da População Inicial do CPA (note que a CES gera proporcionalmente poucas avaliações adicionais). Por outro lado, uma População Inicial menor pode resultar em diminuição da qualidade das filogenias obtidas. Isso é compensado no CPA pela combinação de informações de vários particionamentos, todos obtidos a partir de uma mesma População Inicial.

Outra vantagem da geração de vários particionamentos é que podem ser obtidos de forma paralela, como esquematizado na Figura 6.13. Com isso, evita-se aumento significativo do tempo computacional para se realizar as reamostragens (gerando os vários particionamentos), fundamentais para o desempenho do CPA (Capítulo 8) e, consequentemente, da OPA.

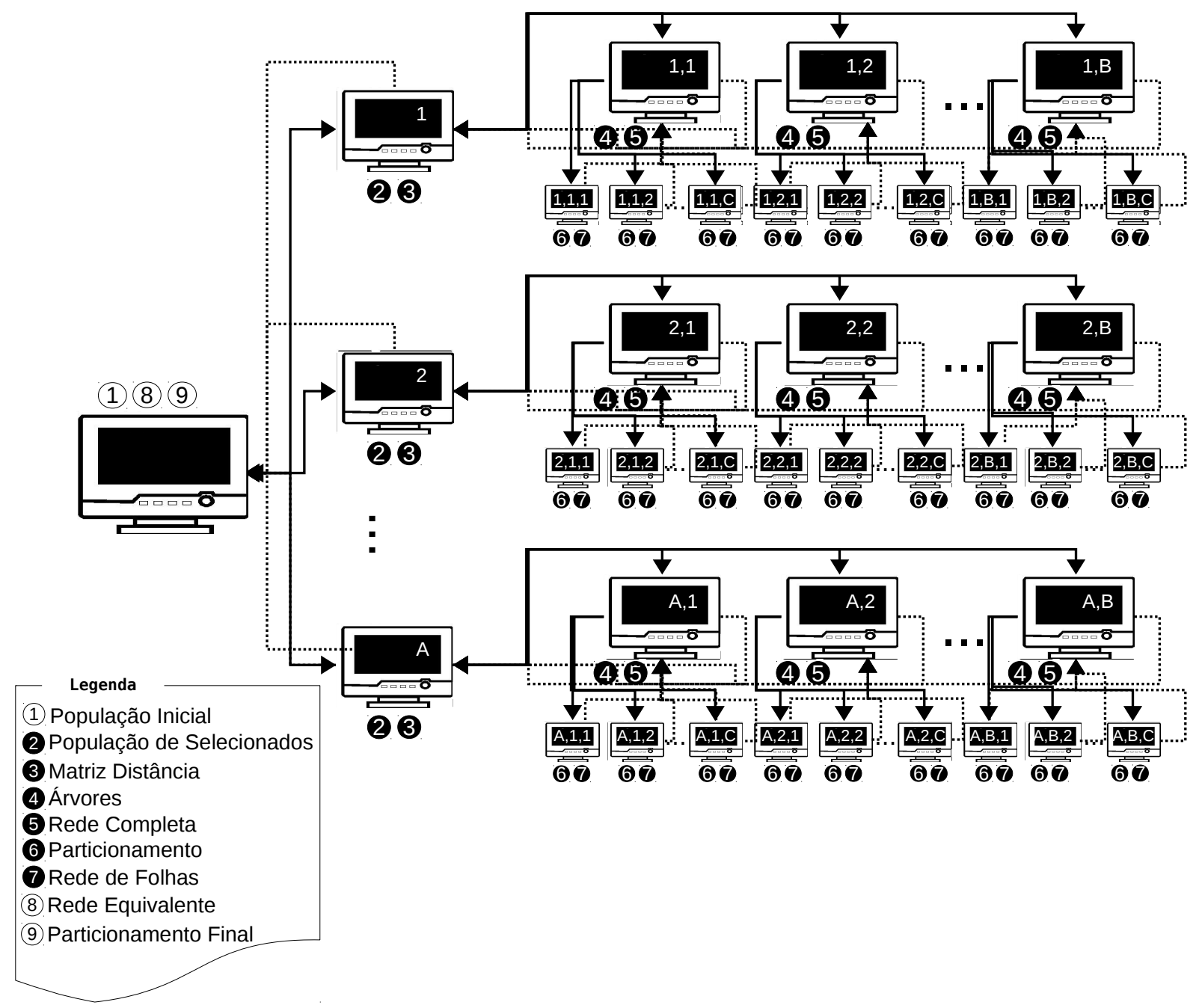

Figura 6.13: Esquema de paralelização da construção do Particionamento Final (Seção 6.1) do CPA usando $A B C+1$ Elementos de Processamento. 
A complexidade da OPA pode ser calculada pela complexidade de suas principais etapas, como calculado a seguir:

1. $C_{M I}=O\left(n \ell^{2}\right)$, complexidade da métrica de distância MI (Duque \& Goldberg, 2010), mostrada na Seção F;

2. $C_{N J}=O\left(\ell^{3}\right)$, complexidade do método de reconstrução de filogenia NJ (Studier \& Keppler, 1988), mostrado na Seção 3.1.1;

3. $C_{F A}=O((a+\ell) \ell)$, complexidade da técnica de identificação de BBs pelo FA (Newman \& Girvan, 2004), mostrado na Seção 5.1.1, em que $a$ é o número de arestas na rede e $\ell$, seu número de nós. Quando o FA é chamado pela primeira vez (na Etapa 5, Seção 6.1), $a=\ell$, pois cada nó somente pode se ligar a apenas um outro, o que resulta em uma complexidade da ordem de $O\left(\ell^{2}\right)$. Na segunda e demais vezes que o FA é chamado, $a \leq(k-1) \ell$. No pior caso, o BB encontrado pelo CPA corresponde a todo o cromossomo, ou seja, $k=\ell$, assim, $a=(\ell-1) \ell$. Substituindo este valor em $C_{F A}$, obtém-se $C_{F A}=O(((\ell-1) \ell+\ell) \ell)=$ $O\left(\left(\ell^{2}-\ell+\ell\right) \ell\right)$ e resulta em $O\left(\ell^{3}\right)$

4. $C_{E S}=O\left(\frac{\ell}{k} 2^{k}\right)$, complexidade da ES (Seção 4.3). Esse tipo de busca é aplicado a um tamanho máximo $k_{\text {max }}$ de $\mathrm{BB}$, resultando em complexidade $O(1)$. Para BB maiores, usase a CES como método proposto para encontrar a solução do problema. Os BBs na CES possuem tamanho estimado de $k^{*}=2 \log \ell$ (Seção 6.4). Assim, $\frac{\ell}{k^{*}} 2^{k^{*}}$ (ES em uma partição de tamanho $k^{*}$ ) resulta em $\frac{\ell}{2 \log \ell} 2^{2 \log \ell}=\frac{\ell^{3}}{2 \log \ell}$. Dessa forma $C_{E S}=O\left(\frac{\ell^{3}}{\log \ell}\right)$.

5. $C_{C E S}=O\left(\frac{\ell^{3}}{\log \ell}\right)$. Para $\chi=2$, a complexidade da CES pode ser estimada conforme descrito na Seção 6.4 e no Apêndice E, isto é, $O\left(\frac{\ell^{3}}{\log \ell}\right)$.

A soma das complexidades $C_{O P A}=C_{M I}+C_{N J}+C_{F A}+C_{E S}+C_{C E S}$, pode ser reescrita como na Equação 6.2, que resulta na Equação 6.3.

$$
\begin{gathered}
C_{O P A}=O\left(n \ell^{2}\right)+O\left(\ell^{3}\right)+O\left(\ell^{3}\right)+O\left(\frac{\ell^{3}}{\log \ell}\right)+O\left(\frac{\ell^{3}}{\log \ell}\right) \\
C_{O P A}=O\left(n \ell^{2}+\ell^{3}\right)
\end{gathered}
$$

Pelo modelo teórico de EDAs (Seção 2.4), $n=O\left(k 2^{k}\right)$, se $\chi=2$. Como $k=\ell / m$, obtém-se $n=O\left((\ell / m) 2^{\ell / m}\right)$. Com isso, o termo à direita na Equação 6.3 pode ser reescrito da seguinte forma $\left[\frac{1}{m} 2^{\ell / m}+1\right] \ell^{3}$. Isso evidencia que o termo $n \ell^{2}$ da Equação 6.3 domina assintoticamente o termo $\ell^{3}$ conforme cresce $\ell$. Portanto, $C_{O P A}=O\left(n \ell^{2}\right)$, que corresponde a complexidade da MI. Assim, o limitante do desempenho da OPA é o cálculo da MI. 


\subsection{OPA Multiobjetivo}

A extensão multiobjetivo da OPA, foi chamada de OPA multiobjetivo (moOPA, do inglês multiobjetive $O P A$ ). Esse algoritmo foi desenvolvido com base no mo $\Phi$ GA apresentado em Martins et al. (2011). A Figura 6.16 mostra as principais etapas do novo algoritmo multiobjetivo. Inicialmente é aplicado torneio à População Inicial de forma a compor, uma População de Selecionados para cada objetivo do problema. Ao final, os Particionamentos Finais em cada objetivo são combinados para formar soluções da Fronteira de Pareto.

Duas etapas extras em relação à OPA são necessárias para a moOPA resolver problemas multiobjetivos:

1. Após a geração da População Inicial, é necessário selecionar os melhores indivíduos para cada objetivo. Para isso, usa-se torneio para selecionar indivíduos para cada objetivo, formando $M$ População de Selecionados diferentes, em que $M$ é o número de objetivos. O NA do CPA para os problemas multiobjetivos é $N A=n^{\prime} M$, em que $n^{\prime}=\max _{i}\left\{n_{i}\right\}$, em que $n_{i}$ é o tamanho da população adequada para o objetivo $i$;

2. Após a execução do CPA para cada objetivo, tem-se $M$ Particionamentos Finais que são combinadas de forma a compor o conjunto Pareto-ótimo. A Figura 6.14 mostra como os BBs de cada objetivo compõem todo o conjunto Pareto-ótimo. Após identificação dos BBs, a composição do conjunto Pareto-ótimo é feita combinando a instância ótima do primeiro BB de um objetivo com as instâncias ótimas dos BBs restantes do outro objetivo. Em seguida são combinadas as duas instâncias ótimas de BBs do primeiro objetivo com as instâncias ótimas dos BBs restantes do segundo objetivo e assim sucessivamente. A Figura 6.15 mostra como é realizada combinação dos BBs de cada objetivo para compor o conjunto Pareto-ótimo mesmo quando o tamanho dos BBs identificados segundo cada objetivo são de tamanhos diferentes. Observe que a notação inv-ftrap3[i:j] e ftrap4[i:j] indica os índices do cromossomo de $i$ a $j$ associados à função inv-ftrap3 e ftrap4 na composição de novas soluções.

A moOPA garante a fronteira Pareto-ótima completa para ASDP se $n^{\prime}$ for adequado (Equação 2.3, Seção 2.3). Para problemas mais complexos, a moOPA pode encontrar soluções na fronteira (não obrigatoriamente todas) ou obter soluções significativamente próximas da fronteira Pareto-ótima (Capítulo 8). 

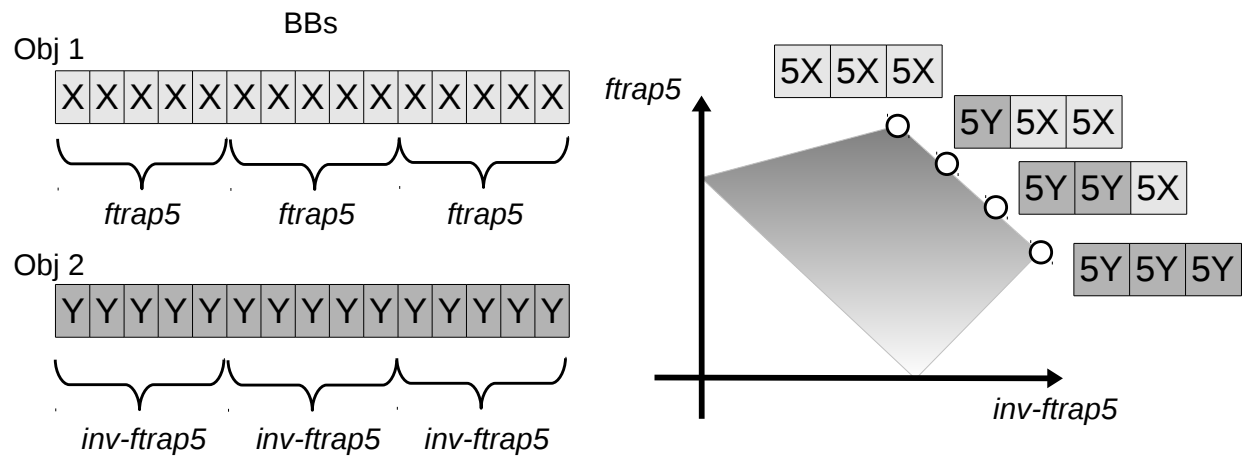

Figura 6.14: Combinação de instâncias de BBs de soluções no extremo da Fronteira Pareto-ótima para o problema ftrap5 vs inv-ftrap5 (Seção 8.4).

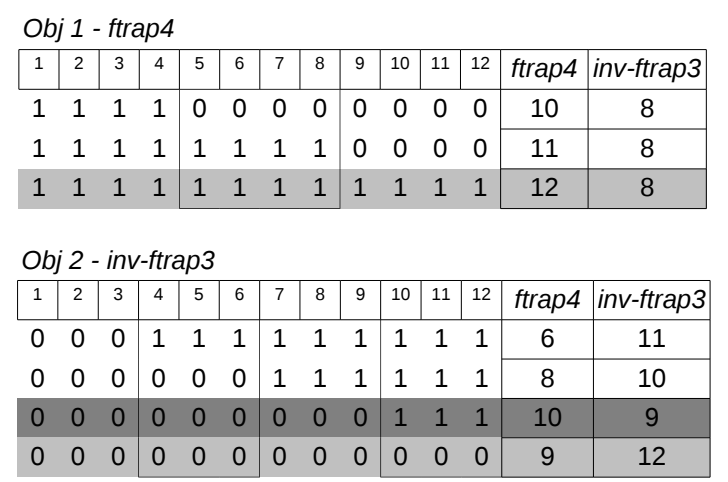

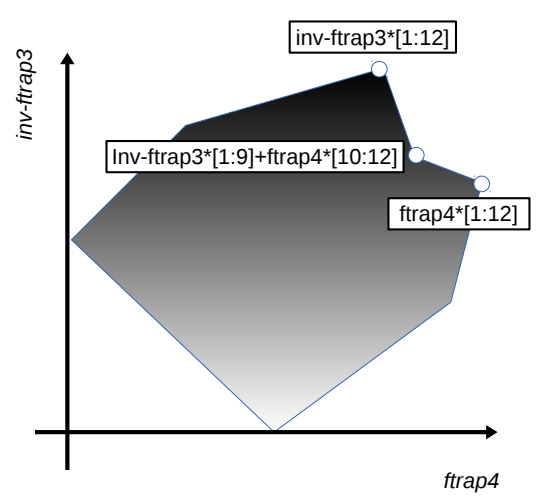

Figura 6.15: Combinação de instâncias de BBs de solução da Fronteira Pareto-ótima para o problema ftrap4 vs inv-ftrap3.

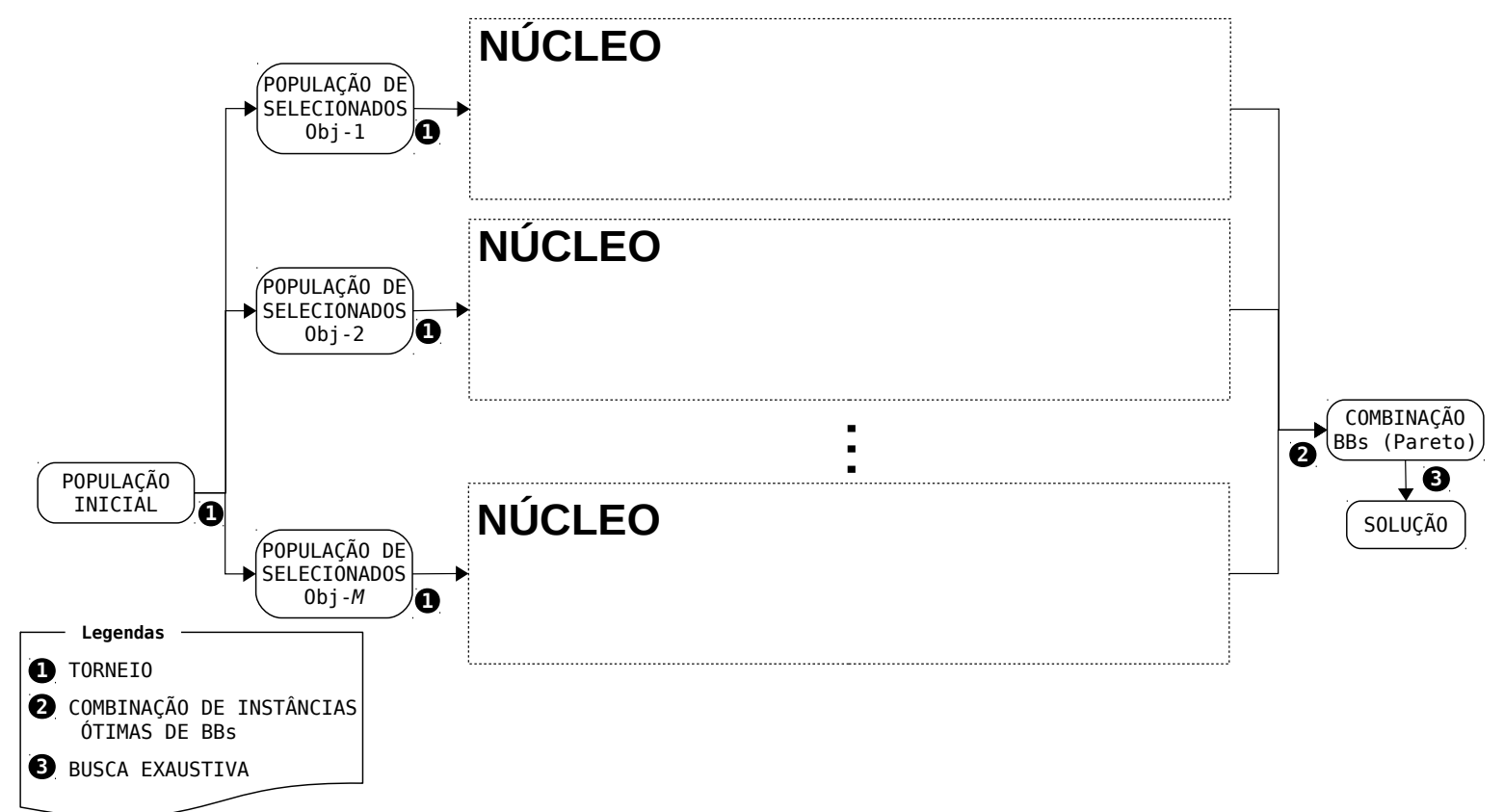

Figura 6.16: Principais etapas da moOPA, em que o bloco com o nome NÚCLEO é mostrado na Figura 6.9. 



\section{CAPÍTULO 7 \\ Problemas para avaliação de EDAs}

Além de problemas do mundo real, várias funções são conhecidas e usadas para testar e comparar algoritmos de otimização. Este capítulo reúne problemas que têm sido utilizados para o teste de EAs, em especial, para EDAs. O estudo desses problemas é de interesse para que sejam adequadamente elaborados os experimentos para avaliação das competências e limitações de cada um dos algoritmos propostos neste projeto.

Conforme apresentado na Seção 2.3, vários problemas relativamente complexos podem ser decompostos (perfeitamente ou de forma aproximada) em subproblemas. Além de resolver cada subproblema, é necessário primeiramente encontrar as subestruturas (como BBs) que os compõem. $\mathrm{O}$ fato é que as subestruturas de um problema e as formas como essas relacionam-se afetam diretamente a complexidade computacional do problema. Dessa forma, o entendimento das propriedades que afetam a complexidade dos problemas é importante para o desenvolvimento de algoritmos competentes, isto é, que resolvam problemas relativamente complexos de forma eficiente e eficaz (Goldberg, 2002). Nesse sentido, este capítulo apresenta um conjunto de problemas que têm sido utilizados na literatura para avaliar EDAs, uma vez que tais problemas possuem as principais subestruturas que podem ser utilizados para gerar problemas com variado grau de dificuldades.

A Seção 7.1 apresenta os problemas OneMax e BinInt e explica o fenômeno de convergência à deriva. A Seção 7.2 explica funções armadilha. A Seção 7.3 apresenta os problemas multimodais de interesse para avaliação de EDAs. A Seção 7.4 explica os Problemas Deceptivos Aditivamente Separáveis (ASDPs, do inglês Additively Separable Deceptive Problems). Por fim, a Seção 7.5 apresenta os problemas com sobreposição de BBs. 


\subsection{OneMax, Binlnt e o problema de convergência à de- riva}

O problema OneMax é um ponto comum de partida para se testar EAs. Consiste em maximizar o número de uns em uma string binária de tamanho $\ell$, conforme representa a Equação 7.1. O caso genérico do OneMax busca minimizar a soma do número de bits diferentes entre uma solução $X$ e um vetor alvo $O$, conforme a Equação 7.2.

$$
\begin{gathered}
f_{U M}(X)=\sum_{i=0}^{\ell-1} x_{i} . \\
f_{U M}(X, O)=\sum_{i=0}^{\ell-1}\left|x_{i}-o_{i}\right| .
\end{gathered}
$$

Um problema BinInt pode ser visto como uma generalização da Equação 7.1 em que cada bit é ponderado conforme mostra a Equação 7.3.

$$
f_{B I}(X)=\sum_{i=0}^{\ell-1} x_{i} 2^{i}
$$

Ambas as funções são utilizadas para se testar a eficiência dos algoritmos ao se aumentar a escala do problema (número $\ell$ de bits da string) (Goldberg, 2002). Enquanto o OneMax e o BinInt podem ser resolvidos por uma busca local (Cormen et al., 2001) mesmo conforme $\ell$ aumenta assintoticamente, EAs apresentam uma dificuldade maior de resolver o BinInt, uma vez que bits mais significativos (com maior coeficiente) no cálculo da função de fitness destacam-se no processo de seleção das melhores soluções. Por esse motivo, quando os parâmetros de entrada do algoritmo não são adequados, bits menos significativos frequentemente convergem prematuramente para valores aleatórios. A essa convergência prematura para qualquer valor, dá-se o nome de convergência à deriva (drift, em inglês).

\subsection{Funções armadilha}

Para verificar o desempenho de diversos EDAs, em geral usam-se funções chamadas de armadilha, cujo comportamento induz algoritmos baseados em busca local a encontrem ótimos locais, diferentes do ótimo global (Harik et al., 2006; Pelikan et al., 1999; Vargas \& Delbem, 2009). A forma geral dessas funções é descrito pela Equação 7.4:

$$
f(X)=\sum_{i=0}^{m} f_{i}\left(u_{i}\right),
$$

em que: 
- $X$ é uma string binária de entrada;

- $m$ é a quantidade de BBs que compõem o problema;

- $B B_{i}$ é um BB do problema;

- $u_{i}$ é a quantidade de bits com o valor igual ao total de 1 s presentes no $B B_{i}$;

- $f_{i}$ é a função a ser aplicada sobre o $B B_{i}$.

Em geral, as funções $f_{i}$ (Equação 7.4) são armadilhas, isto é, possuem uma ou mais inflexões com a presença de ótimo local e global. São exemplos desse tipo de funções, a f3deceptive, representada pela Equação 7.5 e a ftrap5, Equação 7.6. As duas funções encontram-se ilustradas pela Figura 5.1.

$$
\begin{gathered}
\text { f3deceptive }(u)= \begin{cases}0,9 & \text { se } u=0, \\
0,8 & \text { se } u=1, \\
0,0 & \text { se } u=2, \\
1,0 & \text { se } u=3 .\end{cases} \\
\text { ftrap5 }(u)= \begin{cases}4-u & \text { se } u<5, \\
5 & \text { caso contrário. }\end{cases}
\end{gathered}
$$

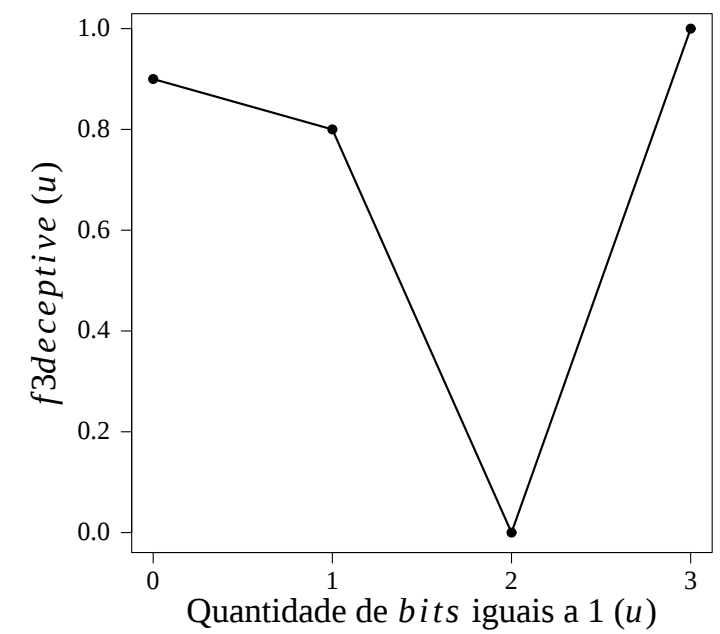

(a)

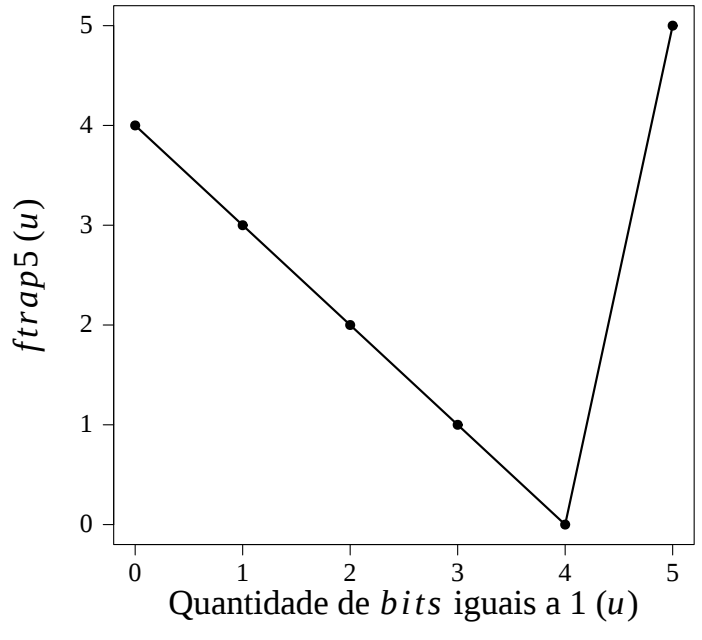

(b)

Figura 7.1: Exemplos de funções armadilhas: (a) f3deceptive e (b) ftrap5.

Em funções armadilha, meta-heurísticas que utilizam informações locais para orientar a busca tendem a concentrar as soluções próximo a ótimos locais, reduzindo a concentração na vizinhança 
do ótimo global. Por esse motivo, GAs convencionais podem não apresentar desempenho satisfatório para tais funções (Harik et al., 2006). A Figura 2.4 (Seção 2.3) mostra como o tamanho dos BBs aumenta a complexidade desses problemas. Variando o número de BBs $(m)$ da Equação 7.4 e o tamanho $k$ deles, pode-se gerar problemas com grau variado de dificuldade e, com isso, encontrar os limites de desempenho de vários EDAs. Por exemplo é possível construir uma função armadilha genérica para BBs de tamanho $k$, como a representada pela Equação 7.7.

$$
\operatorname{ftrapk}(u)= \begin{cases}(k-1)-u & \text { se } u<k, \\ k & \text { caso contrário. }\end{cases}
$$

Nem todas as funções derivadas da Equação 7.7 garantem a decepção para algoritmos baseados em busca local. Por esse motivo, existe a diferenciação entre funções armadilhas e funções deceptivas (Goldberg, 2002). Uma função armadilha é deceptiva se consegue enganar ou gerar informações confusas sobre a proximidade do ótimo global. Isso pode ser avaliado comparando as pontuações médias dos esquemas (Goldberg, 2002) com comprimento menor que $\ell$. Por exemplo, a função $f 3$ deceptive, a pontuação média do esquema $00 *$ é 0,85 , obtida ao calcular a média das pontuações das strings 000 e 001 , que são respectivamente 0,9 e 0,8 . Dessa forma, o esquema $00 *$ possui uma pontuação média maior que a do esquema $11 *$ (dada por 0,5 ), em geral, direcionando um algoritmo baseado em busca local para soluções longe do ótimo global 111. Por outro lado, a função ftrap2 (Figura 7.2, derivada a partir da Equação 7.7) apresenta comportamento oposto. A pontuação média do esquema $1 *$ é maior que a do esquema $0 *{ }^{1}$. Com isso, a informação não é enganosa e, portanto, ftrap2 não é uma função deceptiva. A garantia de que uma função armadilha seja deceptiva é dada pela Inequação 7.8 (Goldberg, 2002). A Figura 7.3 mostra a relação entre os parâmetros da Inequação 7.8 .

$$
r \geq \frac{2-(\ell-z)^{-1}}{2-z^{-1}}
$$

em que:

- $r$ é a razão $a / b$ (Figura 7.3): $a$ é a pontuação do ótimo local e $b$ é a pontuação do ótimo global;

- $\ell$ é o tamanho da string de entrada;

- $z$ é o ponto de inflexão da função armadilha, em que $f(z)=0$ (Figura 7.3).

\footnotetext{
${ }^{1}$ A pontuação do esquema $1 *$ é 1,5 , dada pela média das pontuações 2 e 1 , respectivamente para as soluções 11 e 10. De forma análoga, a pontuação do esquema $0 *$ é 0,5 , dada pela média das pontuações 0 e 1 , respectivamente para as soluções 01 e 00 .
} 


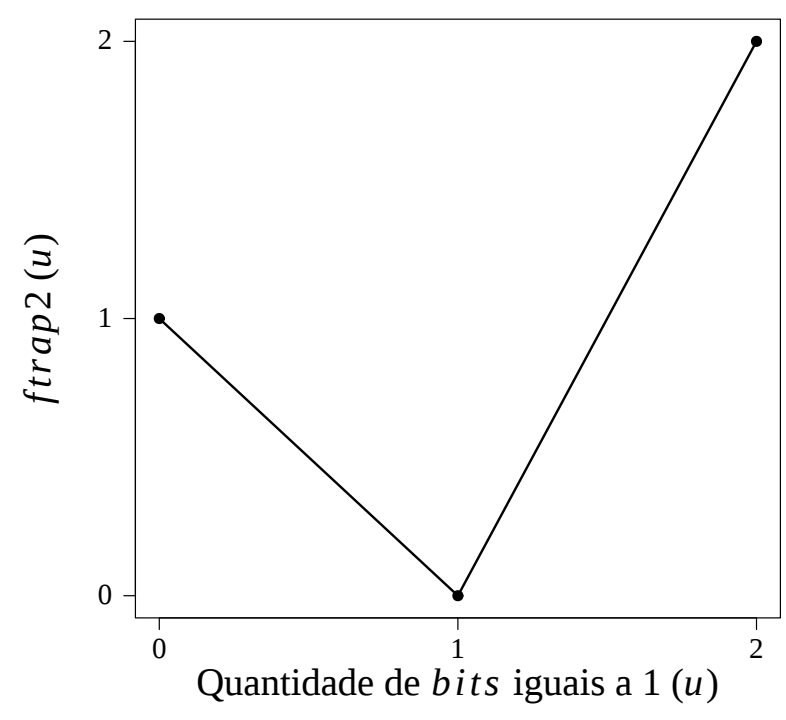

Figura 7.2: Função armadilha ftrap2.

\subsection{Problemas Multimodais}

Problemas multimodais apresentam uma grande quantidade de ótimos locais. Tais problemas podem possuir mais de um ótimo global. Estudos de técnicas para resolver esse tipo de problema têm sido realizados (Qu \& Suganthan, 2010). Diversos problemas do mundo real podem ser modelados como problemas multimodais. Nesses casos pode ser interessante encontrar diversas das soluções ótimas. Por exemplo, dentre as ótimas poderia ser escolhida a com maior robustez (com baixa variabilidade na resposta) segundo algum aspecto prático envolvido no problema. Em problemas do mundo real envolvendo classificadores da área de aprendizado de máquinas (Mahfoud, 1995) também é comum multimodalidade envolvendo instâncias grandes.

Para ilustrar uma função multimodal, considere a função f6bipolar definida na Equação 7.9, baseada na Equação 7.5 e representada na Figura 7.4. Ao combinar funções como essa, obtém-se problemas com diversos valores ótimos, isto é, funções multimodais.

$$
\text { f6bipolar }=\text { f3deceptive }(|3-u|) \text {. }
$$




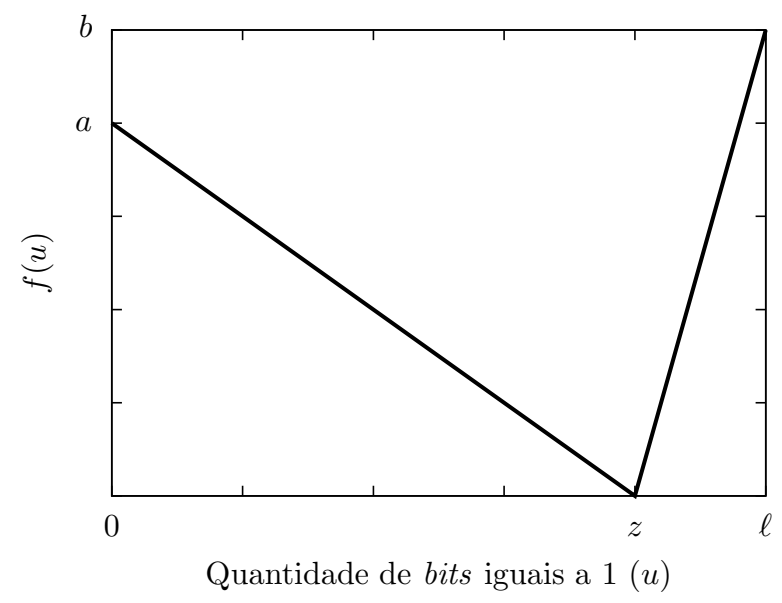

Figura 7.3: Modelo de função armadilha apresentando os parâmetros utilizados para verificar se a função é deceptiva (Inequação 7.8).

\subsection{Problemas deceptivos aditivamente separáveis}

Um problema pode ser composto de um conjunto de subestruturas (Seção 2.3). Considere um problema composto por dez variáveis, cuja função de fitness é dada pela soma de duas funções ftrap5 (Equação 7.6), representada pela Equação 7.10.

$$
f\left(x_{1}, x_{2}, x_{3}, x_{4}, x_{5}, x_{6}, x_{7}, x_{8}, x_{9}, x_{10}\right)=f^{\prime}\left(x_{1}, x_{2}, x_{3}, x_{4}, x_{5}\right)+f^{\prime}\left(x_{6}, x_{7}, x_{8}, x_{9}, x_{10}\right),
$$

em que $f$ é a função de fitness e $f^{\prime}\left(x_{1}, x_{2}, x_{3}, x_{4}, x_{5}\right)=f \operatorname{trap} 5\left(x_{1}+x_{2}+x_{3}+x_{4}+x_{5}\right)$. Naturalmente o problema referente a Equação 7.10 é composto por funções deceptivas. Uma forma mais genérica para definir esse tipo de problema é apresentado na Equação 7.11.

$$
f(X)=\sum_{i=0}^{m} f_{i}\left(S_{i}\right), S_{a} \cap S_{b}=\{\}, \forall a \neq b,
$$

em que:

- $X$ é uma string binária de entrada;

- $m$ é o número de partições do problema (quantidade de BBs);

- $f_{i}$ é a função deceptiva, cujo argumento é $S_{i}$;

- $S_{i}$ é um subconjunto de variáveis de $X$.

O modelo NK-landscapes (Choi et al., 2008) é outra abordagem que busca sintetizar os aspectos principais de problemas complexos do mundo real. Por exemplo, NK-landscapes podem representar problemas com sobreposição de BBs, que podem ser derivados da Equação 7.11 trocando a restrição $S_{a} \cap S_{b}=\{\}, \forall a \neq b$, por $\exists a$ e $b \mid S_{a} \cap S_{b} \neq\{\}$. Apesar de ASDPs serem em 


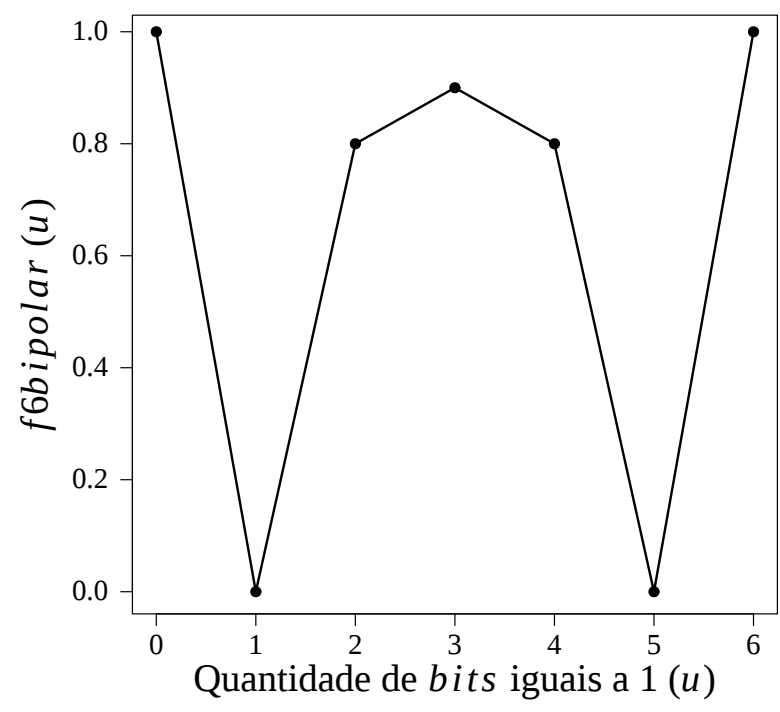

Figura 7.4: Função f6bipolar.

geral menos complexos que $N K$-landscapes (ASDPs são casos particulares de $N K$-landscapes), os ASDPs ainda assim representam problemas computacionalmente difíceis (Goldberg, 2002) e têm sido utilizados para testar a eficiência e a eficácia de EDAs (Harik et al., 2006; Melo et al., 2011; Pelikan, 1999b).

De posse das partições de um ASDP, uma ES pode ser aplicada a cada partição de um ASDP para encontrar a solução ótima do problema usando NA igual a $\sum_{i=0}^{m} 2^{k_{i}}$ para cada partição, em que $k_{i}$ é o número de variáveis em $S_{i}$. Supondo o $\max \left\{k_{i}\right\}$ não seja grande, essa estratégia para solução de ASDPs é computacionalmente viável. No entanto, os subconjuntos $S_{i}$ 's geralmente não são conhecidos a priori no contexto de EDAs e de otimização de caixa preta (He et al., 2007). Assim, é necessário em geral encontrar o particionamento das variáveis em subconjuntos $S_{i}$ 's. Isso pode ser realizado conforme proposto neste trabalho, por meio da construção de modelos probabilísticos capazes de determinar variáveis mais fortemente correlacionadas.

\subsection{Sobreposição de BBs e problemas hierárquicos}

Problemas hierárquicos podem ser vistos como uma mistura de problemas multimodais e problemas com sobreposição de BBs. Goldberg (2002) propõe uma função que sintetiza as relações presentes em problemas hierárquicos. A Equação 7.12 é similar a função usada em Goldberg (2002), mantendo as características hierárquicas do problema.

$$
f\left(x_{1} \ldots x_{72}\right)=f_{1}\left(x_{1} \ldots x_{6}\right)+f_{1}\left(x_{7} \ldots x_{12}\right)+\ldots+f_{1}\left(x_{67} \ldots x_{72}\right)+f_{2}\left(x_{1}^{\prime} \ldots x_{6}^{\prime}\right)+f_{2}\left(x_{7}^{\prime} \ldots x_{12}^{\prime}\right),
$$


em que $f_{1}\left(x_{i}, x_{i+1}, \ldots x_{i+5}\right)=$ f6bipolar $\left(x_{i}+x_{i+1}+\ldots+x_{i+5}\right)$ e $f_{2}\left(x_{i}^{\prime}, x_{i+1}^{\prime}, \ldots x_{i+5}^{\prime}\right)=\operatorname{ftrap} 6\left(x_{i}^{\prime}+\right.$ $\left.x_{i+1}^{\prime}+\ldots+x_{i+5}^{\prime}\right)$.

As variáveis hierárquicas representadas por $x_{i}^{\prime}$ são funções das variáveis originais $x_{i}$ do problema. O valor de uma variável $x_{i}^{\prime}$ é função dos valores das variáveis do subconjunto $S_{i}^{\prime}=$ $\left\{x_{6 i-5}, x_{6 i-4}, \ldots, x_{6 i}\right\}$. Se cada variável de $S_{i}^{\prime}$ tiver valor igual a 1 , então $x_{i}^{\prime}=1$. Caso todas as variáveis de $S_{i}^{\prime}$ possuam o valor 0 , então $x_{i}^{\prime}=0$. Para qualquer outra combinação de valores de $S_{i}^{\prime}, x_{i}^{\prime}$ tem valor indeterminado e $f_{2}$ retorna 0 . Por exemplo, se $x_{1} x_{2} \ldots x_{6}=011000$, então $x_{1}^{\prime}$ é indeterminado, portanto $f_{2}\left(x_{1}^{\prime}, x_{2}^{\prime}, \ldots, x_{6}^{\prime}\right)=0$. Caso $x_{1} x_{2} \ldots x_{6}=000000, x_{1}^{\prime}=0$ e o valor de $f_{2}\left(x_{1}^{\prime}, x_{2}^{\prime}, \ldots, x_{6}^{\prime}\right)$ depende das outras variáveis (hierárquicas) $x_{2}^{\prime} \ldots x_{6}^{\prime}$.

A estrutura hierárquica da Equação 7.12, em geral, resulta em convergência por etapas de um EA (Seção 2.1). Inicialmente, a função $f_{1}$ possibilita uma maior diferenciação entre as soluções, direcionando o processo de convergência. Por exemplo, o conjunto de variáveis $x_{1}, x_{2}, \ldots, x_{6}$ pode convergir para 000000 ou 111111. Embora as contribuições dos BBs $000000 * *$...* e $111111 * * . . * *$ para o fitness possam ser iguais as primeiras gerações, na prática, apenas um desses BBs domina a população. Note que se $000000^{* *}$...* dominar a população por completo, o ótimo global não será mais atingido, pois em um estágio mais a frente do EA, a função $f_{2}$ iria salientar as soluções com o BB $111111^{* *} \ldots *$, porém, tal BB não se encontraria mais na população impossibilitando obter o ótimo global.

Pelikan \& Goldberg (2003) mostram que o algoritmo h-BOA é capaz de resolver, com eficácia relativamente alta, casos particulares de dois problemas hierárquicos do mundo real, chamados Ising Spin Glass e MAXSAT, que são explicados a seguir. É importante observar que resolver problemas hierárquicos específicos não é o foco dos EDAs desenvolvidos neste trabalho.

\section{Ising Spin Glass}

$\mathrm{Na}$ área da física e engenharia de materiais existe o problema de encontrar o estado fundamental de um sistema Ising para vidros Spin (do inglês: Ising Sping Glass)(Bolthausen \& Bovier, 2007). Esse sistema pode ser descrito conforme segue:

1. Um vetor $\sigma=\left[\sigma_{0}, \sigma_{1}, \ldots \sigma_{T-1}\right]$, em que $\sigma_{i}=\{0,1\}$ e $T$ é o total de spins do sistema;

2. Uma matriz $J$ de acoplamentos $J_{i j} \in \mathbb{R}$ relacionando cada par $\left(\sigma_{i}, \sigma_{j}\right)$ de spins.

O estado fundamental do sistema, corresponde ao mínimo de energia $H(\sigma)$, dada pela Equação 7.13 .

$$
H(\sigma)=-\sum_{i, j=0}^{T} J_{i j} \sigma_{i} \sigma_{j} .
$$

Encontrar o mínimo de $H(\sigma)$ é um problema NP-Completo (Garey \& Johnson, 1979; Sipser, 2007), portanto, não se conhece um algoritmo capaz de resolvê-lo em tempo polinomial. Por 
outro lado, o hBOA mostrou-se capaz de encontrar soluções com exatidão para instâncias deste problema em tempo polinomial (Pelikan \& Goldberg, 2003) com alta eficácia. Tais instâncias limitam o número de interações entre os spins, dispondo-os em uma matriz bidimensional em que ocorrem apenas interações entre os vizinhos mais próximos. Além disso, valores de acoplamento $J_{i j}$ são limitados por uma constante positiva. Esse resultado do hBOA é um indicativo de que avanços no desenvolvimento de EDAs podem possibilitar melhorias significativas na obtenção de soluções para esse problema desafiador.

\section{MAXSAT}

Encontrar predicados que satisfaçam o maior número de cláusulas possível em uma expressão lógica na forma normal conjuntiva (CNF, do inglês Conjunctive Normal Form) (Sipser, 2007) é outro exemplo de problema NP-Completo (Garey \& Johnson, 1979; Sipser, 2007). Também conhecido como MAXSAT (do inglês, Maximum Satisfiability Problem), este problema é de interesse principalmente nas áreas de Teoria da Complexidade e Inteligência Artificial, além de ter sido explorado por meio de EDAs (Pelikan \& Goldberg, 2003).

Considere, por exemplo, a expressão lógica: $\left(X_{1} \vee X_{2}\right) \wedge\left(X_{2} \vee \neg X_{3}\right) \wedge\left(\neg X_{3} \vee X_{1}\right)$, em que $X_{i}$ 's são variáveis binárias e $\vee, \wedge \mathrm{e} \neg$ são operações de conjunção, disjunção e negação, respectivamente. A solução desse problema consiste em encontrar valores de $X_{1}, X_{2}$ e $X_{3} \in\{0,1\}$ para os quais a expressão resulta em 1. Por exemplo, para a string binária 110, isto é ( $X_{1}=1, X_{2}=1$ e $X_{3}=0$ ) a expressão retorna 1 (é satisfeita). A função de fitness para avaliar uma solução pode ser dada pela quantidade de cláusulas que são satisfeitas.

O MAXSAT é um exemplo de problema em que EAs convencionais não produzem resultados relevantes. Além disso, problemas MAXSAT não triviais são do tipo armadilha (Rana \& Whitley, 1998). Por outro lado, algumas instâncias desse problema já foram resolvidos com eficácia relativamente alta e de forma eficiente pelo hBOA (Pelikan \& Goldberg, 2003) nos seguintes casos: (i) expressões na CNF geradas aleatoriamente, e (ii) problema de coloração de grafos (Galinier \& Hao, 1999; Garey \& Johnson, 1979) convertidos para o MAXSAT. 



\section{Análise de desempenho da OPA}

A OPA (Capítulo 6) é avaliada por meio das análises apresentadas neste capítulo. A descrição dos experimentos encontra-se organizada conforme segue. A Seção 8.1 apresenta critérios, códigos e equipamentos utilizados nos experimentos. A Seção 8.2 analisa a eficiência do algoritmo para problemas baseados em armadilhas. A Seção 8.3 avalia a eficácia do algoritmo em cenários envolvendo problemas não deceptivos e problemas com sobreposição de BBs. A Seção 8.4 apresenta a avaliação de desempenho para problemas multiobjetivos. Por fim, a Seção 8.5 sintetiza os principais resultados.

\subsection{Critérios e recursos utilizados}

A seguir, descrevem-se procedimentos experimentais comuns a todos os testes realizados:

- Em geral, os experimentos possuem parâmetros comuns representados pelas letras:

$\ell$ : tamanho do problema;

$m$ : quantidade de BBs que compõem o problema sendo otimizado;

$k$ : tamanho do BB;

$n$ : tamanho da população. O valor de $n$ utilizado é definido pelo método da bisseção (Sastry, 2001) cujo critério de convergência é aceitar no máximo apenas 1 BB com instância errada em cada uma das 30 repetições realizadas utilizando diferentes sementes para o gerador de números aleatórios; 
v: parâmetro de entrada para o BOA (Seção 2.7) que define o número máximo de nós pais na Rede Bayesiana construída;

$v_{l}$ e $v_{u}$ : são os parâmetro de entrada para o CD-BOA, StrOp e StrOp+REDA (do inglês, Resampling for EDAs proposto em Crocomo (2012)) que definem, respectivamente, $\left(v_{l}\right.$ lower $v$ ) o número máximo de nós pais na primeira execução recursiva da Rede Bayesiana, e $\left(v_{u}\right.$ - upper $\left.v\right)$ o número máximo de nós pais após a estrutura de comunidades ser detectada na Rede Bayesiana e ocorrer a adição de arestas (Seção 2.9). Os parâmetros $v_{l}$ e $v_{u}$ representam um intervalo de valores para o parâmetro $v$ (Seção 2.7).

- O critério de parada utilizado pelo BOA e o CD-BOA foi o de convergência, isto é, o algoritmo para quando cada variável possui o mesmo valor em pelo menos $99 \%$ das soluções que compõem a população. StrOp, StrOp+REDA e a OPA tem sua execução em uma única iteração;

- O critério de seleção utilizado pelo BOA, CD-BOA e o StrOp foi o de truncamento em 50\%, da mesma forma que é realizado no BOA. Ocorre exceção quando a REDA é utilizada, nesse caso, aplica-se torneio de 8 indivíduos (Seção 4.1.2) para reamostrar cada nova População de Selecionados, o mesmo critério de seleção utilizado na OPA;

- A OPA utiliza o parâmetro $\Phi$ (relação entre o tamanho da População de Selecionados e a População Inicial). Por simplicidade de notação, uma OPA usando $\Phi$ é denotada por $\mathrm{OPA}_{\Phi}$;

- Usam-se problemas de benchmark que são descritos por uma combinação de funções (armadilha e deceptivas). Tais funções são explicadas no Capítulo 7;

- Cada ponto representado nas figuras deste capítulo é obtido calculando a média de 30 repetições do experimento correspondente com sementes diferentes do gerador de números aleatórios em cada execução (realizadas para aumentar a confiança estatística nos resultados). Foi utilizado o gerador de números aleatórios disponível em (Lobo et al., 2006);

- Os critérios usados para se avaliar a eficiência computacional são os seguintes:

+ Número de Avaliações (NA) até que o critério de convergência tenha sido atingido. Esse tem sido o critério mais utilizado para se medir a eficiência de um EDA;

+ Tempo de Execução (TE) do algoritmo. Embora esse critério não tenha sido tão utilizado na literatura quanto o NA para verificar a eficiência de EDAs, o TE é importante uma vez que o tempo de computação de um EDA tende a aumentar significativamente ao se construírem modelos probabilísticos mais verossímeis.

Todos os experimentos foram executados no cluster do LCR (ICMC-USP), com vinte e uma máquinas contendo as seguintes especificações: Processador Intel Core i7-2600 (com oito Cores cada um), Clock 3.4GHz, Cache 8MB, com memória RAM de 32GB, 1333 MHz. O conjunto 
de experimentos das Seções 8.2 e 8.3 são similares aos realizados por Crocomo (2012) devido à importância da comparação da OPA (a implementação utilizada está disponível em Soares (2014)) com o BOA e com os EDAs proposto por (Crocomo, 2012): CD-BOA, StrOp e StrOp+REDA (Capítulo 2)(todas implementações utilizadas estão disponíveis em Crocomo (2011)). É importante observar que a implementação do hBOA (Seção 2.8) pelos autores do método não possui código aberto à comunidade, conforme possui o BOA (a implementação utilizada está disponível em Pelikan (1999a)). Devido a isso, as extensões que resultaram no CD-BOA e StrOp não foram realizadas sobre o hBOA, uma vez que a comparação de desempenho poderia ser prejudicada por aspectos do método que poderiam ser implementados de forma diferente.

Por fim, observa-se que o tamanho utilizado (relativamente grande) para os gráficos mostrou-se fundamental para que se possa separar por inspeção visual as curvas descrevendo o desempenho de cada algoritmo testado.

\subsection{Avaliação com problemas deceptivos}

Os experimentos desta seção utilizam problemas armadilha deceptivos. O desempenho da OPA é em geral comparado com do BOA (Seção 2.7) e de outros três algoritmos desenvolvidos em (Crocomo, 2012): CD-BOA (Seção 2.9), StrOp (Seção 2.10) e StrOp+REDA. O BOA tem sido um dos algoritmos mais utilizados na literatura para comparações de desempenho de EDAs. É importante destacar que os algoritmos CD-BOA, StrOp e StrOp+REDA foram derivados do BOA, mostrando que é possível aumentar significativamente o desempenho original de EDAs baseados em Redes Bayesianas para cada subconjunto de problemas de benchmark considerados.

Por outro lado, o BOA utiliza o parâmetro de entrada $v$, que fixa o número máximo de vértices pais por variável na Rede Bayesiana. O valor ideal de $v$ é $(k-1)$, em geral o desempenho do BOA é reduzido se $v$ for diferente do ideal. Observe que o valor ideal pode ser previamente obtido para ASDP (Seção 7.4), conforme por exemplo é feito pelo StrOp.

Os algoritmos derivados do BOA desenvolvidos em (Crocomo, 2012) também requerem alguma informação sobre $v$, uma vez que utilizam como entrada um intervalo $\left[v_{l}, v_{u}\right]$ que deve conter todos os tamanhos de BBs presentes no problema. Por outro lado, a OPA não tem necessidade de nenhum parâmetro em relação ao tamanho do BB. Uma vantagem direta é conseguir lidar eficientemente com problemas em que os BBs possuem tamanhos significativamente diferentes.

Esta seção é divida em seis experimentos que avaliam o desempenho da OPA. O Experimento 1 utiliza problemas armadilhas (traps) de tamanhos variados para o teste do método (inicialmente os experimentos utilizam $\Phi=1,00$, ver Seção 6.1). O Experimento 2 avalia a OPA para problemas baseados em funções mais complexas, com tamanho de BBs, números de ótimos globais e locais (multimodalidade maior) em quantidade variada. O Experimento 3 apresenta testes para a função ftrap 5 avaliando a OPA tanto em termos de NA quanto de TE. O Experimento 4 avalia a influência da quantidade de reamostragens para os valores de NA e TE. O Experimento 5 mostra o efeito de $\Phi$ 
sobre os valores de NA e TE. Por fim, o Experimento 6 mostra que pode existir $\Phi$ que resulte em OPA com um compromisso adequado entre NA e TE.

\section{Experimento 1}

\section{Problemas compostos por 5 ftraps, variando $k$}

Para a realização deste experimento inicial, executam-se testes para funções $f \operatorname{trap} 3(k=3 \mathrm{e}$ $\ell=15), \operatorname{ftrap} 4(k=4$ e $\ell=20), \operatorname{ftrap5}(k=5 \mathrm{e} \ell=25)$ e $f \operatorname{trap} 6(k=6$ e $\ell=30)$ de forma que todos esses subproblemas tenham $m=5$. Os resultados da Figura 8.1 mostram os valores de NA da OPA comparando com os valores obtidos pelos algoritmos BOA, CD-BOA, StrOp e StrOp+REDA. Tanto a OPA quanto o StrOp+REDA usam 10 amostras para a reamostragens da População de Selecionados nesses testes. Na Figura 8.1, assim como nas demais Figuras deste Capítulo, cada ponto no gráfico é composto por média, máximo e mínimo dos valores obtidos por trinta execuções do algoritmo, substituindo apenas a semente de números aleatórios em cada execução. Estes primeiros resultados com problemas relativamente pequenos mostram certa equiparação da OPA com o StrOp+REDA e melhor desempenho desses em relação ao BOA, CD-BOA e StrOp em termos de NA. A Figura 8.1 também mostra que o BOA, CD- BOA e StrOp perdem muito em NA para $k>5$. Isso provavelmente deve-se ao fato da construção da BN requerer uma estimativa de $v=k-1$ (Seção 2.7). Assim, para $k>5$, $v$ é sobre-estimado possibilitando gerar BNs computacionalmente mais complexas de se computar e, com isso, reduzindo a representatividade das BNs encontradas. Por outro lado, a OPA não requer esse parâmetro para obter desempenho em problemas com BBs de tamanho variado. O StrOp+REDA provavelmente consegue, pelo processo de reamostragem descartar os BBs equivocadamente grandes, mantendo certo desempenho para $k>5$.

\section{Experimento 2}

\section{Problemas compostos por diferentes tipos de funções deceptivas}

O desempenho da OPA é comparado com o BOA, CD-BOA, StrOp e StrOp+REDA usando parâmetros ideais para otimizar quatro ASDP, cada um composto por BBs envolvendo uma das seguintes funções: f3deceptive $(\ell=90, m=30)$, ftrap5 $(\ell=90, m=18)$, f6bipolar $(\ell=90$, $m=15)$ e 15 funções $f 3$ deceptive em conjunto com 9 funções ftrap5 ( $\ell=90, m=24$ ). A Figura 8.2 sintetiza a comparação entre os algoritmos. Assim como no Experimento 1, esses resultados mostram que a OPA tem desempenho, em termos de NA, similar ao StrOp+REDA, ambos usando 10 reamostragens da População de Selecionados. 


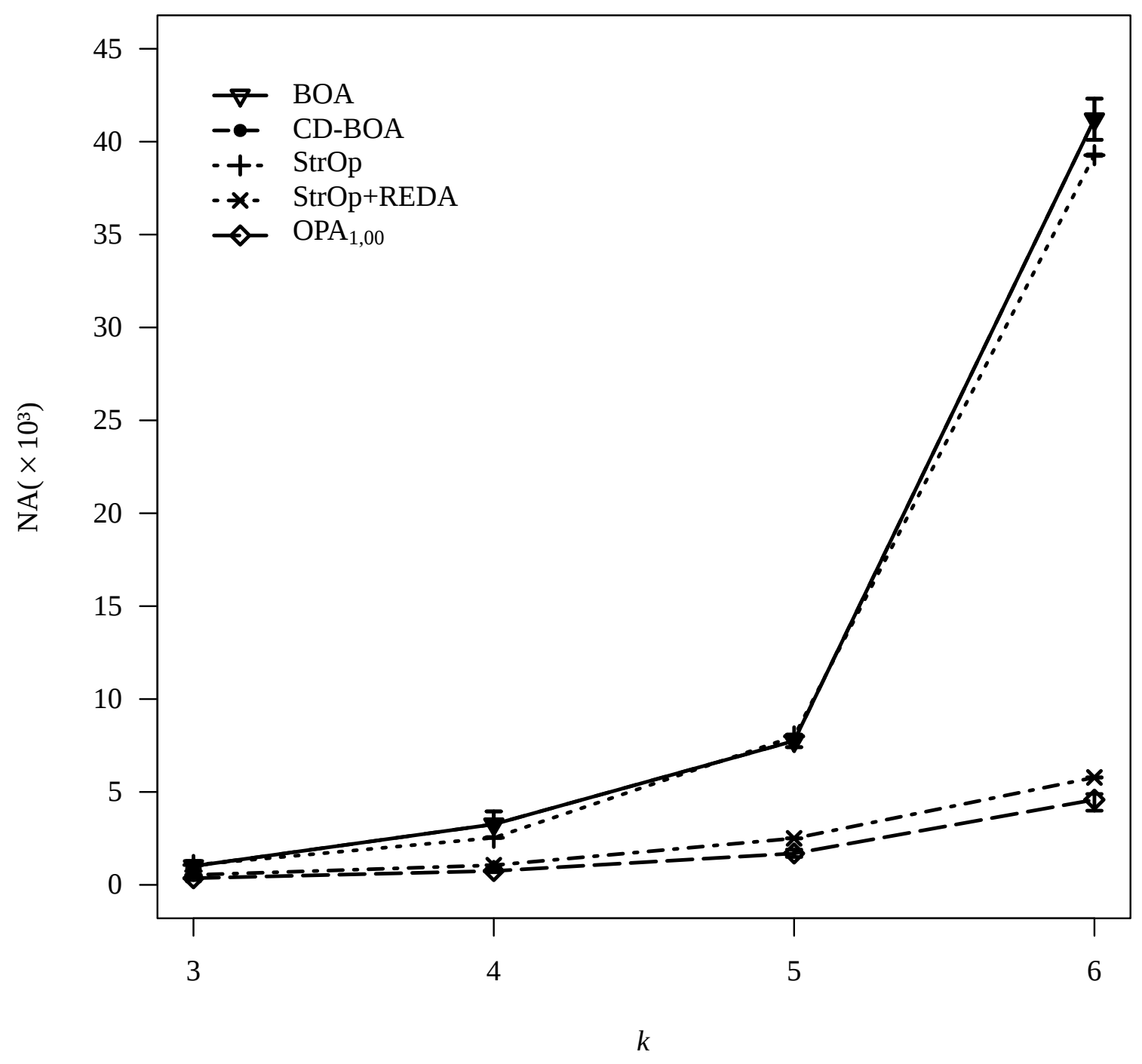

Figura 8.1: Comparação em NA entre BOA $(v=4)$, CD-BOA, StrOp e StrOp+REDA $\left(v_{l}=3\right.$ e $v_{u}=7$ ) e OPA para problemas compostos por 5 ftraps com $k$ variando de 3 a 6 .

\section{Experimento 3}

\section{Problemas compostos por $f$ trap $5, \mathbf{N A} \times \mathbf{T E}$}

Neste Experimento usa-se o ASDP composto por $f \operatorname{trap} 5(k=5)$ e $m$ variando com o tamanho $\ell$ do problema ( $m=\ell / k$ ) para analisar o desempenho da OPA tanto em termos de NA quanto de TE, conforme $\ell$ aumenta. Os testes foram realizados com $\ell$ variando segundo os valores 30,60 , 90, 120, 150 e 180. As Figuras 8.3 e 8.4 comparam o desempenho da OPA para NA e TE, em relação ao desempenho do BOA, CD-BOA, StrOp e StrOp+REDA. Este experimento novamente mostra uma equiparação da OPA com StrOp+REDA com certa vantagem para a OPA em termos 


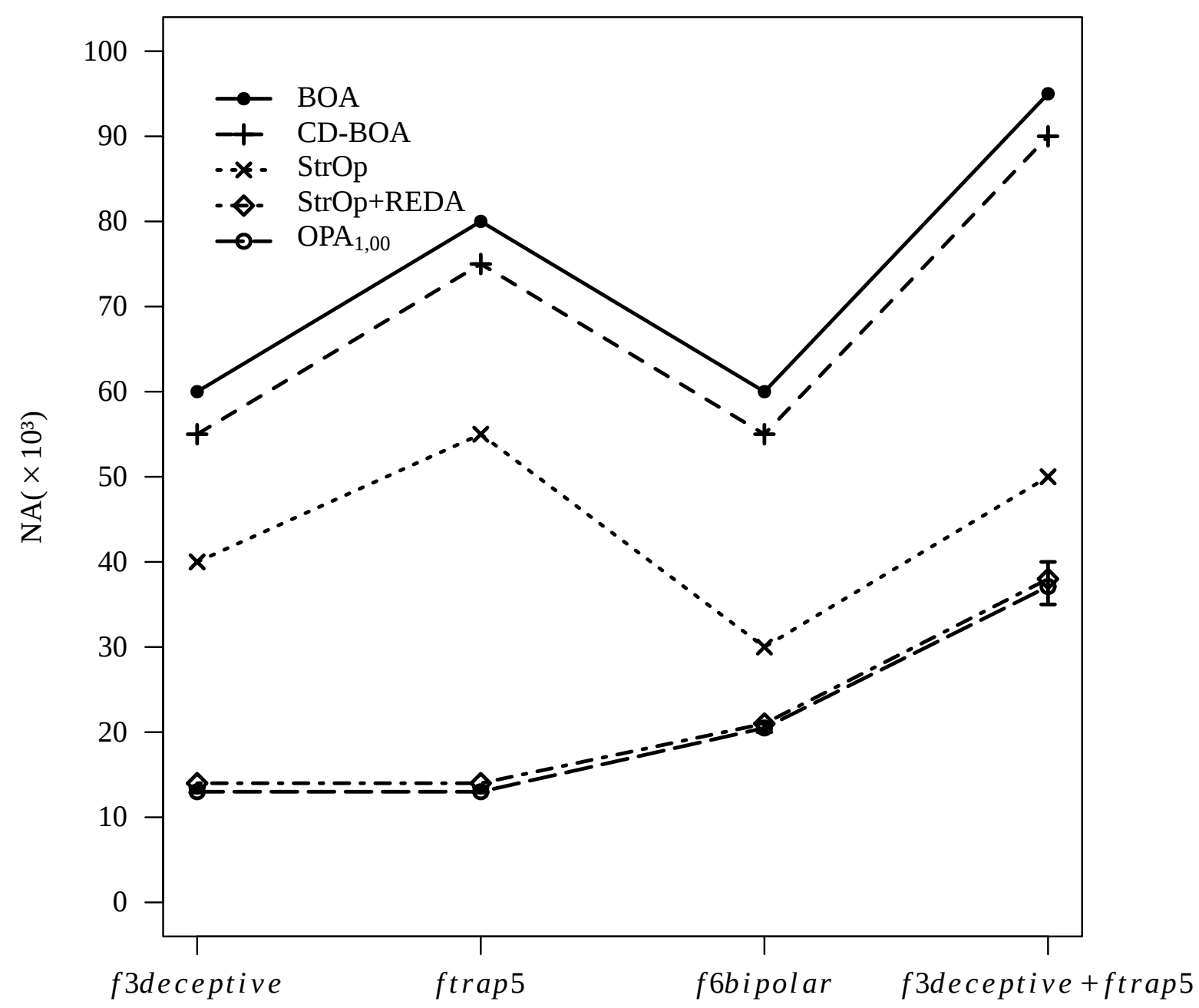

Figura 8.2: Desempenho em NA sobre diferentes tipos de funções deceptivas com $\ell=90$ para os algoritmos BOA $(v=4)$, CD-BOA, StrOp e StrOp+REDA $\left(v_{l}=3\right.$ e $\left.v_{u}=7\right)$.

de NA. A OPA supera em TE os EDAs (BOA, CD-BOA e StrOp+REDA) conforme $\ell$ cresce. Isso pode ser explicado pela maior complexidade de construção de um modelo probabilístico a cada geração pelo StrOp+REDA baseada na Rede Bayesiana, que o BOA também utiliza. Por outro lado, o StrOp constrói esse modelo apenas uma vez, mantendo o TE sempre abaixo de 5 segundos para todos os testes. Observe que, em termos de NA, o StrOp requer valores intermediários entre os obtidos pelo BOA e CD-BOA (piores em NA) e StrOp+REDA e OPA (melhores em NA). 


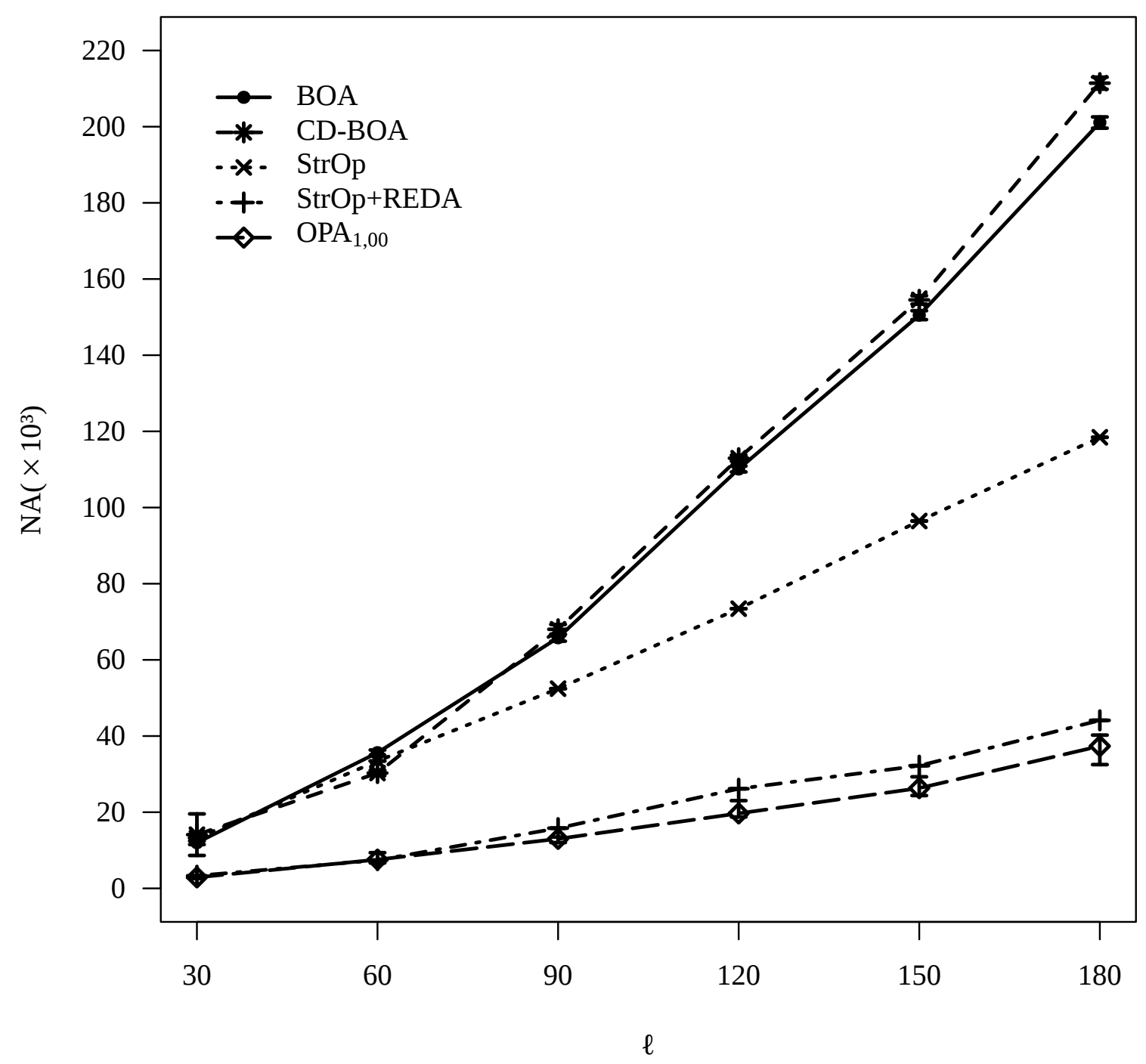

Figura 8.3: Comparação em NA da OPA com BOA $(v=4)$, CD-BOA, StrOp e StrOp+REDA $\left(v_{l}=3\right.$ e $\left.v_{u}=7\right)$ para o problema composto por funções ftrap5. 


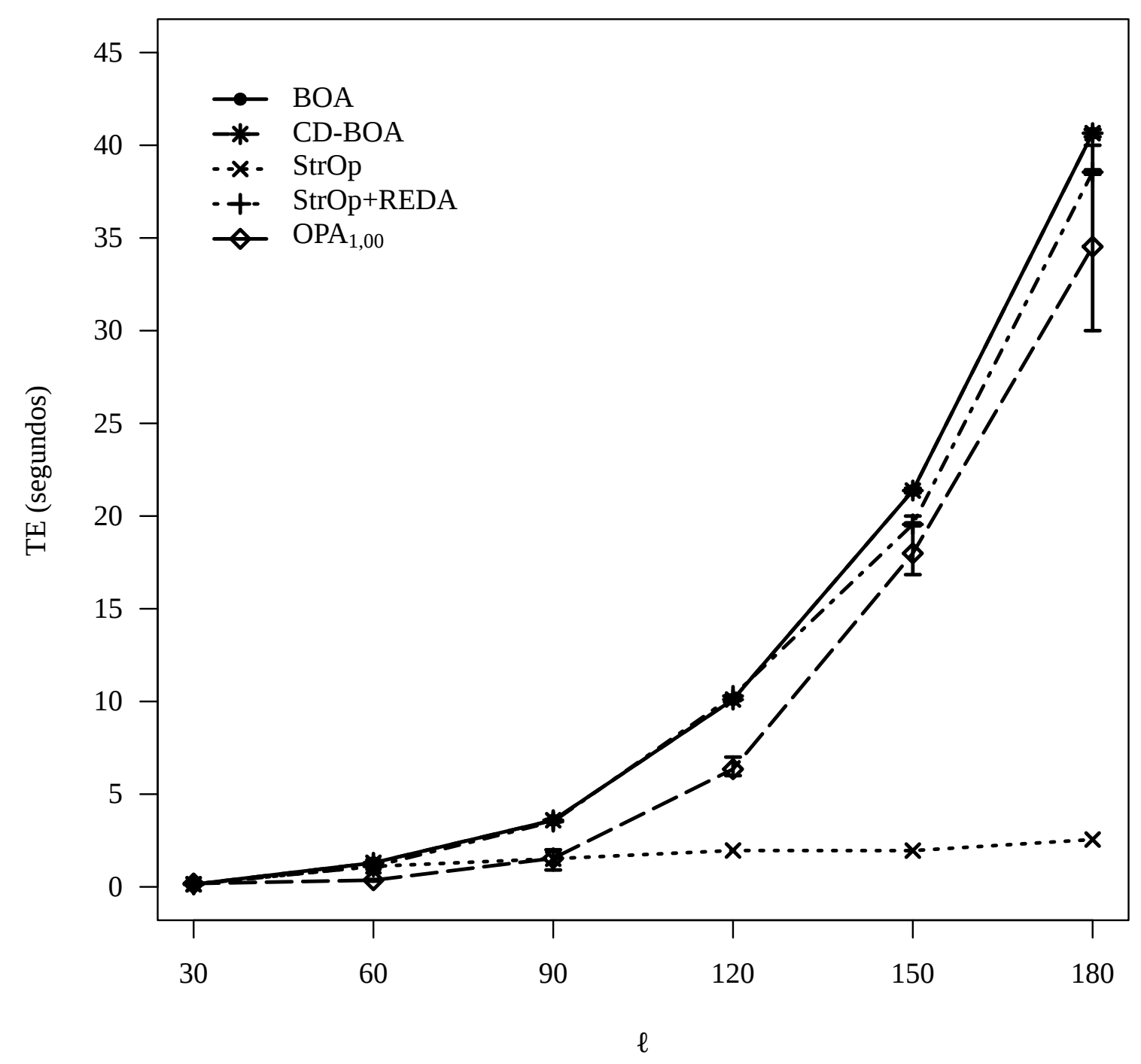

Figura 8.4: Comparação em TE da OPA com BOA $(v=4)$, CD-BOA, StrOp e StrOp+REDA $\left(v_{l}=3\right.$ e $\left.v_{u}=7\right)$ para o problema composto por funções $f t r a p 5$. 


\section{Experimento 4}

\section{Efeito de reamostragens da População de Selecionados no NA e TE}

Para verificar a influência da quantidade de reamostragens ${ }^{1}$ utilizada no comportamento do algoritmo, testes foram realizados para o problema composto por ftrap5 com $\ell=90$, variando o número de reamostragens de 1 até 10 . A OPA é apenas comparada ao $\operatorname{StrOp+REDA}\left(v_{l}=3 \mathrm{e}\right.$ $v_{u}=7$ ), pois o BOA, CD-BOA e StrOp não realizam reamostragens.

As Figuras 8.6 e 8.7 mostram, respectivamente, os resultados com relação ao NA e TE, conforme aumenta-se a quantidade de reamostragens. Os resultados deste experimento evidenciam uma das principais diferenças entre os dois algoritmos. A OPA tem resultados satisfatórios mesmo usando poucas quantidades de reamostragens (quatro ou menos). Isso acontece devido à OPA gerar mais modelos (Redes Equivalentes, ver Seção 6.1) a partir de uma mesma reamostragem da População de Selecionados (conforme mostrado na Figura 6.9, Capítulo 6) e também devido ao seu tempo de comunicação médio ser limitado por uma constante.

Os valores de NA do StrOp+REDA para um e duas reamostragens correspondem ao máximo de NA testado pelo método da bisseção (Sastry, 2001), isto é, nesses casos o StrOp+REDA não consegue resolver o problema com o máximo de NA testado e o TE é relativamente alto. A vantagem em termos de TE da OPA acontece devido a menor complexidade para construção do modelo probabilístico e ao processamento poder ser distribuído entre um número de processadores igual ao número de reamostragens, conforme mostra a Figura 6.13 (Capítulo 6).

É importante observar que o tempo de comunicação entre as máquinas foi desprezado na computação dos TE's, uma vez que o esquema de paralelização utilizado (Figura 6.13) requer $2 A B C$ comunicações entre cada Elementos de Processamento, resultando em tempo de comunicação total $t_{t} \leq c_{t} 2 A B C$, em que $c_{t}$ é uma constante positiva indicando o tempo máximo de comunicação ocorrido entre 2 elementos. Esse tempo pode ser amortizado por $A B C$ processamentos em paralelo, resultando em tempo amortizado $O(1)$.

Para melhor verificar esse aspecto, observe que o esquema de paralelização forma uma estrutura de árvore em que as arestas estão associadas às comunicações entre duas máquinas (uma vez para enviar dados e outra para receber). Assim, o total de nós é $A B C+1$ e de arestas é $A B C$. Conforme mostra a Figura 8.5, $t_{t}=t_{A} A+t_{B} B+t_{C} C$, em que $t_{A}, t_{B}$ e $t_{C}$ são os maiores tempo de comunicação associados aos níveis $A, B$ e $C$ da árvore. Seja $t_{m}=\max \left\{t_{A}, t_{B}, t_{C}\right\}$, então $t_{t} \leq A B C t_{m}$. Esse tempo é amortizado por $A B C$ processamentos da OPA em paralelo que ocorre no nível $C$ para gerar cada uma das Redes de Folhas, resultando em tempo médio $O(1)$.

Observe que essa paralelização pressupõe $A B C$ Elementos de Processamento. os testes realizados neste trabalho requisitaram até $A=16, B=10, C=10$ para o experimento de maior custo

\footnotetext{
${ }^{1}$ A quantidade de reamostragens contabiliza a primeira amostragem da População de Selecionados como uma reamostragem (mesmo que não tenha sido gerada a $2^{\mathrm{a}}$ População de Selecionados).
} 
computacional. Portanto, a realização de todos os testes com a OPA em tempo amortizado $O(1)$ utilizariam ao máximo um cluster com 1600 Elementos de Processamento.

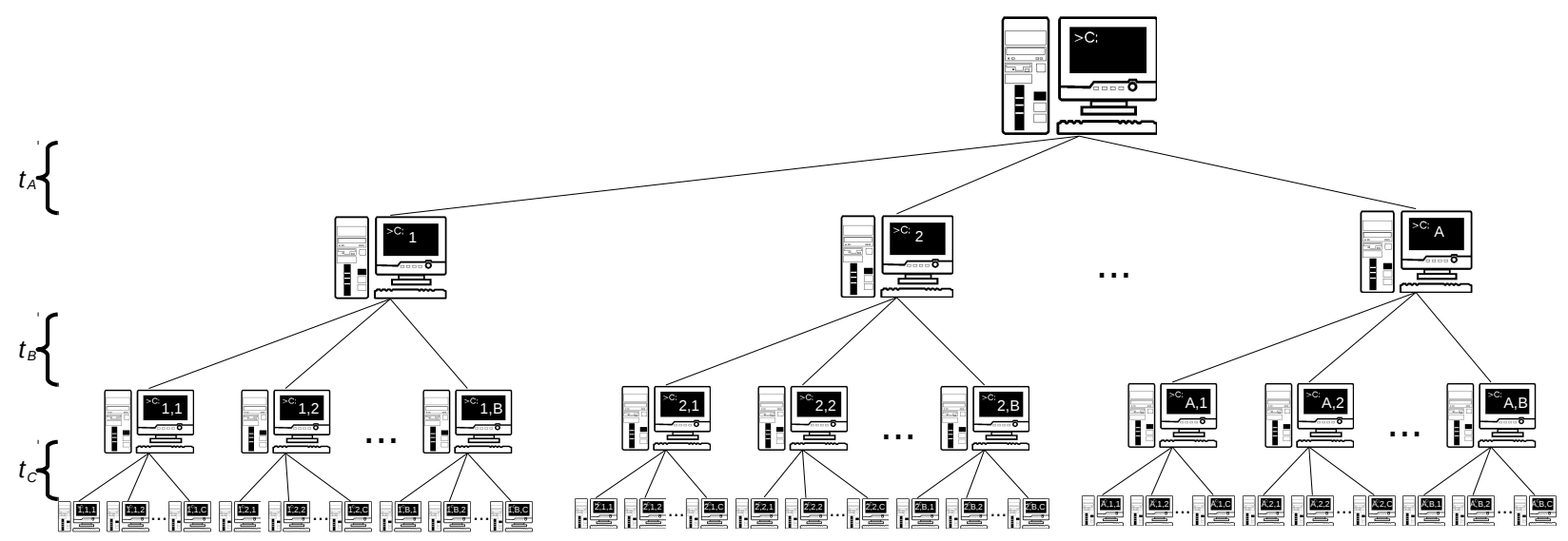

Figura 8.5: Configuração do tempo de comunicação entre os Elementos de Processamento da Figura 6.13. 


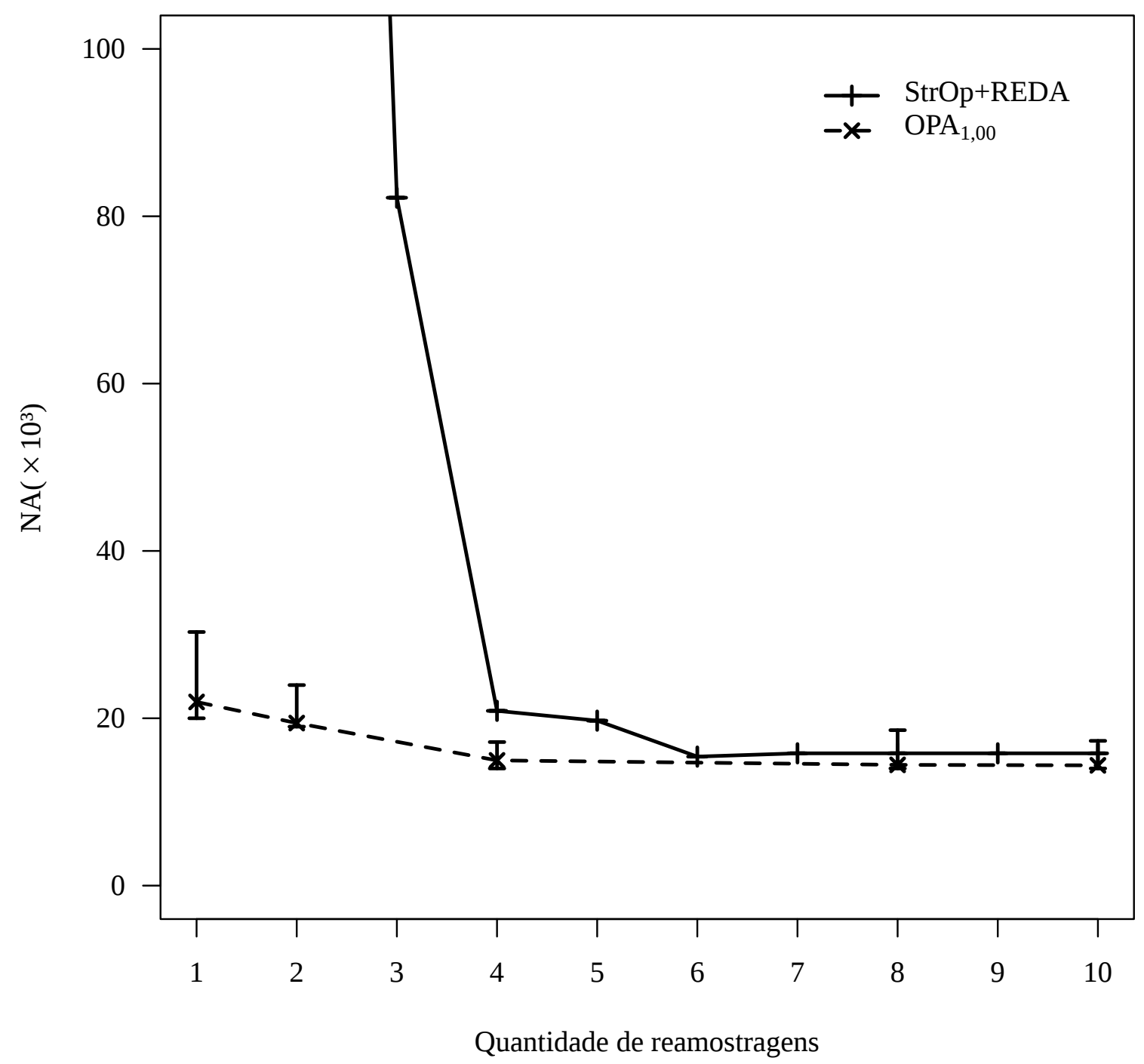

Figura 8.6: NA da OPA variando a quantidade de reamostragens de 1 a 10 para o problema composto por funções ftrap5 $\operatorname{com} \ell=90$. 


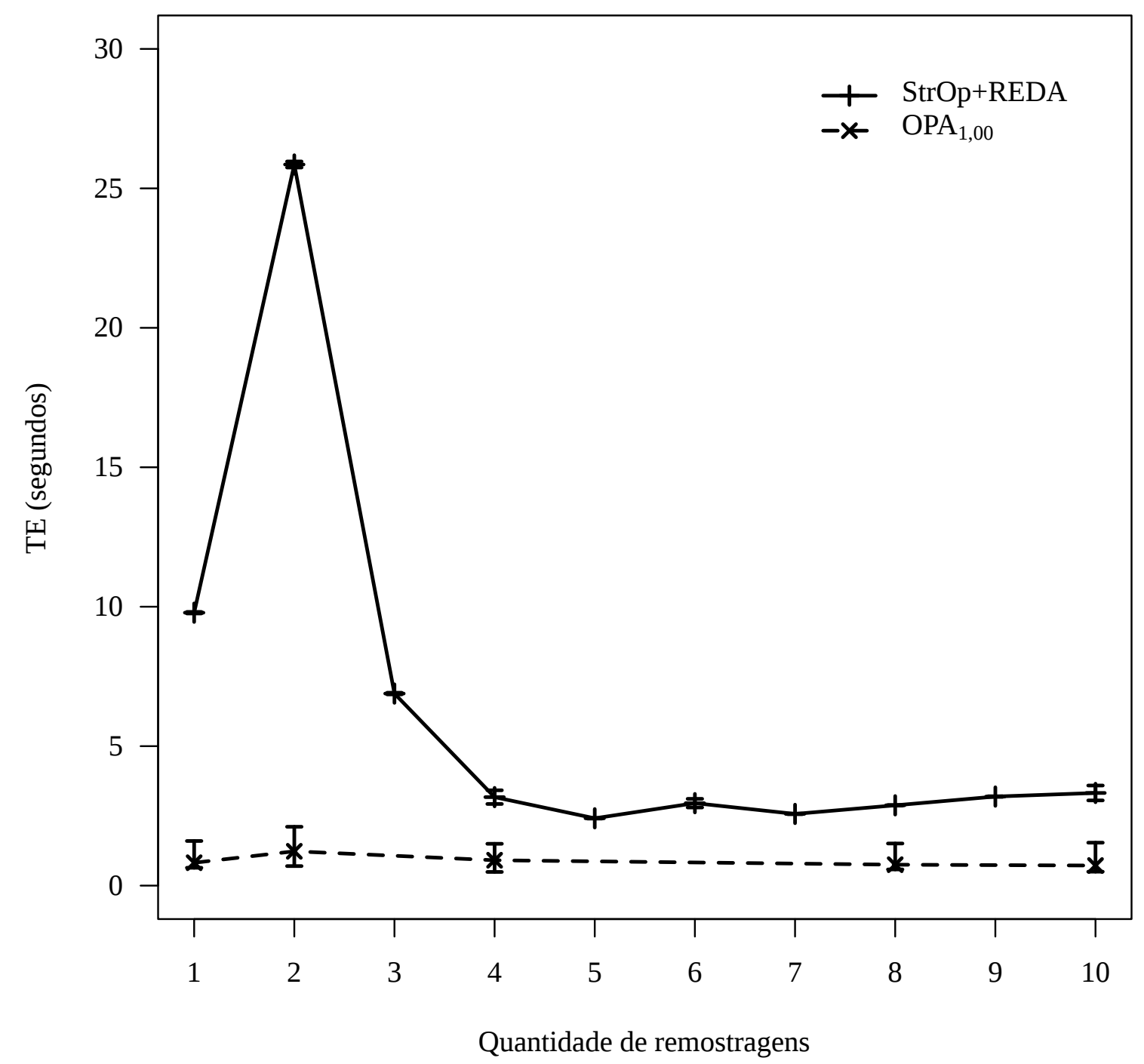

Figura 8.7: TE da OPA pela quantidade de reamostragens de 1 a 10 para o problema composto por funções $f$ trap 5 com $\ell=90$. 


\section{Experimento 5}

\section{Influência de $\Phi$ no NA e TE}

O Experimento 4 foi refeito com a OPA variando $\Phi$ de forma a mostrar a influência no desempenho do algoritmo do tamanho $n_{s}$ (Seção 6.1) da População de Selecionados reamostrada. As Figuras 8.8 e 8.9 indicam que a OPA possui certa robustez em relação a variação do parâmetro $\Phi$, uma vez que há uma faixa de valores de $\Phi$ que resulta em NA relativamente baixos (sempre menores que do StrOp+REDA): $\Phi$ entre 0,25 a 16,00. Resultados equivalentes ocorrem para TE, em que $\Phi$ de 0,07 a 1,00 correspondem a TE significativamente mais baixos.

É importante destacar que esses dois intervalos para $\Phi[0,25 ; 16,00]$ e $[0,07 ; 1,00]$ possuem a seguinte intersecção: $[0,25 ; 1,00]$. Tal intervalo indica que há valores de $\Phi$ que possibilitam desempenho da OPA que pode ser adequado simultaneamente em termos de NA e TE.

\section{Experimento 6}

\section{TE no intervalo $0,07 \leq \Phi \leq 1,00$}

Com o Experimento 5, verificou-se que no intervalo $0,07 \leq \Phi \leq 1,00$, a OPA possui TE relativamente baixo (Figura 8.9). O Experimento 6 refaz a análise do Experimento 3 (que avaliou o desempenho em função de $\ell$ para ASDP compostos por ftrap5) utilizando valores de $\Phi$ no intervalo associado aos menores TE's encontrados no Experimento 5.

A Figura 8.10 mostra que a $\mathrm{OPA}_{0,13}$ possui desempenho próximo da $\mathrm{OPA}_{1,00}$ (melhor algoritmo em termos de NA) considerando que as curvas das OPA's com $0,13 \leq \Phi \leq 1,00$ e do StrOp+REDA formam uma agrupamento na Figura 8.10. Para TE (Figura 8.11), $\Phi=0,13$ e $\Phi=0,07$ mantém a OPA significativamente próximo do StrOp, porém $\Phi=0,25$ resulta em curva claramente separada do agrupamento formado por StrOp, $\mathrm{OPA}_{0,13}$ e $\mathrm{OPA}_{0,07}$ para os valores mais altos de $\ell$. Portanto, a $\mathrm{OPA}_{0,13}$ está próxima do algoritmo rival com melhor desempenho em NA (StrOp+REDA) e do rival em TE (StrOp). Isso indica que a $\mathrm{OPA}_{0,13}$ possui um compromisso entre NA e TE, que pode ser relevante em aplicações em que não se sabe de antemão se NA ou TE é prioritário. 


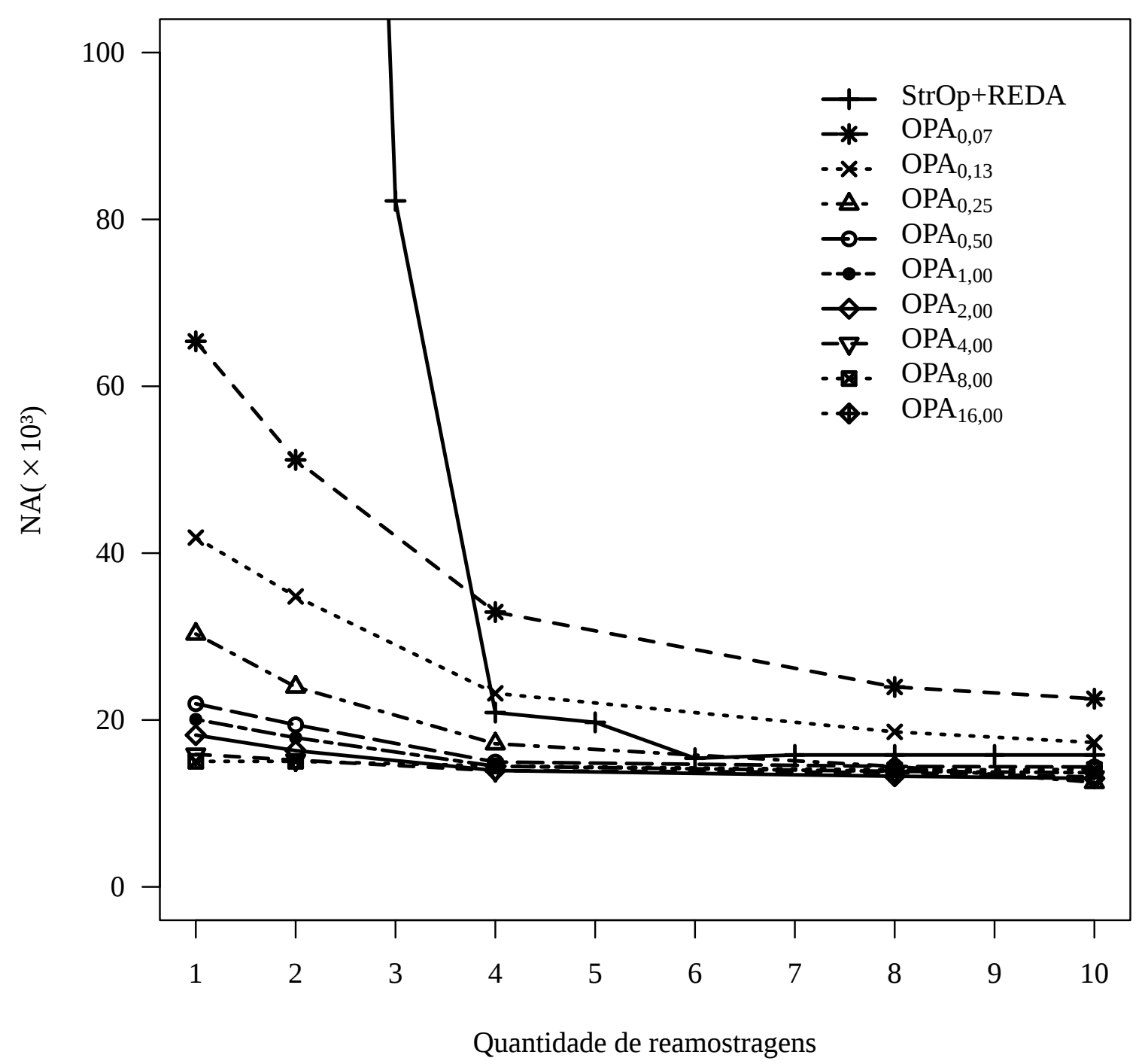

Figura 8.8: NA para o Experimento 4 (funções ftrap $5 \operatorname{com} \ell=90$ ) refeito variando $\Phi$ entre 0,07 e 16,00 . 


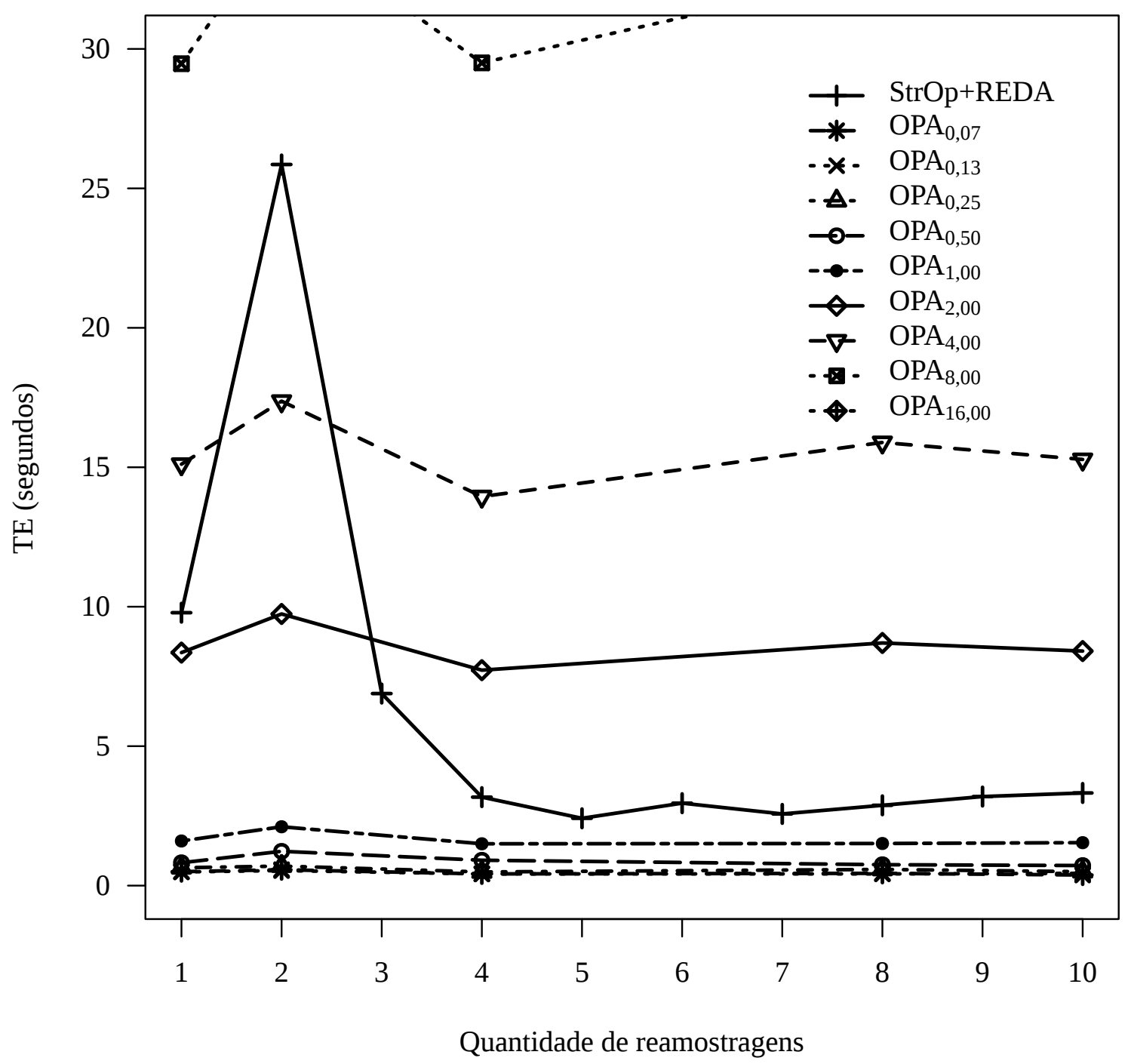

Figura 8.9: TE para o Experimento 4 (funções $f \operatorname{trap} 5 \operatorname{com} \ell=90$ ) refeito variando $\Phi$ entre 0,07 e 16,00 . 


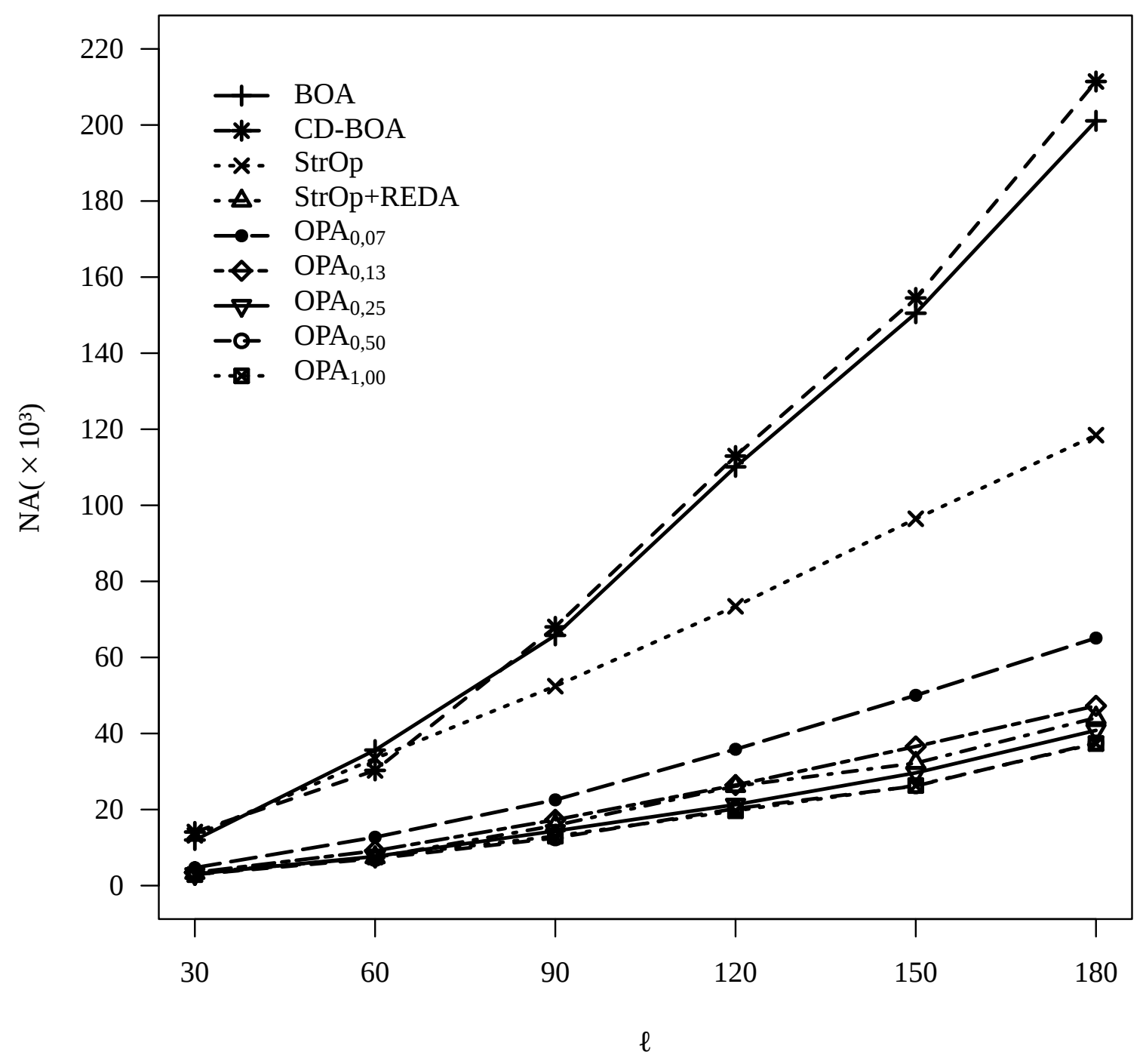

Figura 8.10: Comparação entre NA da OPA, com BOA $(v=4)$, StrOp e StrOp+REDA (ambos $\operatorname{com} v_{l}=3$ e $v_{u}=7$ ) para o problema composto por funções ftrap5. 


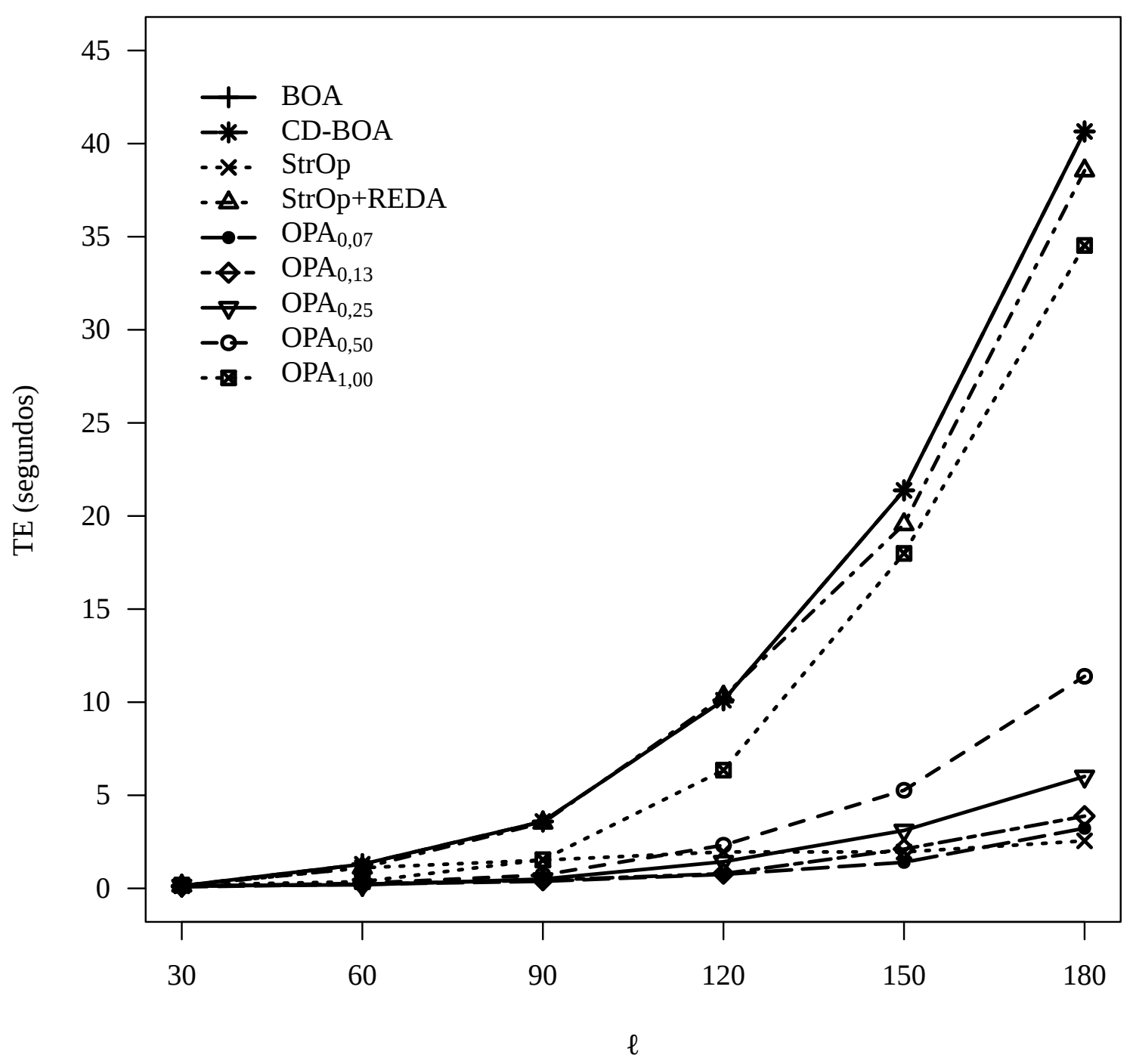

Figura 8.11: Comparação entre TE da OPA, com BOA $(v=4)$, StrOp e StrOp+REDA (ambos $\operatorname{com} v_{l}=3$ e $v_{u}=7$ ) para o problema composto por funções ftrap5. 


\section{Experimento 7}

\section{$\Phi$ vs quantidade de Reamostragens}

O Experimento 7 faz conjuntamente as análises presentes no Experimento 3 (avaliando o desempenho em função de $\ell$ para ASDP compostos por ftrap5) e no Experimento 5 (verificando a influência no NA de $\Phi$ e da quantidade de reamostragens). As Figuras 8.13 e 8.12 sumarizam os resultados referentes a esse experimento.

Esses resultados indicam que, para quantidades de reamostragens igual ou maior a 4 e $\Phi \geq$ 0,50, o NA é relativamente estável e próximo do patamar mais baixo encontrado. Por outro lado, $\Phi \geq 0,50$ pode não ser o mais adequado em termos de TE (ver Experimento 6), mas ainda apresenta um compromisso interessante, uma vez que possui intersecções com o intervalo $0,07 \leq \Phi \leq 1,00$ obtido no Experimento 5. Além disso, a $\mathrm{OPA}_{0,13}$ que apresentou o melhor compromisso em termos de NA e TE (Experimento 6) aproxima-se significativamente dos melhores resultados em termos de NA para quantidade de reamostragem igual a 10. Esse resultado é interessante, uma vez que a maior reamostragem pôde ser realizada com paralelização envolvendo um número de Elementos de Processamento constante em relação ao tamanho do problema e com tempo de comunicação entre os elementos também limitado por uma constante (Experimento 6).

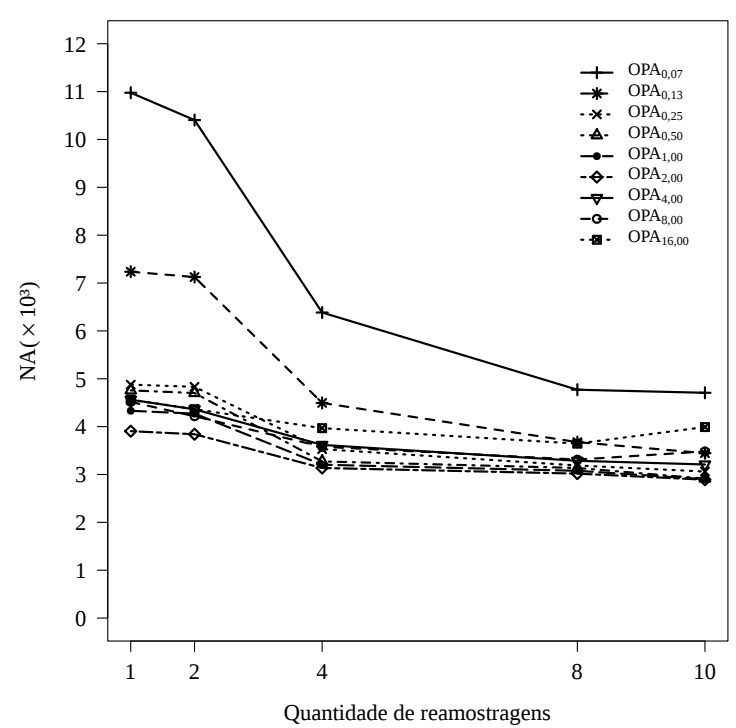

(a)

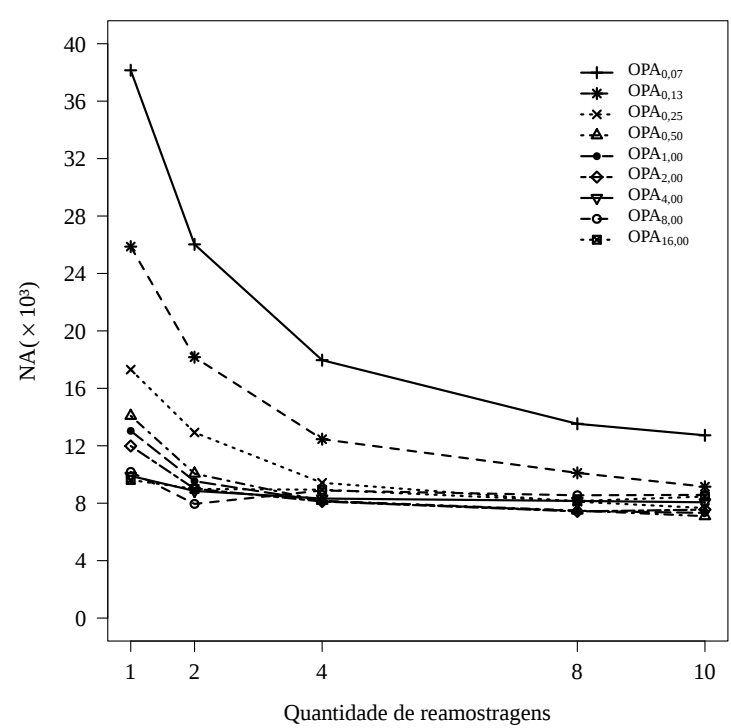

(b)

Figura 8.12: Problemas armadilha compostos por ftrap5 para (a) $\ell=30$, (b) $\ell=60$. 


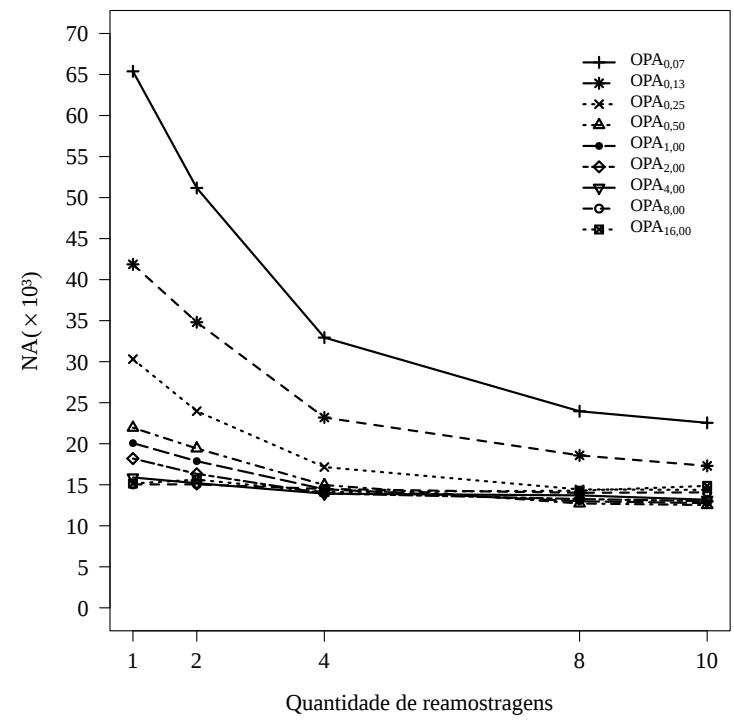

(a)

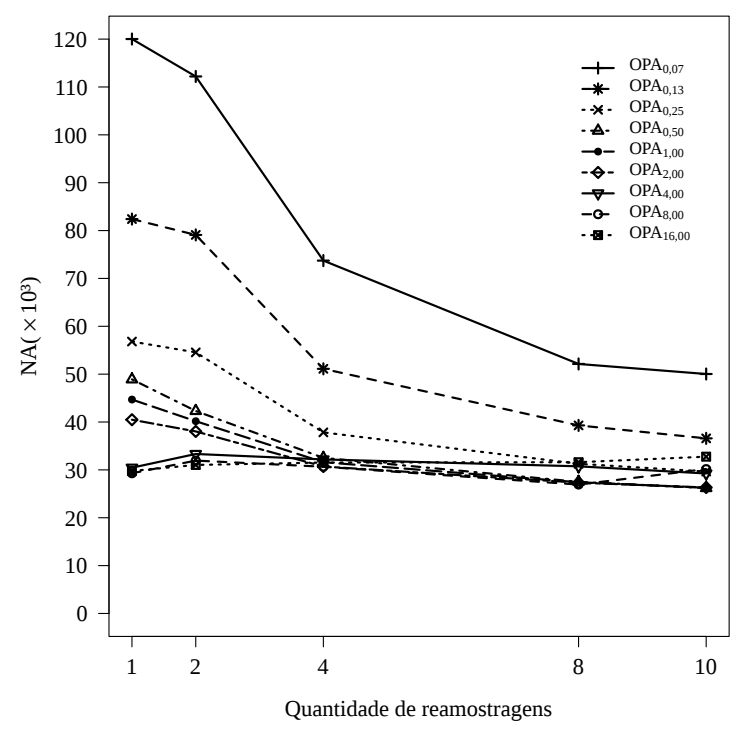

(c)

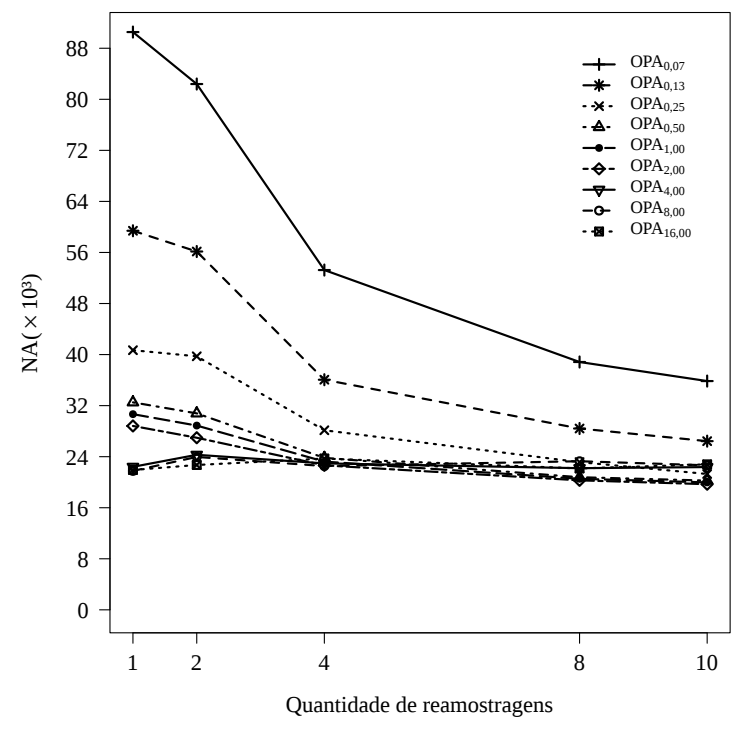

(b)

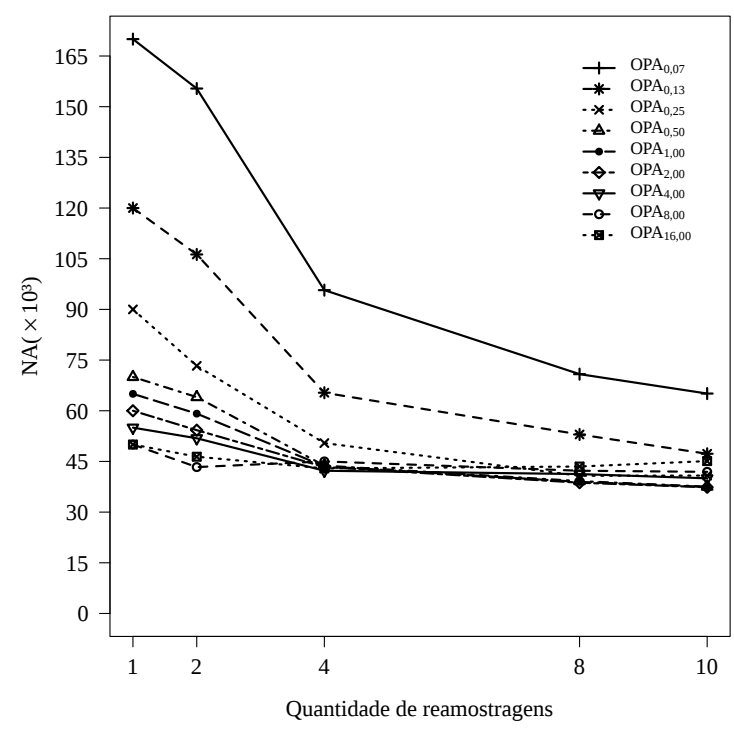

(d)

Figura 8.13: Problemas armadilha compostos por ftrap5 para (a) $\ell=90$, (b) $\ell=120$, (c) $\ell=150$, (d) $\ell=180$.

\subsection{Avaliação com problemas OneMax, Binlnt e com so- breposição de BBs}

Os experimentos apresentados a seguir possuem como objetivos testar o desempenho dos algoritmos para: ( $i$ ) problemas com sobreposição de funções armadilha e (ii) problemas não deceptivos 
BinInt e OneMax. O Experimentos 1 avalia o algoritmo desenvolvido para problemas envolvendo funções ftrap5 com sobreposição de BBs em dois bits de cada BB. Esses testes verificam o desempenho dos algoritmos ao tratar aspectos importantes de problemas hierárquicos.

Os Experimentos 2 e 3 da Seção 8.3 testam os algoritmos propostos em dois problemas não deceptivos (OneMax e BinInt) que modelam aspectos importantes de problemas do mundo real. Em especial o BinInt é um problema difícil para EAs típicos e também EDAs. A OPA 1,00 é comparado ao BOA, CD-BOA e StrOp+REDA que foram os EDAs rivais testados com melhor desempenho encontrado para esses tipos de problemas. O valor de $\Phi=1,00$ para a OPA foi utilizado nos experimentos da Seção 8.3 para que a comparação com o StrOp+REDA fosse a mais adequada possível, uma vez que o StrOp+REDA gera uma População de Selecionados com o mesmo tamanho da População Inicial.

\section{Experimento 1}

\section{Problemas contendo sobreposição de funções ftrap5}

O problema é composto por funções armadilhas deceptivas com BBs de tamanho 5 , ftrap5, com sobreposição de BBs em dois bits em todos BBs do problema, conforme a Equação 7.12 (Seção 7.5). Este tipo de problema é utilizado para representar problemas hierárquicos (Pelikan \& Goldberg, 2003). A partir de tal problema foi possível verificar certas limitações dos primeiros EDAs multivariados (Harik et al., 2006), uma vez que esses algoritmos garantiam uma solução próxima do ótimo (no máximo um BB com instância errada) somente para ASDP.

Nos testes foram utilizados os seguintes valores para $\ell:$ 20,38,56,74,92 e 110. A Figura 8.14 mostra uma diferença significativa para todos os resultados entre a $\mathrm{OPA}_{1,00}$ e os outros algoritmos. Isso ocorre devido ao uso da CES (Seção 6.4), pois para problemas com sobreposição, a OPA 1,00 tem como Particionamento Final (Seção 6.1) apenas uma partição envolvendo todas as variáveis. Isso indica que correlações entre blocos menores não são tão fortes quanto a correlação entre todas as variáveis. Observe que, nesse contexto, a $\mathrm{OPA}_{1,00}$ utiliza o particionamento ideal $k^{*}$ (Seção 6.4) buscando reduzir o NA. 


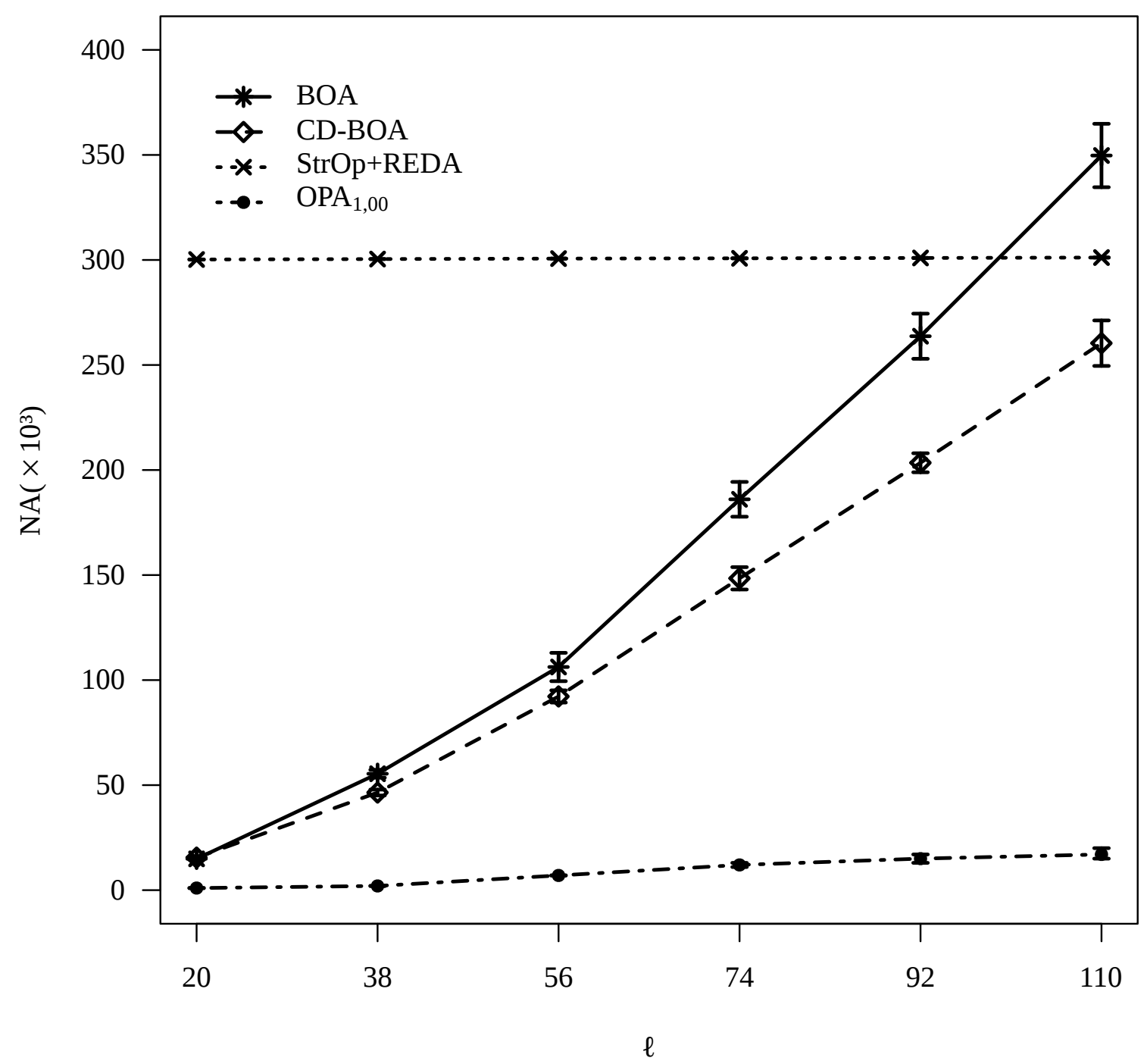

Figura 8.14: NA da $\mathrm{OPA}_{1,00}$ comparado ao BOA $(v=4)$ e StrOp+REDA $\left(v_{l}=3\right.$ e $\left.v_{u}=7\right)$ para o problema composto por funções ftrap 5 com sobreposição de dois bits. 


\section{Experimento 2}

\section{Problemas com o OneMax}

O problema OneMax foi testado para $\ell$ igual a 5,10,15,20 e 25. Assim como o problema de sobreposição (Experimento 1), cada reamostragem resulta em um particionamento diferente. $\mathrm{O}$ consenso dos particionamentos obtido das Redes Equivalentes (Seção 6.1) é um Particionamento Final que não representa os Particionamentos Amostrais, evidenciando que não é possível encontrar (ou não existe) correlação entre as variáveis do problema (todos os BBs relativamente fracos, são unidos em um único clado (Seção 6.2)). Novamente, a CES da $\mathrm{OPA}_{1,00}$ resulta em NA relativamente baixo, como mostrado nos resultados da Figura 8.15, indicando certa equidade entre a $\mathrm{OPA}_{1,00}$ e o StrOp+REDA, com a vantagem da OPA 1,00 apresentar NA praticamente constante.

\section{Experimento 3}

\section{Teste com o Binlnt}

Este Experimento é similar ao Experimento 2 da Seção 8.3, mas utilizando desta vez o problema BinInt. Apesar da similaridade com o OneMax em termos de tamanho de BBs $(k=1)$, tal problema estressa a possibilidade de algoritmos probabilísticos convergirem por deriva (Goldberg, 2002), ou seja, os bits mais significativos para o cálculo do fitness direcionam a evolução inicialmente, possibilitando que os bits menos significativos convirjam mais facilmente por deriva (Capítulo 1), isto é, aleatoriamente. Os resultados são apresentados na Figura 8.16. Assim como no Experimento 2, a $\mathrm{OPA}_{1,00}$ e o StrOp+REDA mostram desempenho equiparável. 


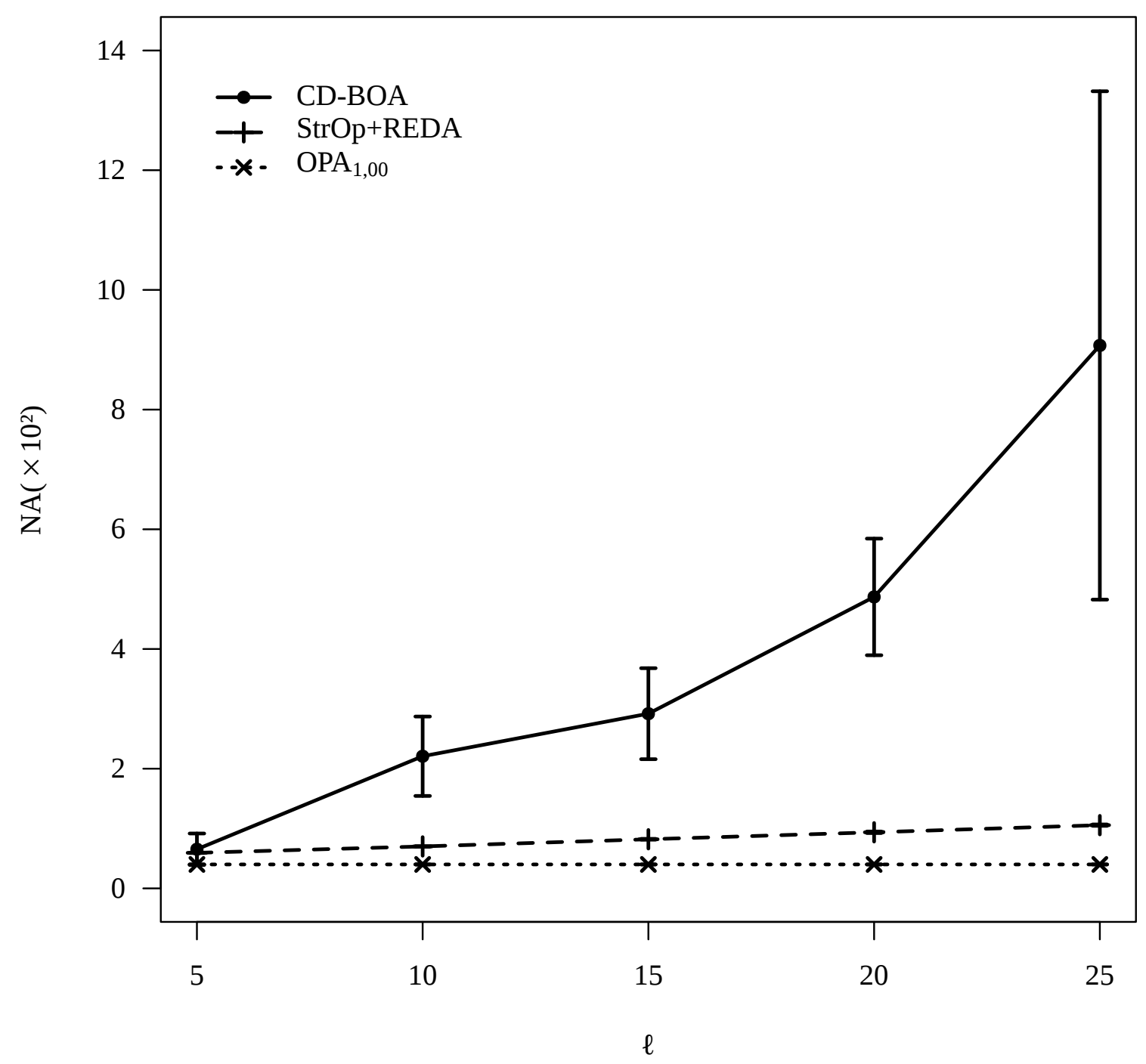

Figura 8.15: NA da $\mathrm{OPA}_{1,00}$ comparado ao CD-BOA e StrOp+REDA (ambos com $v_{l}=1 \mathrm{e}$ $v_{u}=1$ ) para o problema OneMax. 


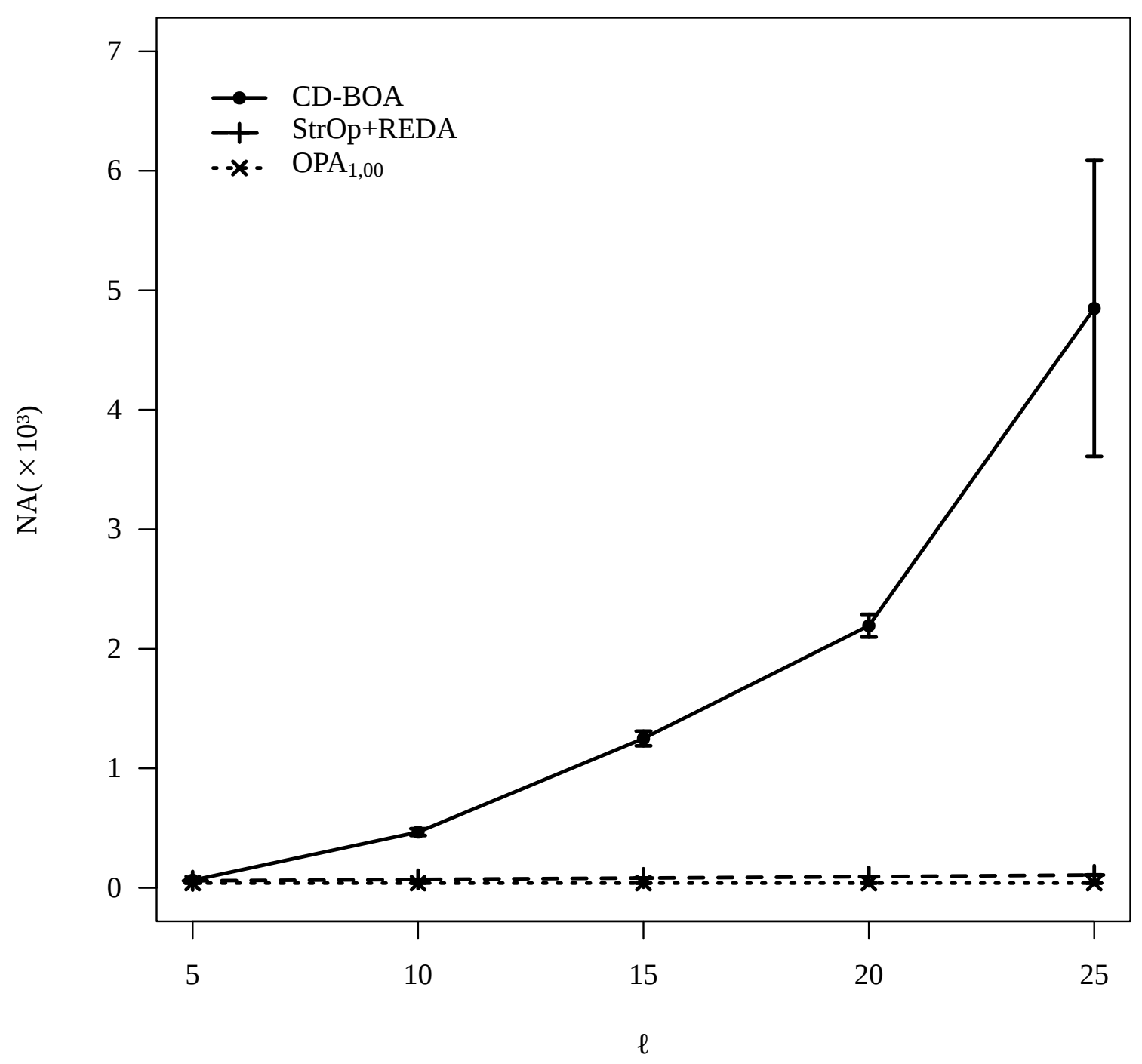

Figura 8.16: NA da $\mathrm{OPA}_{1,00}$ comparado ao CD-BOA e StrOp+REDA (ambos com $v_{l}=1 \mathrm{e}$ $v_{u}=1$ ) para o problema BinInt. 


\section{Experimento 4}

\section{Problema composto por BBs separáveis e sobrepostos}

Este Experimento apresenta um novo problema em que metade do cromossomo é composto por funções ftrap5 com sobreposição de dois bits da mesma forma que o Experimento 1 e a outra metade é composto por funções ftrap 5 sem sobreposição, como no Experimento 3 da Seção 8.2. O Experimento 4 mostra que a $\mathrm{OPA}_{1,00}$ é é capaz de resolver problemas com dificuldades bem distintas, com NA crescendo de forma aparentemente linear em relação ao tamanho do problema $(\ell)$. A Figura 8.17 mostra os valores de NA obtidos para o Experimento 4, com 10 reamostragens.

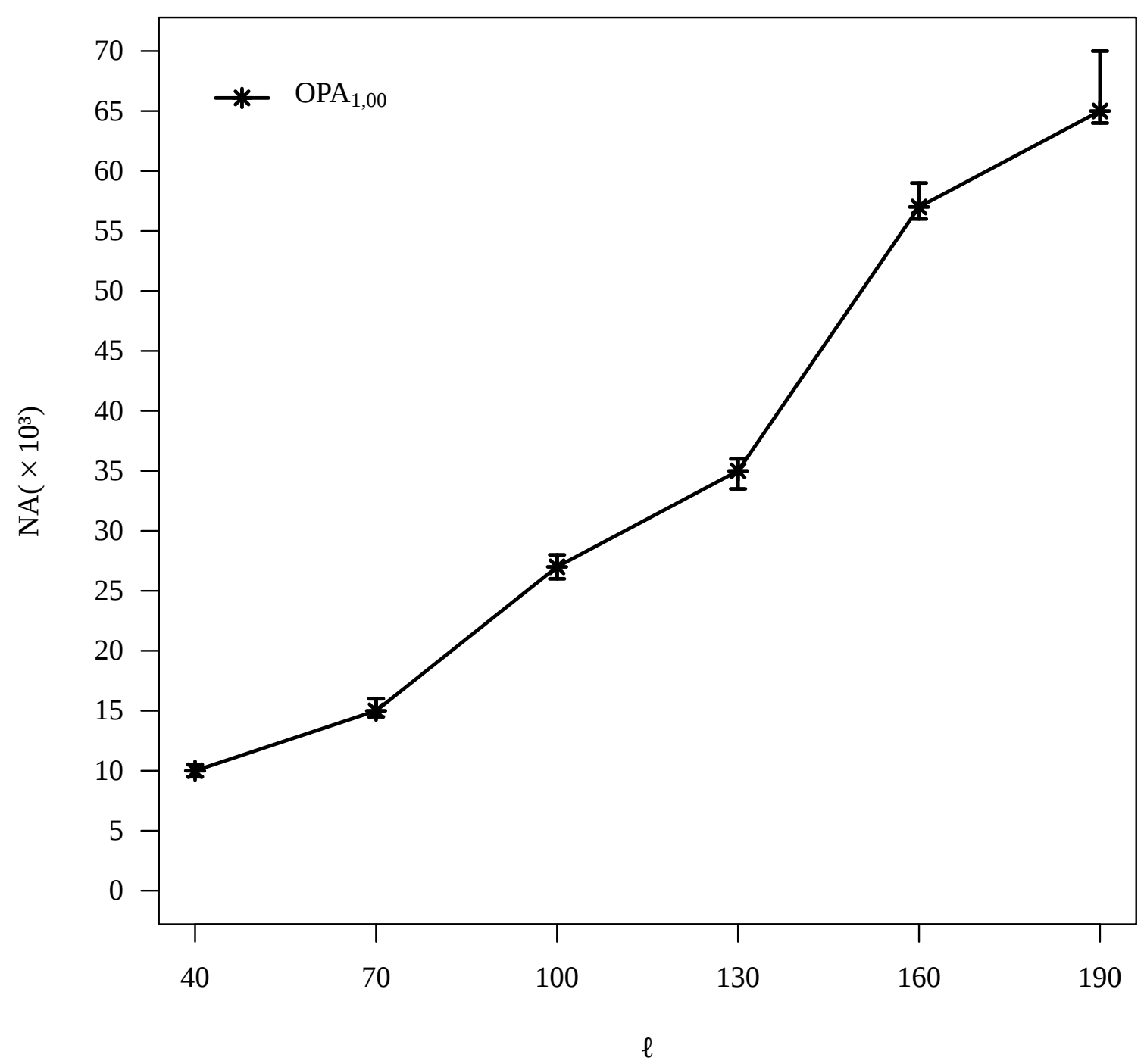

Figura 8.17: $\mathrm{NA}$ da $\mathrm{OPA}_{1,00}$ para um problema em que metade do cromossomo é composto por funções ftrap 5 com sobreposição de dois bits e a outra metade é composto por funções ftrap5. 


\section{Considerações sobre os Experimentos 1,2, 3 e 4}

No Experimento 1, a $\mathrm{OPA}_{1,00}$ conseguiu resultado melhor que o melhor algoritmo testado em problemas com sobreposição de variáveis, o CD-BOA. Nos Experimentos 2 e 3, a $\mathrm{OPA}_{1,00}$ obteve desempenho equiparável ou melhor que o do StrOp+REDA, melhor rival testado para os problemas sem correlação de variáveis (BBs de tamanho um): OneMax (Experimento 2) e BinInt (Experimento 3). O Experimento 4 mostra que a OPA consegue resolver também problemas que combinam aspectos considerados desafiadores e problemas de benchmark de EDAs, em que todos os BBs possuem alguma sobreposição.

Dessa forma, a OPA mostrou que é possível construir um algoritmo que obtém desempenho similar aos melhores desempenhos encontrados para problemas com dificuldades significativamente diferentes. Esse fato deve-se à capacidade da OPA de identificar os tipos de correlação das variáveis de um problema e explorar adequadamente essa informação por meio da CES (Seção 6.4).

\subsection{Avaliação com problemas multiobjetivos}

A proposição da moOPA busca alcançar um algoritmo multiobjetivo mais eficaz, capaz de resolver problemas relativamente complexos com significativa amostragem da Fronteira Paretoótima (Seção 6.6). Para validar a moOPA foram considerados dois problemas que são desafiadores para EDAs multiobjetivos: ( $i$ ) um problema com dois objetivos com esquemas (instâncias ótimas de BBs) conflitantes, em que o ótimo de um problema consiste unicamente de zeros e o outro, unicamente de uns; (ii) um problema em que, além de esquemas conflitantes, o particionamento das variáveis do problema conflitam segundo cada objetivo, nesse caso, um dos problemas tem partições de tamanho 3 e o outro de tamanho 4.

\section{Experimento 1}

\section{Esquemas Conflitantes}

A Figura 8.18 mostra o mapeamento de todas as soluções do espaço de busca no espaço de objetivos (pontos), além das soluções do conjunto Pareto-ótimo, destacados por um círculo em volta dos pontos, para o problema com $\ell=30$ composto por ftrap5 e inv-ftrap5 (Figura 8.19). A Figura 8.20 apresenta um comparativo em termos de NA da moOPA (Seção 6.6) com outros algoritmos, avaliando esse mesmo problema com diferentes valores de $\ell$. Conforme realizado em (Martins et al., 2011), o gráfico com os resultados de Pelikan et al. (2005) para vários MOEAs (Seção 2.11), dentre eles o mohBOA (um dos algoritmos evolutivos mais relevantes da literatura para problemas multiobjetivos), foi editado para inclusão dos resultados da moOPA. A Figura 8.21 mostra o TE para o problema. Não há comparação em TE com os algoritmos apresentados na 
Figura 8.20 por indisponibilidade dos respectivos códigos para teste. Os experimentos evidenciam a eficácia do algoritmo, pois foi capaz de encontrar todo o conjunto Pareto-ótimo (determinado por uma busca exaustiva).

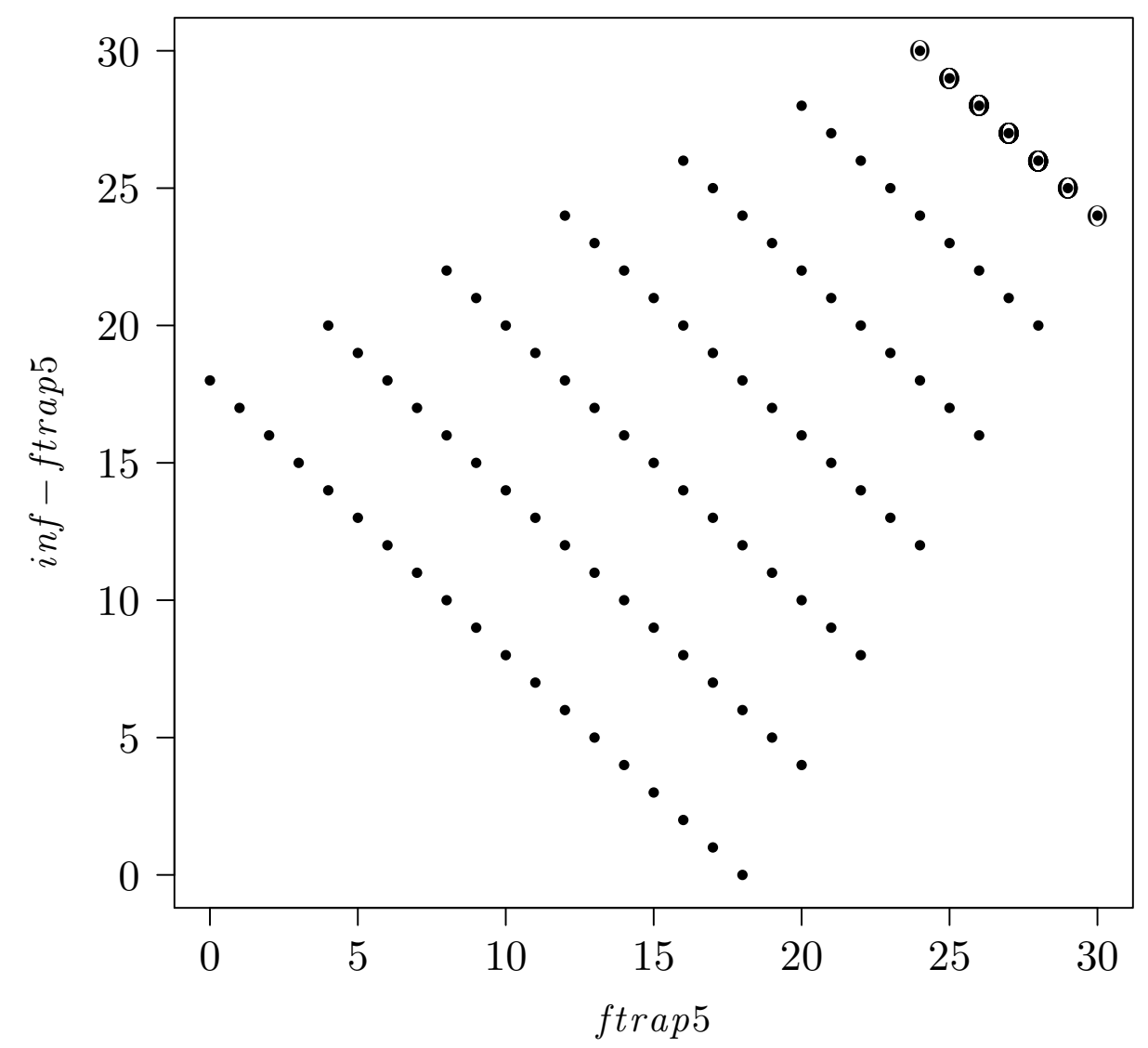

Figura 8.18: Mapeamento de todas as soluções no espaço de objetivos e conjunto Pareto-ótimo (pontos circulados) para o problema multiobjetivo ftrap5 vs inv-ftrap5 de tamanhos $\ell=30$. 


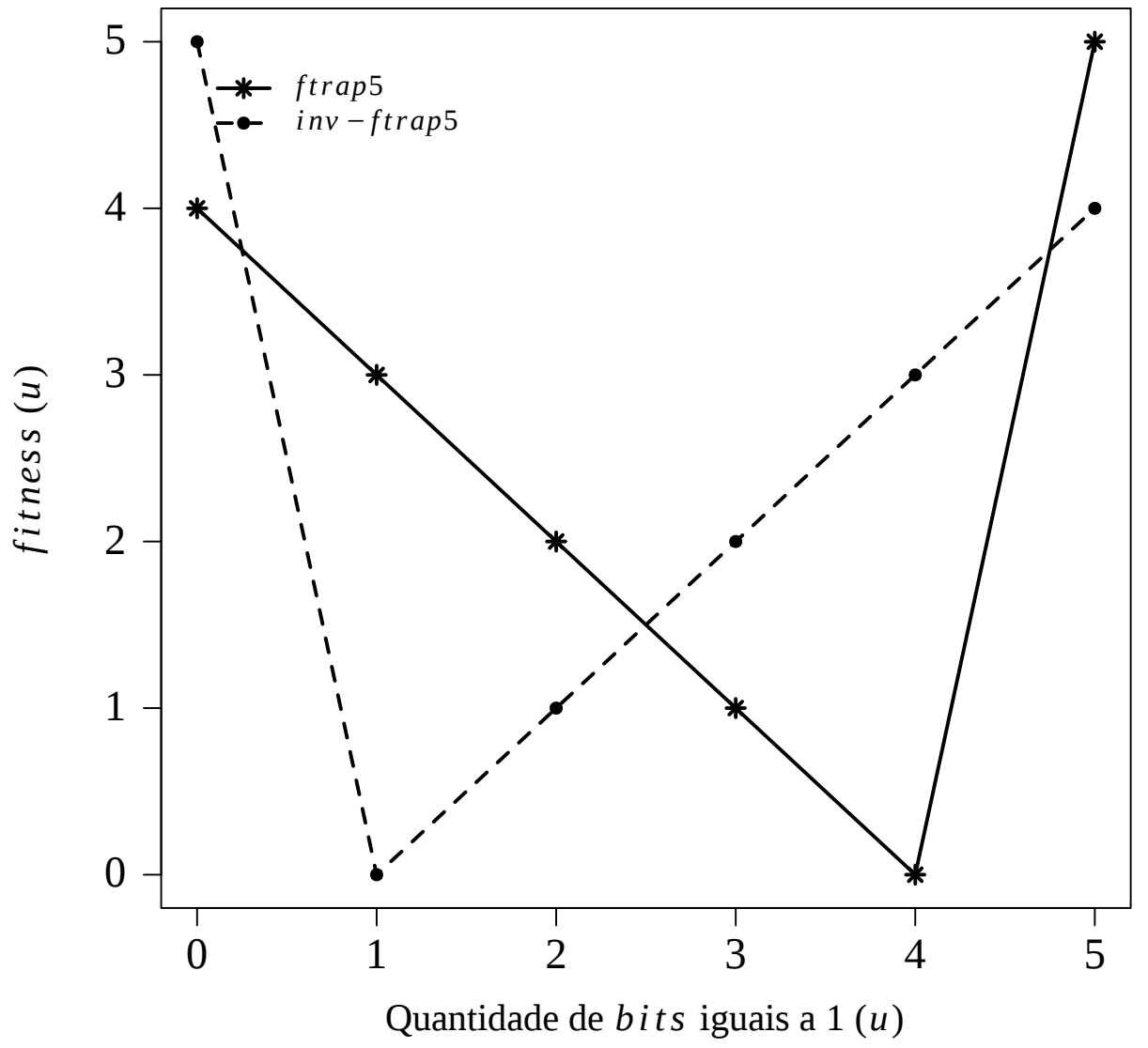

Figura 8.19: Relação do problema multiobjetivo ftrap5 vs inv-ftrap5. 


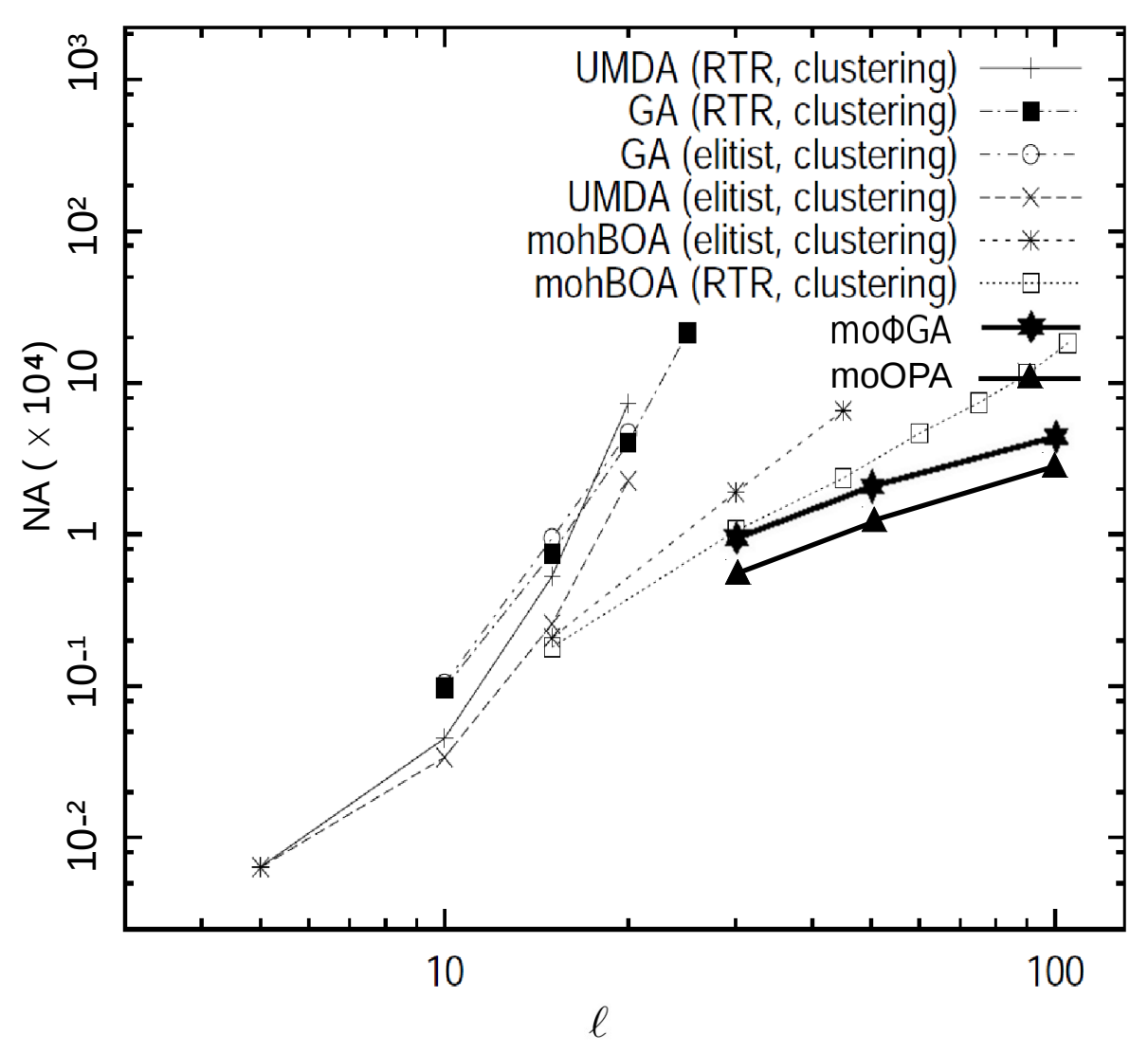

Figura 8.20: Comparação do desempenho da moOPA com os principais MOEAs da literatura. 


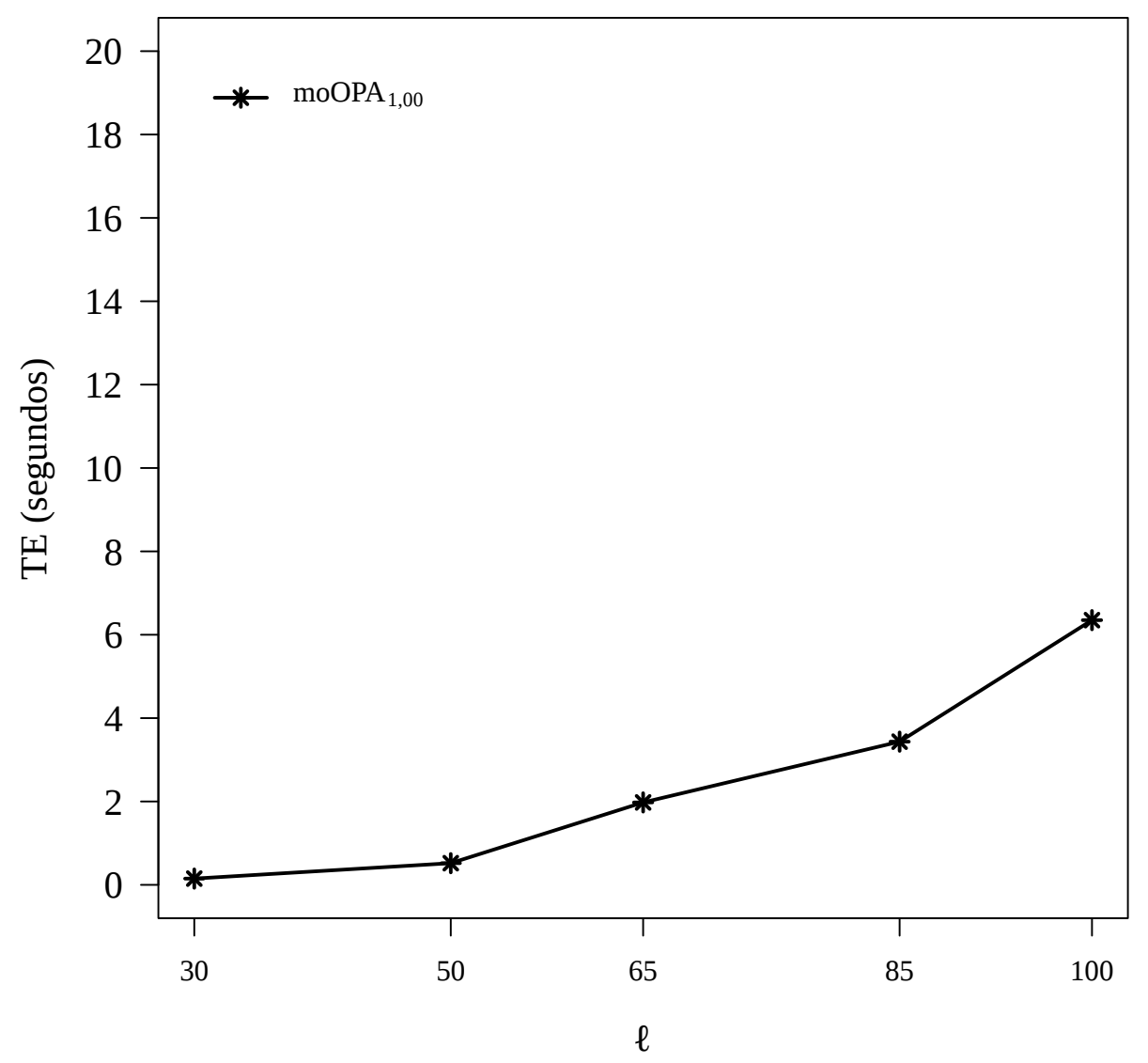

Figura 8.21: TE do problema multiobjetivo ftrap5 vs inv-ftrap5 obtido para a moOPA. 


\section{Experimento 2}

\section{Esquemas Conflitantes e Particionamento Conflitantes}

Um novo problema multiobjetivo foi criado para o experimento envolvendo tanto esquemas quanto particionamento conflitantes, visto que nenhum benchmark foi encontrado na literatura para esse caso. O problema proposto consiste de uma função ftrap4, em que o ótimo contem somente uns, além de uma função inv-ftrap3 cujo ótimo consiste unicamente de zeros. Dessa forma, o problema é composto por duas funções que conflitam tanto em termos de particionamento ideal de cada uma, quanto em termos de valores dos bits ótimos. A Figura 8.22 destaca alguns desses aspectos entre as duas funções. A Figura 8.23 mostra o mapeamento do espaço de soluções no espaço dos objetivos e o conjunto Pareto-ótimo (pontos circulados) para o problema de tamanho $\ell=12$. Novamente, a moOPA encontrou todas as soluções do conjunto Pareto-ótimo. O NA e o TE correspondentes da moOPA são mostrados nas Figuras 8.24 e 8.25, respectivamente.

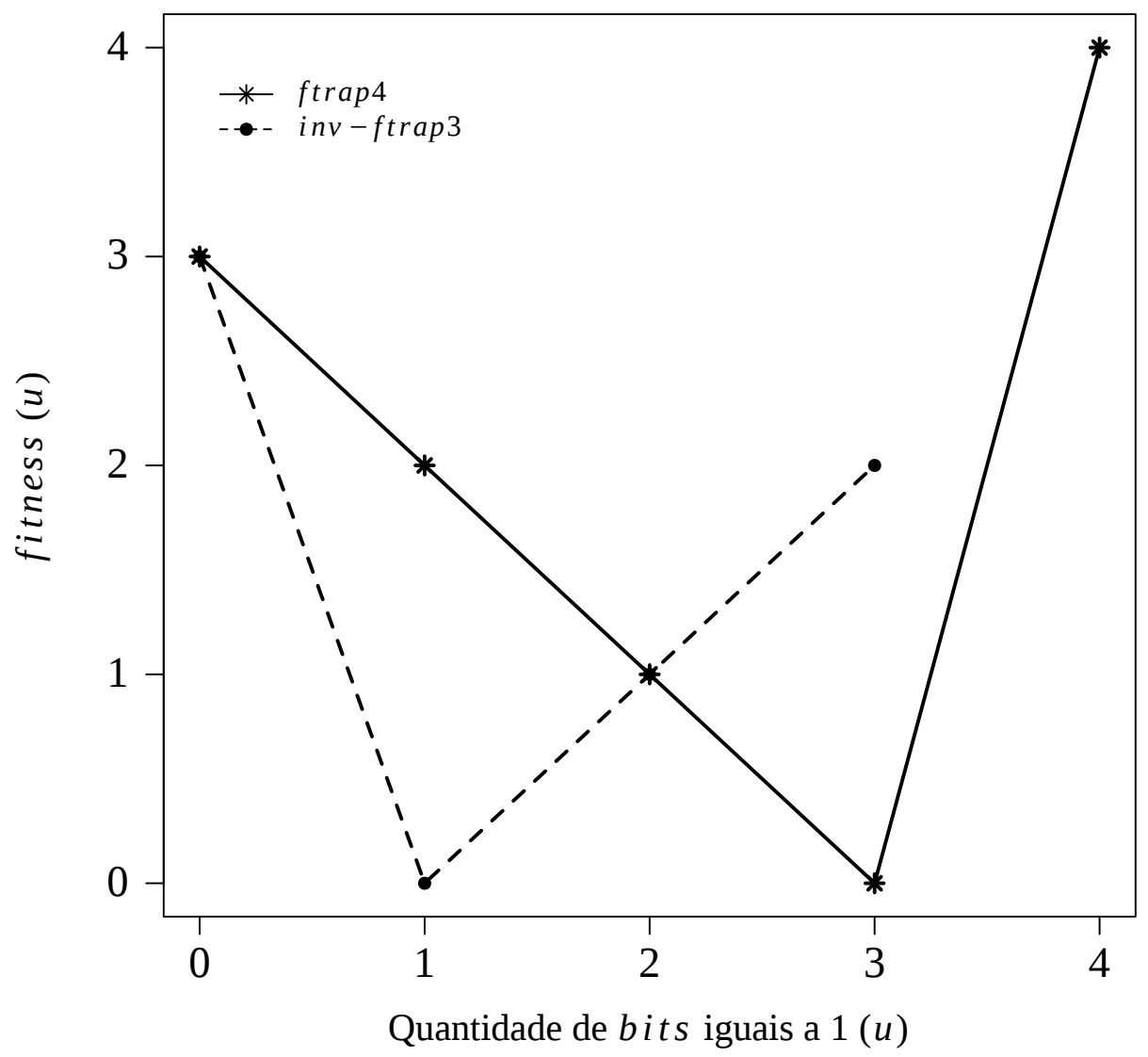

Figura 8.22: Comparativo de ótimos locais e globais da ftrap4 e inv-ftrap3. 


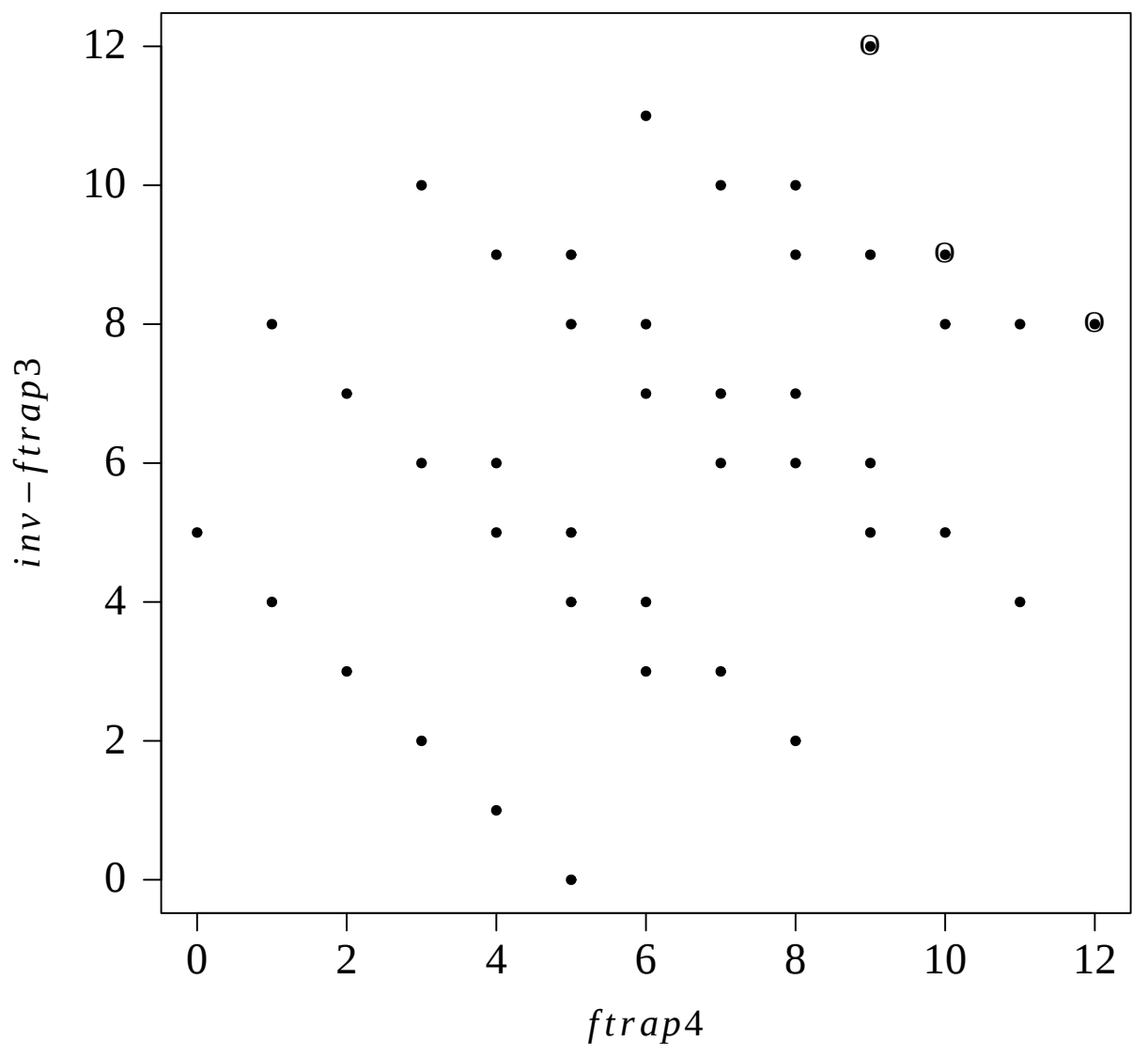

Figura 8.23: Mapeamento de todas as soluções no espaço de objetivos e conjunto Pareto-ótimo (pontos circulados) de tamanho $\ell=12$. 


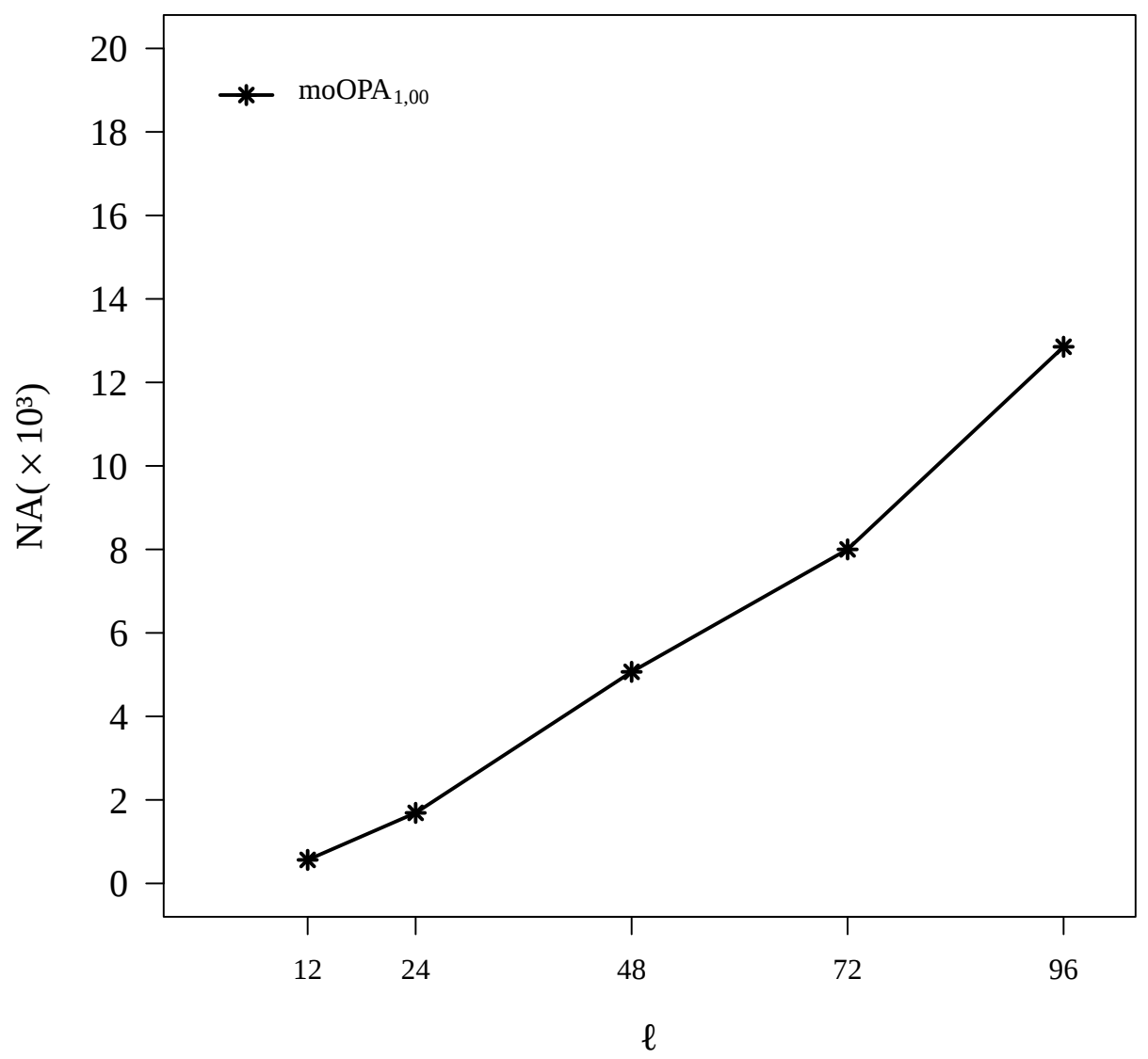

Figura 8.24: NA da moOPA para o problema multiobjetivo ftrap4 vs inv-ftrap3. 


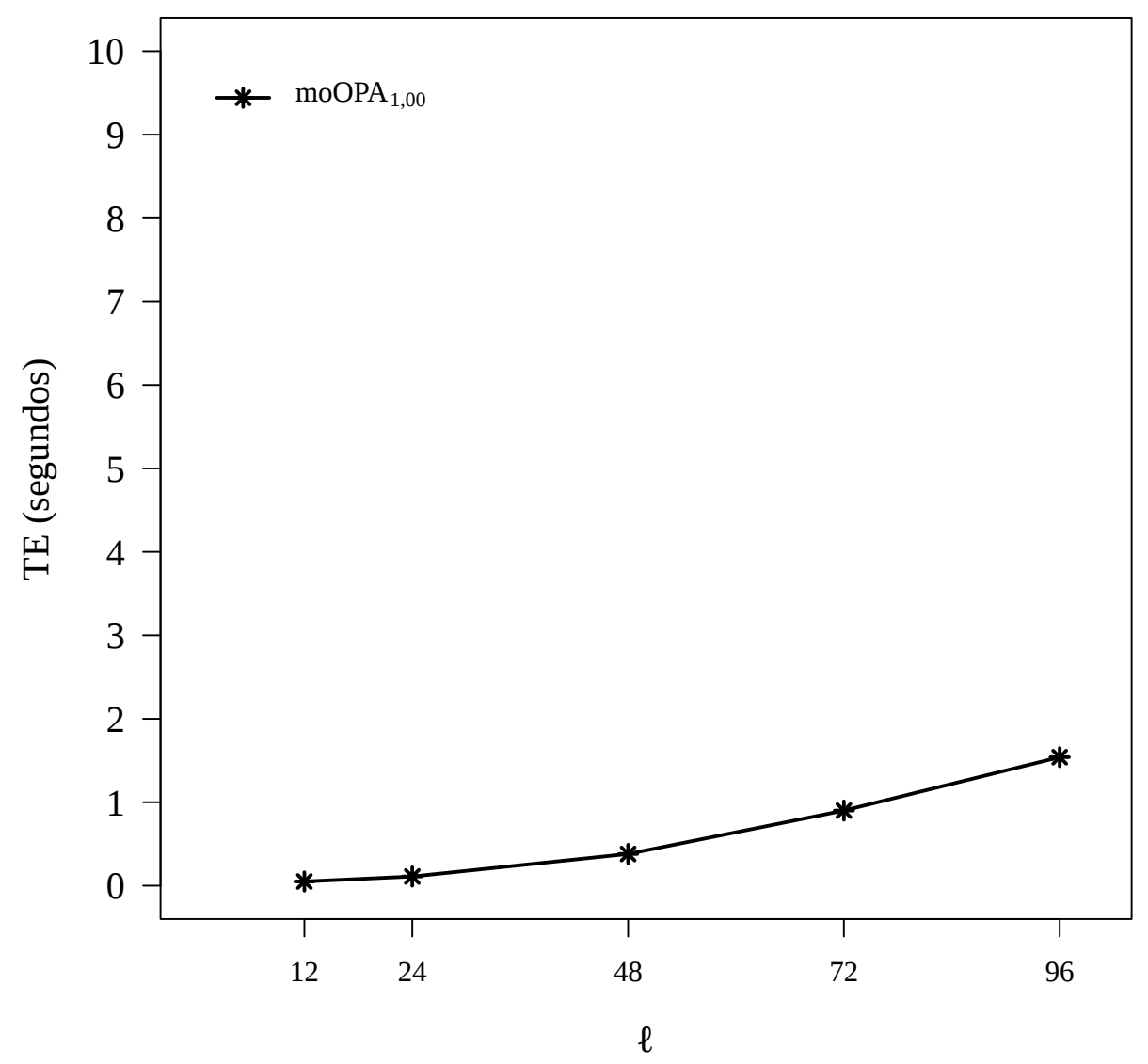

Figura 8.25: TE da moOPA para o problema multiobjetivo ftrap4 vs inv-ftrap3. 


\subsection{Considerações finais}

Os resultados apresentados neste Capítulo demonstram o potencial da OPA para resolver ASDP e diferentes tipos de problemas com sobreposição de BBs (com todos os BBs sobrepostos ou parte deles), além de problemas envolvendo aspectos que, em geral, induzem EAs a convergir à deriva. Os resultados da Seção 8.2 indicam que a OPA pode obter resultados, para problemas significativamente diferentes, equiparáveis aos de EDAs de certa forma especializados em cada tipo de problema. Além disso, verifica-se que, por adequar combinações de $\Phi$ e da quantidade de reamostragens, que a OPA pode atingir compromissos interessantes entre o NA e TE.

Os Experimentos da Seção 8.3 mostram que a nova busca em partições proposta neste trabalho, a CES (Seção 6.4), pode resolver problemas com sobreposição de diferentes tipos utilizando NA relativamente baixos. Por fim, a Seção 8.4 mostra que a OPA pode encontrar soluções do conjunto Pareto-ótimo de problemas multiobjetivos envolvendo particionamento e esquemas conflitantes, além de apresentar ganhos em termos de NA. 



\section{CAPÍTULO \\ 9 \\ Conclusões e Trabalhos Futuros}

Os EDAs usam um modelo probabilístico dos valores das variáveis de um conjunto de indivíduos selecionados para a geração de novos indivíduos. A qualidade do modelo depende do quão bem esses indivíduos amostraram regiões promissoras do espaço de busca. Em outras palavras, o Número de Avaliações (NA) em geral aumenta com a multimodalidade e a dimensão do problema. A construção de modelos mais representativos pode requerer métodos com custo computacional relativamente alto, como o algoritmo K2 usado para Redes Bayesianas no BOA. Isso resulta em aumento do Tempo de Execução (TE) do EDA. Neste trabalho, foi proposta a construção de modelos que proporcionam um compromisso em termos de NA e TE. O CPA possibilita obter modelos que representam adequadamente os BBs de um problema com um custo computacional que pode ser controlado pelo parâmetro $\Phi$ (Seção 6.1) e a quantidade de reamostragens da População Inicial (Seção 8.2).

Os avanços atingidos ao longo desta pesquisa geraram várias extensões do CPA, organizados nos Apêndices A, B, C e D. Essencialmente esses resultados mostram que o CPA pode ser utilizado para encontrar correlações em diferentes campos das Engenharias e Ciências. Para isso, é preciso ou utilizar uma métrica adequada ao contexto da aplicação, no lugar da MI (como por exemplo a F84 para sequências de nucleotídeos, ver Apêndice F) ou utilizar uma métrica universal como a NCD (Apêndice F).

Além do potencial do CPA em si, o modelo gerado por esse método pode ser utilizado em EDAs para os diversos contextos em que o CPA tem obtido sucesso. Neste trabalho, o CPA foi estendido para ser aplicado a problemas combinatórios de benchmark de EDAs que possuem diferentes níveis de dificuldade, gerando a OPA. Com isso, buscou-se avaliar os aspectos da OPA que produzem 
benefícios na resolução desses problemas, utilizando para isso acomparação com o desempenho de EDAs que têm sido avaliados na literatura para os mesmos problemas de benchmark.

Em geral os EDAs têm seu melhor desempenho para problemas específicos, como o hBOA para problemas hierárquicos, CD-BOA para problemas com sobreposição e o StrOp para ASDPs. A OPA conseguiu resolver um conjunto maior de problemas (ASDPs, não deceptivos e com sobreposição) com resultados similares aos melhores EDAs da literatura em cada problema. A seguir são enumeradas as principais contribuições da OPA e da moOPA baseados nos experimentos realizados:

1. A reamostragem da População de Selecionados utilizada pela OPA resulta em maior eficácia na identificação do particionamento do problema;

2. A geração de vários particionamentos, por meio da permutação de linhas e colunas da Matriz Distância e da Matriz de Adjacências (com todos os nós da filogenia) mostra a importância de procedimentos de reamostragem para EDAs;

3. Com o parâmetro $\Phi$, é possível reduzir o tamanho da População de Selecionados sem redução da eficiência do algoritmo;

4. O mesmo parâmetro pode ser ajustado de forma que a OPA consiga eficiência relativamente alta tanto em termos de NA quanto de TE. A OPA ${ }_{0,13}$, por exemplo, apresentou desempenho similar ao do algoritmo que obteve o melhor TE e também ao do algoritmo que atingiu o melhor NA nos experimentos realizados;

5. A estrutura de paralelização das reamostragens envolvidas no CPA mostra-se escalável, possibilitando resolver problemas combinatórios complexos com certo compromisso em termos de tempo computacional;

6. Para problemas multiobjetivos, a moOPA conseguiu resolver problemas em que as instâncias ótimas de um BB em objetivos diferentes eram conflitantes. Além disso, o algoritmo resolveu um novo problema em que, não somente as instâncias dos BBs são conflitantes, mas também as partições nos particionamentos encontrados para cada objetivo são de tamanhos diferentes;

7. A moOPA também apresenta NA inferior aos demais EDAs comparados (Figura 8.20);

8. O fato de a OPA ter sido capaz de resolver ASDP, problemas não deceptivos e problemas com sobreposição de BBs com eficiência computacional comparável aos melhores resultados encontrados por diferentes algoritmos para cada um desses problemas evidencia que é possível um mesmo EDA resolver eficientemente uma quantidade maior de tipos de problemas, desde que: $i$ ) melhores modelos possam ser obtidos com um compromisso em termos de custo computacional e $i$ i) as partições obtidas sejam melhor exploradas, de acordo com suas instâncias ótimas globais e ótimas locais. 
Os resultados apresentados nos Apêndices A, B, C e D são preliminares, mas ilustrativos da contribuição que o CPA e a OPA podem produzir em diferentes áreas das Ciências e Engenharias. Esses Apêndices buscam mostrar também como os aspectos modelados nos problemas de benchmark de EDAs utilizados no Capítulo 8 são representativos dos principais fatores que caracterizam vários problemas do mundo real.

Com isso, foi atingido o objetivo de desenvolver um EDA eficiente (em termos de NA e TE) e eficaz (capaz de resolver problemas de complexidade significativamente diferente). Esse resultado mostra um horizonte promissor de pesquisa na área. Dessa forma, como continuação do trabalho desenvolvido, é proposto:

1. O desenvolvimento de uma biblioteca de EDAs baseados no CPA, unindo todas as extensões já desenvolvidas (Apêndices A, B, C e D). Isso deve possibilitar soluções melhores para uma maior diversidade de domínio de problemas de otimização envolvendo espaços reais, inteiros e mistos, além dos correspondentes problemas com múltiplos objetivos;

2. Realização de novos trabalhos em controle e navegação de robôs com o uso do CPA e de uma diversidade de tipos de dados que se pode tratar e organizar (com base em BBs e suas melhores instâncias). Por exemplo, pode-se investigar o CPA com diferentes tipos de dados (streams de laser, imagens, sonares, etc), comuns em robótica. Com isso, espera-se facilitar o desenvolvimento de soluções inovadoras nessa área;

3. Extensão dos experimentos realizados com a técnica inovadora CES em um conjunto maior de problemas combinatórios;

4. Investigação da OPA em problemas combinatórios maiores, com milhares de variáveis de forma a melhor verificar a escalabilidade dessa técnica. 



\section{Referências Bibliográficas}

Aghagolzadeh, M.; Soltanian-Zadeh, H.; Arani, B.; Aghagolzadeh, A. A hierarchical clustering based on mutual information maximization. In: IEEE International Conference on Image Processing, 2007. ICIP 2007, 2007.

Alba, E.; Blum, C.; Roli, A. Parallel metaheuristics: A new class of algorithms. Hoboken, New Jersey, USA: Wiley-Interscience, 3-42 p., 2005.

Almeder, C. A hybrid optimization approach for multi-level capacitated lot-sizing problems. European Journal of Operational Research, v. 200, p. 599-606, 2010.

Aporntewan, C.; Ballard, D.; Lee, J.; Lee, J.; Wu, Z.; ZhaO, H. Gene hunting of the genetic analysis workshop 16 rheumatoid arthritis data using rough set theory. In: $B M C$ proceedings, BioMed Central Ltd, 2009, p. S126.

AxElsson, S. The normalised compression distance as a file fragment classifier. Digital Investigation, v. 7, Supplement, n. 0, p. S24 - S31, <ce:title >The Proceedings of the Tenth Annual \{DFRWS $\}$ Conference $</$ ce:title $>, 2010$.

Disponível em http://www.sciencedirect.com/science/article/pii/ S1742287610000319

Boettcher, S.; Percus, A. G. Optimization with extremal dynamics. Complex., v. 8, n. 2, p. 57-62, 2002.

Bolthausen, E.; Bovier, A. Spin glasses, v. 1900 de Lecture Notes in Mathematics. New York: Springer, 368 p., 2007.

Cancino, W.; Delbem, A. Inferring phylogenies by multi-objective evolutionary algorithms. international journal of information technology and intelligent computing, v. 2, p. 1-26, 2007. 
CANCINO, W. G. T. Algoritmos evolutivos multi-objetivo para a reconstrução de árvores filogenéticas. Tese de Doutoramento, Universidade de São Paulo (USP) - Instituto de Ciências Matemáticas e de Computação (ICMC), 2008.

Cerra, D.; Datcu, M. A fast compression-based similarity measure with applications to content-based image retrieval. Journal of Visual Communication and Image Representation, v. 23 , n. 2 , p. $293-302,2012$.

Disponível em http://www.sciencedirect.com/science/article/pii/ S1047320311001441

Chol, S.-S.; JUnG, K.; KIM, J. H. Phase transition in a random nk landscape model. Artificial Intelligence, v. 172, n. 23, p. 179 - 203, 2008.

Disponível em http://www.sciencedirect.com/science/article/pii/ S0004370207001099

Cilibrasi, R.; Vitányi, P. M. B. Clustering by compression. IEEE Transactions on Information Theory, v. 51, p. 1523-1545, 2005.

CoOper, G. F.; Herskovits, E. A bayesian method for the induction of probabilistic networks from data. Machine Learning, v. 9, p. 309-347, 1992.

Cormen, T. H.; Stein, C.; Rivest, R. L.; Leiserson, C. E. Introduction to algorithms. 2nd ed. McGraw-Hill Higher Education, 2001.

Crocomo, M. K. Cd-boa, strop e strop+reda code in C++. 2011.

Disponível em http://lcrserver.icmc.usp.br/projects/cd-boa/wiki (Acessado em 10 set. 2012)

Crocomo, M. K. Algoritmo de otimização bayesiano com detecção de comunidades. Tese de Doutoramento, Universidade de São Paulo (USP) - Instituto de Ciências Matemáticas e de Computação (ICMC), 2012.

Disponível em http://www.teses.usp.br/teses/disponiveis/55/55134/ tde-23012013-160605/

Crocomo, M. K.; Martins, J. P.; Delbem, A. C. B. Decomposition of Black-box Optimization Problems by Community Detection in Bayesian Networks. International Journal of Nature Computing Research (IJNCR), v. 3, n. 4, p. 1-19, 2013.

DARWIN, C. On the origin of species by means of natural selection, or the preservation offavored races in the struggle for life. (first edition). London: John Murray, 1859.

DARWIN, C. The origin of species. Signet Classic, 2003.

DEB, K. Multi-objective genetic algorithms: Problem difficulties and construction of test problems. Evolutionary Computation, v. 7, p. 205-230, 1999. 
DEB, K. Multi-objective optimization using evolutionary algorithms. 2001.

Deb, K.; Pratap, A.; Agarwal, S.; Meyarivan, T. A fast and elitist multi-objective genetic algorithm: Nsga-ii. 2000.

DEJONG, K. Evolutionary computation: a unified approach. In: Proceedings of the 2008 GECCO conference companion on Genetic and evolutionary computation, ACM, 2008, p. 2245-2258.

Delbem, A. C. B.; Melo, V. V.; VArgas, D. V. Algoritmo filo-genético. In: $2^{a}$ Escola Luso-Brasileira de Computação Evolutiva (ELBCE), APDIO, 2010.

Diestel, R. Graph theory. Electronic library of mathematics. Springer, 2006.

Disponível em http://books.google.com.br/books? id=aR2TMYQr2CMC

Dionísio, A.; Menezes, R.; Mendes, D. Entropy-based independence test. Nonlinear Dynamics, v. 44, n. 1, p. 351-357, 2006.

Donetti, L.; Muñoz, M. A. Detecting network communities: a new systematic and efficient algorithm. Journal of Statistical Mechanics: Theory and Experiment, v. 2004, n. 10, p. P10012, 2004.

DuCH, J.; Arenas, A. Community detection in complex networks using extremal optimization. Physical Review E, v. 72, n. 2, p. 027104+, 2005.

DuQue, T. S. P. C.; Goldberg, D. E. Clustermi: Building probabilistic models using hierarchical clustering and mutual information. In: Hiot, L. M.; ONG, Y. S.; CHEN, Y.-P., eds. Exploitation of Linkage Learning in Evolutionary Algorithms, v. 3 de Adaptation, Learning, and Optimization, Springer Berlin Heidelberg, p. 123-137, 2010.

EPPStEIn, D. Fast hierarchical clustering and other applications of dynamic closest pairs. 1998.

Felsenstein, J. Evolutionary trees from dna sequences: a maximum likelihood approach. Journal of molecular evolution, v. 17, n. 6, p. 368-376, 1981.

Felsenstein, J. Phylip (phylogeny inference package). 2000.

Disponível em http: / / evolution.genetics.washington.edu/phylip.html

Felsenstein, J. Inferring phylogenies. 2 ed. Sinauer Associates, 2003.

Disponível em http://www.amazon.ca/exec/obidos/redirect?tag= citeulike09-20\&amp; path=ASIN/0878931775

Fitch, W. M. A non-sequential method for constructing trees and hierarchical classifications. Journal of Molecular Evolution, v. 18, p. 30-37, 10.1007/BF01733209, 1981.

Disponível em http://dx.doi.org/10.1007/BF01733209 
Fitch, W. M.; Margoliash, E. Construction of Phylogenetic Trees. Science, v. 155, p. 279284, 1967.

Fourment, M.; GiBbs, M. Patristic: a program for calculating patristic distances and graphically comparing the components of genetic change. BMC Evolutionary Biology, v. 6, n. 1, 2006.

Disponível em http://dx.doi.org/10.1186/1471-2148-6-1

GAlinier, P.; HAO, J.-K. Hybrid evolutionary algorithms for graph coloring. Journal of Combinatorial Optimization, v. 3, p. 379-397, 10.1023/A:1009823419804, 1999.

Disponível em http://dx.doi.org/10.1023/A:1009823419804 (Acessado em 10 set. 2012)

Garey, M. R.; Johnson, D. S. Computers and intractability: A guide to the theory of npcompleteness. W. H. Freeman, 338 p., 1979.

GASCUEL, O. Mathematics of evolution and phylogeny. New York, NY, USA: Oxford University Press, Inc., 2007.

Disponível em http://portal.acm.org/citation.cfm?id=1557209

GASPAR-CUnHA, A. Rpsgae-reduced pareto set genetic algorithm: Application to polymer extrusion. In: Metaheuristics for Multiobjective Optimisation, Springer, 2004, p. 221-249.

Gaspar-Cunha, A.; TAKahashi, R.; Antunes, C. Manual de computação evolutiva e metaheurística. Coimbra: Imprensa da Universidade de Coimbra, 2012.

Glover, F. W.; Kochenberger, G. A. Handbook of metaheuristics (international series in operations research \& management science). Springer, 2003.

Disponível em http://www.amazon.com/exec/obidos/redirect?tag= citeulike07-20\&path=ASIN/1402072635

Goldbarg, M.; LunA, H. Otimização combinatória e programação linear: modelos e algoritmos. Campus, 2000.

Disponível em http://books.google.com.br/books?id=kctuAQAACAAJ

GOLDBERG, D. E. The design of innovation: Lessons from and for competent genetic algorithms. Norwell, MA, USA: Kluwer Academic Publishers, 2002.

GronaU, I.; Moran, S. Optimal implementations of upgma and other common clustering algorithms. Relatório Técnico, 2007.

Guindon, S.; Gascuel, O. Phyml phylogenetic maximum-likelihood. 2003.

Disponível em http://atgc.lirmm.fr/phyml/ 
Hall, P.; Park, B. U.; SAmworth, R. J. Choice of neighbor order in nearest-neighbor classification. The Annals of Statistics, v. 36, n. 5, p. 2135-2152, 2008.

Disponível em http://dx.doi.org/10.1214/07-AOS537

Hamming, R. W. Error detecting and error correcting codes. Bell System Technical Journal, v. 29, n. 2, p. 147-160, 1950.

Disponível em http://dx.doi.org/10.1002/j.1538-7305.1950.tb00463.x

HARIK, G. Finding multiple solutions in problems of bounded difficulty. Relatório Técnico, 1994.

HARIK, G.; LOBO, F.; SASTRY, K. Linkage learning via probabilistic modeling in the extended compact genetic algorithm (ecga). Scalable Optimization via Probabilistic Modeling, p. 39-61, 2006.

Harik, G. R.; Lobo, F. G.; GoldberG, D. E. The compact genetic algorithm. IEEE Trans. Evolutionary Computation, v. 3, n. 4, p. 287-297, 1999.

He, J.; ReEves, C.; WitT, C.; YaO, X. A note on problem difficulty measures in black-box optimization: Classification, realizations and predictability. Evol. Comput., v. 15, n. 4, p. 435443, 2007.

Disponível em http://dx.doi.org/10.1162/evco.2007.15.4.435

Helber, S.; SAhling, F. A fix-and-optimize approach for the multi-level capacitated lot sizing problem. International Journal of Production Economics, v. 123, p. 247-256, 2010.

HIGGINS, D.; SHARP, P. Clustal - a package for performing multiple sequence alignment on a microcomputer. Gene, v. 73, n. 1, p. 237-244, 1988.

Huelsenbeck, J.; RonQuist, F.; Nielsen, R.; Bollback, J. Bayesian inference of phylogeny and its impact on evolutionary biology. Science, v. 294, n. 5550, p. 2310, 2001.

Huelsenbeck, J. P.; Ronquist, F. Mrbayes: Bayesian inference of phylogenetic trees. Bioinformatics, v. 17, n. 8, p. 754-755, 2001.

Disponível em http://bioinformatics.oxfordjournals.org/content/17/ $8 / 754$. abstract

Ito, K.; Zeugmann, T.; ZHU, Y. Clustering the Normalized Compression Distance for Influenza Virus Data. Algorithms and Applications, p. 130-146, 2010.

Javadi, A. A.; FARmani, R.; TAn, T. P. A hybrid intelligent genetic algorithm. Adv. Eng. Inform., v. 19, n. 4, p. 255-262, 2005.

Disponível em http://dx.doi.org/10.1016/j.aei.2005.07.003 
Jukes, T.; Cantor, C. Evolution of protein molecules. In: Munro, H., ed. Mammalian Protein Metabolism, v. III, cap. 24, New York: Academic Press, p. 21-132, 1969.

KIMURA, M. A simple method for estimating evolutionary rates of base substitutions through comparative studies of nucleotide sequences. Journal of Molecular Evolution, v. 16, n. 2, p. 111-120, 1980.

KRASKOV, A. Synchronization and interdependence measures and their application to the electroencephalogram of epilepsy patients and clustering of data. Report Nr.: NIC series; 24, 2008.

Kraskov, A.; Stogbauer, H.; Andrzejak, R.; Grassberger, P. Hierarchical clustering based on mutual information. Arxiv preprint q-bio/0311039, 2003.

Larkin, M.; Blackshields, G.; Brown, N.; Chenna, R.; McGettigan, P.; McWilliam, H.; Valentin, F.; Wallace, I.; Wilm, A.; Lopez, R.; Thompson, J.; Gibson, T.; Higgins, D. Clustal w and clustal x version 2.0. Bioinformatics, v. 23, n. 21, p. 29472948, 2007.

Disponível em http://bioinformatics.oxfordjournals.org/content/23/ 21/2947. abstract

Larrañaga, P.; LozAno, J. A. Estimation of distribution algorithms: A new tool for evolutionary computation (genetic algorithms and evolutionary computation). Springer, 2001. Disponível em http://www.amazon.com/exec/obidos/redirect?tag= citeulike07-20\&path=ASIN/0792374665

Li, M.; Vitnyi, P. M. An introduction to kolmogorov complexity and its applications. 2 ed. Springer-Verlag New York, Inc., 1997.

Lillo-Castellano, J.; Mora-Jiménez, I.; SAntiago-Mozos, R.; Rojo-Álvarez, J.; Ramiro-Bargueño, J.; Algora-Weber, A. Weaning outcome prediction from heterogeneous time series using normalized compression distance and multidimensional scaling. Expert Systems with Applications, v. 40, n. 5, p. 1737 - 1747, 2013.

Disponível em http://www.sciencedirect.com/science/article/pii/ S0957417412010810

LIPSCHUTZ, S.; LiPson, M. Matemática discreta: Coleção schaum. BOOKMAN COMPANHIA ED, 2004.

Disponível em http://books.google.com.br/books?id=2S9bwDmD1P0C

LObO, F.; SAStry, K.; HARIK, G. Extended compact genetic algorithm in c++: Version 1.1. IlliGAL Report, v. 2006012, 2006.

Mahfoud, S. W. Niching methods for genetic algorithms. Relatório Técnico 1894, Department of Computer Science, University of Illinois, Urbana, 1995. 
Mansour, E. R. M. Método automático de determinação de clados utilizando algoritmo de detecção de comunidades. Dissertação de Mestrado, Bioengenharia, Universidade de São Paulo, 2013.

Disponível em http://www.teses.usp.br/teses/disponiveis/82/82131/ tde-24012014-105240/

Martins, J.; SoAres, A.; VArgas, D.; Delbem, A. Multi-objective phylogenetic algorithm: Solving multi-objective decomposable deceptive problems. In: TAKAHASHI, R.; DEB, K.; Wanner, E.; Greco, S., eds. Evolutionary Multi-Criterion Optimization, v. 6576 de Lecture Notes in Computer Science, Springer Berlin / Heidelberg, p. 285-297, 10.1007/978-3642-19893-9_20, 2011.

Disponível em http://dx.doi.org/10.1007/978-3-642-19893-9_20

Melo, V. V. Técnicas de aumento de eficiência para metaheurísticas aplicadas a otimização global contínua e discreta. Tese de Doutoramento, Instituto de Ciências Matemáticas e de Computação, Universidade de São Paulo, 2009.

Melo, V. V.; Vargas, D. V.; Crocomo, M. K.; Delbem, A. C. B. Phylogenetic differential evolution. International Journal of Natural Computing Research, v. 2, n. 1, p. 21-38, 2011.

Morrison, D. A. Phylogenetic tree-building. International Journal for Parasitology, v. 26, n. 6, p. $589-617,1996$.

Disponível em http://www.sciencedirect.com/science/article/ B6T7F-3WF 7DY2-2/2/2601d58d3c814088a3926971e167c030

MüHLEnbein, H. The equation for response to selection and its use for prediction. Evolutionary Computation, v. 5, n. 3, p. 303-346, 1997.

Newman, M. E. J.; Girvan, M. Finding and evaluating community structure in networks. Physical Review E, v. 69, n. 2, p. 026113, pT: J; PN: Part 2; PG: 15, 2004.

Page, R. D. M.; Holmes, E. C. Molecular evolution: A phylogenetic approach. Blackwell, 1998.

PElikAn, M. Bayesian optimization algorithm (BOA) code in C++. 1999a.

Disponível em http://illigal.org/1999/03/24/ bayesian-optimization-algorithm-boa-code-in-c/ (Acessado em 02 oct. 2012)

Pelikan, M. A simple implementation of bayesian optimization algorithm in c++(version1. 0). Illigal Report, v. 99011, p. 1-16, 1999 b. 
Pelikan, M.; Goldberg, D. E. Escaping hierarchical traps with competent genetic algorithms. In: Proceedings of the Genetic and Evolutionary Computation Conference (GECCO2001, Morgan Kaufmann, 2001, p. 511-518.

Pelikan, M.; Goldberg, D. E. Hierarchical boa solves ising spin glasses and maxsat. In: Proceedings of the 2003 international conference on Genetic and evolutionary computation: PartII, Berlin: Springer-Verlag, 2003, p. 1271-1282.

Disponível em <http://portal.acm.org/citation.cfm?id=1756582. $1756586>$ (Acessado em 09 fev. 2011)

Pelikan, M.; Goldberg, D. E.; Cantú-Paz, E. Boa: The bayesian optimization algorithm. In: BanzhaF, W.; Daida, J.; Eiben, A. E.; Garzon, M. H.; Honavar, V.; Jakiela, M.; SMith, R. E., eds. Proceedings of the Genetic and Evolutionary Computation Conference GECCO-99, Orlando, FL: Morgan Kaufmann Publishers, San Fransisco, CA, 1999, p. 525-532.

Pelikan, M.; Goldberg, D. E.; Lobo, F. G. A survey of optimization by building and using probabilistic models. Comput. Optim. Appl., v. 21, n. 1, p. 5-20, 2002.

PelikAn, M.; SASTRY, K.; CANTÚ-PAZ, E. Scalable optimization via probabilistic modeling: From algorithms to applications (studies in computational intelligence). Secaucus, NJ, USA: Springer-Verlag New York, Inc., 2006.

Pelikan, M.; SAstry, K.; GoldberG, D. E. Multiobjective hboa, clustering, and scalability. Relatório Técnico, In Proceedings of the Genetic and Evolutionary Computation Conference GECCO-2005, 2005.

Philippsen, G. S. Estudo da influência de elementos transponíveis nos genomas das algas c. reinhardtii e v. carteri. Tese de Doutoramento, Física - IFSC - USP, 2014.

Qu, B.-Y.; Suganthan, P. N. Novel multimodal problems and differential evolution with ensemble of restricted tournament selection. In: IEEE Congress on Evolutionary Computation, Los Alamitos: IEEE, 2010, p. 1-7.

RANA, S.; WhitLEY, D. Genetic algorithm behavior in the MAXSAT domain. Berlin: Springer, 1998, p. 785-794.

Rokas, A.; Williams, B.; King, N.; Carroll, S. Genome-scale approaches to resolving incongruence in molecular phylogenies. Nature, v. 425, n. 5, p. 798-804, 2003.

RonQuist, F.; Huelsenbeck, J. P. Mrbayes 3: Bayesian phylogenetic inference under mixed models. Bioinformatics, v. 19, n. 12, p. 1572-1574, 2003.

Disponível em http://bioinformatics.oxfordjournals.org/content/19/ 12/1572. abstract 
Rzhetsky, A.; NeI, M. Theoretical foundation of the minimum-evolution method of phylogenetic inference. Molecular Biology and Evolution, v. 10, p. 1073-1095, 1993.

SAdROZINSKI, H. F.-W. H. F.-W.; WU, J. Applications of field-programmable gate arrays in scientific research. Boca Raton, Fla. : CRC Press, includes bibliographical references and index, 2011.

Disponível em http://trove.nla.gov.au/work/38511482

SAITOU, N.; NeI, M. The neighbor-joining method: a new method for reconstructing phylogenetic trees. Mol Biol Evol, v. 4, n. 4, p. 406-425, 1987.

Disponível em http://mbe.oxfordjournals.org/content/4/4/406. abstract

Salemi, M.; VAndamme, A.-M. The phylogenetic handbook: A practical approach to dna and protein phylogeny, v. 16. Cambridge University Press, 354-355 p., 2003.

Disponível em http://doi.wiley.com/10.1002/ajhb.20017

Sanches, A.; Cardoso, J.; Delbem, A. Identifying merge-beneficial software kernels for hardware implementation. In: Reconfigurable Computing and FPGAs (ReConFig), 2011 International Conference on, 2011, p. 74-79.

SASTRY, K. Evaluation-relaxation schemes for genetic and evolutionary algorithms. Master's thesis, University of Illinois at Urbana-Champaign, Department of General Engineering, Urbana, IL, 2001.

Sastry, K.; Pelikan, M.; Goldberg, D. E. Limits of scalability of multiobjective estimation of distribution algorithms. In: Proceedings of the Congress on Evolutionary Computation, 2005, p. 2217-2224.

Silva, B. D. A.; Cuminato, L. A.; Delbem, A. C. B. An application-oriented cache memory configuration for energy efficiency in multi-cores. Accept by IET Computers \& Digital Techniques, v. 0, p. 0, 2014.

Simpson, N.; EREnguC, S. Multi-item lot-sizing problems with backlogging: A library of test instances. http://personal.strath.ac.uk/kerem.akartunali/research/multi-lsb/, 2010.

SIPSER, M. Introdução à teoria da computação. São Paulo: Cengage Learning, 459 p., 2007.

SoARes, A. H. M. CPA and OPA code in C. 2014.

Disponível em http://lcrserver.icmc.usp.br/projects/netphyga/wiki (Acessado em 05 nov. 2014)

SoKAL, R.; Michener, C. A statistical method for evaluating systematic relationships. Multivariate Statistical Methods, Among-groups Covariation, p. 269, 1975. 
StADTLER, H. Multilevel lot sizing with setup times and multiple constrained resources: Internally rolling schedules with lot-sizing windows. Operations Research, v. 51, p. 487-502, 2003.

StAmATAKIS, A. Raxml: Randomized axelerated maximum likelihood. 2005.

Disponível em http: //www.phylo.org/news/RAxML

StUdier, J.; KePPLER, K. A note on the neighbor-joining algorithm of saitou and nei. Molecular Biology and Evolution, v. 5, n. 6, p. 729, 1988.

Swofford, D. L.; Olsen, G. J.; Waddell, P. J.; Hillis, D. M. Phylogenetic inference. Molecular Systematics, v. Sinauer, p. pp 407-514, 1996.

TAdmor, Z.; Klein, I. Engineering principles of plasticating extrusion. Polymer science and engineering series. Van Nostrand Reinhold Co., 1970.

Disponível em http://books.google.com.br/books?id=pth_PbbUezQC

TAlBI, E.-G. Metaheuristics : from design to implementation, v. 10 de The Sciences Po series in international relations and political economy. John Wiley \& Sons, 1-6 p., 2009.

Disponível em http: //www.worldcat.org/isbn/9780470278581

Toledo, C. F. M. Problema conjunto de dimensionamento de lotes e programação da produção. Tese de Doutoramento, UNICAMP: Programa de Pós-Graduação em Engenharia Elétrica, 2005.

Vargas, D. V.; Delbem, A. C. B. Algoritmo filogenético. Relatório Técnico, Universidade de São Paulo, 2009.

Vargas, D. V.; Delbem, A. C. B.; Melo, V. V. Algoritmo filo-genético. In: $2^{a}$ Escola Luso-Brasileira de Computação Evolutiva (ELBCE), APDIO, 2010a.

Vargas, D. V.; Delbem, A. C. B.; Melo, V. V. Uso de otimização contínua na resolução de problemas binários: um estudo com evolução diferencial e algoritmo filo-genético em problemas deceptivos aditivos. In: $2^{a}$ Escola Luso-Brasileira de Computação Evolutiva (ELBCE), APDIO, 2010b.

YANG, Z. Computational molecular evolution. Oxford University Press, USA, 2006.

Disponível em http: / / www . amazon. com/Computational-Molecular-Evolution-Oxforddp/0198567022/ref=pd_sim_b_title_5/002-8056378-2973632

YE, Z.; HU, S.; YU, J. Adaptive clustering algorithm for community detection in complex networks. Physical Review E (Statistical, Nonlinear, and Soft Matter Physics), v. 78, n. 4, p. $046115+, 2008$.

Disponível em http://dx.doi.org/10.1103/PhysRevE.78.046115 
Zhou, A.; Qu, B.-Y.; LI, H.; Zhao, S.-Z.; Suganthan, P. N.; Zhang, Q. Multiobjective evolutionary algorithms: A survey of the state of the art. Swarm and Evolutionary Computation, v. 1, n. 1, p. 32 - 49, 2011.

Disponível em http://www.sciencedirect.com/science/article/pii/ S2210650211000058

ZitzleR, E.; ThIELE, L. Multiobjective evolutionary algorithms: A comparative case study and the strength pareto approach. 1999. 

APÊNDICE

\section{$A$}

CPA em Dimensionamento de lotes

multi-nível

O problema de dimensionamento de lotes multinível com possibilidade de atraso em atender a demanda (backlogging), consiste em escalonar um processo de produção com várias etapas intermediárias e interdependentes (Toledo, 2005). Uma das abordagens mais promissoras para resolver esse problema usa a heurística Relaxa-e-Fixa (RF, do inglês Relax-and-Fix) (Stadtler, 2003) para construir uma solução inicial, esta é então melhorada através de aplicações da heurística Fixae-Otimiza (FO, do inglês Fix-and-Optimize (Helber \& Sahling, 2010). O CPA (Capítulo 6) é proposto para identificar subproblemas que são resolvidos pelas duas heurísticas anteriores.

A abordagem proposta, chamada CPA com FO (CPA-FO), utiliza três métodos da literatura baseados em heurísticas, cada uma responsável por obter um conjunto específico de informações. Figura A.1 mostra esquematicamente o que cada uma das heurística requer e o que produz. A execução sequencial das três heurísticas, conforme mostrado na Figura A.1 é chamada de ciclo do CPA-FO.

O primeira método é um GA (Seção 2.2). Seu objetivo principal é a obtenção de uma população com soluções promissoras através das gerações. A população gerada pelo GA é a base de informações para particionar as variáveis binárias em grupos correlacionados pelo CPA. Por fim, a heurística FO usa o particionamento fornecido pelo CPA para melhorar o indivíduo de maior fitness da população gerada pelo GA. A heurística é aplicada a cada partição buscando encontrar a melhor instância de cada partição. Enquanto uma partição é investigada pelo FO, as variáveis das demais partições permaneceram com seus valores atuais fixos. 


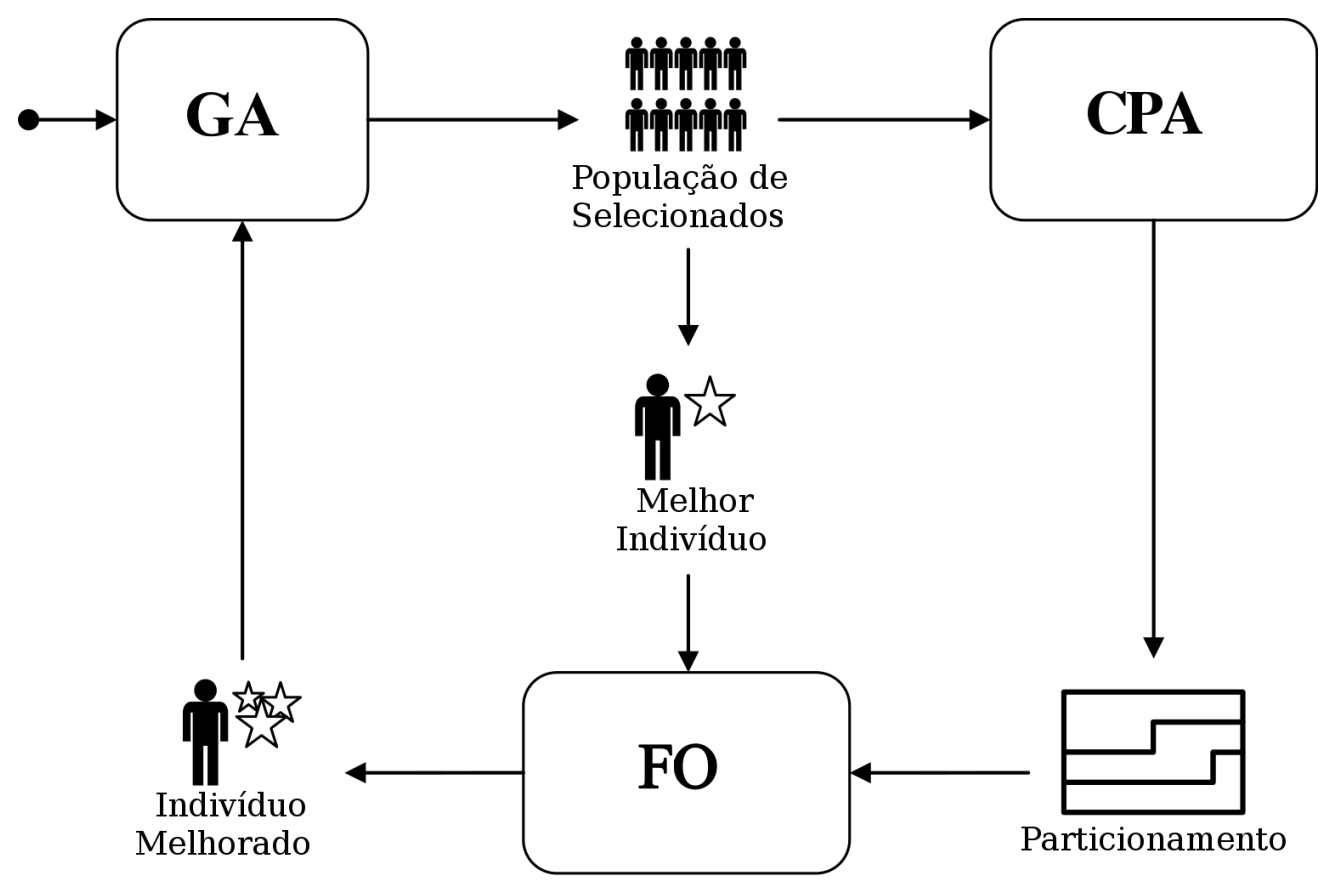

Figura A.1: Principais etapas de um ciclo de execução da CPA-FO.

Depois de terminar um ciclo de execução, o Melhor Indivíduo é repassado para o GA, que gera outros indivíduos com base no Indivíduo Melhorado e reinicia o processo para o próximo ciclo.

Os testes computacionais foram executados utilizando quatro conjuntos de teste da biblioteca (MULTILSB, Multi-Item Lot-Sizing with Backlogging) (Almeder, 2010). A Tabela A.1 resume os resultados em termos de média e desvio do número de acertos da solução ótima do problema testado. O desvio é calculado de acordo com a Equação A.1, em que Ref deve ser substituído pelo nome de um dos métodos de referência da literatura (Simpson \& Erenguc, 2010) usados para comparação. Na equação um desvio negativo significa que o CPA-FO obteve um resultado melhor do que os métodos de referência para os conjuntos de teste SET1, SET2, SET3 e SET4 definidos em Simpson \& Erenguc (2010).

$$
\operatorname{Dev}(\%)=\left(\frac{S o l^{C P A-F O}-S o l^{R e f}}{S o l^{R e f}} \cdot 100\right)
$$

Tabela A.1: Número de acertos (encontrados pelo CPA-FO) e desvios (Equação A.1) de valores para todos os conjuntos.

\begin{tabular}{cccrccr}
\hline & \multicolumn{2}{c}{ vs. Aheur } & \multicolumn{2}{c}{ vs. LugNP } & \multicolumn{2}{c}{ vs. HMPGA } \\
Conjunto de Teste & Ganha & Dev $(\%)$ & Ganha & Dev $(\%)$ & Ganha & Dev $(\%)$ \\
\hline SET1 & 19 & -0.12 & 21 & -0.15 & 26 & -0.36 \\
SET2 & 18 & 0.13 & 18 & 0.12 & 30 & -3.74 \\
SET3 & 10 & 2.46 & 8 & 4.38 & 1 & 6.67 \\
SET4 & 28 & -1.61 & 25 & -1.11 & 18 & 0.38 \\
\hline
\end{tabular}

Em termos de valores médios (30 execuções com diferentes sementes para o gerador de números aleatórios), o CPA-FO superou os três métodos de referência aplicados ao SET1, embora por 
uma diferença relativamente pequena, de no máximo -0,36\%. Em SET2, os resultados mostram vantagem relativamente pequena do Aheur $(0,13)$ e $\operatorname{LugNP}(0,12)$, enquanto supera o HMPGA em $-3,74 \%$. O CPA-FO, no entanto, teve um desempenho inferior para o SET3, com desvio positivo de 2,46, 4,38 e 6,67, respectivamente em relação ao Aheur, LugNP e HMPGA. Os melhores resultados do CPA-FO ocorreram para o SET4 coms desvios de $-1,61 \%$ em relação ao Aheur e $-1,11 \%$ contra $\operatorname{LugNP}$, além de um desvio positivo relativamente pequeno de 0,38 para o HMPGA.

Essa aplicação do CPA ilustra como sua capacidade de identificar correlações em problemas multivariados pode contribuir para o desenvolvimento de novas abordagens para diversos tipos de problemas. Para isso, basta o CPA receber um conjunto de soluções promissoras, que retornará um particionamento das variáveis, cujas partições e seus valores mais frequentes podem representar regiões promissoras do espaço de busca, a serem exploradas mais intensamente. 



\section{CPA em problemas com variáveis contínuas}

Para se lidar com problemas de variáveis reais, uma nova extensão do CPA (Capítulo 6), o $\mathrm{CPA}_{R}$, foi desenvolvido substituindo a MI pela métrica NCD (ambas descritas no Apêndice F). A investigação de métricas alternativas à MI foi motivada principalmente pela complexidade de tempo relativamente alta dos cálculos desta métrica para variáveis reais. Observe que a partir da NCD, geram-se matrizes de distância de forma similar ao realizado usando a MI no CPA. Com isso, o $\mathrm{CPA}_{R}$ difere apenas do CPA na entrada (vetores de números reais) e na aplicação da NCD sobre essa entrada. As Seções B.1 e B.2 apresentam a utilização do $\mathrm{CPA}_{R}$ para dois problemas de otimização global bem distintos, de forma a ilustrar a diversidade de contextos envolvendo variáveis contínuas que podem ter modelos probabilísticos obtidos automaticamente pelo CPA ${ }_{R}$.

\section{B.1 Problema da extrusora}

O Problema da definição do Parafuso da Extrusora de Polímeros (SSE, do inglês Single Screw Extrusion) (Tadmor \& Klein, 1970) apud (Gaspar-cunha, 2004) é um interessante problema de otimização global do mundo real. Definido no espaço de variáveis contínuas, este problema motivou o desenvolvimento do $\mathrm{CPA}_{R}$, buscando ilustrar como o CPA pode ser estendido para outros problemas, não se restringindo a problemas combinatórios (Capítulo 6).

O SSE pode ser definido conforme explicado a seguir. Seja $N$ é a velocidade nominal de rotação do parafuso da extrusora, $T b_{i}$ são as temperaturas no seguimento $i$ do parafuso, $L_{i}$ e $D_{i}$ são comprimentos e diâmetros do parafuso no mesmo seguimento, respectivamente; $P$ é o passo 
entre roscas, por fim, $e$ é a espessura do parafuso. Os objetivos são: maximizar a quantidade de massa processada pela extrusora $(Q)$; minimizar o comprimento total do parafuso $(L)$; minimizar a temperatura da extrusora (T); Minimizar a energia consumida (Power) e maximizar o grau de mistura distribuída (Watts). A Figura B.1 mostra uma extrusora com parâmetros geométricos e operacionais (os demais parâmetros) a serem otimizados na extrusora de rosca simples. Os possíveis valores dos parâmetros operacionais estão entre colchetes na Figura B.1 (esses valores são típicos para processamento de polímeros).

Os experimentos foram organizados em três conjuntos (rotulados por A, B e C, como em Gaspar-cunha (2004)), cada um envolvendo uma combinação de diferentes aspectos de modelagem (variáveis). Para cada uma dessas modelagens, diferentes objetivos são utilizados para se projetar um parafuso de extrusora. Pode-se utilizar até cinco objetivos, resultando em problemas de otimização multiobjetivo. Para lidar com esse tipo de problema, uma estratégia tem sido a determinação de regiões do espaço de busca que mais contribuem com soluções próximas a fronteira Pareto-ótima (Gaspar-Cunha et al., 2012). Nesse contexto, o particionamento das variáveis de acordo com os diversos objetivos mostra-se uma abordagem interessante de orientar o processo de busca de um algoritmo multiobjetivo.

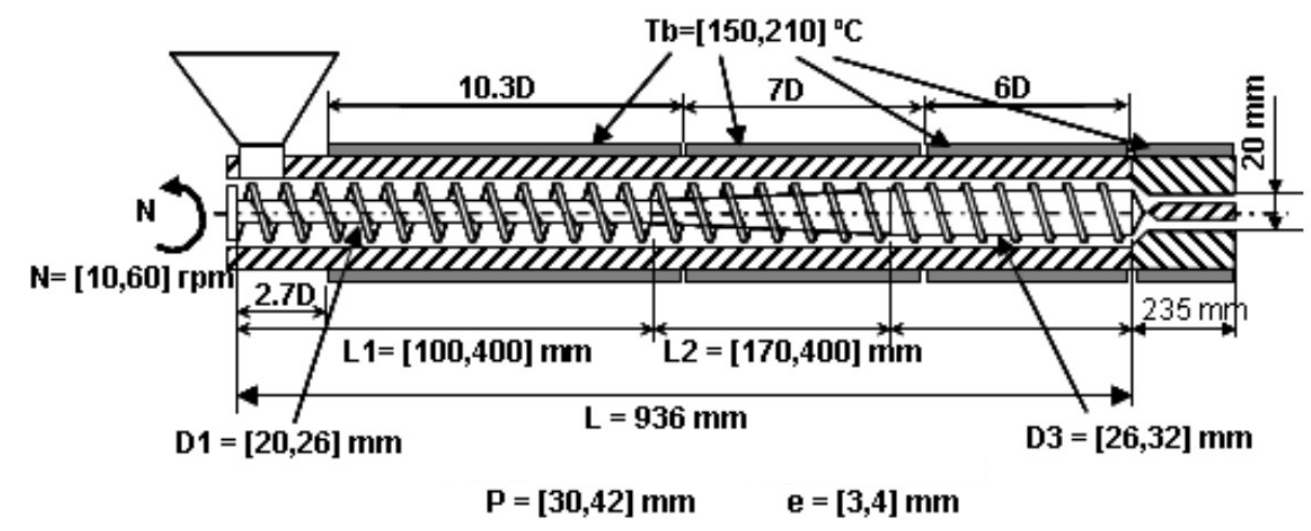

Figura B.1: Extrusora com todas as possíveis variáveis envolvidas, adaptada de Gaspar-cunha (2004).

Os conjuntos A, B e C, e cinco grupos de objetivos dos possíveis objetivos foram organizados em onze problemas multiobjetivos, conforme segue:

A) - Condições Operacionais $(N, T b 1, T b 2 T b 3)$ :

$i \operatorname{Max}(Q) V s \operatorname{Min}(L)$;

ii $\operatorname{Max}(Q) V s \operatorname{Min}(T)$;

iii $\operatorname{Max}(Q) V s \operatorname{Min}($ Power $)$;

iv $\operatorname{Max}(Q) V s \operatorname{Max}($ Watts $)$;

$v \operatorname{Max}(Q) V s \operatorname{Min}(L) V s \operatorname{Min}(T) V s \operatorname{Min}($ Power $) V s \operatorname{Max}($ Watts); 
B) - Condições Geométricas $(L 1, L 2, D 1, D 2, P, e)$

$$
\begin{aligned}
& \text { i } \operatorname{Max}(Q) V s \operatorname{Min}(\text { Power }) \text {; } \\
& \text { ii } \operatorname{Max}(Q) V s \operatorname{Max}(\text { Watts }) \text {; } \\
& \text { iii } \operatorname{Max}(Q) V s \operatorname{Min}(L) V s \operatorname{Min}(T) V s \operatorname{Min}(\text { Power }) V s \operatorname{Max}(\text { Watts); }
\end{aligned}
$$

C) - Condições Operacionais e Geométricas $(N, T b 1, T b 2, T b 3, L 1, L 2, D 1, D 2, P, e)$

$$
\begin{aligned}
& \text { i } \operatorname{Max}(Q) V s \operatorname{Min}(\text { Power }) \text {; } \\
& \text { ii } \operatorname{Max}(Q) V s \operatorname{Max}(\text { Watts }) \text {; } \\
& \text { iii } \operatorname{Max}(Q) V s \operatorname{Min}(L) V s \operatorname{Min}(T) V s \operatorname{Min}(\text { Power }) V s \operatorname{Max}(\text { Watts }) \text {. }
\end{aligned}
$$

Para cada um desses problemas, o $\mathrm{CPA}_{R}$ foi usado para encontrar particionamentos na $5^{\mathrm{a}}$ e $50^{\mathrm{a}}$ iteração do algoritmo multiobjetivo, denominado RPSGAe (Gaspar-cunha, 2004). Dessa forma, pôde-se avaliar o comportamento das variáveis nos estágios iniciais e no final da execução do RPSGAe. As Tabelas B.1, B.2 e B.3 mostram os particionamentos obtidos para cada um desses experimentos. Cada BB é rotulado por um índice. Por exemplo, as variáveis com índice 0 pertencem ao $\mathrm{BB}[0]$, as que possuem índice 1 ao $\mathrm{BB}[1]$, e assim, sucessivamente.

Para todos os experimentos foram encontrados particionamentos com partições de tamanho maior que um. Isso mostra que existem regiões promissoras (BBs) do espaço de busca de acordo com cada objetivo que são detectáveis pelo $\mathrm{CPA}_{R}$. Dessa forma, pode-se orientar a busca do RPSGAe para essas regiões. Além disso, os BBs encontrados diferem com os objetivos considerados em cada experimento (cada um dos onze problemas), relevando o conflito entre os objetivos e a dificuldade em resolver essas instâncias do problema da extrusora.

Com base nos particionamento, pode-se realizar uma busca local no subespaço relativo a cada partição de particionamento. Com isso, estaria-se elaborando um algoritmo híbrido capaz de melhorar a solução obtida pelo algoritmo RPSGAe, de forma similar ao realizado por meio do CPAFO (Apêndice A) para o MULTILSB.

Outra opção é o RPSGAe realizar mais intensamente mutações em um mesmo BB ou aplicar recombinação de forma a misturar os melhores instâncias encontradas de BBs diferentes (Seção 2.3). Em linhas gerais, o $\mathrm{CPA}_{R}$ possibilita a geração de novas abordagens de otimização contínua multiobjetivo ao detectar as regiões promissoras do espaço de busca de acordo com cada objetivo do problema. 
Tabela B.1: Distribuição dos BBs (BB[0] e BB[1]) obtidas pelo $\mathrm{CPA}_{R}$ para os problemas do conjunto A (condições operacionais) para soluções selecionadas na $5^{\mathrm{a}}$ e $50^{\mathrm{a}}$ gerações do RPSGAe.

\begin{tabular}{|c|c|c|c|c|c|c|c|c|c|}
\hline Caso & Objetivos & \multicolumn{4}{|c|}{$5^{\mathrm{a}}$} & \multicolumn{4}{|c|}{$50^{\mathrm{a}}$} \\
\hline & & $N$ & $T 1$ & $T 2$ & $T 3$ & $N$ & $T 1$ & $T 2$ & $T 3$ \\
\hline \multirow[t]{2}{*}{$\mathrm{A}-i)$} & $Q$ & 0 & 1 & 0 & 1 & 0 & 1 & 1 & 0 \\
\hline & $L$ & 0 & 0 & 1 & 1 & 0 & 1 & 0 & 1 \\
\hline \multirow{3}{*}{ A-ii) } & & & & & & & & & \\
\hline & $Q$ & 0 & 1 & 0 & 1 & 0 & 1 & 0 & 1 \\
\hline & $T$ & 0 & 1 & 0 & 1 & 0 & 1 & 0 & 1 \\
\hline \multirow{2}{*}{ A-iii) } & $O$ & 0 & 0 & 1 & 1 & 0 & 1 & 0 & 1 \\
\hline & Power & 0 & 1 & 0 & 1 & 0 & 1 & 0 & 1 \\
\hline & & & & & & & & & \\
\hline \multirow[t]{2}{*}{$\mathrm{A}-i v)$} & $Q$ & 0 & 0 & 1 & 1 & 0 & 0 & 1 & 1 \\
\hline & Watts & 0 & 0 & 1 & 1 & 0 & 1 & 0 & 1 \\
\hline \multirow{5}{*}{$\mathrm{A}-v)$} & & 0 & & & 1 & 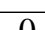 & 0 & 1 & 1 \\
\hline & L & 0 & 1 & 1 & 0 & 0 & 0 & 1 & 1 \\
\hline & $T$ & 0 & 1 & 1 & 0 & 0 & 0 & 1 & 1 \\
\hline & Power & 0 & 1 & 1 & 0 & 0 & 0 & 1 & 1 \\
\hline & Watts & 0 & 1 & 0 & 1 & 0 & 1 & 0 & 1 \\
\hline
\end{tabular}

Tabela B.2: Distribuição dos $\mathrm{BBs}\left(\mathrm{BB}[0]\right.$, BB[1] e BB[2]) obtidas pelo $\mathrm{CPA}_{R}$ para os problemas do conjunto $\mathrm{B}$ (condições geométricas) para soluções selecionadas na $5^{\mathrm{a}}$ e $50^{\mathrm{a}}$ gerações do RPSGAe.

\begin{tabular}{|c|c|c|c|c|c|c|c|c|c|c|c|c|c|}
\hline Caso & Objetivos & \multicolumn{6}{|c|}{$5^{\mathrm{a}}$} & \multicolumn{6}{|c|}{$50^{\mathrm{a}}$} \\
\hline & & L1 & $L 2$ & $D 1$ & D2 & $P$ & $e$ & L1 & $L 2$ & D1 & $D 2$ & $P$ & $e$ \\
\hline \multirow[t]{2}{*}{$\mathrm{B}-i)$} & $Q$ & 0 & 0 & 1 & 2 & 1 & 2 & 0 & 0 & 1 & 0 & 1 & 1 \\
\hline & Power & 0 & 0 & 1 & 2 & 1 & 2 & 0 & 0 & 1 & 1 & 2 & 2 \\
\hline \multirow[t]{2}{*}{ B - ii) } & $Q$ & 0 & 0 & 1 & 1 & 0 & 1 & 0 & 0 & 1 & 1 & 1 & 0 \\
\hline & Watts & 0 & 0 & 1 & 2 & 2 & 1 & 0 & 0 & 1 & 1 & 1 & 0 \\
\hline \multirow{5}{*}{ B - iii) } & $O$ & 0 & 0 & 1 & 1 & 0 & 1 & 0 & 0 & 1 & 2 & 2 & 1 \\
\hline & $L$ & 0 & 0 & 1 & 0 & 1 & 1 & 0 & 0 & 1 & 2 & 2 & 1 \\
\hline & $T$ & 0 & 0 & 1 & 1 & 0 & 1 & 0 & 0 & 1 & 1 & 0 & 1 \\
\hline & Power & 0 & 0 & 1 & 1 & 0 & 1 & 0 & 0 & 1 & 2 & 2 & 1 \\
\hline & Watts & 0 & 0 & 1 & 1 & 0 & 1 & 0 & 0 & 1 & 0 & 1 & 1 \\
\hline
\end{tabular}


Tabela B.3: Distribuição dos BBs (BB[0], BB[1], BB[2] e BB[3]) obtidas pelo $\mathrm{CPA}_{R}$ para os problemas do conjunto $\mathrm{C}$ (condições operacionais + geométricas) para soluções selecionadas na $5^{\mathrm{a}}$ e $50^{\mathrm{a}}$ gerações do RPSGAe.

\begin{tabular}{|c|c|c|c|c|c|c|c|c|c|c|c|}
\hline Caso & Objetivos & \multicolumn{10}{|c|}{$5^{\mathrm{a}}$} \\
\hline & & $N$ & $T 1$ & $T 2$ & $T 3$ & $L 1$ & $L 2$ & D1 & $D 2$ & $P$ & $e$ \\
\hline \multirow[t]{2}{*}{$\mathrm{B}-i)$} & $Q$ & 0 & 1 & 1 & 1 & 2 & 2 & 3 & 0 & 0 & 3 \\
\hline & Power & 0 & 1 & 1 & 1 & 2 & 2 & 3 & 3 & 0 & 3 \\
\hline & & & & & & & & & & & \\
\hline \multirow[t]{2}{*}{ B - ii) } & $Q$ & 0 & 1 & 2 & 2 & 1 & 2 & 3 & 3 & 0 & 0 \\
\hline & Watts & 0 & 1 & 1 & 1 & 2 & 2 & 3 & 0 & 3 & 0 \\
\hline & & & & & & & & & & & \\
\hline \multirow[t]{5}{*}{ B - iii) } & $Q$ & 0 & 1 & 1 & 1 & 2 & 2 & 3 & 3 & 0 & 3 \\
\hline & $L$ & 0 & 1 & 1 & 1 & 2 & 2 & 3 & 0 & 0 & 3 \\
\hline & $T$ & 0 & 1 & 1 & 1 & 2 & 2 & 3 & 0 & 0 & 3 \\
\hline & Power & 0 & 1 & 1 & 1 & 2 & 2 & 3 & 0 & 0 & 3 \\
\hline & Watts & 0 & 1 & 1 & 1 & 2 & 2 & 3 & 0 & 0 & 3 \\
\hline \multirow[t]{2}{*}{ Caso } & Objetivos & \multicolumn{10}{|c|}{$50^{\mathrm{a}}$} \\
\hline & & $N$ & $T 1$ & $T 2$ & $T 3$ & $L 1$ & $L 2$ & D1 & $D 2$ & $P$ & $e$ \\
\hline \multirow[t]{2}{*}{$\mathrm{B}-i)$} & $Q$ & 0 & 1 & 2 & 1 & 2 & 2 & 3 & 0 & 3 & 0 \\
\hline & Power & 0 & 1 & 1 & 1 & 2 & 2 & 0 & 3 & 0 & 3 \\
\hline \multirow[t]{2}{*}{ B - ii) } & $Q$ & 0 & 1 & 2 & 1 & 2 & 1 & 3 & 0 & 3 & 3 \\
\hline & Watts & 0 & 1 & 2 & 1 & 1 & 1 & 0 & 0 & 2 & 0 \\
\hline \multirow{5}{*}{ B - iii) } & $Q$ & 0 & 1 & 1 & 1 & 0 & 0 & 2 & 3 & 3 & 2 \\
\hline & $L$ & 0 & 1 & 1 & 1 & 0 & 0 & 2 & 3 & 3 & 2 \\
\hline & $T$ & 0 & 1 & 1 & 1 & 0 & 0 & 2 & 3 & 3 & 2 \\
\hline & Power & 0 & 1 & 1 & 2 & 1 & 1 & 0 & 0 & 0 & 2 \\
\hline & Watts & 0 & 1 & 1 & 1 & 0 & 0 & 2 & 3 & 3 & 2 \\
\hline
\end{tabular}




\section{B.2 Problema de navegação de Robô}

O problema de navegação de robô investigado é base para várias etapas envolvendo a navegação e consiste em identificar os estados que o robô pode se encontrar em um ambiente. Os dados de entrada do sistema são somente dos espectros dos sinais de laser medindo a distância do robô até um objeto a sua volta (variáveis reais). A cada instante é obtido um sinal com 360 distâncias, com uma medição de distância a cada 0,5 grau (o laser varre 180 graus a sua frente). No ambiente simulado em Player/Stage foi usado um robô Pioneer T3 com laser SICK.

$\mathrm{O} \mathrm{CPA}_{R}$ recebe de cada vez cinco amostras, cada uma correspondente a um sinal com 360 distâncias obtidas pelo laser. Assim, a cada novas cinco amostras, o $\mathrm{CPA}_{R}$ retorna um particionamento de todas as amostras já coletadas. Supõe-se que amostras em partições diferentes no particionamento são significativamente diferentes. Como esses sinais representam regiões do ambiente pelo quais o robô passou, cada partição deve corresponder a uma região do ambiente, indicando estados diferentes do robô.

Para testar o $\mathrm{CPA}_{R}$ nesse contexto, um percurso de corredores foi criado, conforme mostrado na Figura B.2. O robô foi apenas programado para seguir a parede a sua direita mantendo certa distância dela. Nenhuma outra informação ou treinamento é passado ao robô. Conforme o robô inicia seu percurso (Figura B.2(a)), os sinais obtidos pelo laser são particionados. As Figuras B.2(a)-(d) mostram que, enquanto o robô recebe sinais relacionados a uma curva à direita, as amostras formam uma árvore em forma de estrela. Conforme o robô encontra novos cenários (Figuras B.3 a B.6), a árvore obtida mostra claramente um grupo para cada cenário (curva à direita, curva à esquerda, bifurcação, reta e cruzamento). A matriz com intensidade de cores (em que cores claras indicam valores mais altos de correlação entre a amostra $i$ com a $j$ ) mostra que blocos de cores claras se formam conforme o número de amostras e cenários aumentam.

Esses blocos na matriz correspondem a partições (BBs) dos particionamentos, mostrados à direita de cada figura. Ao final, o $\mathrm{CPA}_{R}$ encontra um particionamento com cinco BBs, um para cada cenário pelo qual o robô passou. Com isso, mostra-se que o $\mathrm{CPA}_{R}$ pode encontrar estados para navegação de robôs em ambientes desconhecidos pelo robô.

Por fim, é interessante observar que uma etapa seguinte a descoberta dos estados seria a otimização das ações do robô em cada estado. Em outras palavras, isso corresponderia a explorar o subespaço de busca em cada BB, de forma semelhante ao que se fez usando a CPA-FO (Apêndice $\mathrm{A}$ ), ao que foi proposto para a $\mathrm{CPA}_{R}$ aplicado ao problema da extrusora (Apêndice B.10) e também semelhante ao método OPA para problemas combinatórios do tipo ADSP e com sobreposição de BBs (Capítulo 7). 


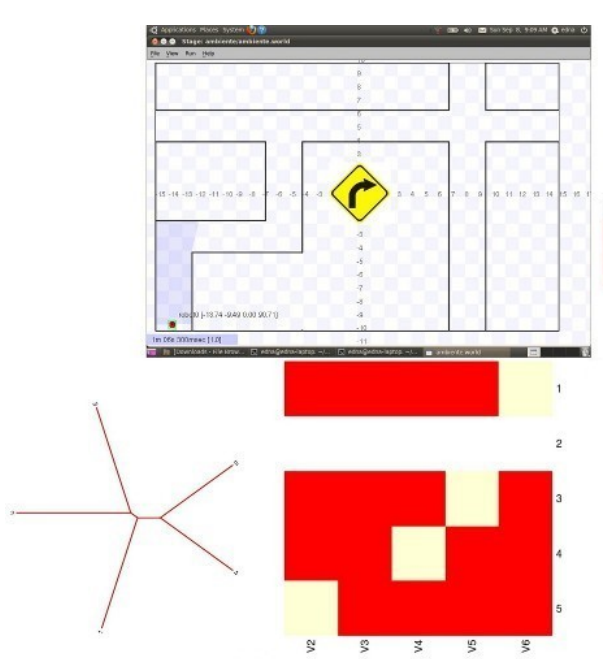

(a)

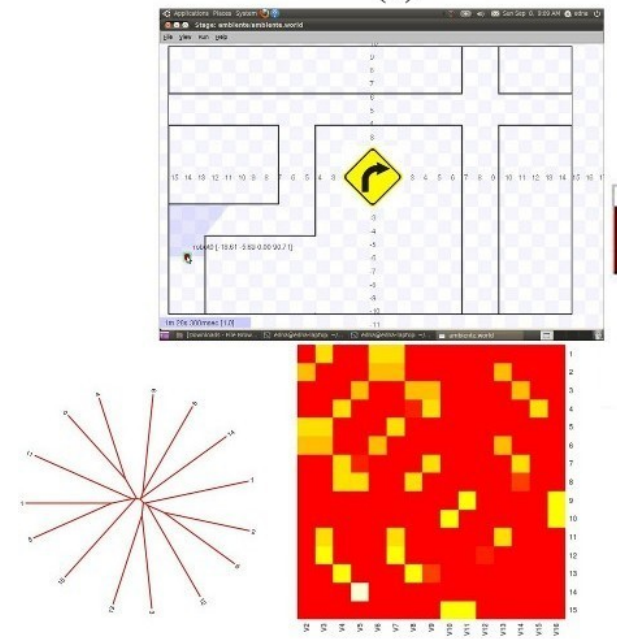

(c)

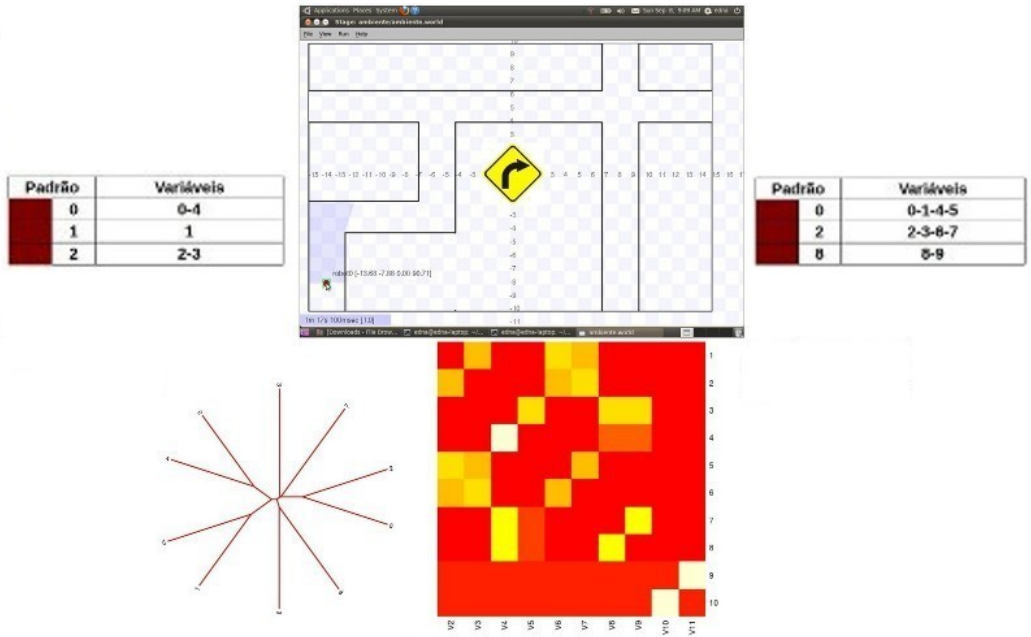

(b)

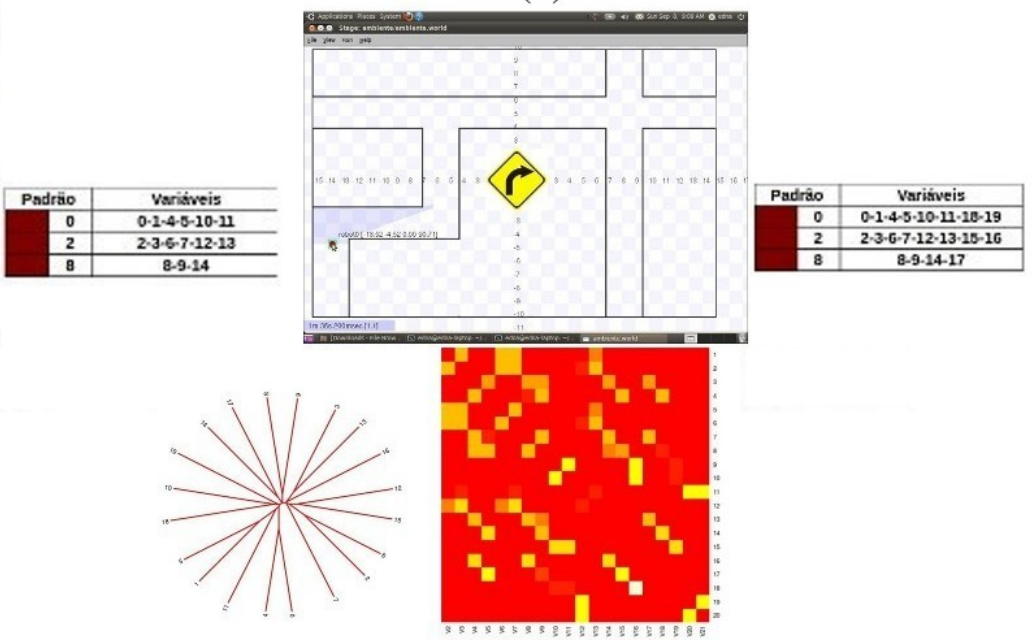

(d)

Figura B.2: Exemplo do $\mathrm{CPA}_{R}$ para um problema de navegação de robôs, identificando os estados do ambiente para: (a) 5 amostras de sinais de laser, (b) 10 amostras de sinais de laser, (c) 15 amostras de sinais de laser, (d) 20 amostras de sinais de laser. 


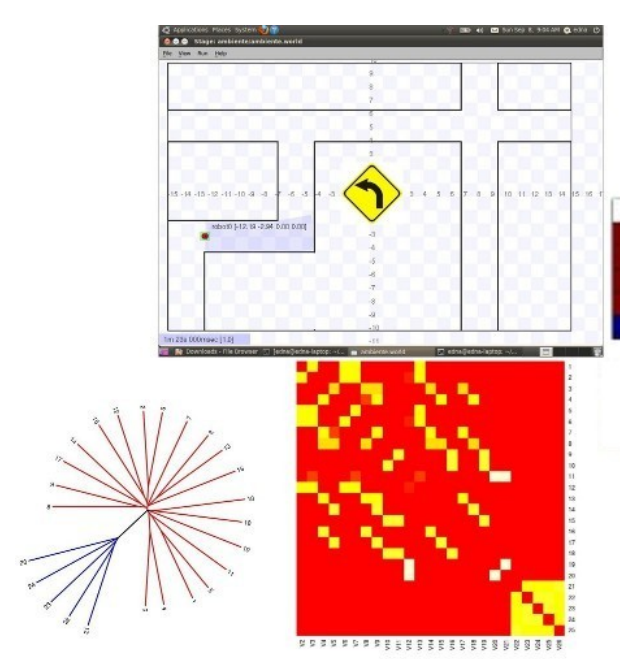

(a)

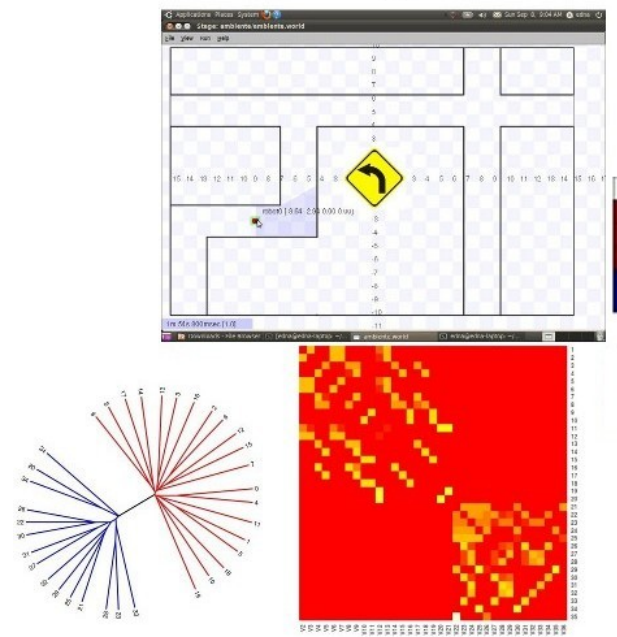

(c)

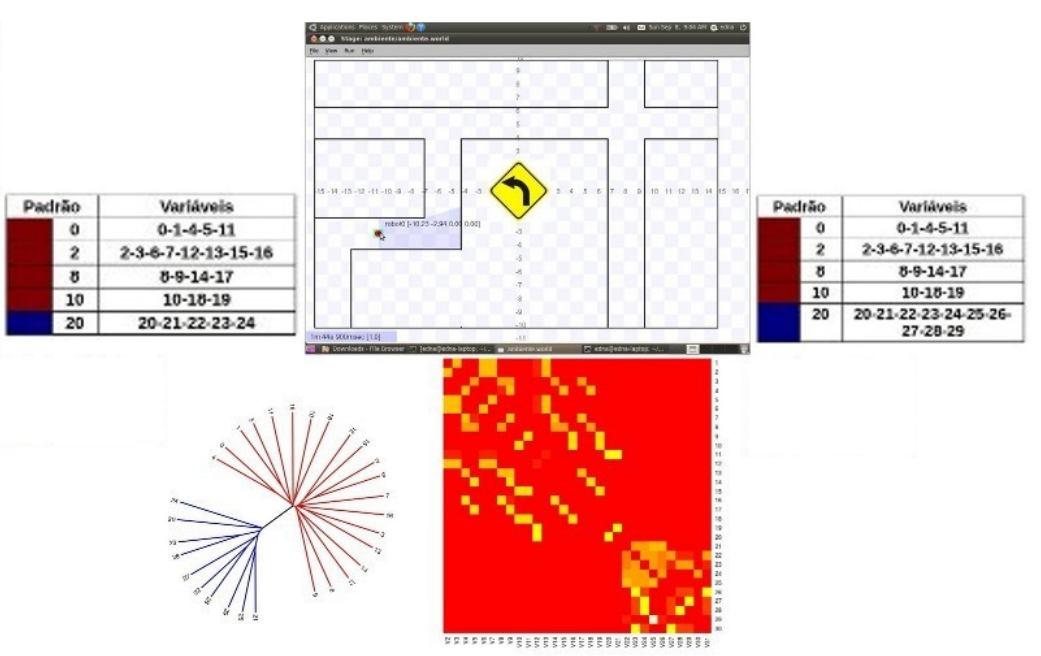

(b)

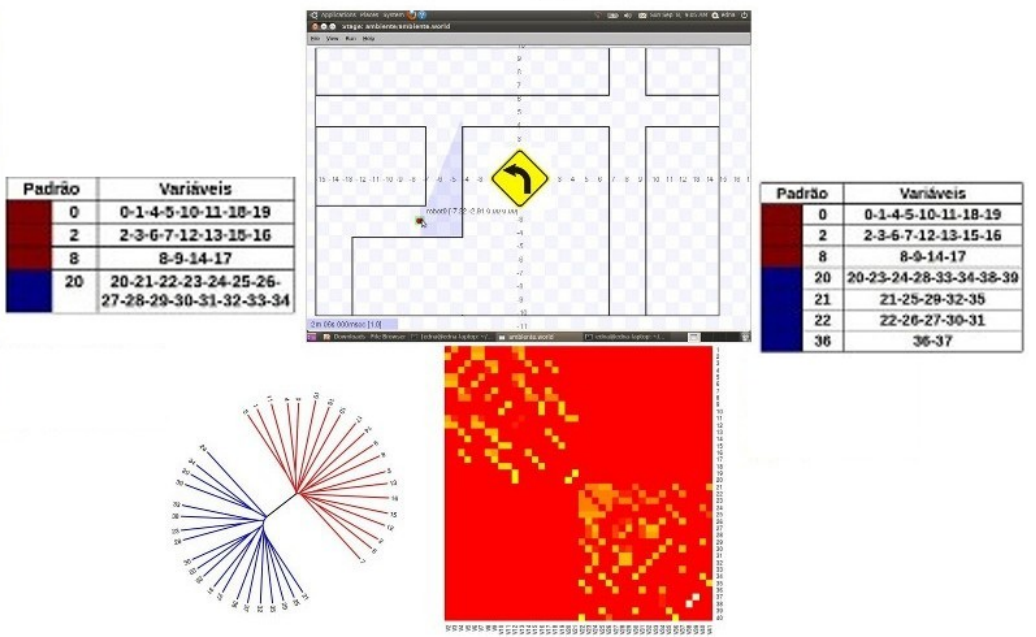

(d)

Figura B.3: Exemplo do $\mathrm{CPA}_{R}$ para um problema de navegação de robôs, identificando os estados do ambiente para (a) 25 amostras de sinais de laser, (b) 30 amostras de sinais de laser, (c) 35 amostras de sinais de laser, (d) 40 amostras de sinais de laser. 


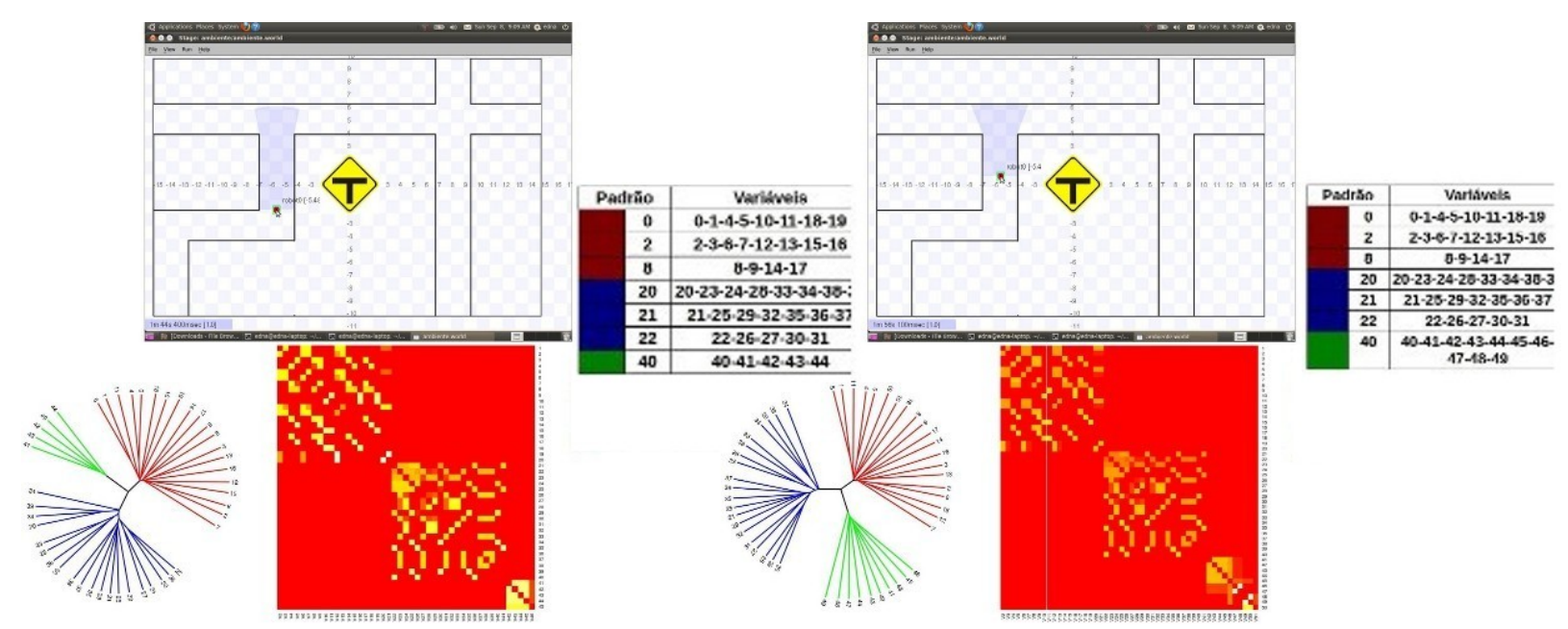

(a)

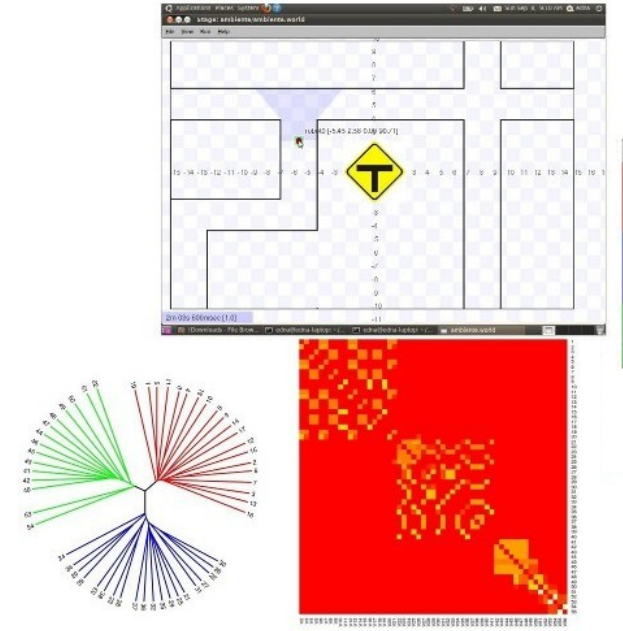

(c) (b)

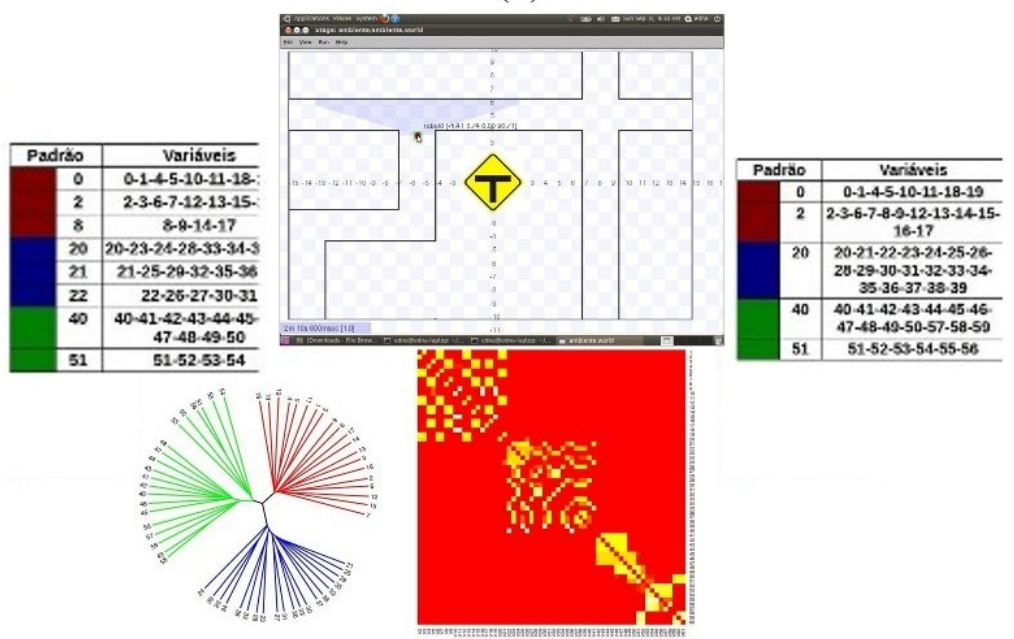

(d)

Figura B.4: Exemplo do $\mathrm{CPA}_{R}$ para um problema de navegação de robôs, identificando os estados do ambiente para (a) 45 amostras de sinais de laser, (b) 50 amostras de sinais de laser, (c) 55 amostras de sinais de laser, (d) 60 amostras de sinais de laser. 


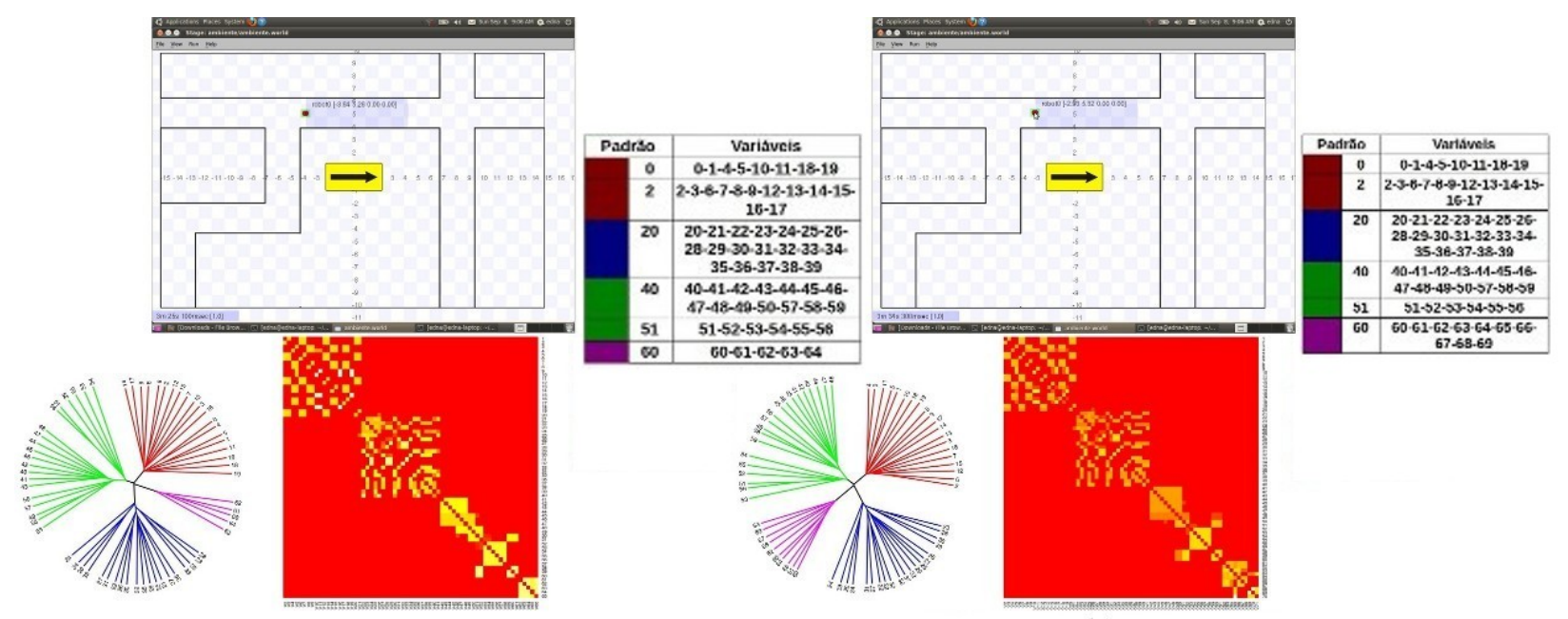

(a)

(b)

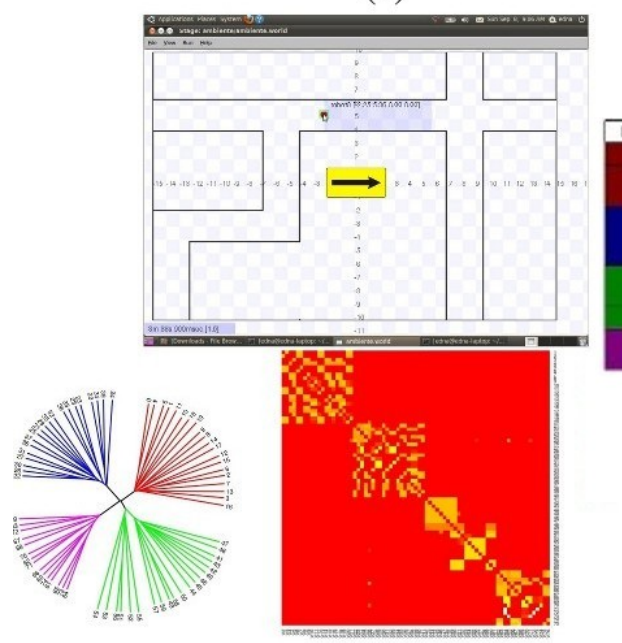

(c)

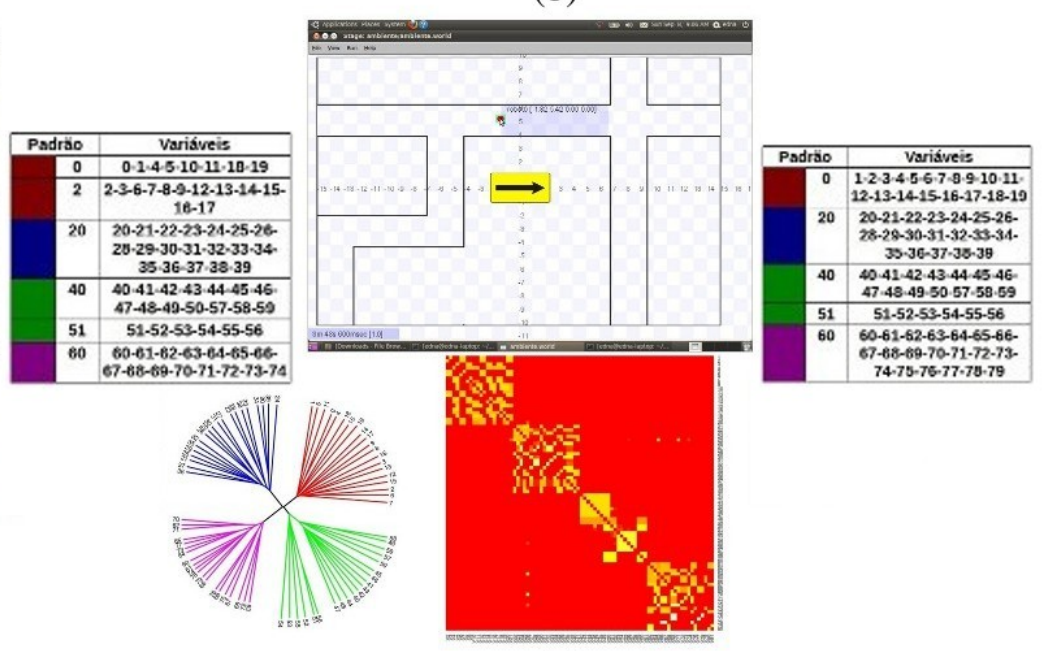

(d)

Figura B.5: Exemplo do $\mathrm{CPA}_{R}$ para um problema de navegação de robôs, identificando os estados do ambiente para (a) 65 amostras de sinais de laser, (b) 70 amostras de sinais de laser, (c) 75 amostras de sinais de laser, (d) 80 amostras de sinais de laser. 


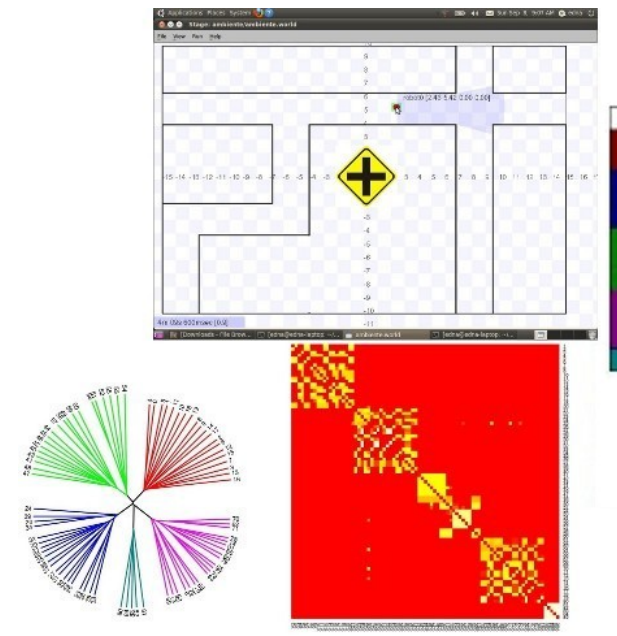

(a)

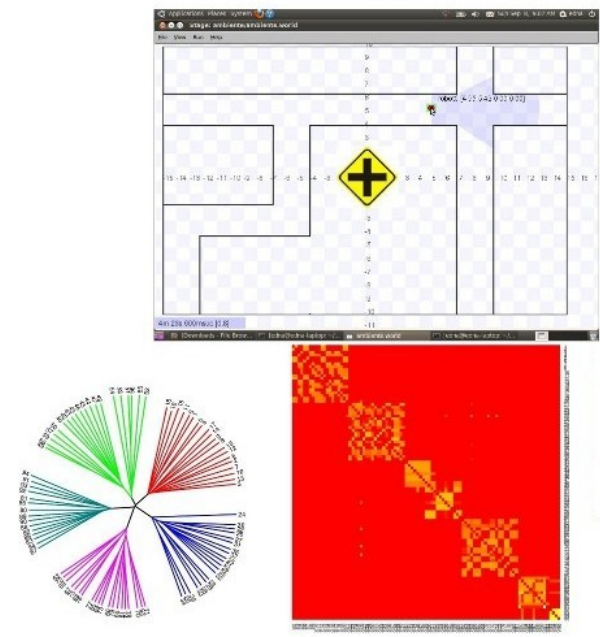

(c)

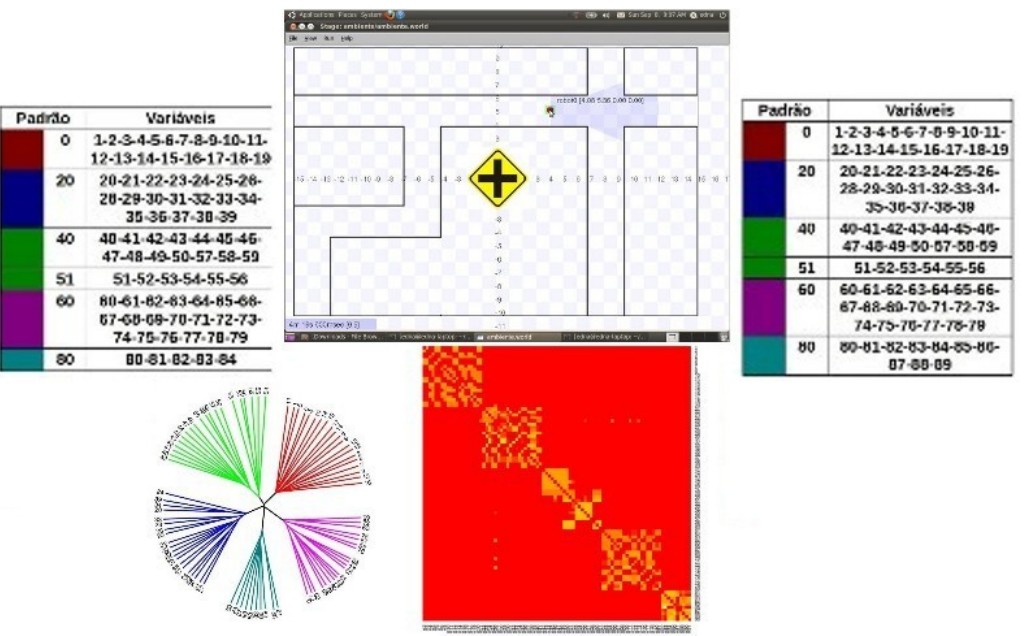

(b)

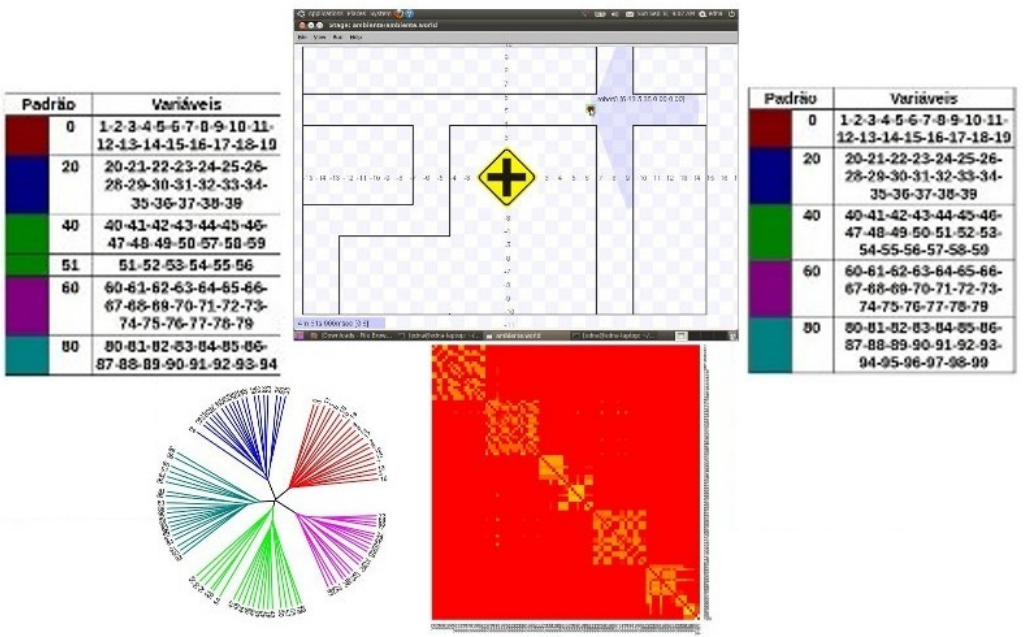

(d)

Figura B.6: Exemplo do $\mathrm{CPA}_{R}$ para um problema de navegação de robôs, identificando os estados do ambiente para (a) 85 amostras de sinais de laser, (b) 90 amostras de sinais de laser, (c) 95 amostras de sinais de laser, (d) 100 amostras de sinais de laser. 



\section{CPA em problemas com variáveis mistas}

Para os problemas de otimização com variáveis mistas, outra extensão do CPA denominado $\mathrm{CPA}_{M}$, foi desenvolvida usando duas métricas de distância para identificar os BBs, a MI (Apêndice F) (para variáveis binárias) e a NCD (Apêndice F) (para variáveis reais). Uma vez encontrado o particionamento de variáveis, a ES (Seção 4.3) ou mesmo o algoritmo DE (Differential Evolution), como anteriormente proposto em Melo et al. (2011), pode ser utilizada para encontrar a solução do problema. A Figura C.1 sintetiza o funcionamento do $\mathrm{CPA}_{M}$.

O problema misto usado para teste foi construído a partir dos seguintes tipos de subproblemas:

1. Binário, composto por funções ftrap5 (Figura 7.1(b));

2. De variáveis reais, composto por funções Rosenbrock (Figura C.2), como em Javadi et al. (2005), definida pela Equação C.1, $\operatorname{com} n=2$.

$$
\begin{gathered}
\max -f_{\text {rosenbrock }}(x), x_{i} \in\{-5.2,5.2\}, \\
f_{\text {rosenbrock }}(x)=\sum_{i=1}^{n-1}\left[100\left(x_{i+1}-x_{i}^{2}\right)^{2}+\left(1-x_{i}\right)^{2}\right],
\end{gathered}
$$

s.a.

$$
C_{1}(x)=1-\left(\prod_{i=1}^{n} x_{i}\right)^{2} \leq 0
$$




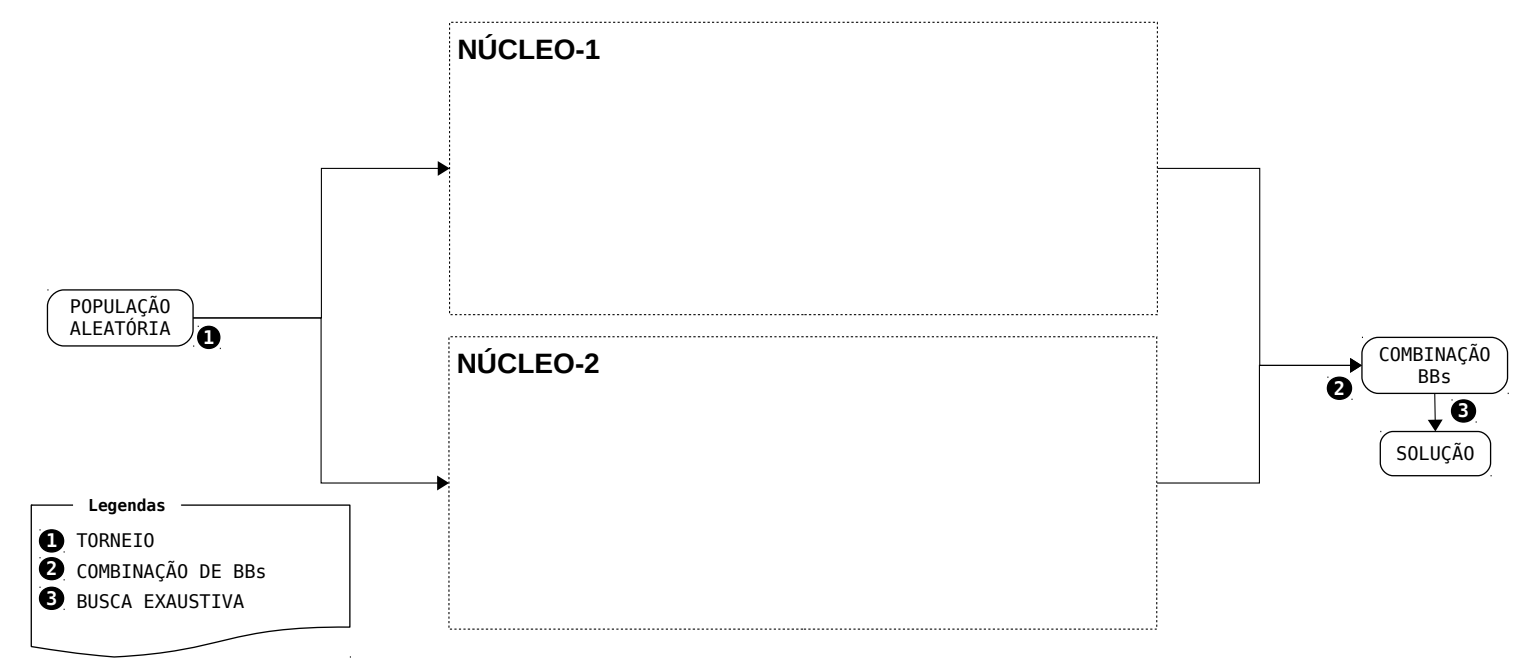

Figura C.1: $\mathrm{CPA}_{M}$, o NÚCLEO-1 (definido na Figura 6.9) usa a MI como métrica de distância; enquanto o NÚCLEO-2, a NCD.

$$
C_{2}(x)=|n-| \sum_{i=1}^{n} x_{i}||=0 .
$$

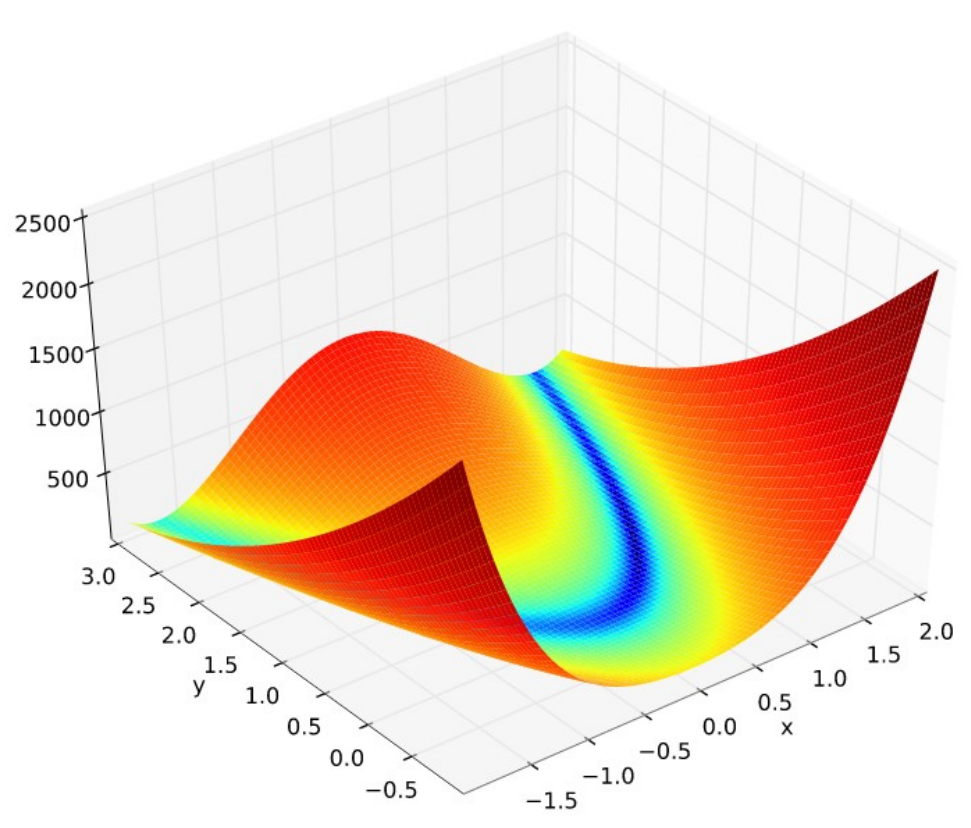

Figura C.2: Função Rosenbrock para duas variáveis.

O vetor de variáveis do problema misto usado nos testes possui três ftrap5 e duas funções Rosenbrock, como mostrado na Figura C.3(a). O CPA ${ }_{M}$ divide o vetor em BBs para as variáveis binárias e também para as reais, conforme indicado pela máscara mostrada na Figura C.3(b). 
A máscara (completa ou parcial) pode ser fornecida previamente, caso haja esse conhecimento. Caso contrário, a NCD é utilizada para todas as variáveis, separando variáveis reais de inteiras. Por fim, o particionamento final é encontrado pelo $\mathrm{CPA}_{M}$ conforme sumarizado na Figura C.1.

(a)

\begin{tabular}{|c|c|c|c|c|c|c|c|c|c|c|c|c|c|c|c|c|c|c|}
\hline 1 & 2 & 3 & 4 & 5 & 6 & 7 & 8 & 9 & 10 & 11 & 12 & 13 & 14 & 15 & 16 & 17 & 18 & 19 \\
\hline $\mathrm{B}$ & $\mathrm{B}$ & $\mathrm{B}$ & $\mathrm{B}$ & $\mathrm{B}$ & $\mathrm{B}$ & $\mathrm{B}$ & $\mathrm{B}$ & $\mathrm{B}$ & $\mathrm{B}$ & $\mathrm{B}$ & $\mathrm{B}$ & $\mathrm{B}$ & $\mathrm{B}$ & $\mathrm{B}$ & $\mathrm{R}$ & $\mathrm{R}$ & $\mathrm{R}$ & $\mathrm{R}$ \\
\hline 1 & 1 & 1 & 1 & 1 & 1 & 1 & 1 & 1 & 1 & 1 & 1 & 1 & 1 & 1 & 1.0 & 1.0 & 1.0 & 1.0 \\
$=$ & $=$ Máscara do vetor & Vetor ótimo
\end{tabular}

$B=$ Binário

$\mathrm{R}=\mathrm{Real}$

(b)

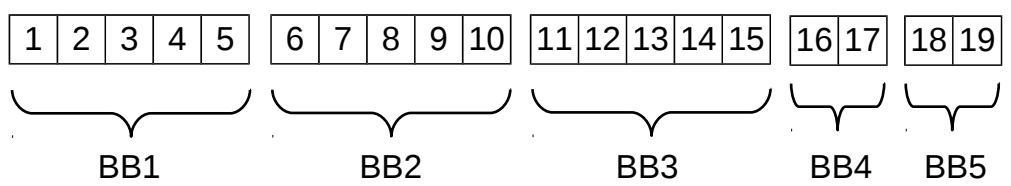

Figura C.3: (a) Máscara, indicando o tipo de variáveis do problema (desconhecida pelo $\mathrm{CPA}_{M}$ ) e (b) Particionamento em BBs obtido pelo $\mathrm{CPA}_{M}$. 



\section{CPA em reconstrução filogenética}

O CPA pode ser aplicado para determinar clados biológicos (Seção 5.2). O CPA, neste contexto denominado $\mathrm{CPA}_{G}$, inova ao formar redes de filogenias utilizando diferentes métricas de distância além da NCD. Dos métodos de reconstrução filogenética, pode-se destacar as seguintes métricas: Jukes-Cantor (Jukes \& Cantor, 1969), Kimura 2 parâmetros (Kimura, 1980) e a Felsenstein 84 (Felsenstein, 2003) (Apêndice F). Cada métrica de distância gera um conjunto de árvores, redes e, por fim, particionamentos, que são unidas de modo a compor uma rede final de consenso. A partir dessa rede, os clados são determinados usando o FA (Fast Algorithm) como método de detecção de comunidade, assim como nas demais extensões do CPA. Quanto mais árvores, melhor deve ser a identificação dos clados entre as filogenias, salientando as relações mais confiáveis. A Figura D.1 mostra as etapas do $\mathrm{CPA}_{G}$ para identificação de clados em sequências de DNA.

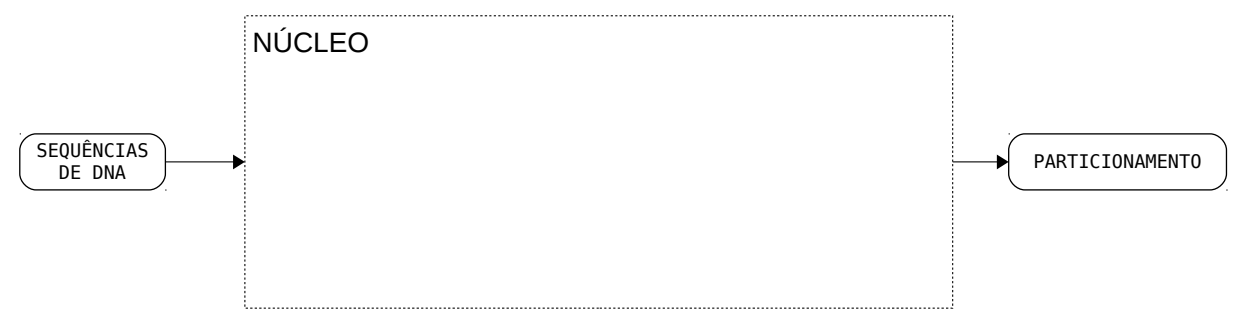

Figura D.1: Etapas da identificação de $\mathrm{BBs}$ do $\mathrm{CPA}_{G}$ para sequências de DNA, usando métricas de distâncias biológicas, em que NÚCLEO definido na Figura 6.9.

Para validar o método, foram escolhidos dois conjuntos de espécies da literatura, o rbcL_55 e o 20mams, ambos sequências de DNA (Cancino \& Delbem, 2007). A Tabela D.1 apresenta clados 
encontrados pelo $\mathrm{CPA}_{G}$ para o conjunto rbcL_55. A Tabela D.2, mostra os clados para o conjunto 20mans.

A identificação de clados na Biologia é basicamente feita a partir de uma filogenia levando em conta experiência ou conhecimento prévio dos objetos biológicos sem um método ou critério formal. $\mathrm{O} \mathrm{CPA}_{G}$ consegue determinar de forma automática, os clados de um conjunto de objetos biológicos. 
Tabela D.1: Clados obtidos pelo $\mathrm{CPA}_{G}$ para o conjunto rbcL_55.

\begin{tabular}{|c|c|}
\hline Espécies & Índicies dos clados \\
\hline Anabaena_s & 0 \\
\hline Volvox_ro & 0 \\
\hline Sirogonium & 0 \\
\hline Zygnema_pe & 0 \\
\hline Pyrami_pa & 0 \\
\hline Chara_conn & 0 \\
\hline Bazzania_J & 0 \\
\hline Porella_4 & 0 \\
\hline Chlor_ell & 0 \\
\hline Conocephal & 1 \\
\hline Dumortiera & 1 \\
\hline Marchantia & 1 \\
\hline Metzgeria_ & 1 \\
\hline Anthoceros & 2 \\
\hline Sphagnum_J & 2 \\
\hline Lycopodium & 2 \\
\hline Tetraphis_ & 3 \\
\hline Fissidens_ & 3 \\
\hline Ptychomitr & 3 \\
\hline Hedwigia_7 & 3 \\
\hline Leucodon_5 & 3 \\
\hline Hookeria_2 & 3 \\
\hline Osmunda_ci & 2 \\
\hline Angiopter & 2 \\
\hline Marsilea & 7 \\
\hline Cheiropleu & 7 \\
\hline Loxoma & 7 \\
\hline Ginkgobil & 4 \\
\hline Podocarpus & 4 \\
\hline Larix & 4 \\
\hline Picea_pun & 4 \\
\hline Heuchera & 5 \\
\hline Gunnera & 8 \\
\hline NothofBal & 5 \\
\hline Celtis & 5 \\
\hline Amaranthu & 8 \\
\hline Platanus & 8 \\
\hline Floerkea & 5 \\
\hline Iris & 6 \\
\hline Aloe & 6 \\
\hline Avena & 6 \\
\hline Carex & 6 \\
\hline Asplenium & 7 \\
\hline Monachosor & 7 \\
\hline Nephrolepi & 7 \\
\hline Xiphopteri & 7 \\
\hline Nicotiana & 8 \\
\hline Gentiana & 8 \\
\hline Cornuscan & 8 \\
\hline Dipsacus & 8 \\
\hline Hedycarya & 9 \\
\hline Tasmannia & 9 \\
\hline Saururus & 9 \\
\hline Victoria & 6 \\
\hline Austrobai & 9 \\
\hline
\end{tabular}


Tabela D.2: Clados obtidos pelo $\mathrm{CPA}_{G}$ para o conjunto $20 \mathrm{mams}$.

\begin{tabular}{|l|c|}
\hline \multicolumn{1}{|c|}{ Espécies } & Índicies dos clados \\
\hline Finbackwha & 0 \\
\hline Cow___ & 0 \\
\hline Bluewhale_ & 0 \\
\hline Harborseal & 0 \\
\hline Grayseal__ & 0 \\
\hline Cat__ & 0 \\
\hline Horse___ & 0 \\
\hline Whiterhino & 0 \\
\hline SOrangutan & 1 \\
\hline Orangutan_- & 1 \\
\hline Gorilla__ & 1 \\
\hline PChimpanze & 1 \\
\hline Chimpanzee & 1 \\
\hline Human_ & 1 \\
\hline Gibbon_ & 2 \\
\hline Mouse__ & 2 \\
\hline Rat_ & 2 \\
\hline Wallaroo__ & 3 \\
\hline Opossum__ & 3 \\
\hline Platypus__ & 3 \\
\hline
\end{tabular}


APÊNDICE

\section{$E$}

\section{Número de Avaliações da Busca Exaustiva Composta}

A Equação E.1 calcula o Número de Avaliações (NA) da Busca Exaustiva Composta (CES, Seção 6.4) proposta nesse trabalho.

$$
N A=2\left(m 2^{k}+2^{m}\right)
$$

em que $m=\frac{\ell}{k}, \ell$ é o tamanho do cromossomo e $k$ é o tamanho do BB.

O termo $m 2^{k}$ corresponde a Etapa 3 da Seção 6.4, em que são identificadas as melhores instâncias para cada BB de tamanho $k$ através de uma ES (Seção 4.3). O termo $2^{m}$ corresponde a Etapa 4 da Seção 6.4, em que são permutas todas as $m$ instâncias de BB encontradas da Etapa 3. Os dois termos são multiplicados por dois por conta das Etapas 3 e 4 identificarem a melhor instância encontrada pela ES no BB além de seu complemento, gerando sempre duas possíveis combinações dessas instâncias, denominadas $C_{1}$ e $C_{2}$, conforme mostra a Etapa 1 da Seção 6.4.

A Equação E.1 é exata somente se $m$ for um número inteiro. Isso pode não ocorrer, por exemplo ao se calcular $m=\frac{\ell}{k}$. Observe que as estimativas de NA são realizados considerando todos os BBs do problema de mesmo tamanho $k$. A Equação E.1 pode ser generalizada, primeiramente decompondo o termo $m 2^{k}$ em dois outros, como segue:

1. Um termo para os $\lfloor m\rfloor$ BBs de tamanho $k$, dado por $\lfloor m\rfloor 2^{k}$, em que $\lfloor m\rfloor$ é o maior inteiro menor que $m$;

2. Outro termo para o BB contendo o restante da string de comprimento $\ell$, dado por $(\lceil m\rceil-$ $\lfloor m\rfloor) 2^{\ell-\lfloor m\rfloor k}$, ou seja, as instâncias de um BB $(\lceil m\rceil-\lfloor m\rfloor=1)$ de tamanho $\ell-\lfloor m\rfloor k$. 
Com relação ao termo $2^{m}$ da Equação E.1, o $\lceil m\rceil$ naturalmente inclui o BB "adicional" de tamanho $\ell-\lfloor m\rfloor k$ (ver Item 2), devendo o termo $2^{m}$ da Equação E.1 ser substituído por $\lceil m\rceil$, de forma a incluir o caso em que $m \neq\lfloor m\rfloor$. Substituindo esses resultados nos termos correspondentes da Equação E.1, obtém-se a Equação E.2.

$$
N A=2\left(\lfloor m\rfloor 2^{k}+(\lceil m\rceil-\lfloor m\rfloor) 2^{\ell-\lfloor m\rfloor k}+2^{\lceil m\rceil}\right) .
$$

Outro aspecto importante relacionado à Equação E.2 é a estimação de um limitante superior do NA ao se utilizar $k^{*}$, conforme calculado na Seção 6.4. Para se obter um limitante, primeiramente pode-se considerar o caso em que $\lceil m\rceil-\lfloor m\rfloor=1$, usar $m$ no lugar de $\lfloor m\rfloor$, além de $m+1$ em vez de $\lceil m\rceil$ e o fato de $\ell-\lfloor m\rfloor k<k$, conforme mostra a Equação E.3.

$$
\begin{aligned}
& N A \leq 2\left(m 2^{k}+2^{k}+2^{m+1}\right) . \\
& N A \leq 2\left[(m+1) 2^{k}+2^{m+1}\right] .
\end{aligned}
$$

Usando $k=\frac{\ell}{m}$,

$$
\begin{gathered}
N A \leq 2\left[(m+1) 2^{\frac{\ell}{m}}+2^{m+1}\right] . \\
N A \leq 22^{m}\left[(m+1) 2^{\frac{\ell}{m}-m}+2\right] . \\
N A=O\left(m 2^{\frac{\ell}{m}}\right) .
\end{gathered}
$$

Reescrevendo a Equação E.7 em relação a $k, m=\frac{\ell}{k}$.

$$
\begin{aligned}
& N A=O\left(\frac{\ell}{k} 2^{\frac{\ell}{k}}\right) . \\
& N A=O\left(\frac{\ell}{k} 2^{k}\right) .
\end{aligned}
$$

Usando o resultado experimental de que $k=2 \log \ell$ (Seção 6.4), obtém-se:

$$
\begin{gathered}
N A=O\left(\frac{\ell}{2 \log \ell} 2^{2 \log \ell}\right) . \\
N A=O\left(\frac{\ell}{\log \ell} \ell^{2}\right) . \\
N A=O\left(\frac{\ell^{3}}{\log \ell}\right) .
\end{gathered}
$$


Métodos de distância aplicados a dados biológicos (sequências de nucleotídeos de DNA, sequência de aminoácidos ou características morfológicas) requerem uma métrica para estimar a distância entre as espécies, que consideram a relevância de cada tipo de informação no processo evolutivo.

1. Jukes e Cantor

O modelo de Jukes e Cantor (JC) (Jukes \& Cantor, 1969) é relativamente simples, uma vez que considera que os nucleotídeos aparecem em igual frequência em uma sequência de DNA e todas as substituições (taxa de troca entre quaisquer dois tipos de nucleotídeos em um mesmo sítio de duas sequências) ocorrem a mesma frequência. Assim, todas as possíveis mudanças entre nucleotídeos podem ocorrer com igual probabilidade. A Figura F.1 mostra a relação de mudança para cada base, em que $a$ representa a probabilidade da mudança de um nucleotídeo para outro e os rótulos em cada linha e coluna indicam um tipo de nucleotídeo (Adenina (A), Guanina (G), Citosina (C) e Timina (T)). Em Felsenstein (2003), descrevese a estrutura molecular desses nucleotídeos. A Equação F.1 mostra como é calculado a distância entre os $\operatorname{taxa}^{1} \mathrm{c} X$ e $Y$.

$$
D_{J C}(X, Y)=-\frac{3}{4} \ln \left(1-\frac{4}{3} p(X, Y)\right),
$$

em que $p(X, Y)$ é a proporção de nucleotídeos diferentes entre as sequências $X$ e $Y$. Por exemplo, para $p(X, Y)=0,25, D_{J C}(X, Y)=-0,75 \ln (1-1.33 \times 0,25)=0,30$; enquanto que para $p(X, Y)=0,70, D_{J C}(X, Y)=-0,75 \ln (1-1.33 \times 0,70)=2,03$.

\footnotetext{
${ }^{1}$ Um objeto ou material biológico em análise de filos.
} 


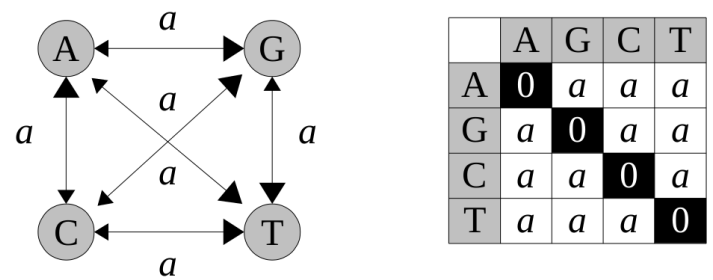

Figura F.1: Relação de substituição proposto por JC.

2. Modelo Kimura dois parâmetros

O modelo Kimura (KI) é baseado no fato de que substituições (TS) do tipo transições (substituições entre bases de aminoácidos purinas ou entre pirimidinas) ocorrem com mais frequência do que transversões ( $T V$, entre uma purina e uma pirimidina ou vice-versa). Assim, esse modelo considera que as frequências de transição e as de transversão são diferentes, mas assume frequências iguais para transições de um mesmo tipo. A Figura F.2 demonstra a relação de mudança para cada base: valor $a$ para mudanças $T V$ e $b$ para $T S$. A Equação F.2 mostra como é calculado a distância entre os taxa $X$ e $Y$.

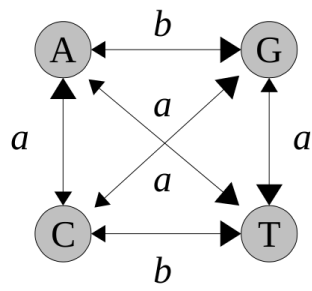

\begin{tabular}{|c|c|c|c|c|}
\hline & $\mathrm{A}$ & $\mathrm{G}$ & $\mathrm{C}$ & $\mathrm{T}$ \\
\hline $\mathrm{A}$ & 0 & $b$ & $a$ & $a$ \\
\hline $\mathrm{G}$ & $b$ & 0 & $a$ & $a$ \\
\hline $\mathrm{C}$ & $a$ & $a$ & 0 & $b$ \\
\hline $\mathrm{T}$ & $a$ & $a$ & $b$ & 0 \\
\hline
\end{tabular}

Figura F.2: Relações de substituição proposto por Kimura.

$$
D_{K I}(X, Y)=-\frac{1}{2} \ln (1-2 P-Q)-\frac{1}{4} \ln (1-2 Q),
$$

em que $P$ e $Q$ representam a proporção de pares de nucleotídeos diferentes entre as duas sequências envolvendo substituições do tipo $T S$ e $T V$ respectivamente. Por exemplo, para $P=0,10$ e $Q=0,40, D_{K I}(X, Y)=-0,50 \ln (1-2 \times 0,10-0,40)-0,25 \ln (1-2 \times 0,40)=$ 0,86 .

\section{Modelo Proporcional}

Partindo do fato de que a frequência dos quatro nucleotídeos nem sempre são similares, Felsenstein (Felsenstein, 2003) elaborou um modelo (F84) para calcular a probabilidade de substituição considerando a frequência de cada um dos tipos de nucleotídeos nas sequências analisadas. Por exemplo, quando a proporção da sequência composta por nucleotídeos $G$ e $C$ (também chamado frequência $G C$ ou conteúdo $G C$ ) varia entre as sequências, pode haver uma distorção nas distâncias, pois a proporção entre os pares bases $G C$ e $C T$ não é semelhante. Portanto, dois taxa com proporção alta e semelhantes em termos de de base $C$ 
e $G$ em suas sequências parecerão mais próximas do que são na realidade. Nesse caso, são considerados os seguintes aspectos: (i) diferentes valores para substituições diferentes $T V$ e $T S$, (ii) o conteúdo $G C$ e (iii) a taxa de transição/transversão.

Essa distância pode ser calculada somente quando a frequência de $G C$ é bem diferente de 0,50. A Equação F.3 mostra como é calculado a distância entre os taxa $X$ e $Y$.

$$
D_{F 84}(X, Y)=-h \ln \left(1-\frac{P}{h}-Q\right)-\frac{1}{2}(1-h) \ln (1-2 Q),
$$

em que $h=2 t(1-t)$, e $t$ é a proporção do conteúdo $G C$ em ambas as sequências. Por exemplo, para $P=0,10, Q=0,40$ e $t=0,50, D_{F 84}(X, Y)=-0,50 \ln (1-0,10 / 0,50-$ $0,40)-0,50(1-0,50) \ln (1-2 \times 0,40)=0.86$. O modelo proporcional é semelhante ao de KI, pois permite a utilização de diferentes frequências para $T S$ e $T V$. Nos casos em que a proporção de GC e CT estão em equilíbrio, o modelo F84 produz os mesmos resultados que o modelo de KI.

A Figura F.3 mostra as árvores obtidas pelo NJ com essas diferentes métricas de distância: JC, KI e F84, respectivamente. Essas árvores possuem várias semelhanças e algumas diferenças. As partes semelhantes indicam relações entre espécies com certa robustez a variações relativamente pequenas nas métricas. Por outro lado, as diferenças indicam relações sensíveis ao tipo de métrica usada. Tais relações são, de certa forma, menos confiáveis.

Apesar de algumas relações serem menos estáveis, podem envolver informação relevante em relação a um ancestral delas. Por exemplo, em (a) (b) e (c) da Figura F.3 existe um ancestral comum em cada uma das três árvores que agrupam Marsilea, Asplenium, Nephrolepis, Xiphopteris, Monachosorum, Cheiropleuria e Loxoma que são sequências de DNA do conjunto teste rbcL_55 (Cancino \& Delbem, 2007). Dessa forma, filogenias indicam também parentescos hipotéticos entre grupos de espécies. Um grupo de parentes é chamado de Clado (Felsenstein, 2000).

Em problemas de otimização mesmo envolvendo combinação de BBs que não são totalmente descorrelacionados, clados podem ser vistos como potenciais BBs. Procedimentos para identificar clados são descritos na Seção 5.2.

\section{Informação Mútua}

A métrica de Informação Mútua (MI, do inglês Mutual Information), como descrito em Teoria da Informação (Kraskov et al., 2003), é uma medida de similaridade entre duas variáveis que têm alguns casos de sucesso ao ser usada para desenvolvimento de EDAs (Vargas et al., 2010a; Delbem et al., 2010; Duque \& Goldberg, 2010). Essa medida pode ser calculada pela Equação F.4.

$$
I(X, Y)=\sum_{x \in X} \sum_{y \in Y} p_{x y}(X, Y) \log _{2}\left(\frac{p_{x y}(X, Y)}{p_{x}(X) p_{y}(Y)}\right)
$$




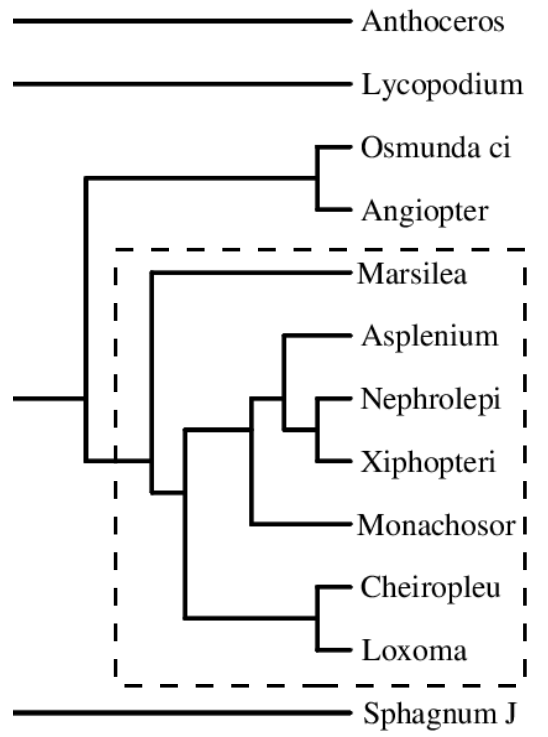

(a)

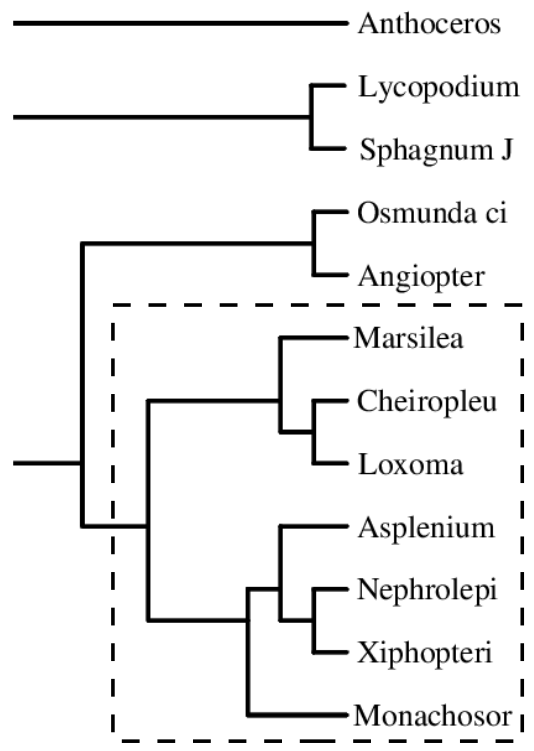

(b)

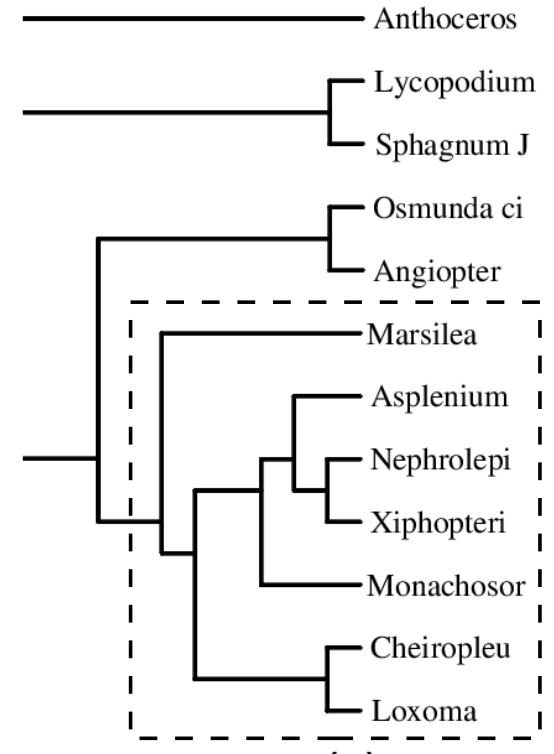

(c)

Figura F.3: Três árvores geradas pelo NJ usando diferentes métricas: (a) JC, (b) KI e (c) F84.

em que $X$ e $Y$ são variáveis aleatórias, $p_{x y}(X, Y)$ é a Probabilidade Conjunta do evento $X=x$ e $Y=y$; enquanto que $p_{x}(X)$ e $p_{y}(Y)$ são as probabilidades marginais de $X=x$ e $Y=y$ respectivamente.

A probabilidade marginal $p_{x}(X=x)$ é definida como a soma de ocorrências de valor $x$ para a variável $X$ dividida pelo número de amostras sobre $X$. A probabilidade conjunta é calculada de forma semelhante, considerando que a contagem de ocorrências é feita em relação à frequência do $\operatorname{par}(X=x, Y=y)$.

Entretanto a MI não é uma métrica, pois não satisfaz a desigualdade triangular estrita (Kraskov, 2008). Por outro lado, $D_{M I}(X, Y)$ como descrito na Equação F.5 é uma métrica que tem sido amplamente usada na literatura (Kraskov, 2008; Dionísio et al., 2006; Aghagolzadeh et al., 2007; Aporntewan et al., 2009). $D_{M I}(X, Y)$ satisfaz todas as propriedades de métrica: desigualdade triangular; não-negatividade; propriedades simétricas e indiscernibilidade.

$$
D_{M I}(X, Y)=H(X, Y)-I(X, Y),
$$

em que $H(X, Y)$ é a entropia do par $(X, Y)$ calculada pela Equação F.6.

$$
H(X, Y)=-\sum_{x \in X} \sum_{y \in Y} p_{x y}(X, Y) \log _{2}\left(p_{x y}(X, Y)\right)
$$

A métrica $D_{M I}(X, Y)$ é também uma métrica universal, no sentido que se alguma medida de distância não trivial para $X$ e $Y$ estabelece que essas variáveis como próximas, então esta distância será determinada igualmente próxima de acordo com $D_{M I}(X, Y)$. A maior restrição ao uso dessa métrica de forma ampla tem sido o seu custo computacional. 
A Complexidade da MI, apresentada em Duque \& Goldberg (2010), é $O\left(n_{s} \ell^{2}\right)$, em que $n_{s}$ é a quantidade de amostras (tamanho da População de Selecionados em EDAs, ver Capítulo 2) e $\ell$ é o tamanho do problema.

\section{Distância por Compressão Normalizada}

A Distância por compressão normalizada (NCD, do inglês Normalized Compression Distance) é uma métrica que pode encontrar relações entre dados, determinando semelhança entre as variáveis com base nos tamanhos de seus dados compactados e descompactados. Esta abordagem, desenvolvida na Teoria da Informação (Cilibrasi \& Vitányi, 2005), não requer qualquer conhecimento específico do domínio de aplicação. De acordo com Cilibrasi \& Vitányi (2005), a NCD é uma métrica universal e robusta que tem sido aplicada com sucesso em áreas como a genética, literatura, música e astronomia.

A NCD é baseada em outra métrica chamada NID (do inglês Normalized Information Distance) (Lillo-Castellano et al., 2013), que considera a semelhança entre as variáveis de acordo com a característica dominante que elas compartilham. No entanto, a NID utiliza diretamente o conceito de complexidade de Kolmogorov (Li \& Vitnyi, 1997) no cálculo da distância, que é computacionalmente inviável para amostras grandes. A NCD substitui o cálculo da complexidade de Kolmogorov por uma aproximação obtida a partir de um algoritmo de compressão. Na prática, a distância entre dois dados $X$ e $Y$ em NCD é um número positivo variando entre $[0 ; 1+\varepsilon]$, que representa o quão diferente essas variáveis são, e o parâmetro $\varepsilon$ é um limitante superior para o erro do compressor usado. $\mathrm{O}$ valor da distância entre $X$ e $Y$ é dado pela Equação F.7:

$$
D_{N C D}(X, Y)=\frac{C(X Y)-\min \{C(X), C(Y)\}}{\max \{C(X), C(Y)\}},
$$

em que $C(X Y)$ é o tamanho obtido após concatenação de $X$ e $Y$ seguida de sua compressão, $C(X)$ e $C(Y)$ são os tamanhos de $X$ e $Y$ comprimidas, respectivamente.

A escolha do compressor interfere diretamente na distância calculada pela NCD. A quantidade e o tipo de dados envolvidos são os principais fatores para decidir sobre o melhor compressor. Muitos compressores são encontradas na literatura, os mais comuns têm sido bzip, gzip e ppmz (Ito et al., 2010).

Sanches et al. (2011) mostraram que a NCD pode encontrar padrões em códigos-fonte de programas, quando combinado com técnicas como NJ e FA. A abordagem chamada DAMICORE (do inglês DAta MIning of COde REpositories), que usa a NCD, mostra que é possível trabalhar com diferentes tipos de representações de códigos. A NCD integrada ao DAMICORE gera Matrizes Distância para um conjunto de códigos, possibilitando verificar níveis de semelhança entre eles e propriedades em comum desses códigos que podem ser exploradas, por exemplo, em projeto de Hardware de alto desempenho utilizando FPGAs (Sadrozinski \& Wu, 2011; Silva et al., 2014).

Em Axelsson (2010), a NCD foi aplicada para o problema de determinar o fragmento de arquivos. A NCD é combinado com o kNN (do inglês $k$-Nearest-Neighbor), que é utilizado como 
algoritmo de agrupamento. O método foi aplicado a um conjunto de amostras aleatórias de fragmentos de 3000 arquivos com 512 bytes cada um, envolvendo 28 tipos diferentes de arquivos. Os resultados encontrados alcançaram cerca de $70 \%$ de precisão.

Em Cerra \& Datcu (2012), é definida uma medida de similaridade baseada em compressão chamado FCD (do inglês Fast Compression Distance), que combina a precisão da NCD com a complexidade reduzida do algoritmo de Representação Padrão para Compressão de Dados (PRDC, do inglês Pattern Representation using Data Compression). A FCD foi investigada em bases de dados de imagens e mostrou não perder em precisão em relação à NCD. 